THE WOOLLEN AND

\title{
WORSTWD INDUSTRIES
}

$$
J \cdot H \cdot \text { CLAPHAM }
$$



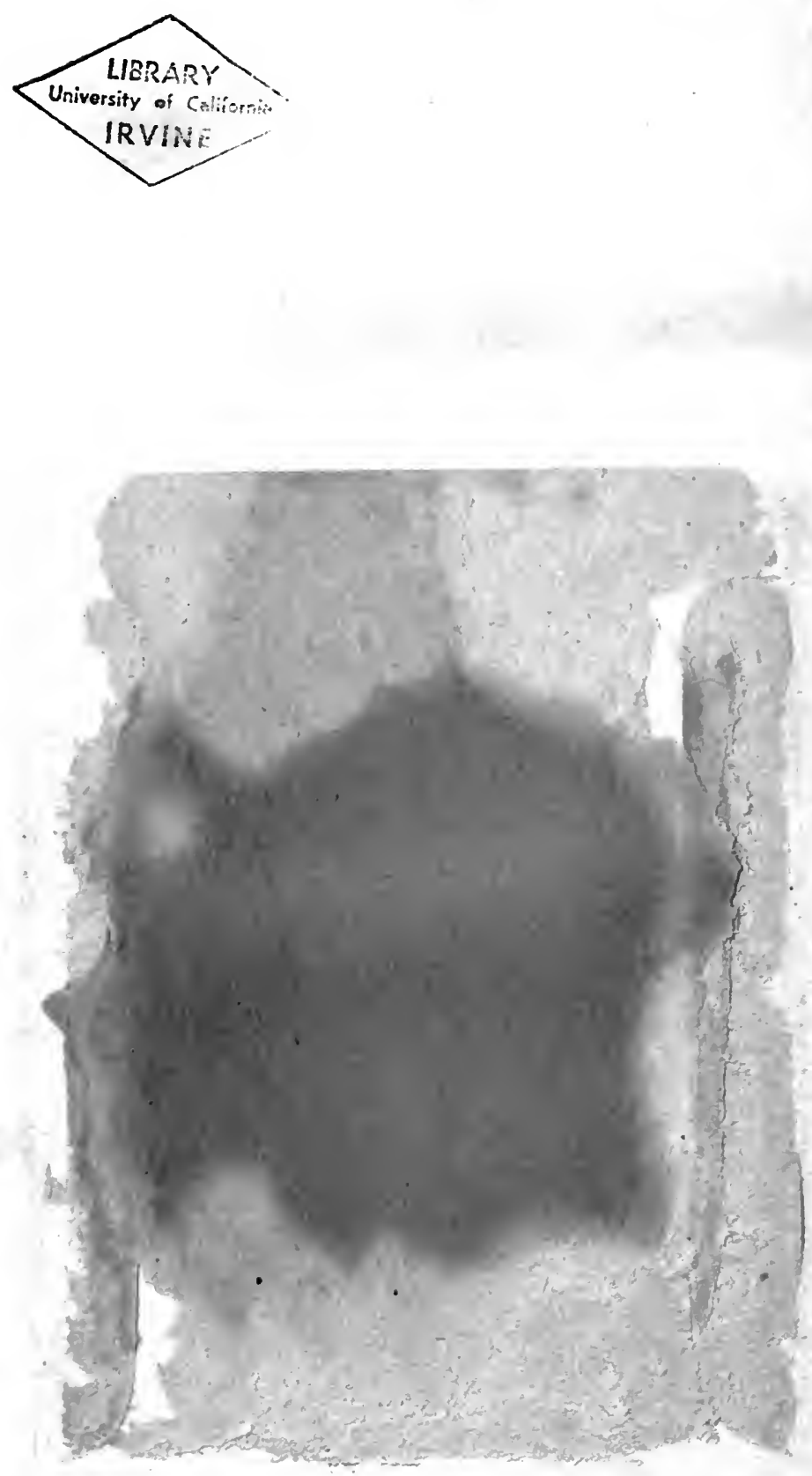


\section{Date Due}

C 
Digitized by the Internet Archive in 2007 with funding from Microsoft Corporation
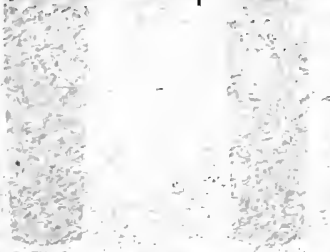

http://www.archive.org/details/woollenworstedinooclapiala 
THE WOOLLEN AND WORSTED

INDUSTRIES 


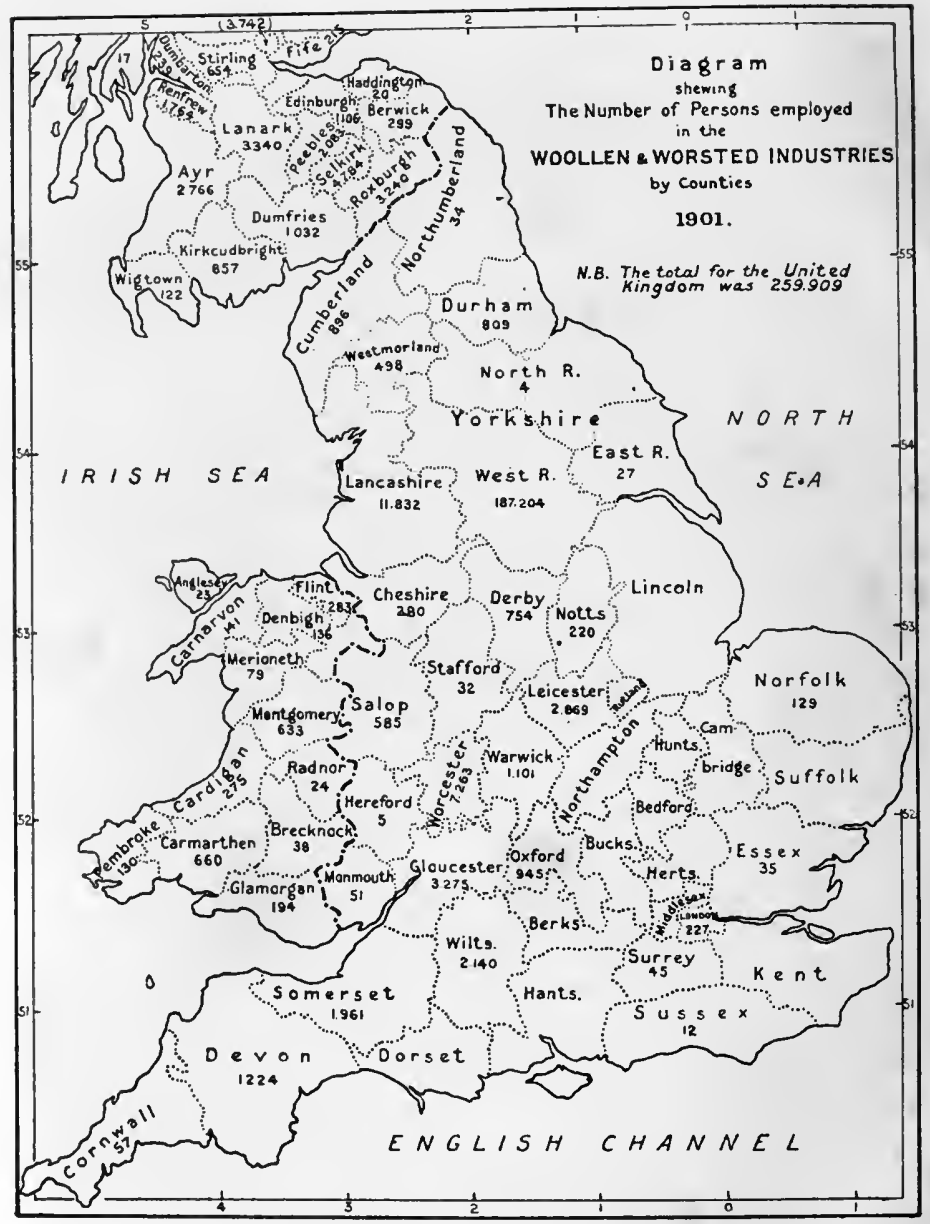

NUMBER OF IERSONS EMYIOYED IN THE WOOLLEN AND WORSTED INDUSTRIES BY COUNTIES, IgOI

N.B.-The total for the United Kingdom was 259,909 . 


\title{
THE WOOLLEN
}

\section{AND \\ WORSTED INDUSTRIES}

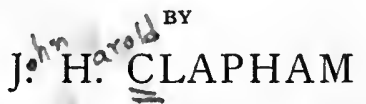

PROFESSOR OF ECONOMICS IN THE UNIVERSITY OF LEEDS, FORMERLY FELLOW OF KING'S COLLEGE, CAMBRIDGE
\end{abstract}

WITH DIAGRAMS AND ILLUSTRATIONS

METHUEN \& CO.

36 ESSEX STREET W.C.

LONDON 
$H D$

9890.5

c 6

First Published in 1907

7130 


\section{3}

\section{PREFACE}

THIS general sketch of the Woollen and 1 Worsted Industries is the first of its kind. Therefore there are sure to be some mistakes and omissions, though every effort has been made to make it accurate so far as it goes. But it is a sketch, not a fully finished picture. I shall be only too glad to receive criticisms and additional facts from any source.

I have received help from all sorts and conditions of men and from some women. Most of the manufacturers, merchants, trade unionists and others who have given me information prefer to remain anonymous. But I can thank my colleagues, Professor Beaumont and Mr. W. H. Shaw; Mr. F. Hooper, late Secretary of the Bradford Chamber of Commerce; Mr. Frankland, Secretary of the Ossett Chamber; Professor Armitage of the Huddersfield Technical College; Professor Barker of the Bradford Technical College; Miss Maud Sellers, and Mr. Howard Priestman, 


\section{vi WOOLLEN AND WORSTED INDUSTRIES}

who has read my proofs and given me much valuable advice, especially in technical matters-where I have no expert knowledge. For American facts I am much indebted to Mr. J. B. Macpherson, Secretary of the National Association of Wool Manufacturers, and for Belgian facts to Professor M. E. Bodard of Verviers.

The printed sources of information are exceedingly miscellaneous. I should like to acknowledge my special indebtedness to the technical works of Professor Beaumont, Mr. Priestman, Mr. Maclaren and Dr. Bowman; to Dangerous Trades, edited by Dr. T. Oliver; to the daily and annual trade reports of the Yorkshive Observer (formerly the Bradford Observer); to the Bulletin of the National Association of Wool Manufacturers and to IIndustrie Textile, for America and France; to Mr. Hooper's valuable Statistics, published annually; to Mr. A. L. Bowley's and Mr. T. A. Coghlan's well-known statistical writings ; to Gain or Loss? by Messrs. Ogden and Macaulay of Bradford; to the wool trade reviews of Messrs. Helmuth, Schwartze \& Co., and to the official publications of the Australian, New Zealand and Canadian Governments supplied to me by the Agents-General and commercial representatives of those parts of the Empire. 
Some of the printed sources of information for foreign countries are referred to in the text. Besides official publications of various kinds and our own Consular Reports, I am under special obligations to Dr. Senkel's Wollproduktion und Wollhandel im $19^{\text {ten }}$ Fahrhundert, the publications of the Verein für Socialpolitik, and the article on the Wool Industry in the Handbuch der Wirthschaftskunde Deutschlands.

For assistance in procuring photographs or for gifts of photographs I wish to thank Professor Beaumont; Mr. E. B. Fry of Shipley; Messrs. Prince Smith, and Robert Clough of Keighley; Messrs. James Mathers \& Sons, Taylor, Wordsworth \& Co., and Beaumont \& Smith of Leeds; Mr. H. Dudding of Riby Grove, Lincoln; Mr. R. Welch of Belfast, and the Agent-General for New South Wales.

For the Index and a number of other things I am indebted to my wife.

J. H. C.

LEEDS

June, r907 



\section{CONTENTS}

CHAPTER

I. INTRODUCTORY

II. The Manufacturing Processes • • $~ \cdot \quad$ 25

III. The Raw Materials and the Trade in them • $\quad 76$

IV. Industrial and Commercial Organisation . . . 126

V. LABOUR IN THE INDUSTRIES $\quad \cdot \quad \cdot \quad \cdot \quad \cdot \quad \cdot \quad$ • $\quad$ I74

VI. The Industries Abroad • $\quad$ - $\quad$ - $\quad$ - $\quad$ - 221

VII. IMPORTS AND EXPORTS $\quad \cdot \quad \cdot \quad \cdot \quad \cdot \quad \cdot \quad \cdot \quad \cdot 272$

INDEX $\quad \cdot \quad \cdot \quad \cdot \quad \cdot \quad \cdot \quad \cdot \quad \cdot \quad \cdot 305$ 



\section{LIST OF DIAGRAMS AND ILLUSTRATIONS}

\section{DIAGRAMS}

The Distribution of the Industries by Counties Frontispiece Facing Page

Exports from the United Kingdom and Wool Prices . 276 Exports from the United Kingdom, France and Germany • 292 IMPORTS INTO THE UNITED KINGdom • • • • . 296

\section{ILLUSTRATIONS}

Magnified Fibres of Merino and Cheviot Wool a $\quad 26$ Hand Carding and Spinning in Donegal . . . 32 Woollen Carding and Condensing . . . . . . 34 Noble Combs at Work . . . . . . . . 42 LISTER CoMbs AT Work $\quad . \quad$. . . . . . 44 Flyer Spinning Frames . . . . . . . . 50 Cap Spinning Frames . . . . . . . . 52

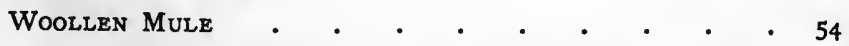
Twistino Frame for Fancy Yarns with Ring Spindles . 56 Irish CotTage Hand-Loom . . . . . . 58 Woollen Power Loom . . . . . . . . 60 


\section{xii WOOLLEN AND WORSTED INDUSTRIES}

Facing Page

Flock of Merino Sheep, New South Wales . $\quad$ - 88

Wool in Transit to Market, New South Wales • • 90

Baling Wool for Export, Australia • • • • 96

Group of Prize Lincoln Rams • • • • • . 104

The Connemara Spinning Wheel . • • . . 128

A Woollen Weaving Shed . . . . . . . . Igo 


\section{THE WOOLLEN \\ AND \\ WORSTED INDUSTRIES \\ CHAPTER I \\ INTRODUCTORY}

ПHE group of industries with which this little L book deals has a long and famous past. Its development has attracted economists and historians in an uncommon degree, and rightly; for it is connected at all points with the rise both of the economic and the political life and strength of the nation. To condense into a single chapter a story that began before ever William of Normandy brought Flemish weavers over the Channel or the Lord Chancellor sat on a woolsack would be almost irreverent and altogether unwise. To condense it into an Introduction would be impertinent. I shall, therefore, make no attempt to deal with any but the most recent history, except where the 
past throws direct light on the facts of the present. And such history as the book contains will be found scattered throughout the various chapters where it is likely to be of most use.

In the absence of history, some definition of the ground to be covered is needed. Grammatically, anything made of wool is woollen; but, technically, the woollen manufacture is but a part of what one may call, in the absence of any simple popular name, the wool-working industries. The technical differences between woollen and worsted will be dealt with in Chapter II. Here it is enough to mention that those differences are primarily connected with the structure of the yarn and the mechanical treatment of the wool before and during the process of spinning. On the Continent this fact is emphasised in the names given to the two branches of the industry. The French and German equivalents of woollen and worsted are "carded" and "combed"- -terms descriptive of the distinctive preliminary processes through which the wool goes. Our term worsted comes, as the philologists still think, from a quiet Norfolk village with a great church, where now there is no sound of the loom, but where once fabrics woven of combed wool were produced in 
quantities great enough to make the place famous throughout England.

When finished and ready for market, worsted fabrics are usually lighter and finer than woollens. Most of the softer and lighter materials for women's dress, the "stuffs," are made in whole or in part of worsted, more often in part than in whole. Silk or cotton yarns are the usual accompaniments. Other typical worsted fabrics are the fine napless cloth of which men's dress suits are now made, the smooth fancy "trouserings," and so forth. Among heavier worsteds are some of the serges and other plain or fancy "coatings". But here the boundary line between woollen and worsted fabrics is blurred by the now not uncommon practice of using both classes of yarn in one piece of cloth. Typical woollens are the old fine broadcloths, uniform cloths, boxcloths and the like; pilot cloths and the stout materials of which winter overcoats are made; flannels, blankets and tweeds. Cotton yarns are used in woollen as well as in worsted weaving, in the construction of what are known as union cloths; but, in spite of the presence of cotton, such cloths are as a rule fairly heavy. Cotton is also mixed with wool before spinning, in many cases, as a cheap and effective substitute.

${ }^{1}$ The term serge is now used very widely and loosely. 
Thus on the one side the woollen and worsted industries stand in very close relations with the cotton trade and industry, and have points of contact with the silk industry. With these industries, of course, this book has nothing to do. On the other side stand the carpet and the hosiery industries. The former is sometimes treated not as a distinct branch of manufacture, but as a mere subdivision of woollen and worsted. It is so treated in all English official employment statistics, both those issued by the factory inspectors and those printed in the census returns; also in foreign trade statistics. Therefore it will have to be included in certain sections of this book. But its processes are so different from those of cloth or stuff manufacture, that no attempt can be made to describe them or to discuss the organisation of the carpet trade. Reference to it will be necessary from time to time, but there will be no pretence of making these references exhaustive.

The manufacture of hosiery is a distinct trade from every point of view-a trade in which the knitting machine takes the place of the loom. It is a great consumer of worsted and woollen yarns, but in no sense a part of the woollen or of the worsted industry. To it, therefore, no 
reference will be made except in its capacity of consumer.

In estimating the national importance of any group of industries various tests may be applied - the number of persons engaged in it, the sum annually paid in wages, the quantity of machinery at work, the value and amount of raw material consumed, and the value and quantity of finished goods produced. In the present state of our statistical knowledge, some only of these tests can be applied to the woollen and worsted group; and even those that are applicable must be handled cautiously, for the group presents more statistical problems and pitfalls than almost any other important section of British industry.

The number of persons employed in I90I, according to the factory inspectors' returns, was 259,909. This figure covers spinning and weaving and all preliminary and allied processes, shoddy-making and carpet-making, but not hosiery-making. It also includes about 3000 dyers, bleachers or printers, but not the bulk of these classes of workpeople, since most of them do not work in what are technically known as textile factories and are not engaged in handling woollens and worsteds only. Besides this small body of dyers and others, the inspectors report 
that 355 persons were employed in all the other "non-textile" processes in the mills of the United Kingdom. This is clearly a grotesque underestimate of the miscellaneous employés. It is a pity that so misleading a figure should be included at all.

The inspectors' figures are based on returns from all the registered mills in the country, but how complete these returns are only the millowners know. It is sometimes maintained that there is a considerable risk of error, due to carelessness in filling in the inquiry forms, but a comparison of the inspectors' returns with the census returns of occupations-which, of course, are collected in a totally different way-shows that this risk is in all probability not serious.

To illustrate this point reference may be made to the Yorkshire returns. The inspectors' figure for "wool, worsted and shoddy" in the West Riding was 187,204 . The census figures in the same year were: "wool and worsted," I 81,004; and "mixed or unspecified materials," I I,20I. This second heading includes all those textile workers who merely returned themselves as spinners, weavers or what not, or as workers with mixed materials. The bulk of them would certainly be wool workers; but a minority would be classed by the inspectors under some other 
head-cotton, silk, or linen perhaps. When a reduction of, say, 20 per cent. from the I I, 20 I has been made to allow for this minority, the census total of wool wurkers comes to nearly 190,000. But in the census all dyers and bleachers are entered separately, whereas the inspectors' total includes 3032 of this class. On the other hand, the census includes employers, the inspectors do not, and there are certainly some thousands of employers. So that the discrepancies are not serious, and the maximum possible error in the inspectors' figures is inconsiderable.

In the case of machinery we have statements in connection with which there seems to be no great risk of error. They are more recent than the figures of employment, having been collected in I904. Woollen, worsted and shoddy mills are treated separately. There were I 377 woollen factories in the kingdom in 1904, containing 329 rag-grinding machines for making shoddy, $60 \$_{3}$ sets of carding machinery, 2,6 13,759 spinning spindles, 21 I,353 doubling spindles for twisting yarns together, and 50,357 power looms. The I6 I shoddy mills had 566 rag-grinding machines, 3 r9 carding sets, 77,815 spinning spindles, 2520 doubling spindles and 1432 looms. ${ }^{1} \quad$ In the $84 \mathrm{I}$ worsted mills there were

${ }^{1}$ These figures, when examined critically, show that the 
2823 combing machines, 2,937,900 spinning spindles, 845, I66 doubling spindles, and 52,725 power looms. Some of the "woollen" mills contained a little worsted machinery and vice versâ, but the amount of this overlapping was small. The items are IO I combs in woollen mills and 298 woollen carding sets in worsted mills.

Nearly all the machinery is steam driven. A few mills-some of them of considerable sizeuse both steam and water power. In out-of-theway places water power may occasionally be found working unassisted - a rare relic of the past. Here and there steam is being displaced by electricity. The new motive force has so far made slow progress; some doubt whether it will ever win the day. There are technical difficulties connected with its adoption and the existing mill-engines are remarkably economical. But it can be used and it is being used. I have visited an important woollen mill in which it has been applied to nearly every process; and there seems no reason why this should not eventually become common.

Since I 889 the number of worsted spindles main business of the shoddy mills was making the shoddy, not working it up. There is no hard and fast line between some of these shoddy mills and some of the woollen mills. 
has risen by 22 per cent. ; the number of woollen spindles has fallen by nearly i 6 per cent. The number of woollen looms has fallen from $6 \mathrm{I}, 83 \mathrm{I}$ to 50,357 ; that of worsted looms from $67,39 \mathrm{I}$ to 52,725 . It should be borne in mind that during the fifteen years from ' 89 to 1904 , the pace of both spindles and looms and the average width of the looms had considerably increased. The figures of raw material consumption show clearly enough that a steady increase in productive power accompanied this numerical decline in certain forms of machinery.

These consumption figures are by no means so certain as one could wish. At several points it is necessary to rely on estimates, which can never be quite satisfactory, however carefully they are framed. The certain data are the imports and re-exports of foreign and colonial wool, the exports of British wool, and the number of sheep in the United Kingdom. From the last figure an estimate of the home clip has to be made, based on the probable average weight of the fleeces of different breeds of sheep; and from the figure thus arrived at must be deducted the exports of British wool. The greatest difficulty arises in connection with the "home-grown" rags and the quantity of raw material made from 
rags generally. Another estimated figure is that of the wool taken from imported sheepskins; but this is not entirely a matter of guess work, and moreover the item is not an important one. Elaborate figures of consumption, worked out on these lines, have been published annually for the last few years by Mr. F. Hooper, late secretary of the Bradford Chamber of Commerce. For the year I906 he estimates that the amount of new wool retained for consumption was $5^{1} 7^{\circ} \mathrm{I}$ million lbs., ${ }^{1}$ the amount taken from sheepskins 32 millions, and the amount made out of rags I 90 millions.

For the five years 1900-4 the new wool retained averaged $484^{\circ} 5$ million lbs., the skin wool $29^{\circ} 6$, and the rag wool 145 millions. The quinquennial averages in millions of lbs. for the years since 1870 are as follows :-

\begin{tabular}{|c|c|c|c|}
\hline I 900-4 & $\begin{array}{c}\text { New Wool } \\
\text { RetaINed. } \\
4^{8} 4^{\circ} 5\end{array}$ & $\begin{array}{c}\text { SkIN Wool. } \\
29.6\end{array}$ & $\begin{array}{c}\text { RAG WooL. } \\
\text { I } 45^{\circ} \circ\end{array}$ \\
\hline I 895-9 & $519^{\circ} 5$ & $33^{\cdot 6}$ & $132^{\circ} \circ$ \\
\hline I 890-4 & $472 \cdot 6$ & $32 \cdot 2$ & I I $8 \cdot 0$ \\
\hline I $885-9$ & 4134 & $25^{\circ} \circ$ & IOI'O \\
\hline I $880-4$ & $353^{\circ} 6$ & $20 \%$ & $123^{\circ} 0$ \\
\hline I $875-9$ & $353^{\circ} 3$ & $20 \cdot 1$ & $104^{\circ} 0$ \\
\hline I $870-4$ & $34 I^{\circ} 7$ & 23.0 & $89^{\circ} 0$ \\
\hline
\end{tabular}

${ }^{1}$ This includes alpaca, mohair, and other raw materials akin to wool. 
This is not the place to comment on the details of consumption. The chapters which follow will throw some light on them. But it should be mentioned here that one possible source of error connected with the figures has not yet been referred to. It is that the words "a pound of wool" are not so simple as they seem. Wool may be dirty or clean, fine or coarse. It so happens that in the earlier years covered by the table, there was relatively more wool imported clean than there now is, which means that a part of the increase is but grease and dirt. But the possible error due to this cause is not great. Nor need much weight be given to the fact that the very fine wool from Australia and elsewhere formed a smaller fraction of the whole at the end of the period than at the beginning; though the fact deserves to be put on record.

Besides the new wool, skin wool, and rag wool there is cotton, both spun and unspun, to be taken into account. Estimates of the quantity consumed have been put forward from time to time; but they are necessarily much more uncertain than any of the other estimates, which is saying a good deal. I do not propose, therefore, to quote any figures; but to content myself with 
stating the certain fact that the consumption of cotton has increased of late years.

A calculation of the value of the raw material consumed in the industries could not be made with any certainty; nor would it be of great use, unless coupled with reasonably accurate valuations of the output of finished goods from the mills, and of the total amount paid in wages. Neither valuation is to be had; so that these particular tests of the national importance of the wool manufactures cannot be applied.

Everyone is more or less familiar with the way in which the industries are distributed over the face of the country-the primacy of the West Riding, and the importance of the parts of Lancashire round about Rochdale, the significance of the Tweed towns and of Kidderminster, the continued activity of the famous old "West of England" manufacturing district in Gloucester, Wiltshire, and Somerset. The map which gives the distribution of the industry by counties to a large extent speaks for itself. It shows how widely scattered the business of wool manufacturing still is, in spite of the fact that wellnigh 80 per cent. of the workers in it live in the comparatively narrow bit of hill country between 
the valley of the Wharfe and the valley of the Irwell. The scattering would be still more apparent if the map included Ireland and the Highlands; for the 3523 Irish woollen mill "hands," reported in 1901, were spread over twenty-six counties, and in Scotland the 2976 work people not accounted for on the map were divided among eleven northern counties.

The mills of Ireland and the north of Scotland are without exception woollen mills-well, not quite without exception: twelve worsted looms are reported from Monaghan. So are the Welsh mills and all the mills-they are not very many - in Northumberland, Hereford, Monmouth, Oxford, Essex, Sussex, and Cornwall. These are in most cases the remnants of old local industries from the days when there was no power-driven machinery and manufacturing was but little concentrated. In a few instances they bave risen, under the new order, to positions of national importance, as in the case of the blanket industry of Witney in Oxford. But in many cases they have even now only partially adopted power and have retained much of their old character. Some of the Welsh and Scotch and Irish mills still provide yarn for domestic weavers. In the four counties of Cardigan, 
Carmarthen, Glamorgan, and Pembroke, for example, there were in 1904 a hundred and six "factories" that did nothing but spin. They had on an average one set of carding machinery and II 6 spindles each. It is true there were some other "factories" thereabouts that did nothing but weave, and that with power looms too; but no doubt much yarn from the spinning mills went to the cottage looms. The factories of all kinds in the four counties numbered I9I; the workpeople, three years earlier, exactly I259. A simple division sum reveals the size and probable character of these quaint little mills. There are other Welsh counties whose industry is of much the same type as this.

So also in Ireland. There are ninety-nine Irish mills all told. Some are fair-sized concerns of the English type. But thirty-four of themsix in Cork, six in Kerry, and the rest divided among eleven other counties-are spinning mills of the type just described, though slightly larger, with one or two carding sets and from 150 to 200 spindles each. The same type is to be found in parts of Scotland, though there it is far less common, and perhaps it still survives in the English counties along the Welsh border.

These are the curiosities of the industry, the 
survivals of an earlier time. Elsewhere are to be found relics of what once were great concentrated industrial districts, that have declined under the stress of competition. East Anglia was the chief of the worsted districts down to r8oo. Her industry had little in common with the parochial woollen manufacture of the Welsh and Irish hills; it was of national and international importance. But it has disappeared utterly, save for a few worsted spindles and a handful of workpeople in Norwich. Devon has fared rather better. She has some half-dozen mills, mainly for woollens. But she has fallen from her high place. In I 800 Exeter was "essentially a manufacturing city". It was, we are told, "the emporium for the thinner kinds of woollen goods, such as serges, druggets, estamines and long ells; which being spun and woven in the towns and villages around were dyed and finished in the city, whence they were shipped to Spain, Portugal, Holland, Italy and the East Indies". It was reckoned that 80 per cent. of Exeter's population of over 16,000 was in one way or another connected with the trade. By $183 \mathrm{I}$ this had all ceased; and in the factory age the ground lost has never been recovered. ${ }^{1}$

${ }^{1}$ Second Report of the Health of Towns Commission, 1845, p. 354 . 
Somerset, Wiltshire and Gloucester also lost much ground, as compared with the North, between 1800 and 1900 . Fashion was unkind to them towards the close of the century, so that in some districts decline has been almost continuous up to the present time. In Somerset there are ten factories-woollen with just a little worsted spinning. The familiar headquarters of the trade are at Wellington. In Gloucester and Wiltshire the valleys on either side of the Cotswolds and the upper valley of the Avon, where most of the mills lie, form an idyllic manufacturing district, that one instinctively contrasts with the hard-edged grey moorlands, fouled rivers and grimy air of the West Riding. It is a woollen district altogether, so far as spinning is concerned; and some of its thirty mills turn out the finest woollen cloth in the world. The chief of them are on the Gloucestershire side, round about Stroud. Those on the Wiltshire side seem to have suffered more from outside competition than those in Gloucester: it is from the neighbourhood of Bradford-on-Avon that one hears most of firms going out of business and factories deserted or turned to other uses.

The manufacturing industry of the Midlands centres about the carpets of Kidderminster and 
the hosiery of Leicester. Worcestershire, thanks to the carpet trade, comes next after Yorkshire and Lancashire as a wool-working county. Warwickshire also does a little spinning and weaving -about Coventry. As has already been mentioned, the figures given on the county map include carpets but exclude hosiery. This explains the comparatively low figure for Leicestershire. Besides its 2869, woollen or worsted operatives, it had over 19,000 hosiery makers, and there were another I0,000 or so in Derbyshire and Nottingham. Those returned for these three counties under "woollen and worsted" are the spinners in mills that supply the hosiery trade. Nearly all these mills are in and about Leicester itself, though there are a few in Derbyshire and Notts. Some are of firstrate importance. The majority of them are classed as worsted mills ; but there is a good deal of overlapping in the hosiery yarn trade, mills classed as woollen containing worsted machinery and vice versâ. There was no weaving machinery returned from the whole hosiery district, with the exception of fifteen worsted looms from Leicester.

The three figures on the map of Yorkshire show the relative manufacturing importance of the Ridings. As is well known, the factory district covers 
only a part even of the West Riding. North of the course of the Wharfe, south of the courses of the Calder and the Colne, and east of a line drawn north and south just beyond Wakefield, there are but few mills. Roughly speaking, woollens are made principally in the east and south, worsteds in the west and north of this area. But there is no sharp line of division. There is very little woollen spinning or weaving in Bradford, Halifax, Keighley or in Wharfedale, very little worsted in Batley or Dewsbury; but there is now a good deal of worsted in and about Leeds, and the Huddersfield neighbourhood has long practised both branches.

Inside the district there is a vast amount of local specialisation. Bradford is the chief seat of wooldealing, yarn-dealing, and of all things commercial. Its supremacy is unquestionable; though it by no means holds a position in Yorkshire analogous to that of Manchester beyond the Pennines. Leeds, a much larger city and an older seat of the textile industries, naturally does not stand to Bradford at all as Oldham stands to Manchester. Halifax and Huddersfield would hardly be prepared to admit that Bradford was more than primus inter pares. They have their specialities, which are not those of Bradford, their 
commercial as well as their industrial activities, and their ancient renown. Yet Bradford is actually by far the greatest wool-working city in the Riding or, for that matter, in the world; although, owing to its having so little to do with woollens, it can hardly be called the centre of the woollen and worsted industries. It is the headquarters of wool-combing and of the manufacture of worsteds for women's wear. At Huddersfield are made the best worsteds for men's wear and some fine woollens. Halifax is best known in connection with the carpet trade, though it also spins various kinds of worsted yarns-including hosiery yarns-and makes stuffs. The Colne valley above Huddersfield now specialises in tweeds and other woollens, of the cheaper but not the cheapest sorts. Dewsbury and Batley are in the old "heavy woollen district," which might perhaps now better be called the "cheap woollen district". It was the first home of the shoddy trade. Its business is now miscellaneous, as is the woollen trade of the Leeds neighbourhood. The latter ranges from the lowest tweeds, with little or no new wool in them, up to some excellent substantial woollens of the soundest, if not quite the most finished, workmanship. The old Leeds broadcloth trade, 
which still figures in some commercial geographies, is now almost extinct. Wakefield, at one end of the district, and Keighley at the other, are largely spinning towns, though their yarns have not very much in common; and so on.

Of the worsted industry, especially of combing and spinning, Yorkshire has almost a monopoly. All the combing machines of the United Kingdom except 280 are in the West Riding. Its proportion of the worsted spindles is much about the same. So is its proportion of the looms ; but in this case the figures cannot quite be taken as they stand, because a good deal of worsted yarn is woven in woollen mills, both in Yorkshire and out of it. Considerable quantities of Yorkshire worsted yarn go into other parts of the country, for hosiery and carpet-making, as well as for weaving.

In the woollen branch Yorkshire occupies a different position. It contains only a little over half the spindles and just under three-fifths of the looms in the kingdom. And although the West Riding is by far the greatest woollen district in the country, it could hardly claim to be the best. It is the most economical and the most highly organised, of that there is no sort of doubt. And it produces some of the very best qualities of 
cloth. But, taken as a whole, it has never won a reputation for such fine workmanship as that of the Tweed towns or the Cotswold mills. Your tailor still calls his best woollen cloths Scotch or West of England, and often enough he is right; though it may well be that what he sells under those names really come from somewhere about Huddersfield or even about Leeds. It is as a producer of sound, ordinary, woollen materials, and of all the cheaper grades away down to the least sound and flashiest, that Yorkshire is mainly known. With worsteds it is otherwise. The very best that England can produce are Yorkshire made.

The Lancashire industry is concerned mainly with woollens and its centre is at Rochdale. There is a little worsted spinning and a very little weaving in Manchester itself, where cotton's seat is. But all the worsted of Lancashire is of no great account; some six or seven businesses exhaust the list. Rochdale alone has six-andtwenty woollen mills, and there are others at Bury and elsewhere in the neighbourhood. All told there are nearly eighty mills in the county, somewhat larger concerns as a rule than the woollen mills of Yorkshire. The average spinning department in Lancashire contains 4258 
spindles, in Yorkshire 3182 ; the Lancashire weaving shed averages eighty-six looms, the Yorkshire shed sixty-three. Flannel, with its variants and derivatives, is the staple product of the Lancashire woollen district.

Northward of the great manufacturing area lies a tiny outlier of the worsted industry, on the Durham side of the Tees, at Darlington. It is one of the many products of Quaker enterprise in the north-east; but it has never shown much vitality. To the west and north are remnants of the old and once famous manufactures of Kendal, and a few mills in Cumberland.

Across the Tweed the woollen industry retains its scattered character and spreads into nearly every lowland county, besides those Highland counties already referred to. Of worsted there is but little in Scotland, only some 70,000 spindles and Iooo looms. The latter are mostly in the neighbourhood of Glasgow, Paisley or Edinburgh; the former also at Paisley and about Ayr and Kilmarnock. Hosiery yarns are extensively spun, and are worked up by over 4000 operatives in ten different counties. It should be added that worsted yarn is now used in the Scotch woollen factories, and that a good deal of worsted machinery - combs and spinning frames 
-is employed in the woollen yarn mills of Alloa in Clackmannan. ${ }^{1}$

The true "Tweed" and "Cheviot" trades, upon which the fame of the Scotch woollen industry depends, is principally found in the three counties of Roxburgh, Selkirk and Peebles, at Hawick and Jedburgh, Galashiels and Selkirk, Peebles and Innerleithen. But it spreads into Dumfries, Edinburgh, and other neighbouring counties. Lanark has a considerable weaving industry, in the Glasgow neighbourhood, though it does little or no spinning. So has Clackmannan. All kinds of woollens are produced, blankets and flannels, as well as cheviots and tweeds; but it is from the latter that the Scotch industry derives its international reputation. Judged numerically, it is a relatively small industry after all. Selkirk, the most important tweed county, has only about I 200 looms. Lanark, with a more miscellaneous trade, has about the same number. Roxburgh comes next, with just under 700, followed by Clackmannan and Ayr. Peebles has barely 500 ; and no other

${ }^{1}$ See below, p. I50. Only thirty-one combs were reported from Scotch worsted mills in 1904, and twenty-five from woollen mills. The latter were all in Clackmannan, where there were also I 2,000 worsted spindles. 
county has so many. But it is more to quality than to quantity that the south of Scotland looks for its success.

Having completed this rough preliminary sketch of the dimensions and the distribution of the woollen and worsted industries, we are in a position to handle, with rather more detail, some of their chief technical, industrial, commercial and social features, and from these things to pass to the condition of the industries abroad and the course of international trade. 


\section{CHAPTER II}

THE MANUFACTURING PROCESSES

WTRITTEN accounts of mechanical operations are apt to be both dull and misleading, save when they are of great length and fully supplied with diagrams. To avoid if possible both dangers, no attempt will be made in the present chapter to describe in full technical detail any, much less all, the long series of processes which go to make up the woollen and worsted industries. The object of the chapter is not to instruct the manufacturer or the technical student, but to indicate as clearly as may be the broad principles and results of the leading processes and their relations to one another, in order that the commercial and economic aspects of the businesses in which they are carried on may be the better understood.

The wool which the woollen and worsted industries employ is of two kinds-that which has been "through the mill" once before and that which has not. It is only the woollen branch 
which regularly uses the first kind; but that use is now great enough to justify this preliminary division of wools. Wool made from rags is no longer an occasional ingredient of a few despised fabrics, but a standard raw material for a considerable section of the trade; and, as in this case the raw material itself has to be made, some account of how it is made should come early in the list of manufacturing processes. But, first of all, the distinctive properties of wool must be mentioned; for it is the lack of some of these properties which differentiates the twice-born from the once-born wool. Both nature and the manufacturer draw a line between wool and hair ; but fibres of an intermediate character grow and are used, since nature makes no leaps and the manufacturer no objections. Hair, human hair for instance, has a smooth surface of fairly uniform texture; but the surface of the wool fibre is distinctly broken up into a series of overlapping scales or serrations. Intermediate fibres, such as goat's hair and camel's hair, have these serrations less clearly marked. All wools have more or less of wave or curl, are very elastic, and can only be straightened with difficulty. To the combination of curl, elasticity and serration wool owes the clinging property, which enables even its shortest fibres to be spun into a continuous thread. The best wools, for most purposes, are those whose 


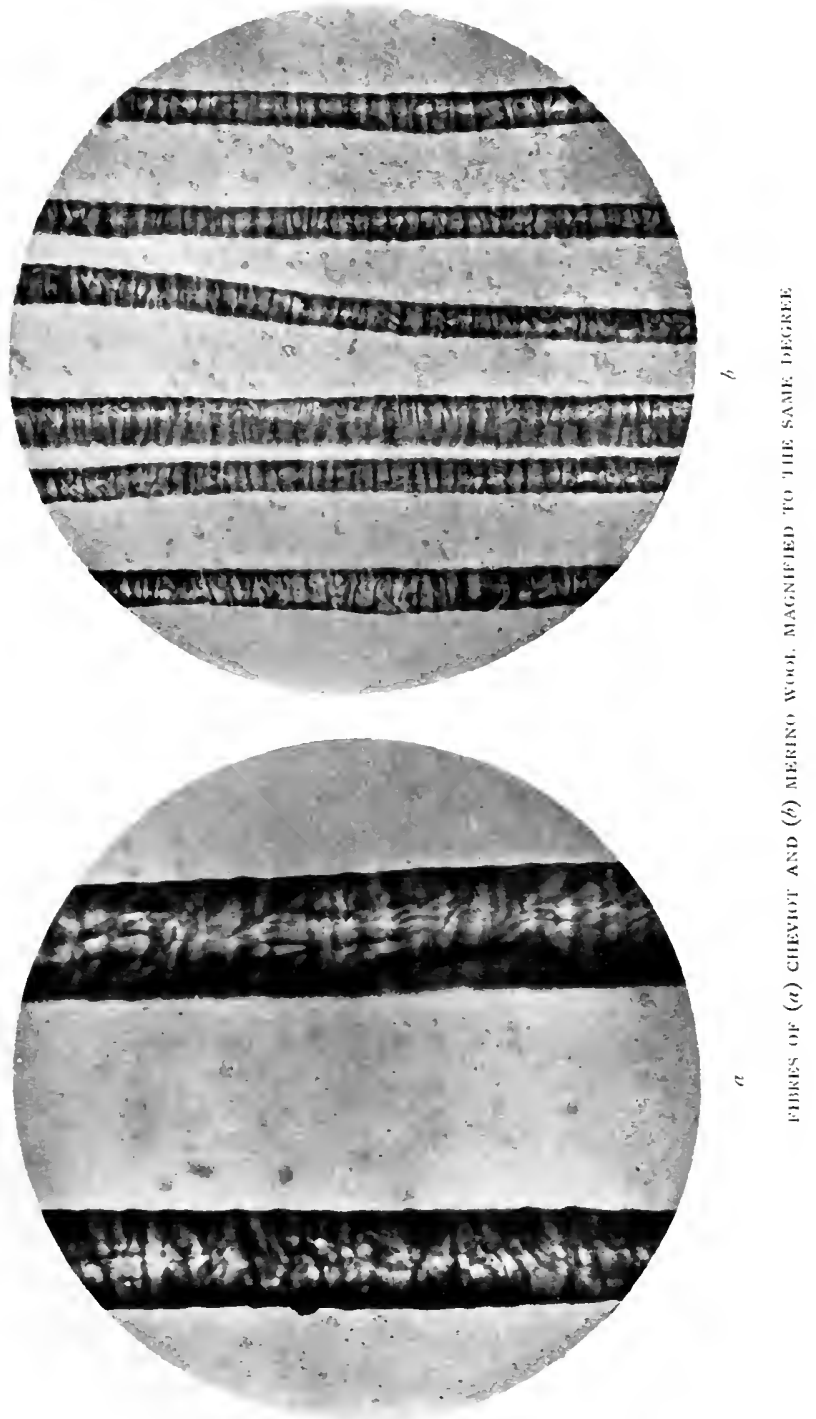



fibres are very fine, very wavy and elastic, very close growing, and covered with the maximum number of serrations to the inch. Such is merino wool, which can be spun into the finest of yarns and woven into the softest of fabrics.

Wool that has seen service as cloth is apt to have its fibres broken; it loses much of its curl and spring; its scales are in part worn away; and with these things it loses a measure of its spinning and felting properties. This explanation bears directly on the problem, Why do cheap trousers so quickly get baggy at the knees?

The method by which woollen rags are turned back into wool again is fairly simple. A difficulty arises at the outset from the fact that so many rags contain cotton as well as wool. Such are usually treated with a mixture of acid and water, raised to a high temperature, and well shaken in a revolving cylinder through which a strong air draught passes, to remove the carbonised vegetable fibre. "Extract," as the rag wool made by this process is called, is naturally inferior to the other varieties; for the wool has been more roughly handled. Pure wool rags are sorted and "seamed," that is to say, have all seams cut out by hand, and are then put into the rag-grinder, a machine of which the main working part is a short thick-set roller, covered with thousands of curved teeth and driven at several 


\section{WOOLLEN AND WORSTED INDUSTRIES}

hundred revolutions a minute. It rapidly tears the rags, as they come within its reach, held between two feed-rollers, into a fluffy mass of fibres, which an amateur cannot easily distinguish from short new wool that has gone through some of the processes preparatory to spinning.

There is of course very little resemblance between rag wool and wool as it comes from the sheep's back; and among wools there are infinite variations in length, fineness, serration and wave. Admirable wool exists in which the average length of the fibres in a lock is about an inch; in others it may be upwards of a foot. In the short fine Saxon wool there are 50 per cent. more serrations to the inch and a much more pronounced curl than in the long, relatively coarse Leicester; and so on. All characteristic properties, except length, are more or less retained in the rag wool; but the wear and tear of the first life tends to reduce the fibres to a dead level of mediocrity at their second birth. They have lost also the greasiness conspicuous in new wool.

Sorting is usually the first distinct process to which new wool is submitted, though large quantities of wool are scoured before they come on to the sorting board. Every fleece contains locks of very varied quality, from the coarse, fouled covering of the legs and breech to the fine wool of the shoulders; and these various sorts must be 
picked out, for they are put to different uses. The care with which this work is done, and the names given to the different grades of wool, vary so much from time to time and from place to place, that short accounts of sorting practice are apt to mislead. The grades may be described by fine old traditional English names, or merely by numbers, or by the description of the yarn into which they will spin. The writer has even met with a case in which Spanish terms are still in use, a curious relic of the time-over Ioo years ago -when the true merino wool from Spain was the recognised raw material of fine English cloth. Generally speaking, sorting tends to become a more summary business than it was in the past. A great quantity of wool is now hardly sorted at all, and most wool is sorted rapidly and rather roughly. If it is of good uniform quality and if it has been "skirted," that is to say, has had the dirty edges of the fleece removed, before being sold, the process may be dispensed with altogether. Very elaborate sorting is now confined to the more conservative sections of the two industries.

The fleece in its natural condition necessarily contains an immense amount of grease, and a varying amount of dust, vegetable matter, and miscellaneous impurities. One of the main objects of the careful flockmaster is to keep down 
the foreign matter; but all flockmasters are not careful, and in many cases no amount of care will ensure freedom from certain vegetable impurities, which become entangled with the wool while it is yet on the sheep's back. An instance of foreign matter due to unscientific management is the tar with which British and Irish sheep are still sometimes marked. The presence of fragments of hemp or jute among the wool may be traced to careless packing. Against these practices merchants and Chambers of Commerce in the manufacturing districts have constantly waged war. The grease, on the other hand, is not without its value. For one thing, its presence keeps imported wools supple and workable throughout their long journey. The accumulated sweat and the fatty secretion of the hair follicles are its ingredients, substances which in their turn are made up of animal fat and a variety of salts that do not concern us. As a rule it represents from a quarter to a third of the total weight of an unwashed fleece. When to this are added the other impurities, it will not seem surprising that in extreme cases the yield of clean wool from a fleece may be as low as 30 per cent. of its original weight. A yield of 45 to 50 per cent. is about normal.

Most classes of wool must be beaten or shaken in some way before they are washed, and in addition to this it may be advisable to open out the 
locks mechanically. The machine employed for the purpose, the willey, is one of the many applications of the principle of the toothed roller; but it is by no means so drastic in its operation as the rag-grinding machine, its object being to shake, dust and disentangle the locks with the minimum of damage.

The chemical problems which come up for solution in connection with wool washing are too complex to be handled here. The composition of soaps or other cleaning materials, the hardness or softness of the water, its temperature, the character of the wool and the chemical composition of any accompanying impurities, all have to be taken into account. Wool thoroughly cleaned but in no way damaged is the ideal product of the washing process, and to secure this infinite care and no little knowledge are essential. Only during the last twenty years has the work been done mechanically. The old "bowls," in which the wool was stirred about with long forks, are still in use here and there; but the washing is done for the most part in a series of troughs, through which the wool is moved steadily by mechanically driven forks to rollers which squeeze it out and pass it on. After washing it may be dried artificially by one of many competing hot air processes. But not all wool requires this artificial treatment; for the shorter and finer grades the pressure of the rollers is generally regarded as sufficient. 
By this time grease and dirt are gone, but vegetable impurities may remain. Scraps of hemp and jute too often escape detection, until their refusal to take the dye suitable for wool makes them show up as scars on the face of the finished material. But such things as seeds and burrs are visible and can be removed. The burr, which is the special plague of comber and spinner, is not the great, spiny English burr, but a thing from the southern hemisphere no bigger than a pea, consisting of a neatly rolled-up length of spiked vegetable fibre, which, whether coiled or uncoiled, sticks to the wool like a leech. Should the wool be able to stand the process, the burrs may be removed by carbonisation with acids, much as cotton is extracted from rags. But this is apt to damage the fibres, so that mechanical methods are now generally preferred. The wool is sometimes put between rollers, set so close together that the burrs are cut and crushed; but in this method, if the wool is at all "lumpy," it may be cut too. More commonly, while the wool is slowly moving in one direction, on the surface of a roller set close with wire teeth, the burrs are knocked out by the wings of another roller, whose section resembles a wheel without its rim, moving in the opposite direction. The revolving wings come close to the teeth and the burrs cannot escape. Instead of the clothing of sharp wire 


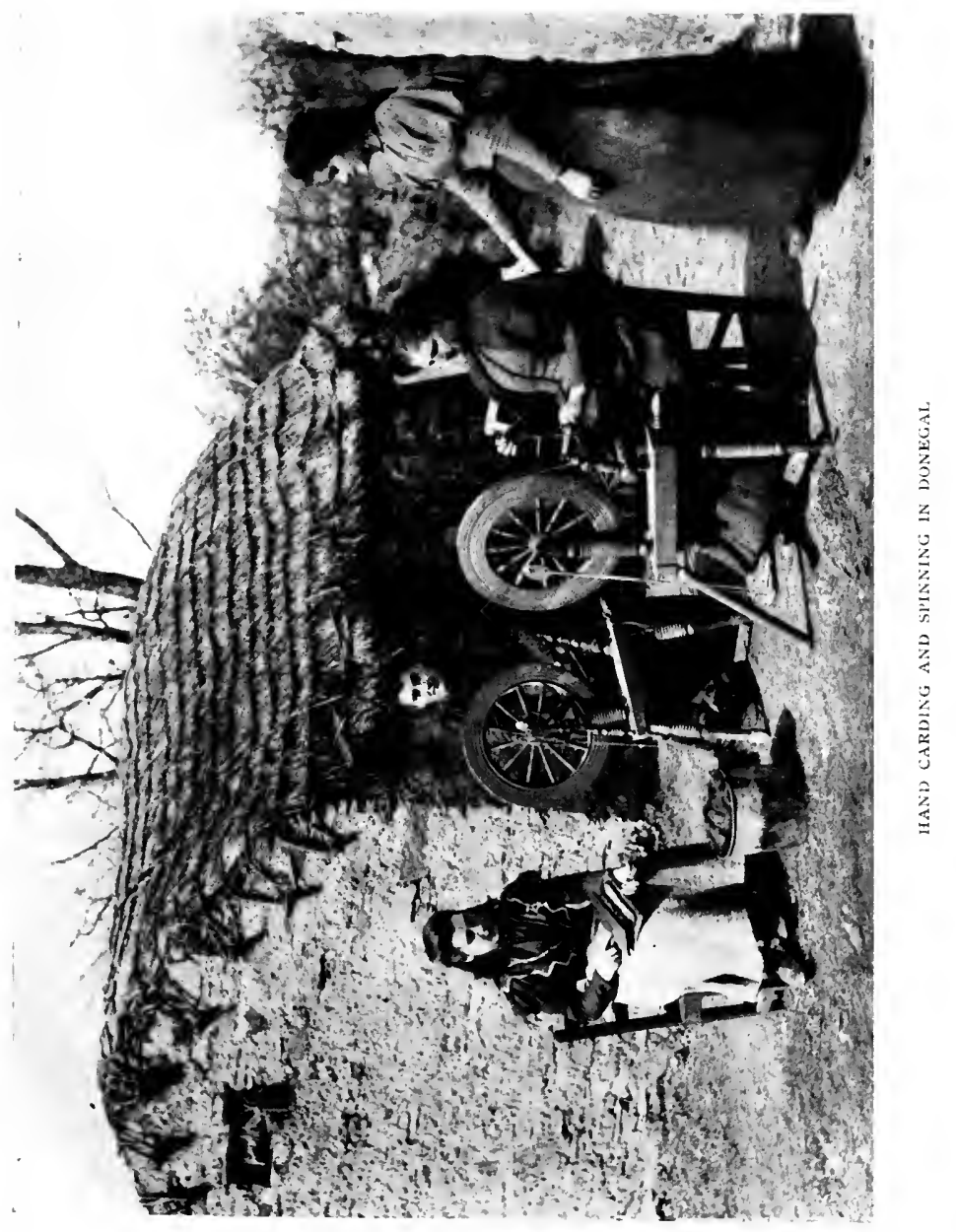



teeth, the carrying roller may be closely wrapped with flattened steel wire cut into blunt teeth and placed edgewise on the roller, in the interstices of which the fibres lie safe, while the wings of the burr extractor are knocking out the burrs. Mechanical burr extraction may be undertaken by a distinct machine, but "burring" rollers are generally attached to the carding engine which has now to be described.

Here, at the starting point of the manufacturing processes proper as distinguished from the cleansing processes, the difference between woollen and worsted yarn arises; and the methods of preparing the two yarns must be followed separately. As the woollen processes are far shorter and simpler, it will be well to take them first. The essence of woollen carding can best be understood by reference to the way in which it was carried out in the days before machinery. Two boards fitted with handles and covered with bent wire teeth set in leather were the simple tools of the old carder. Between them went the wool; and as the carder moved one board over the other by hand, somewhat as maidservants make butter balls, the wool was opened out into a sheet of interlacing fibres of uniform consistency. The more varied the positions taken up by the fibres, the better suited are they for woollen yarn.

In modern carding, rollers working on one 
another take the place of the old hand boards. The rollers are covered over with the "card clothing" of bent wire teeth, so set in leather that they may "give" a good deal when at work. Carding machines are huge erections of many horizontal rollers and cylinders moving at various speeds in different directions. The number and arrangement of the rollers varies a good deal in different classes of machines. The main cylinders, "swifts" as they are often called, are the carriers of the wool, and move fairly rapidly. Their number varies from one to four. Above them lie a number of "working" and "stripping" rollers in pairs. The former move slowly in the same direction as the swifts, but the teeth of the two are opposed; while the strippers move faster than the workers, with teeth inclined in the same direction, and clear them of their wool, returning it subsequently to the carrying swifts. Wherever two rollers meet, moving in different directions or with different surface velocities, there the wool is opened and worked by the teeth of the "clothing" -the amount of working depending on the velocities of the rollers, their nearness to one another and the closeness of the teeth on their surfaces. In the earlier stages of the process, the teeth are set wide and the rollers not too near. The work gets closer and more thorough as it proceeds. Two or three machines in a team do the work, 


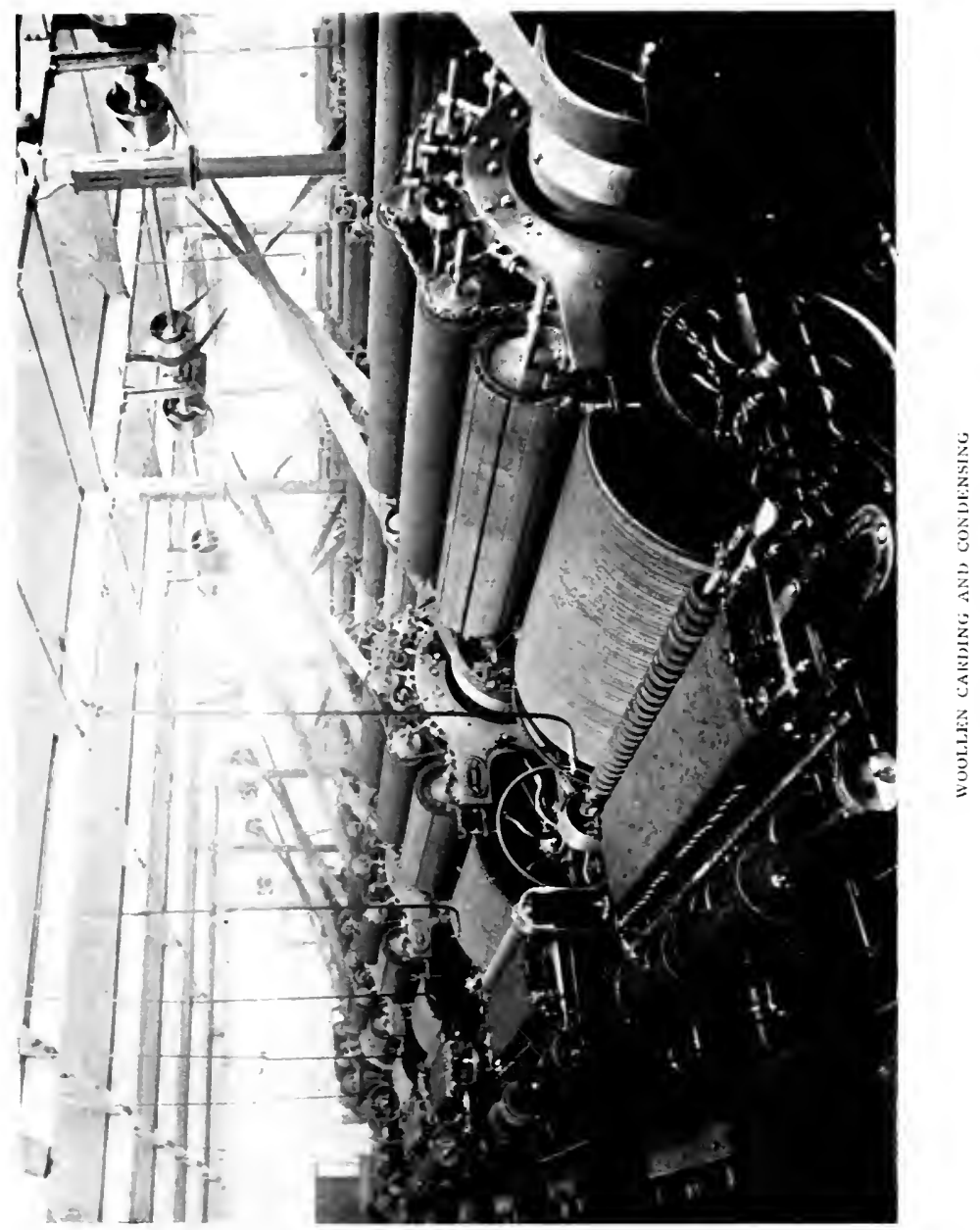



as a rule, ${ }^{1}$ and the wool comes on to the last carrying roller as a gauzy film of fibres, whose power of cohesion is a standing marvel to the layman. As it leaves the last roller it is "condensed" into "slivers" or "rovings" ready to be spun. The operation of condensing is singularly ingenious and effective. First the carrying roller is cleared of wool in continuous strips, by a pair of "doffing" rollers, the surface of each of which is composed of alternate rings of "card clothing" and smooth leather. The clothed rings on one correspond in position to the smooth rings on the other, so that between them they effectually clear the carrying roller. They are stripped in their turn and the narrow bands of wool film then pass between two broad leather belts, which work on one another like a pair of rubbing hands, reducing the bands to round, loose ropes of untwisted fibre, which are wound on bobbins and go to the spinning mule. This is perhaps the most usual method of condensing, but there are several others. Very recent improvements in carding machinery, involving a more exact adjustment of all parts and an increase in the number of working and stripping rollers, bid fair to diminish the expense and add to the speed of the whole operation in the near future.

1 The first machine is usually called the "scribbler," the last the carder. 
The series of carding processes serves, not merely to disintegrate the locks of wool and to distribute the various classes of fibre that they contain throughout the whole mass, but also to complete any desired mixture of wool with other materials, or of different coloured materials. Manufacturers of all but the best woollen fabrics constantly mix rag wool, cotton, or waste from the various processes with the new wool. There are yarns which contain no new wool at all, others which contain a very small proportion, used to give spinning power to the substitute or substitutes -for all sorts of combinations are possible. Where wools already dyed have to be mixed so as to produce a composite colour, thorough blending is also necessary. The method employed is to spread layers of the materials or shades on the floor one above another in the required proportions; then to put the mixture through one or two preparing machines of the willey type, and so to send it to the carding engines. Whether the material is mixed or pure, it is always oiled before being carded, to facilitate the operation. The oil varies from fine olive downwards through a long list of cheaper substitutes, according to the quality of the wool and the cloth. It is still often applied with a watering-can, in some sections of the woollen industry, though more efficient mechanical methods are available and are, I believe, universally employed in the worsted trade. 
Before spinning itself is dealt with, it will be well, by way of contrast, to sketch the long series of processes which come between washing and spinning in the preparation of worsted yarn. Worsted was originally made entirely out of long wool, such as that of Lincoln and Leicester sheep, from which the short fibres were removed by combing; and although to-day wools of all classes are employed, the preliminary processes are invariably regulated with a view to securing the maximum of length and parallelism in the fibres, when they come to be spun. Anything that tends to break a long fibre, to preserve or accentuate the full natural wave of the wool, to arrange the fibres cross ways, or to leave the shortest fibres mixed up permanently with the longer ones is avoided. Short and long are relative terms; for a fibre that might be short in a Lincoln wool would be fairly long in a Port Philip merino.

All ordinary worsted yarns are combed; but the treatment of the wool before combing varies with its length and character. Short, soft, fine wools are carded. Long wools are "prepared" by a separate process. Merino wool is always carded; long English wool is always prepared; in the case of many intermediate types either method may be adopted. Long wools are not carded, because the risk of their fibres being broken, rather than merely straightened out, between the 
teeth of the carding rollers is much too great. This risk is always present; but in the case of fine, short wools, it does not counterbalance the advantages of carding. Such wools require to be opened, their different classes of fibre require to be uniformly distributed throughout the mass, in order to produce a uniform yarn, in worsted as in woollen. Further, the carding can be so arranged as to facilitate one of the main objects of the preparatory worsted process-the straightening out of the fibres.

In general character the worsted carding engine resembles its fellow in the woollen trade. The "clothing" and speeds of all the rollers have to be adjusted so as to treat the wool with the utmost consideration, to avoid breakages, and-so far as possible at this early stage-begin the process of combing. Work between two sets of opposing teeth starts far more gently, owing to a judicious regulation of speeds, in a worsted than in a woollen carder. The fibres have, as it were, to be coaxed apart and, if possible, smoothed in one direction, not merely reduced to a film in which uniformity of direction is immaterial. When the carding process is over a certain number of knots and very short fibres are left sticking in the teeth of the cards and the longer fibres are partially straightened out. At the finish, wool destined for worsted yarn is condensed into a single, thick, untwisted rope 
or "sliver". These ropes are then cleansed of oil and other impurities, by being passed through bowls of suds, between squeezing rollers and over hot metal drums in a "backwashing" machine.

For long wool a series of "preparing boxes" or "gill boxes" take the place of the carding engine. Their task is to comb and straighten out the wool, without definitely removing the short fibres, and their working parts are fairly simple. There are two pairs of horizontal rollers, and between them a number of actual combs, their teeth in a vertical position. The trade does not use the word comb in this connection, but it applies strictly. "Faller" is the technical term-a word which describes the motion rather than the character of these combs; for each in turn moves forward along a pair of screws, with and through the wool, falls as it reaches the second pair of rollers, is carried back on a low-level pair of screws, raised by a lever to its former position, and so da capo. Before entering the first pair of rollers the locks of wool are laid parallel and roughly straightened by hand. As the fallers move faster than the front rollers and the back rollers faster than the fallers, the wool is at the same time dragged straight and combed straight. The boxes are of course graduated. In the first there may be two pins to an inch on the fallers; the last has fourteen or sixteen. Long wool usually goes through half a dozen 
boxes, is then washed, oiled again and put through at least two more boxes before it is sent to be combed, in the technical sense of the word. The "slivers" are joined together and drawn out finer than before, again and again during the process; so that the last sliver of all is sure to be uniform in structure from end to end.

Carded wool has also to go through a couple of gill boxes, as the sliver when it leaves the card is not yet straight and level enough to be quite fit for combing. These boxes closely resemble the final preparing boxes for long wool, and the principle on which they work is identical.

The main end of combing is the separation of the long from the short wool一of the "top" from the "noil". The "noil," as its dialect name implies when translated, is a waste product from the worsted standpoint; though "noils" are often spun up into woollen yarn, where length of fibre is relatively immaterial. "Tops" apparently owe their name to the methods of the hand wool comber, who was accustomed to hang the wool on a post and comb it with a downward motion. Short wool came away in the comb, long wool remained on top. As performed by hand the process was perfectly simple, but no part of modern textile machinery gave the inventors more trouble than the comb. In exact proportion to the difficulty of overcoming the mechanical pro- 
blem in the first instance, is the difficulty of describing concisely the working of the modern combs. Three types have to be dealt with: the Noble comb, which is the one most used in England; the Holden or square motion comb, the use of which has always been almost confined to the various firms at home and abroad that bear its inventor's name; and the Lister or nip comb, which was the first type that met with great success, but is now not very extensively employed. At least one other important type of comb exists, the Heilmann, but it is seldom used in this country.

All English combs have certain structural features in common. 'The central portion of each contains a horizontal, circular band of metal, some four or five feet in diameter over all, upon which are set rows of vertical teeth or pins. In among these teeth the wool is pressed, by one device or another, as the circle rotates, and from them the long fibres of the top are drawn off by one or more pairs of rollers, which grip those fibres as they come within reach. All combs are heated, and the temperature of a combing mill is necessarily high - a direct inheritance from the old hand trade, in which the workman warmed the steel teeth of his combs over braziers of charcoal, whose fumes made his occupation an unattractive one, when carried on in small, ill-ventilated rooms. Why wool combs better when the steel teeth are 
hot has not been fully explained; but the fact is certain. Right through the preliminary processes, indeed, a high temperature is a technical advantage.

The Noble machine is a compact, circular structure, in which the main circle stands at a height of about two feet from the ground, with a steam box below it. Inside this circle are two smaller ones, about a foot and a half in diameter, each touching the main circle at opposite points on the interior of its circumference. All rotate in one direction. The slivers of wool to be combed are rolled up in creels attached to the outer side of the great circle and travelling with it. They move up automatically in turn and fall on to the pins of the circles at the points where the outer one touches the two inner ones. A brush, rising and falling rapidly, dabs the wool down among the two sets of pins, and there true combing begins. Short fibres and miscellaneous impurities stay where the dabbing brush puts them. Long fibres, already straightened by the preparing processes, also fall across both circles. As the latter revolve and draw apart, the long fibres are further straightened and are finally left protruding from the inside of the outer or the outside of the inner circle. They travel thus, until they meet the vertical rollers set to catch them, towards which their points are steered by a leather strap. 


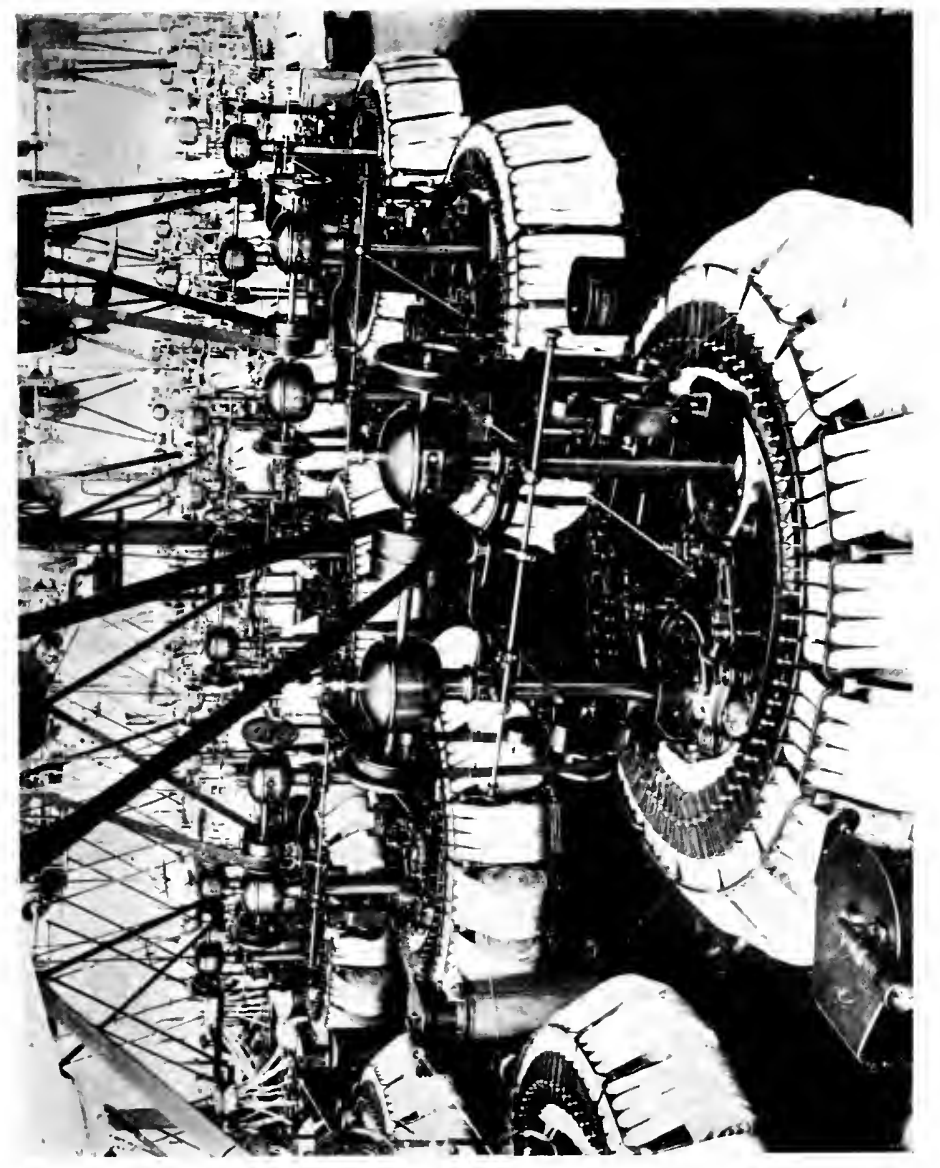



Any fibres too short to reach the point where the rollers grip are denied the honour of becoming tops. Each inner circle has one pair, the outer circle has two pairs, of these drawing-off rollers. After passing the rollers, the pins of each circle run between a series of knives, fixed strips of steel gently inclined upwards until, at their further extremity, they are as high as the tops of the pins. In the case of the outer circle, the wool which these knives lift from between the pins is fed again on to both circles as at the first. What is lifted from the inner circles is the final uncombable material, the noil. It is carried away, down a funnel and out of the worsted trade altogether. The four ribbons of combed fibres, two from the outer and one from each of the inner circles, are condensed by tubes and rollers in the centre of the machine into a beautiful, even band which coils itself softly in a revolving can.

In the Noble machine all the actual combing is done between the two circles of the machine and inside it, so to speak. With the Lister and the Holden machines this is not the case. Both have the great, toothed circle; neither has the internal circles; in both the combing is largely done by mechanism external to the circle. Some way from the circle of the Lister comb stands a so-called "feeding head," which resembles an ordinary gill box, except that the fallers are curved 
downwards in the middle and that the place of the final rollers is taken by the "nip," from which the machine takes its second name. The nip consists of a pair of curved metal jaws, fitting the fallers. These jaws close on the wool as it leaves the fallers, stretching and combing it. Short fibres which do not reach the jaws get left behind. Those whose points are in line with the points of the longer ones are taken on towards the circle; for the jaws swing forward some 30 degrees with their mouthful of wool. There they meet another movable portion of the machine, the curved carrying comb at the end of a jointed metal arm. Now the jaws open and the carrying comb, at this point in an almost vertical position, takes their load and begins its task. It turns over into a nearly horizontal position and places the wool on the circle. Evidently, for the machine to work smoothly, the curves of fallers, nip and carrier must correspond to that of the circumference of the circle; and there must be the most delicate adjustments at each point. The circle has many rows of teeth. Into these the combful of wool is pressed by a dabbing brush. Short fibres are imbedded among the teeth; long ones form a fringe outside the circle. The circle is, of course, in motion, and in time the long fringe is gripped and drawn away by a pair of horizontal rollers. Steel knives between the pins 


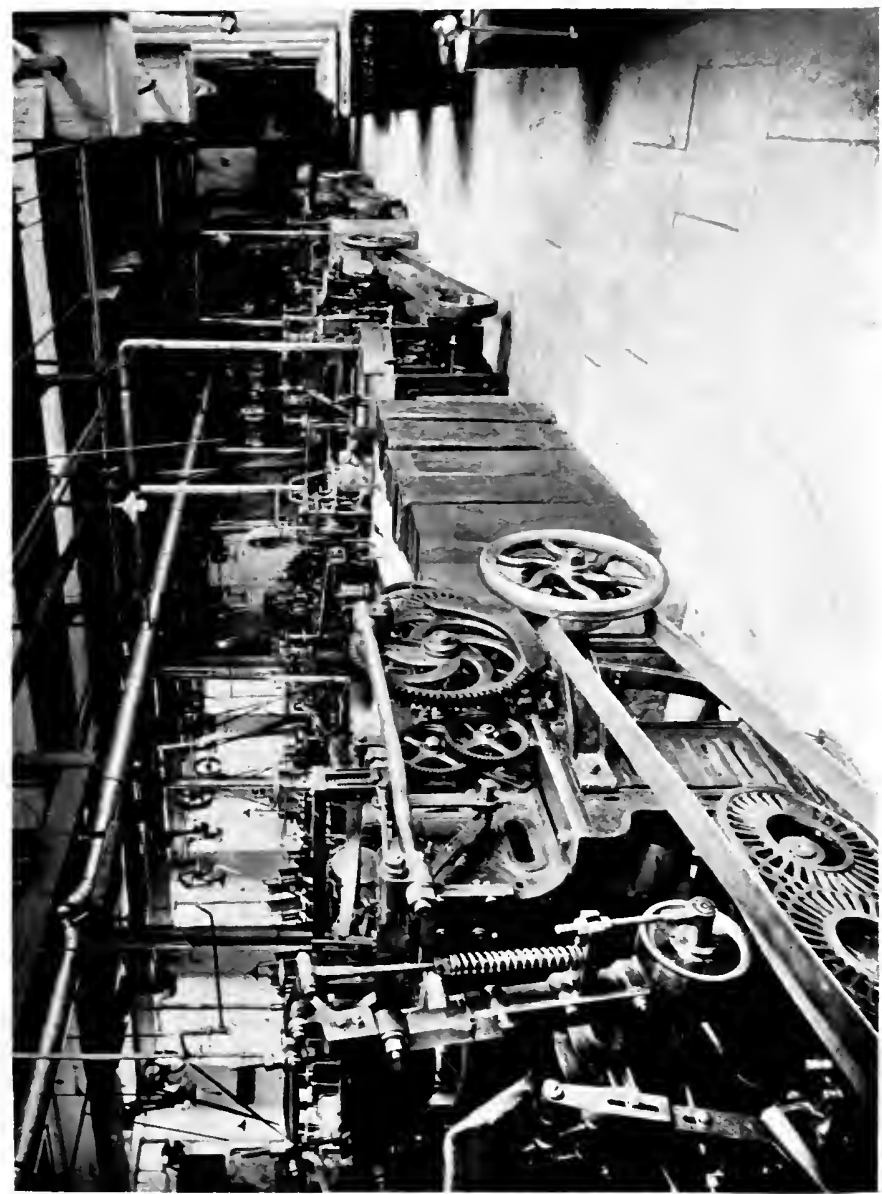



lift out the noil, as in the Noble comb, and the work is done. The Lister comb is best suited to long wools and mohair. For short wools it cannot do as good work as its competitors.

The feeding mechanism of the Holden comb is outside the circle, but has nothing else in common with the Lister feed. First, two slivers are drawn up between a pair of fixed rollers. From these rollers to the circle they are carried by two other pairs of rollers, each on the end of a movable arm. These arms work alternately, i.e., when one is feeding the circle the other is being fed by the fixed rollers. The effect is rather that of a pair of fists striking out in turn. As the wool is in no way combed when the fists deliver it on to the circle, and as it hangs down outside the circle, arrangements have to be made for combing it there. This is the task of the so-called "square motion". It consists of a series of elaborately toothed fallers, or combs, outside the circle, moving upwards through the fringe of wool and then backwards away from the circle. Obviously such fallers, being tangents, although they have a slight horizontal curve, are nearer to the circle at one point than at others. Thanks to this, each section of the fringe is most thoroughly combed. First the coarse teeth of the end of a faller lift and comb the tips of the long fibres; then the finer teeth of the centre of 
another faller dig deeper into the lock as the circle carries it on; lastly, the very fine teeth of the further end of the faller pass through the roots of the lock close to the pins of the great circle. To counteract the pull of the fallers and prevent the wool from being dragged out "by the roots," it is pressed down between the pins of the great circle at the point where the fallers get to work, by a plate or knife from above.

Even then the combing is not complete. Just before the combed fringe is drawn off by the rollers, there descends into it from above-and just outside the main circle pins-another row of pins, fixed to a "segment," i.e., a bar curved exactly like the main circle. These pins prevent any knots, which may have escaped the fallers, from being drawn away with the long wool.

Besides thus making noil in the main circle, the Holden comb makes what are called "robbings" in the fallers. These are recarded and recombed, for they may contain fibres useful for worsted.

After combing it is customary to put the top through gill boxes once more, a large number of combed slivers being put up to each gill box and drawn out into one. Thus any irregularities in the arrangement of fibres are got rid of, and that uniformity of structure which is essential to successful worsted spinning is secured. On leaving the second of these finishing gill boxes, the top 
is built up, by an automatic balling process, into coiled, flat ended balls of equal weight, each containing the same length of sliver. At this stage it is usual to moisten the wool, so as to produce a uniform condition of humidity throughout. There is a standard condition, now officially recognised, according to which a top in the combing of which oil has been employed must not contain more than 16 per cent. of water, or more than $2 \frac{1}{3}$ per cent. of oil. Oddly enough a top that has not been oiled absorbs less moisture than one that has, so that the standard percentage of water is in this case rather lower. The coiled tops ought to be kept for some time before being unwound for use, in order to preserve the straightness that by this time has been imparted to the fibres.

Even now the worsted sliver is not ready for the final spinning operation. It has to be drawn. Drawing, like some other worsted processes, consists in the repetition of a simple treatment, under slightly varying conditions. The object is to attenuate the combed sliver and render it more and more uniform, until it is fit for spinning. The later drawing processes are, in fact, a sort of preparatory spinning. Many machines are employed, the number varying according to the character of the wool. In each the general principle is the same-two pairs of rollers revolving at different speeds and drawing out the sliver. In 
every case two or more slivers are welded into one, finer than either ; and a sliver is never drawn twice in the same direction. The first two or three machines are gill boxes once more, with fallers as well as rollers. From the first of these, and in some cases also from the second, the combined sliver is delivered into a can. Then comes a gill box, from which the sliver is delivered on to bobbins running on vertical spindles. Here it acquires a certain amount of twist. From this point onwards fallers can no longer be used, for they would tear the roughly-twisted rope of wool. So, in all the later machines, the essentials of the mechanism are the two pairs of horizontal rollers, naturally set closer together than in the gill boxes, the vertical spindles and the bobbins. The bobbins run freely on the spindles. Above them and fastened to the spindle is the "flyer," a pair of metal arms projecting horizontally from the spindle, with their ends bent downwards. The sliver is passed through a hole in the top of the spindle and then through an eye at the end of one of the arms of the flyer and so carried to the bobbin. As the flyer rotates, the bobbin is dragged round; but as it moves more slowly than the flyer, it is always winding the thread on to itself. The spindles get lighter, the bobbins smaller, the thread thinner and more twisted from machine to machine; until at last, in what is called 
the roving box, it is already a partially spun yarn.

This short account of ordinary drawing is adequate for present purposes, since the general principles of drawing are most simple; and no attempt is here being made to refer to all details. It should, however, be pointed out that there are two main methods of English drawing, namely "open" and "cone" drawing, and also what is known as French drawing. The difference between "open " and " cone" drawing is a highly technical one, connected with the method of winding the sliver on to the bobbins; but the distinction between English and French is clear, important and easily grasped. It consists in the fact that the French system puts no twist whatever into the thread, which is wound on to horizontal bobbins. Further, in the French system, fallers are not used; but in every drawing frame the sliver is supported by a spike-covered cylinder, or "porcupine," between the back and front rollers. Rubbing-leathers-like those of a woollen condenser-are employed to give firmness to the unspun thread.

In its essentials ordinary worsted spinning differs but little from the last of the drawing processes. There is however in spinning no combining of threads, and there is a vast deal more twisting than at any previous stage. The oldest type of 
spinning-frame, the "flyer" frame, resembles the roving machine very closely. Frames are usually made double, that is, they have rows of spindles on each side. The rovings, wound on bobbins, are placed on pegs on the upper part of the frame. Each thread passes, as it has so often passed before, between two pairs of drawing rollers, revolving at different speeds, and is stretched as much as the length and cohesion of the fibres will permit. Between the drawing rollers are two pairs of small "carrying" rollers, whose main business is merely to conduct the thread to the front rollers. The surfaces of the carriers move rather faster than those of the back rollers. Twist is given to the thread between the "nip" of the front rollers and the arm of the flyer, to which it goes direct from the rollers, by the rapid revolution of the flyer; and the spun thread is wound on to a second bobbin running freely on the spindle. The bobbin is made to rise and fall automatically in order to secure accurate winding. Very great speed is impossible in flyer spinning; for as the flyer is fixed to the spindle some distance from any point where the latter can be supported, high speeds lead to excessive vibration and so are undesirable. The two other types of frames regularly used in worsted spinning are free from this objection. These are the cap and the ring frames. So far as the drawing work is con- 


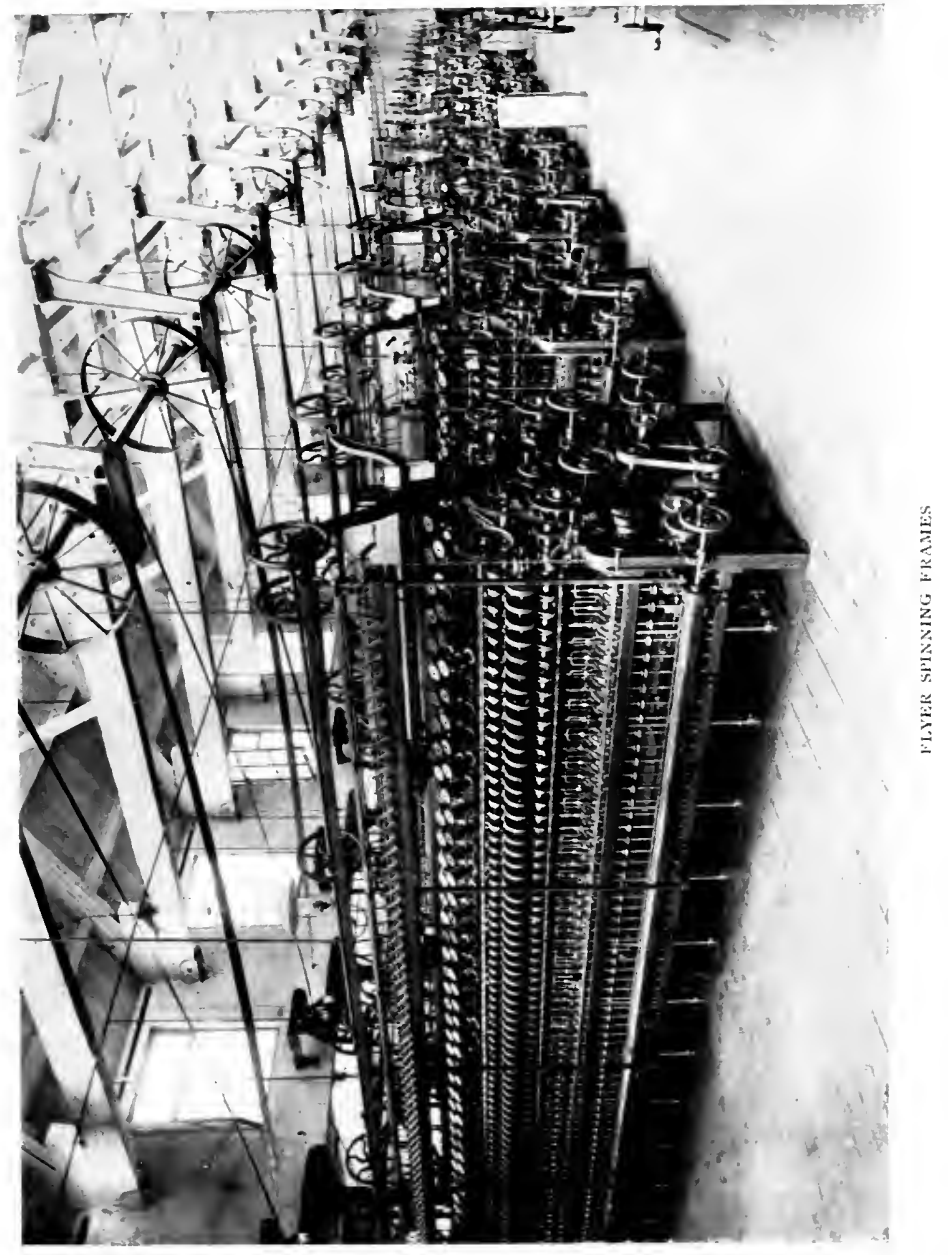



cerned, these frames are identical with that just described. It is the spinning and winding mechanism that differs.

The cap spindle, unlike the flyer spindle, is fixed-a mere peg of metal. The cap from which it takes its name is also fixed. It is a steel tube, closed at the top, where it receives the head of the spindle, over which it fits. Just above the point where the spindle is fastened to the rail that carries it, it passes through a "whorle" or small, solid, horizontal wheel with a grooved edge on which a driving belt works ; so that it is the whorle that rotates, not the spindle. To the whorle is attached a brass tube that fits the spindle closely; and the bobbin rests on the whorle. Thus the bobbin is driven round, not dragged round; and twist is imparted to the yarn between the rollers and the point where it is being wound on the bobbin. The business of the cap is to direct the thread to the proper point on the surface of the bobbin. A "lifter plate" causes the bobbin to rise and fall, so as to secure accurate winding, just as in flyer spinning. In cap spinning, there is a perpetual rubbing of the yarn against the edge of the cap, round which it is travelling at an immense speed. There are also other causes of friction that cannot be dealt with here. Consequently this type of spindle is best adapted for very fine yarns of high-class wool, 
which can stand the friction and which are required to have a smooth surface. In the spindle mechanism itself there is comparatively little friction or vibration, so that cap frames can be driven far faster than flyers.

In ring spinning the spindle rotates and the bobbin with it; for the latter is attached to a plate on the former. But the spindle has no arms and rotates in a long metal "sleeve," so that it can be driven rapidly with little vibration. The ring mechanism, from which the name comes, is responsible for steering the yarn to its place. All the spindles on one side of a frame pass through holes in a horizontal ring rail. Round the upper edges of these holes are fixed the rings, vertical steel circles with a flange at the top. On the ring runs the "traveller," a small steel hoop with a gap in it, that can be squeezed over the flange of the ring, and will then run on.it freely round and round and can only be pulled off with difficulty. The thread passes through the traveller to the bobbin, the motion of which drags the traveller round. Twist is put into the thread between the rollers and the traveller, just as in the flyer frame it is put in between the rollers and the flyer arm. But whereas on the flyer frame the bobbin is dragged, in the ring frame the bobbin does the dragging. Lastly, with this spindle, the accurate winding of the yarn on the 


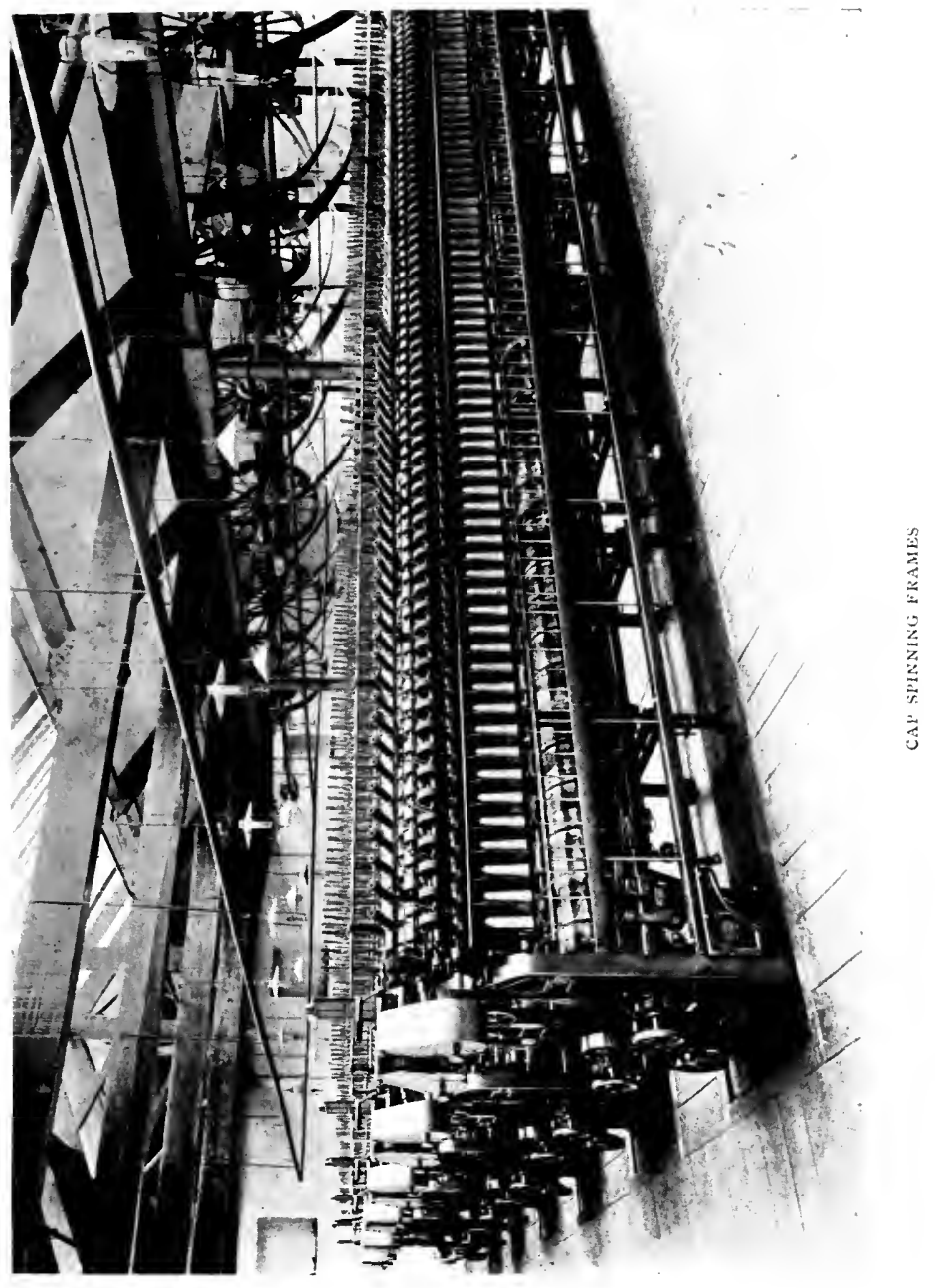



bobbin is due, not to any movement in the spindle, but to the rise and fall of the whole ring plate, with its rings and travellers.

The three methods of spinning just described are all developments of the old water frame or throstle that Arkwright perfected. Very different in principle is the machine invariably used for woollen and occasionally for worsted spinningthe mule. The special feature of the mule is the movable carriage, on which the spindles are fixed, a feature which makes the machine occupy a great deal of floor space. In a woollen mule, bobbins of condensed sliver are placed in a fixed frame, and the sliver passes between a pair of rollers to the spindles. These stand, sloping slightly backwards towards the fixed frame, in a long row upon the carriage ; and on the spindles are fixed the tubes or spools on which the yarn is to be wound. At first the spindles' tips are close to the rollers. Then the rollers pay out sliver and the carriage moves outwards, the spindles rotating meanwhile and imparting twist. At this stage no yarn is wound up; for the tubes move with the spindles, and the backward slope of the latter and the position of a long horizontal guide wire, placed just below their tips, prevent the rotatory motion from doing any winding work. The thread passes from the tip of the spindle to the rollers. It does not gyrate, as in frame 


\section{WOOLLEN AND WORSTED INDUSTRIES}

spinning, but remains taut while it is being twisted. When the carriage has moved part of the way out, the rollers cease to supply fresh sliver, the spindles turn faster than before, and the thread is thus elongated and twisted at the same time. The twisting generally continues for a few seconds, when the carriage has moved out its full distance; but of course the amount of twist put into yarns varies. When enough twist has been given, the spindles take a few turns in the opposite direction to that in which they have previously been moving, in order to unwind the short stretch of thread nearest the spindle, which has become over-twisted and wrapped about the spindle point. Then the guide wire drops and a second wire descends on the threads from above, forcing them down, so that they no longer run to the tip of the spindle, but to a point on the surface of the tube or spool; and as the carriage moves in again, a slow turning of the spindle winds up the finished yarn. After that more sliver is given out and the whole process is repeated.

The mule, when used for worsted yarn, has two pairs of fixed rollers on the stationary frame, between which the sliver is drawn out, just as on a throstle. The front pair pay out the drawn sliver all the time that the carriage moves, while the spindles are imparting the necessary twist. 


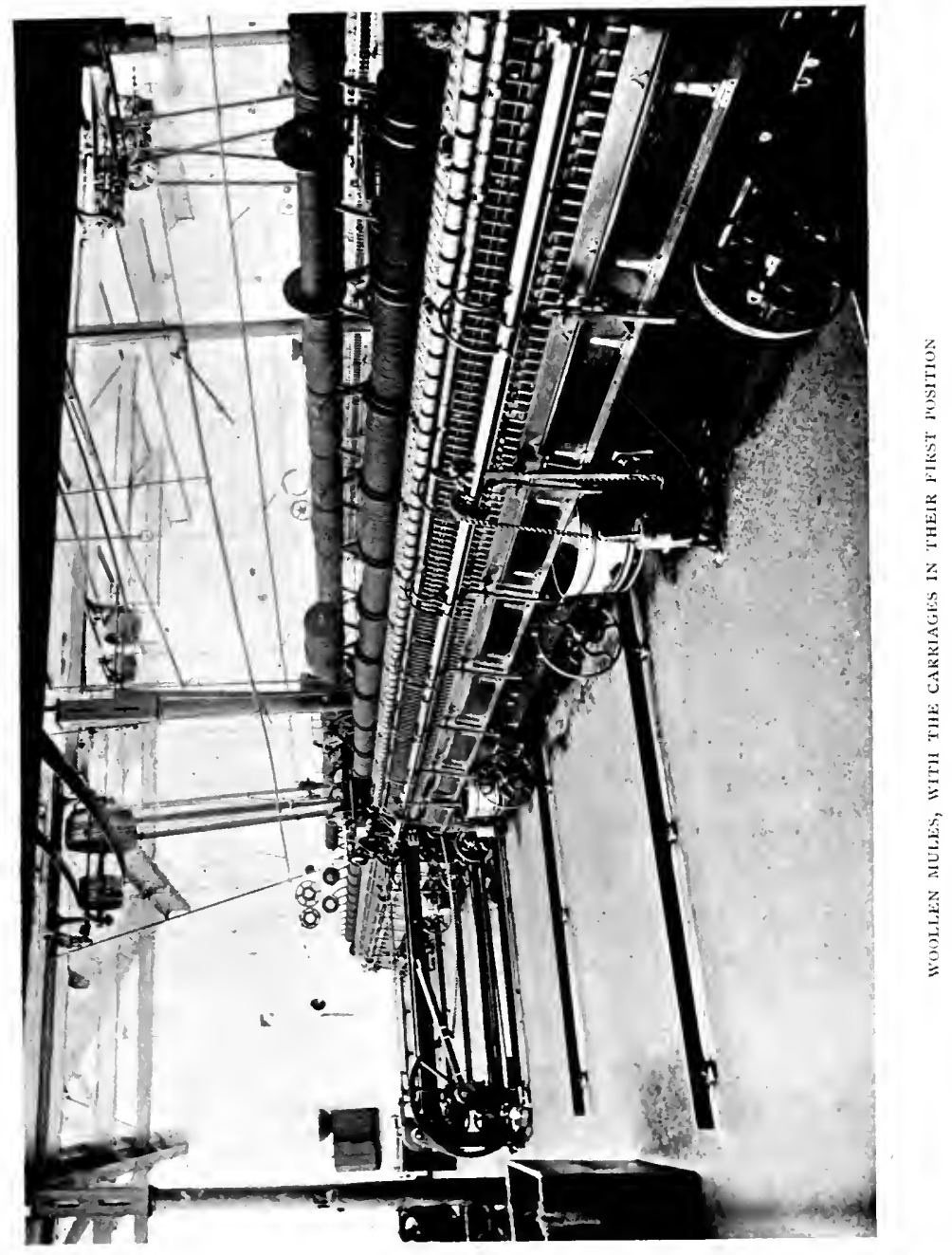



Mule spun worsted yarns, though by no means unknown in this country, are not so common here as on the Continent. They are commonest in the hosiery yarn trade. It is generally admitted that the combination of the so-called French drawing with mule spinning produces a yarn whose softness and fulness cannot easily be attained by any other method; for in mule spinning the friction and drag on the yarn, incidental to flyer, cap and ring spinning, are very largely avoided.

Yarns are usually described by numbers or "counts," indicating their fineness ; but there is still a variety of local customs in this matter, at least so far as the woollen trade is concerned. The worsted practice is simple and uniform. Its basis is the hank of 560 yards. The count is the number of hanks that go to a pound avoirdupois. Hence a high count, such as 6o's, means a fine yarn, a low count, such as 12 's, a coarse. In most systems of reckoning woollen yarn a high count also means a fine yarn; but the starting point is never the hank of 560 yards. Sometimes the calculation is based on the number of yards or skeins to the dram, sometimes on the number of yards to the ounce. Both these methods are employed in Yorkshire. In Scotland the usual basis is the "cut" of 300 yards, in the West of England the "snap" of 320 
yards. Uniformity is obviously desirable, and, failing anything more systematic, there seems no reason why the worsted system, which is very widely known, owing to the extensive dealings in worsted yarn, should not be generally adopted.

There is no need to describe the machinery employed, both in the woollen and worsted industries, for twisting finished threads together. In the worsted industry there is about one doubling to every $3 \frac{1}{2}$ spinning spindles, and in woollen about one to every $12 \frac{1}{2}$. Twisting is used either to strengthen the yarn or give it variety, or for both purposes. It is carried out in very much the same fashion as spinning, with no mechanism of special interest. It is, however, a most important process in relation to cloth designing, all sorts of colour effects being produced by the use of double or treble yarns, especially in the manufacture of fancy woollen cloths; but the details of design lie outside the scope of this chapter. It should, however, be noted that new materials may be introduced at this point, it being, for instance, not unusual to twist threads of silk with threads of woollen or worsted, in order to produce fancy yarns of the best class. In other cases threads of wool and cotton may be twisted together. Then, too, the method of twisting is important as an element in the finished cloth, 


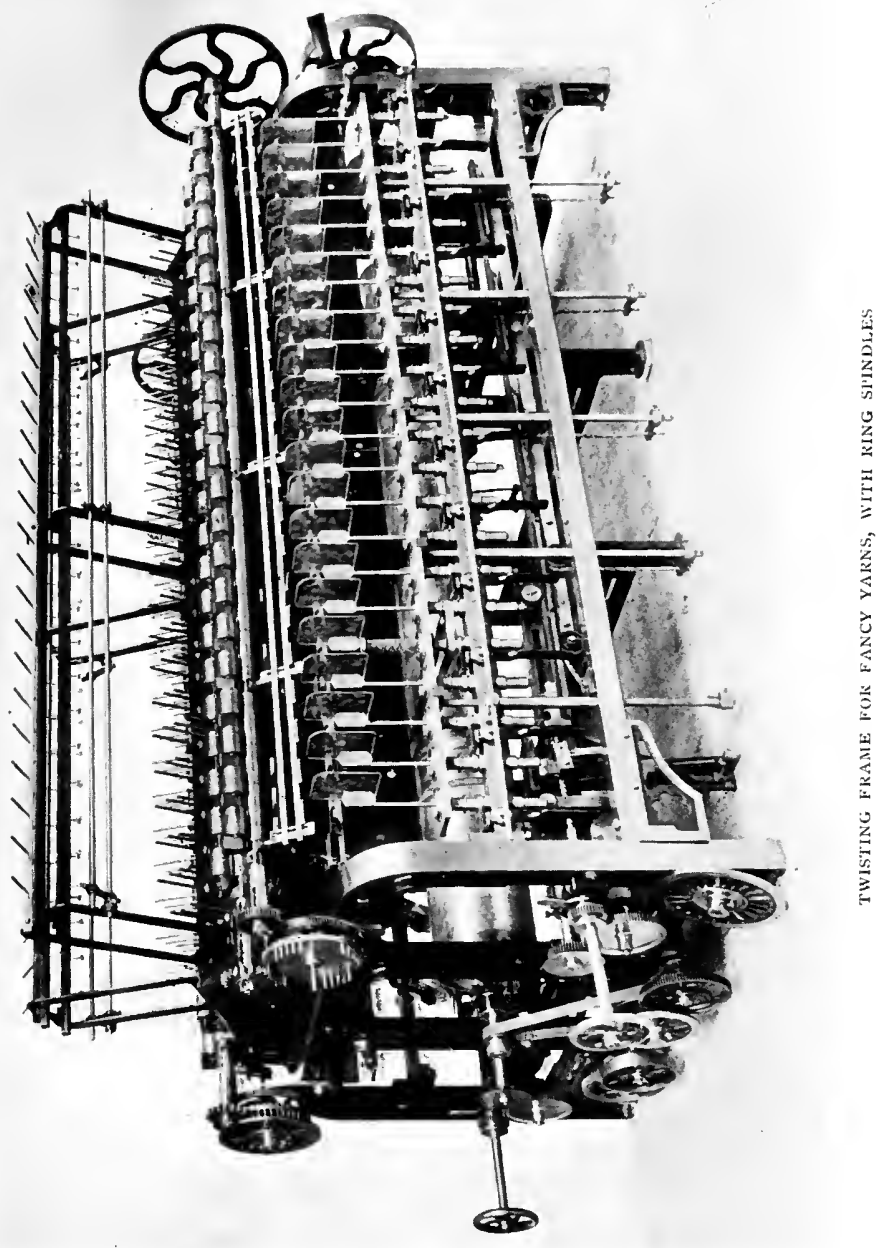



irregular twists being often employed to produce the bizarre effects which from time to time catch the public taste.

All yarns that are to be used in the production of fancy coloured fabrics, whether woollen or worsted, must of course have received their colour before they go to the loom. The yarn itself may be dyed, but more frequently the yarn is made of dyed material, the dye being applied to the uncarded wool in the case of woollen and to the combed top in the case of worsted. Many yarns destined for use in self-coloured cloths are also made of dyed materials, almost all the finest blue, black, and scarlet woollen cloths being what is called wool-dyed, as opposed to piece-dyed. In some cases there may be a double dyeing process, that is to say, both the raw material of the yarn and the finished piece may be dyed, this double dyeing being due either to the desire for a singularly fast colour in fine cloths or to the need for separate treatment of the vegetable and animal fibres in goods made of mixed wool and cotton.

Weaving in Great Britain is not entirely done by power looms ; but the power looms predominate so greatly, that any separate account of the hand loom would be out of place in this short sketch. Not that the hand loom is extinct or likely to become so. It survives not merely as a curiosity 


\section{WOOLLEN AND WORSTED INDUSTRIES}

in out-of-the-way districts, or as a means of weaving a few elaborate and expensive fabrics, of which only small quantities are required, but also as the indispensable tool of the best textile designers and pattern weavers. New designs can be and are worked out on the power loom, and it may be that in time the hand loom will disappear altogether; but this seems improbable, for the older appliance is both economical and convenient for experimental purposes.

The modern power loom is a well-known triumph of automatism, into which have been condensed the inventions of many centuries, but especially of the last century and a quarter. The shuttle moves without human aid. The proper warp or longitudinal threads are raised and lowered to let it pass. Each cross or weft thread, as it is left by the shuttle, is beaten home against the growing stretch of cloth behind. That cloth slowly winds itself on a beam at one end of the loom, while at the other end the parallel threads of the warp are paid out from a second beam. The breaking of a thread in warp or weft brings the loom to a standstill. In some of the latest types of loom even the refilling of the shuttle with weft yarn is performed automatically. And these are only the main motions. It is altogether impossible to give a complete account even of a simple type of loom; so here as in other parts 


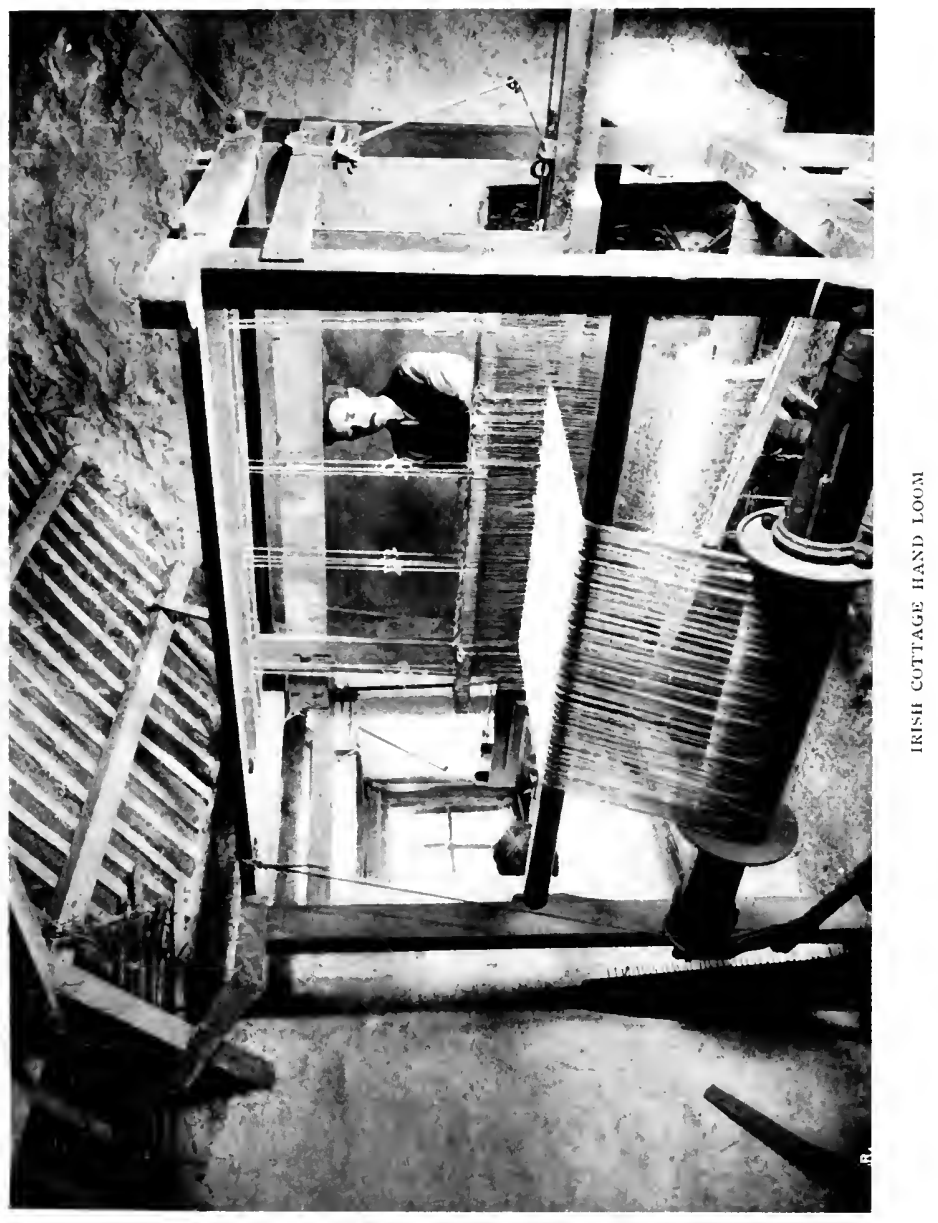



of the present chapter, no attempt will be made to do more than call attention to certain features of outstanding importance.

When once the loom is set agoing, human agency is reduced to mere supervision; but in the "mounting" of the loom much elaborate hand labour is still required. This accounts for the fact that the economy of power over hand weaving only becomes marked when a long piece of material is woven every time the loom is mounted. The first and most complex task is the arranging of the warp. In fancy weaving, each one of many hundreds of distinct threads must be in its place, or the pattern will be spoiled; and in all kinds of weaving careful handling of the warp is necessary. Sometimes this work is still done entirely by hand. Usually the assistance of one of a variety of different types of "warping mill" is called in. But in any case much elaborate arranging of the threads is required. In connection with or immediately after the business of warping, the threads are dressed, that is to say brushed and sometimes treated with size, the object being to keep them smooth and prevent projecting fibres from catching, while the loom is at work. Throughout these processes their relative positions must be retained, and they are eventually wound up on the beam at the back of the loom, at uniform distances one from another 
and with a uniform tension. In all these operations the amount of work done by purely automatic means is small, though the tasks of warpers and beamers are facilitated by various implements and appliances.

To understand the next process in loom mounting it is necessary to return to the structure of the loom itself. It is essential to all weaving that the warp threads running the length of the piece, should be lifted in sections, so that the shuttle may pass over some and under others. In the simplest type of weaving, for example, such as is seen in plain calicoes, linens and cloths, the shuttle passes at one stroke over the odd and under the even threads of the warp, and at the next stroke over the even and under the odd. Different "weaves" are secured by varying, almost ad infinitum, the way in which weft and warp cross and recross each other. In the construction of very elaborate figured fabrics, it is necessary that each warp thread, or at any rate that very many small series of warp threads, should be under separate control ; but in the majority of fabrics the warp threads can be raised or lowered in large series. In the elementary weave just referred to the threads fall into two groups, and simple arrangements for raising and lowering them will suffice. The work is done by means of the healds and heald shafts, which must now be briefly described. 


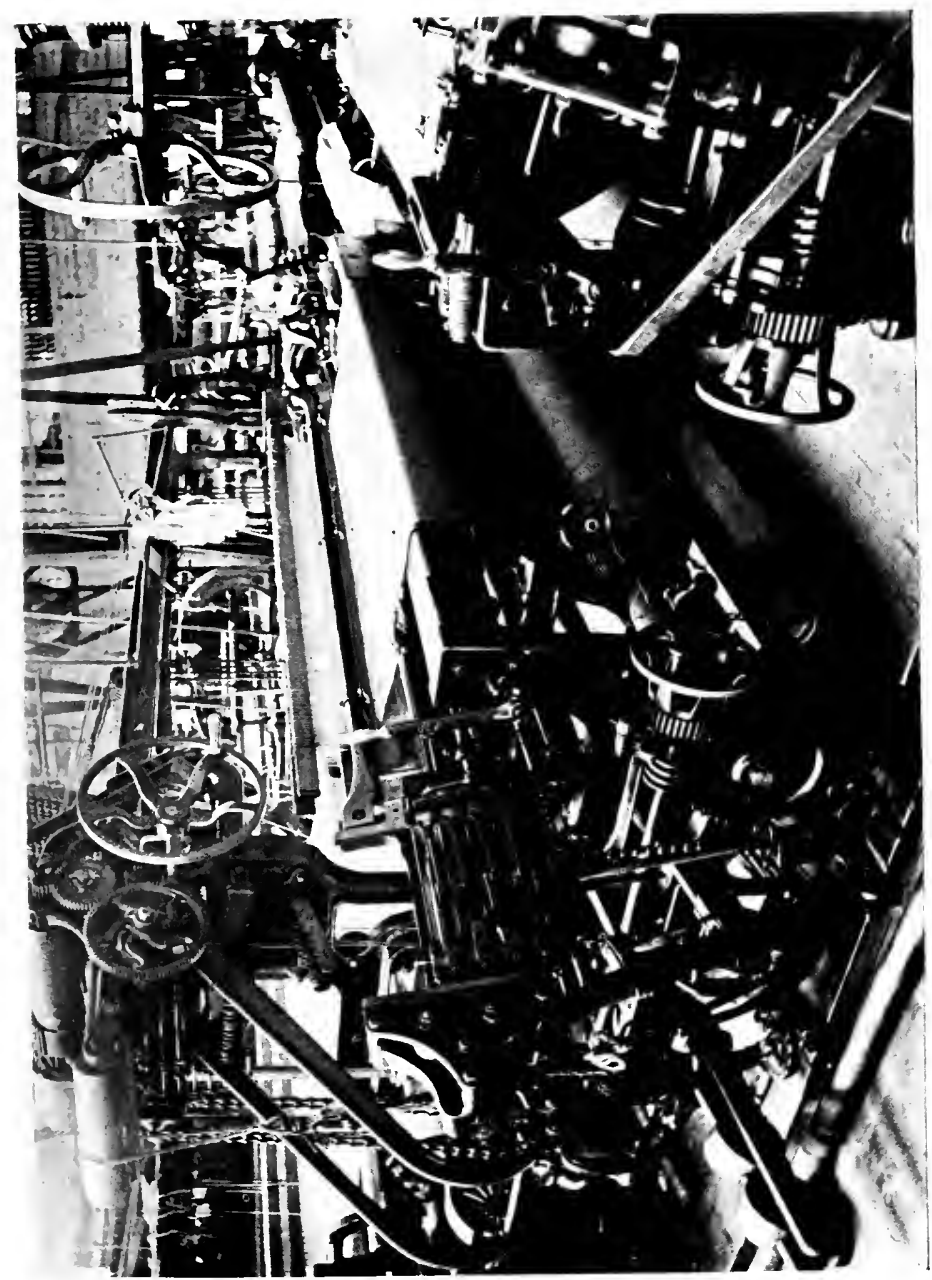



The healds are vertical wires, each with an eyelet hole in the middle, fixed at the top and bottom into horizontal shafts. Another and older method is to attach the eyelets to the shafts by means of stout yarn. The shafts are placed in the loom between the front beam round which the cloth is to be wound, and the back beam, which carries and pays out the threads of the warp. For plain weaving only two sets of healds are required. Through the eyelets of one set are passed the even threads of the warp and through the eyelets of the other the odd threads. When the healds containing the even threads are raised and those containing the odd threads lowered, a $\mathrm{V}$-shaped space is made through which the shuttle passes. This space is known as the "shed," and the various mechanical devices for raising and lowering the threads of the warp are known as shedding motions. Where only two sets of healds are employed, they have only to be raised and lowered alternately to do all that is necessary. This alternate raising and lowering need not take place after each passing of the shuttle. The weave may be varied by putting two or more weft threads over the even threads of the warp, before the healds that carry those threads are raised and the weft is allowed to pass over the odd threads. But the various weaves possible with but two sets of healds are strictly limited. 
In the construction of complicated patterns a large number of shafts - five, ten, twenty, or even more -may be used; for only those warp threads which can always be raised and lowered together can pass through the healds of a single shaft, and for fancy weaving there will be very many such series of threads. It is clear that, beyond a certain point, the multiplication of shafts in the loom -quite apart from the mechanism for moving them-will become exceedingly cumbrous and inconvenient. This is specially the case in the weaving of figured fabrics. For these the Jacquard loom, invented just over a hundred years ago for use in the Lyons silk manufacture, is invariably employed. It is quite impossible to describe here the wonderfully ingenious methods by which this loom does its work. Moreover, its use in the woollen and worsted industries is limited strictly to certain specialised tasks. But the way in which it is mounted can easily be understood. Instead of shafts and healds it has so-called harness cords, hanging in several rows from a framework above the middle of the loom. Each cord has an eyelet at the level of the warp threads and each is kept taut by a weight. Every warp thread has its own cord just as each has its own heald when shafts are used. These cords can be attached in groups to vertical wires in the upper framework, which are raised and lowered in the 
proper order automatically. Even in a simple Jacquard loom, it is perfectly easy to have a hundred such wires, all moving independently of one another and doing work which, in the ordinary type of loom, would require a hundred shafts - an altogether impossible number. Thus the threads of the warp can move up and down in the most complicated manner, allowing designs of any degree of elaboration to be successfully executed. It may be added that in the weaving of some complex figured materials both shafts and harness cords are employed; this is naturally an unusual arrangement.

In the hand looms of the old days a simple mechanism of treadles, cords and levers, worked by the weaver's feet, effected the raising and depressing of the shafts. The treadles being each connected by cords with two sets of levers, the pressing of one treadle pulled one shaft up and the other down, and so produced the shed. Only straightforward work could be done on such a loom ; for the multiplication of shafts carried with it the multiplication of treadles. This is true also of the "tappet" power loom, which is worked on the treadle system and requires a separate treadle for each shaft. The treadles are automatically depressed by the "tappets"-wheels which revolve on a horizontal shaft about a point which is not their centre and therefore only depress their 
respective treadles at regular intervals. The mechanism for lifting the shafts differs considerably from that in the hand treadle loom; but the general principles of the shedding motion in the two looms are very similar. A tappet power loom can be made to carry ten or twelve sets of healds, though it rarely contains more than five or six; and as the mechanism is relatively simple, it is very largely used for the quick-running looms that do the plainer kinds of weaving.

Where a large number of shafts are required, some variety of what is known as the "dobbie" shedding motion is usually employed. The main principles of this motion were worked out in the hand loom days, and have been subsequently modified and improved. Like the Jacquard motions, the dobbie motions are too complex for detailed description; but a few words of explanation as to their essential features may be given. The raising and lowering of the heald shafts is done by horizontal lifting bars in the upper framework of the loom. In one way or another, the wires or levers that work the shafts are connected with these lifter bars. But the connection is not permanent. By means of a series of pegs on the surface of a revolving cylinder, placed close to the lifter bars, the connection between the heald shafts and the lifting mechanism can be severed, and the shafts can be lifted or not as desired. 
The arrangement of the pegs regulates the weave; and as a single lifter bar can control a very large number of shafts, this intricate but effective shedding mechanism is preferable to the more cumbrous tappet motion, for fancy woollen and worsted weaving.

From the account just given it will be clear that healding or drawing in-that is to say, passing the threads of the warp through the proper eyelets in the healds or harness cords - is a task that requires much patience and accuracy. In power-loom weaving it is customary to remove the warp beam and the heald shafts from the loom in order to carry out the operation. A well-appointed mill will have a quiet and well-lighted room set apart 'for the work. The last delicate operation in loom mounting-sleying-is connected with a part of the loom which has not yet been described, the oscillating "fly" or "batten," which contains several important features and performs a variety of functions.

This batten was, in its oldest form, a wooden frame placed in the middle of the loom, at right angles to the warp and free to be moved backwards or forwards by the weaver's hand. In its upper part, at the level of the warp threads, was, and is, fixed the sley or reed. This consists simply of a large number of delicate upright shafts or wires-the "reeds"-between which 
the threads of the warp are passed, after leaving the healds and before arriving at the beam which receives the woven cloth. Several warp threads are usually passed through each gap or split in the sley. The sley's first function is to ensure that the threads shall retain their proper positions and distances from one another, throughout the whole process of weaving. Where many sets of healds are being used, each containing some of the warp threads, this precaution is very necessary, in order to avoid irregularity in the position and movement of those threads. The work of sleying, therefore, closely resembles that of healding and calls for equal accuracy in execution. If the only function of the sley were to keep the warp threads in their places there would be no need to have it movable. But it has also to drive home each weft thread as it is placed in position ; hence the name of batten for that part of the loom in which it is fixed. Immediately after a weft thread has been sent across the shed, the batten and sley are moved sharply towards the weaver, by hand or power driven mechanism as the case may be, until the numerous uprights of the comb-like sley come against the weft, driving it hard into its place in the growing mass of the cloth. Before the shuttle passes again, batten and sley move out to make room for it. Just below the sley, the batten carries the "race," a horizontal ledge along which 
the shuttle can run. When a new weft thread is just about to be inserted, the warp threadsmoving with the heald shafts-are making their $\mathrm{V}$-shaped shed immediately beyond the edge of the woven cloth, and the depressed threads of the warp are resting on the race, ready for the shuttle to pass over them.

The shuttle is driven across the loom by the stroke of a hinged arm, the so-called "picking arm," which is dragged back by a strong spring after delivering its blow. In hand looms the weaver himself jerks a cord which is connected with the picking arms; in power looms the stroke is of course delivered automatically, the mechanism varying with the size and character of the loom and the weight of the shuttle that has to be driven. For ordinary weaving, the arms on either side of the loom have merely to work in turn, throwing the shuttle from side to side, just as it was thrown by the weaver from his right hand to his left and back again, before the first mechanical picking motion was invented. But in fancy weaving arrangements have to be made whereby shuttles can be thrown from either side several times running. For in work of this kind a number of shuttles, each carrying a different type of weft thread, have to be brought into play. The motions by which a series of shuttle boxes are made to rise in turn into position, so 
as to allow the picking arm to strike the right shuttle out of them, are among the most ingenious things in the whole loom; but they cannot be described in a few words.

The pace at which weaving is done depends, apart from breakages and blunders, upon the width of the loom, the weight of the shuttles, and the complexity of the fabric under construction. When there are many sets of healds, several shuttle boxes and a loom from six to eight feet wide, the number of picks, that is traverses of the shuttle, to a minute is comparatively low. A narrow loom, with but two heald shafts and a single shuttle, such as is regularly used for ordinary calico weaving, can work almost incredibly fast. Two hundred and fifty to three hundred picks a minute are quite practicable in a loom of this class. But in the woollen and worsted trades, looms running over a hundred and fifty picks a minute are only met with in simple and light worsted weaving. For quick fancy work, between eighty and a hundred is a fair average pace. The heaviest and broadest looms will put in about one pick a second or at times a good deal less. Even that pace can only be termed slow by comparison with the extraordinary speed of the light looms. The vast majority of woollen looms are very wide, from five to eight feet. Those less than five 
feet wide form only about one-eighth of the total number. Half the worsted looms are under five feet, and one-seventh of them are under forty inches.

A very large number of ordinary heavy cloths, both woollens and worsteds, and many miscellaneous fabrics such as tapestries and woollen rugs, are either made double with two warps and two wefts, or are backed, that is to say, have an entirely different appearance on the reverse side of the material, owing to the presence of a second warp or, perhaps more frequently, a second weft thread. Naturally the back is often coarser than the front, one of its main uses being to give a material weight, without sacrificing that fine texture which can result only from the use of light yarns. As cheap and heavy low grade yarns are usually tender and not adapted for use as warp, a backing of weft is the more economical ; though for fancy backings an extra warp is the more effective. If the backing is inferior to or widely different from the face warp and weft, the weave will be so arranged that the face threads may cover the back threads, as far as possible, when the latter appear on the upper surface of the cloth-as they of course must at intervals, if back and front are to form one fabric. With a weft backing there must be two shuttles, and with a warp backing there should be two warping 


\section{$7 \circ$ WOOLLEN AND WORSTED INDUSTRIES}

beams. Double cloths-with two warps and two wefts-are often of very fine quality, the back being in many cases elaborately designed. Familiar instances of this structure are afforded by travelling rugs and the like; but there are also plenty of plain double cloths, where the doubling is intended to secure weight and warmth, and design is relatively unimportant.

After leaving the loom many woollen and worsted fabrics have to be dyed, and all have to undergo several finishing processes before they are ready for the warehouse. It was at this stage of the manufacture that power-driven machinery first appeared. Centuries before the flying shuttle was invented, before even the spinning wheel had been perfected, there were noisy fulling mills, driven by water, on almost every considerable stream in the country, mills in which the woollen cloth was pounded in fuller's earth and water, in "the stocks," by rough wooden hammers, until it shrank and thickened and felted into a stiff, wear-resisting substance of a type not often met with in these days. The old-fashioned stocks are still used, though now they are driven by steam. Fulling or millingthe name of the process tells its history-is still the most important finishing operation in the case of woollens; but its importance varies with different classes of materials. In some it pro- 
duces a thorough change of character, in others but a slight modification in appearance. Worsteds of many classes, especially the light women's dress goods, are not milled at all, and no worsteds are heavily milled. For, as has been already pointed out, whereas the woollen yarn has innumerable fibres, projecting in all directions and ready to grip with their serrated edges the fibres of neighbouring threads in the woven piece, during the milling process, the worsted yarn is not constructed with a view to milling. However much a worsted fabric were milled, it could hardly reach a uniformly felted consistency, in which no trace of woven pattern remained, such as is often seen in woollen goods.

The first finishing process in all cases is the examination of the piece with a view to finding imperfections and removing them by hand. Scouring the piece, to get rid of the dirt, is another early operation. Where the work of finishing is long drawn out, several scourings may be necessary at different stages. Fulling is now done partly or entirely in closed boxes, within which the material passes between rollers and through abundance of liquid soap or soap and water. The length of the process is regulated by the extent to which the cloth has to be shrunk and felted. Where the object is to secure a material with a thick nap and no visible pattern, fulling will be 


\section{WOOLLEN AND WORSTED INDUSTRIES}

long and thorough. If it is desired merely to add body to the cloth, without sacrificing the effect of the weaving, a brief stay in the fulling mill is sufficient. Thorough fulling will reduce the size of the piece by a quarter or more; and it is possible to make a reduction of a half. The process itself puts no nap on the cloth, but prepares it for the production of one. The nap is the outcome of the operation known as raising.

Fulling, raising and the associated processes of cloth-working-as the old term was-are most elaborately carried out in the production of fine broadcloths, uniform cloths and the like. Immense care and much time are spent on the best fabrics of this class. The fulled piece is raised by being made to revolve in contact with the surface of a great drum set over with teazle heads. This is an operation that must be performed with the utmost care, and it is often long drawn out. The cloths of the class just referred to are always damped before raising. Then the raised fibre is cut or cropped in a machine working somewhat on the principle of the ordinary garden mower. There may be several of these raisings and croppings. Between two of them the piece may be wrapped on rollers and boiled, a process that facilitates the production of the "face". Finally, the material is heated and mechanically pressed; then steamed, in order to get rid of the glazed 
and somewhat stiff surface that pressing imparts; then perhaps pressed again, but this time without artificial heat. Various stretchings and dryings and mendings and beatings take place in the intervals of the more serious operations, and at last the work is done. Many types of woollen cloth, besides the fine broadcloths, are finished with a napped surface that conceals the weave. In their case the processes are less elaborate, and, at certain points, different from those just sketched, but their general character is similar. But in a large class of woollens and in all worsteds to conceal the weave would be a defect. Their treatment is therefore different. Most fancy woollens and many worsted "coatings" and "trouserings" are more or less fulled, to give them strength and body, but the shrinking and felting are comparatively slight. Then, too, the raising of such cloths is not so serious an operation as in the case of the woollen "faced" cloths. It is carried out in a different way and with a different object. Worsteds are, as a rule, only slightly raised, since their close, firm texture would not allow of the rather drastic application of the teazle which some woollens undergo. And the raising of both woollens and worsteds of the type now under consideration is carried out while the fabric is dry. Its aim is to ruffle up loose fibres, which are subsequently cut off short by the cropping 


\section{4 WOOLLEN AND WORSTED INDUSTRIES}

machine, the net result of the two processes being to show up rather than to conceal the weave. The nap is raised in order that it may be got rid of, not in order that it may be retained. Steaming, pressing, stretching, and mending are important parts of the treatment in these cases also, and many processes may be repeated at different stages in the work of finishing.

Indeed, the variety of "finishes" is singularly great. New ones are constantly being devised, many of which are kept more or less secret. It has already been mentioned that light worsted dress materials are not milled at all. Their general treatment naturally differs widely from that of the tougher woollens and worsted "coatings". The introduction of silk or cotton in serious quantities may modify the treatment in all cases; while piecedyed goods must undergo preliminary finishing processes before, and final finishing processes after, they go to the dye vat. Generally speaking, worsted materials are altered but slightly at this stage. As they appear in the loom so they appear in the warehouse, colour, of course, excepted in the case of piece-dyed goods. They may look smoother, more compact, more attractive, but their essential character is not changed. With woollens the reverse is often true. Only an expert, in these cases, could identify the finished cloth with the loose and altogether different substance 
that came out of the loom. In one case finishing is a subsidiary, in the other a primary, process. It is for this reason that in the preceding pages the finishing of woollens has received what might, at first sight, appear undue attention. 


\section{CHAPTER III}

THE RAW MATERIALS AND THE TRADE IN THEM

A LTHOUGH there is hardly an animal or A vegetable fibre that can be spun and woven which may not find its way into the woollen and worsted mills, yet there is neither space nor need, in a book dealing with those industries, to follow the production and marketing of cotton or jute, silk or china grass. We are concerned with wool, with those animal fibres most nearly akin to it, and with woollen rags. Even thus limited the field is wide enough, for there is no country where wool is not grown, few from which it is not now and then brought into England. We grow it largely at home and it comes to us from Iceland and Russia, Persia and Peru, from China, Switzerland, Canada and the West Indies, as well as from the great woolgrowing lands, such as Australia, New Zealand and the Argentine Republic. The rags, too, come from many countries. However, the main lines of the international and domestic trades are 
tolerably simple, though the details are curiously complex.

Every nation of importance is at times both a buyer and a seller of wool; but the purchases of foreign wool greatly exceed the sales of the wool grown at home in every European country except Spain, in Canada, the United States, and, of late years, in Japan. The more temperate lands of Asia all have a regular excess of exports, as have many tropical countries; but the tropics as a whole are not specially fitted for sheep rearing, although the industry may yet develop on a large scale upon the equatorial highlands of Africa and South America. The southern temperate zone, on the other hand, has proved itself admirably fitted to meet the growing needs of the manufacturing North; so that to-day the southern continents and the islands of the southern seas furnish the bulk of the immense surplus imports of Europe, North America and Japan.

With the exception of South Africa, none of the great pastoral lands of the South possessed an indigenous breed of sheep when European settlement began. The story of the creation of their flocks is long, interesting and involved. It is part of the still longer and more intricate story of the way in which two classes of sheep-the fine-wooled merino of Spain and the English 
long-wooled sheep of the Leicester, Lincoln and kindred breeds - have spread from their original homes, mingled with other stocks and with one another, and built up almost all the most important flocks of the earth.

Until the latter part of the eighteenth century the Spanish government, following a commercial policy universally adopted in early modern times, prohibited the export of so valuable a source of wealth as the merino to any foreign land. But the Spanish-American colonies were allowed to draw on the flocks of the mother-country; and so it came about that the first sheep of the merino type were driven over the Andes from Peru into what is now the Tucuman district of the Argentine Republic in, or shortly after, the year I 55 O. There, together with an inferior long-wooled breed, also of Spanish extraction, they ran wild and deteriorated for over two hundred years; so that eventually the Argentine flocks were as sorely in need of new blood as were those of France, Germany or Russia, which until the middle of the eighteenth century had never had the benefit of a cross with the old Spanish strain. Between I760 and I840, thanks to a change in the commercial policy of Spain, such crossing took place in almost every country of Europe and in many European colonies. The governments of England and France, of Prussia, Saxony, 
Austria and Russia-to mention only the chief countries concerned-all encouraged the work, some directly, some indirectly; and from the numerous crosses sprang varieties of the merino, whose wool in certain cases rapidly surpassed that of the parent stock in the estimation of manufacturers. The most important of these new varieties, so far as the English industry was concerned, were the Saxon, the Silesian, the South African and the Australian-all of which came into existence round about the year I 800 . At the same time pure-bred rams from Spain were brought into the La Plata states; and these were followed, between i 820 and I 860 , by heavy importations not only of the old Spanish, but also of the new Saxon and French stocks. In Australia the conditions of climate and food proved most favourable to the growth of a close, fine, wavy and much serrated wool. Even flocks whose blood was not entirely pure soon furnished a clip superior to that of Spain, though inferior, from most points of view, to the improved merino wool of Germany. These mixed flocks sprang from the crossing of merinos with a poor East Indian stock, which was the first breed introduced into Australia, and with various English breeds.

The Australian fleeces began to appear in the English market before 1830 , but only in small 
quantities. At that time approximately a quarter of the wool used in the country was foreign grown -almost entirely German-and these foreign wools were mainly used by the fine cloth manufacturers of the West and North. Between I 830 and I 860 Australia, Tasmania and the Cape displaced Saxony and Silesia, and became the chief sources of English imports ; though the fine German wools are still bought in small quantities for English consumption, as their felting properties are remarkable. Meanwhile the slow and difficult task of improving the South American flocks went on, and before I 840 the import of Buenos Ayres and Monte Video wools, to continental and even to English ports, had begun. But England was so well served by her own colonies that she paid little attention to the South American supplies, the trade in which became mainly a continental one-and a continental trade it is still. By i 850 the export of the improved wools of South Africa was well established. Between I 850 and I870 New Zealand took her place beside Australia and the Cape as a great exporter of wool. The dry Eastern parts of the south island were well suited to the merino, which was found to yield a heavier fleece there than in New South Wales. But the New Zealand squatters soon ceased to concentrate their attention on this single breed. In the '6o's systematic 
crossing with long-wooled English sheep, at the outset mainly Leicesters, began throughout Australasia. The movement was encouraged by the Bradford Chamber of Commerce-for there chanced to be a short supply of long wool on the Bradford market - and the results were specially successful in New Zealand, where the conditions of pasture and climate suited the English strain in the new flocks. The cross-bred sheep is far heavier in the carcase and generally better suited for slaughtering than the merino; consequently when, shortly after 1880 , the preparation and transport of frozen mutton became regular branches of trade, while the demand for cross-bred wools continued, New Zealand found herself in a most favourable situation. Since that time her flocks have become mainly cross-bred, the breed being now a complex one, in which the pure merino strain plays no great part. Of late years breeding for mutton has been taken up eagerly in the Commonwealth; and already the crossbred is to be found in many parts of Victoria and South Australia. But the flocks of New South Wales, which produces about three-fifths of the wool of the Commonwealth, and of Queensland are still mainly merino.

In the La Plata states, much of the low alluvial land near the river had always been ill suited for merino breeding, since the merino, a product of 
the sunny uplands of North Africa and Spain, thrives best in a dry climate and on a dry soil, and is apt to deteriorate in rank pastures. So it is not surprising that experimental crosses with English varieties began there almost, if not quite, as early as in Australia. But for years such crossing was unpopular; for the imported Lincolns had some superficial resemblance to the old breed of long-wooled pampas sheep, a wretched stock against whose influence the Argentine breeders had long been struggling. Twenty years ago, however, a fall in the price of merino wool and the beginning of the frozen meat trade converted the flockmasters; hence at the present time fully three-quarters of the Argentine sheep are of the so-called Lincoln cross-bred type, though the proportion of true merino is greater in Uruguay.

Taking the whole mass of Australasian, South African and River Plate wools, it appears that almost exactly a half is now merino and a half cross-bred. Ten years ago the proportions were two-thirds merino to one-third cross-bred.

When first the merino wools came to Europe they were employed almost exclusively in the woollen cloth manufacture, for which their fine, short, wavy and easily felted fibres perfectly fitted them. But, as was pointed out in the last chapter, the perfection of the combing and allied processes, 
during the course of the nineteenth century, made it possible to employ such wool for worsted yarn ; and now the greater part of the merino and crossbred wools go into the worsted branch of the industry, although the short "noils," which are the waste product of the combing process, regularly pass back into the woollen manufacture. The better grades of woollen cloth, especially those that are heavily milled, are of course made largely of merino; but these goods are not in demand to anything like the extent that they were, in the days when "to wear broadcloth" was the mark of a gentleman.

In connection with the wool supplies from the Southern Hemisphere, reference may be made here to an interesting development that has taken place, during the last ten or fifteen years, in the far extremities of the Argentine and of Chili. Terra del Fuego and the adjacent coasts and islands have been turned rapidly into sheep runs, just as were the neighbouring Falkland Islands long ago. Punta Arenas, the port of shipment on the Straits of Magellan, has been changed from a mere waterside hamlet into a town, better paved and lighted, so our consuls report, than any in Chili. The sheep in these moist and stormy lands of the far South are naturally not merinos. Besides long-wooled breeds, there are short or medium-wooled Norfolks and Cheviots, 
the latter brought by Scotchmen either from home or from the Falklands. For here, as elsewhere, both sheep and flockmasters are largely of British origin.

The present state of the world's wool supplies presents most fascinating problems to the outside observer. To manufacturers and merchants it has proved difficult and sometimes discouraging; but it has brought, and may continue to bring, great gain to many sheep owners. In most countries of Europe, though not in Great Britain, a remarkable fall in the stock of sheep took place during the last twenty years of the nineteenth century. Germany-to take the most extreme case-contained about 20,000,000 head of sheep in 1880, and less than $10,000,000$ in 1900 . Even in European Russia the fall was considerable; though in France, which with England and Russia raises about two-thirds of the wool of Europe, it was not very marked. From 1895 to I902 a fearful drought afflicted Australia and swept away about half the flocks. There had been 106,000,000 sheep in the country in I891; there were but 53,000,000 in 1902. Recovery has been rapid but is not yet complete. War has interfered with the growth of the South African flocks. The trade in sheep and mutton, and above all the trade in lamb, have limited those of New Zealand and South America. It 
is not easy to increase the numbers of the flocks and at the same time to export-as New Zealand does-upwards of a million and a half carcases of lamb every year.

Other causes are at work in the same direction. In the Argentine a rough and greedy agriculture, whose single crop system finds no room for sheep, is spreading in the old pasture lands of the province of Buenos Ayres, and forcing flockmasters to seek fresh "pastures in the provinces to the south and south-west. In some districts cattle and not corn crops are supplanting sheep. Further, malignant diseases are prevalent- "foot and mouth disease," and the more deadly and persistent "lombriz" or bronchial worm. The prevalence of this latter pest is said to be due to the overworking of the natural pastures; and it is believed that the disease will decline with the partial ploughing up and resting of these pastures, together with the more frequent use of fodder crops of various kinds. However that may be, the fact remains that the shipments of wool from the River Plate have declined appreciably since I 903 ; and there is at the present time (1906) no reason to anticipate a rapid recovery in the near future.

The situation in the United States further complicates the problem of the world's wool supply. In spite of its vast agricultural resources, the 
Union at present only contains about twice as many sheep and lambs as the United Kingdom, -in round figures sixty as against thirty millions -and in consequence it is very far from supplying its own needs. Every breed and mixture of breed is represented in America; but the most important flocks, by far, are the merinos and Lincoln or Cotswold cross-breds of the dry mountainous western States and Territories. Until recently large stretches of free pasture have been at the disposal of the flockmasters, and the sheep have migrated to the mountains in summer, returning to the lower land for winter. But various circumstances have checked this type of sheep ranching in such States as Utah, Wyoming, Colorado and Arizona. These circumstances are the conversion of pasture lands into arable, owing to the growth of population, competition for the use of the remaining pastures between sheep-men and cattle-men, the extension of forest reservations which cannot be freely used as ranches, and the legal restrictions on indiscriminate migration. So the flocks of the Union show a tendency to decline in numbers; and the American manufacturer, like his European colleague, has to buy more and more in the international markets. There is thus a contraction of supplies all the world over, a contraction which produces abnormally high prices in seasons of brisk demand, such as the 
years I 905 and I906. This contraction is likely to make itself felt for some years to come; though the enormous amount of substitution possible in the woollen and worsted industries, and the variations of demand, prohibit any confident prophecy that the present high level of prices will be maintained. That the "shortage" is likely to be permanent is most improbable; but, as some of the restricting causes have by no means spent their force, it will only be gradually overcome. In a country like the United Kingdom, with a highly developed system of mixed farming, which can be adapted to varying phases of demand, good wool prices are apt to bring about an increase in the flocks-so far as the demand for mutton and lamb will permit. But the experience of the whole nineteenth century renders it improbable that any very great increase in numbers-an increase of five millions, let us say-will take place in this country; for the consumption of meat grows steadily. Farmers in the lowlands are not likely to run the risks incidental to an excessive concentration on sheep breeding, and the available mountain pastures are already fully stocked.

Australia can never again be free from the spectre of drought ; but another great drought need not be apprehended for many years, and when (or if) it comes there will be means at hand for limiting the harm it may do, that were not avail- 
able in 1895 . The sinking of artesian wells in the dry uplands of New South Wales and Queensland, and the storage of water in reservoirs, although they will not make the wilderness blossom like the rose, as some sanguine engineers would have us think, should at least greatly add to the supplies both of water and fodder in times of need. But unfortunately the pastures suffer from that plague of rabbits, with which Australia and New Zealand have been contending for years, a plague which is a really important factor in the problem of the world's wool supply. Then, too, account must be taken of Australia's obvious anxiety to share in the profits of the frozen meat trade, which will act as a check on the growth of the flocks. The policy of breaking up the large estates and so enabling the land to carry a denser stock of men, a policy popular throughout Australasia, would also - if generally adopted - tend to discourage sheep rearing as at present carried on; but it need not in the long run produce those disastrous effects on the pastoral industry, that its critics sometimes assume to be inevitable. For the squatter and the rancher have no monopoly of the power to rear sheep.

We are here at the heart of the problem for the future. The question is this: How soon and how completely can and will the great exporting lands and the United States comebin with the existing 


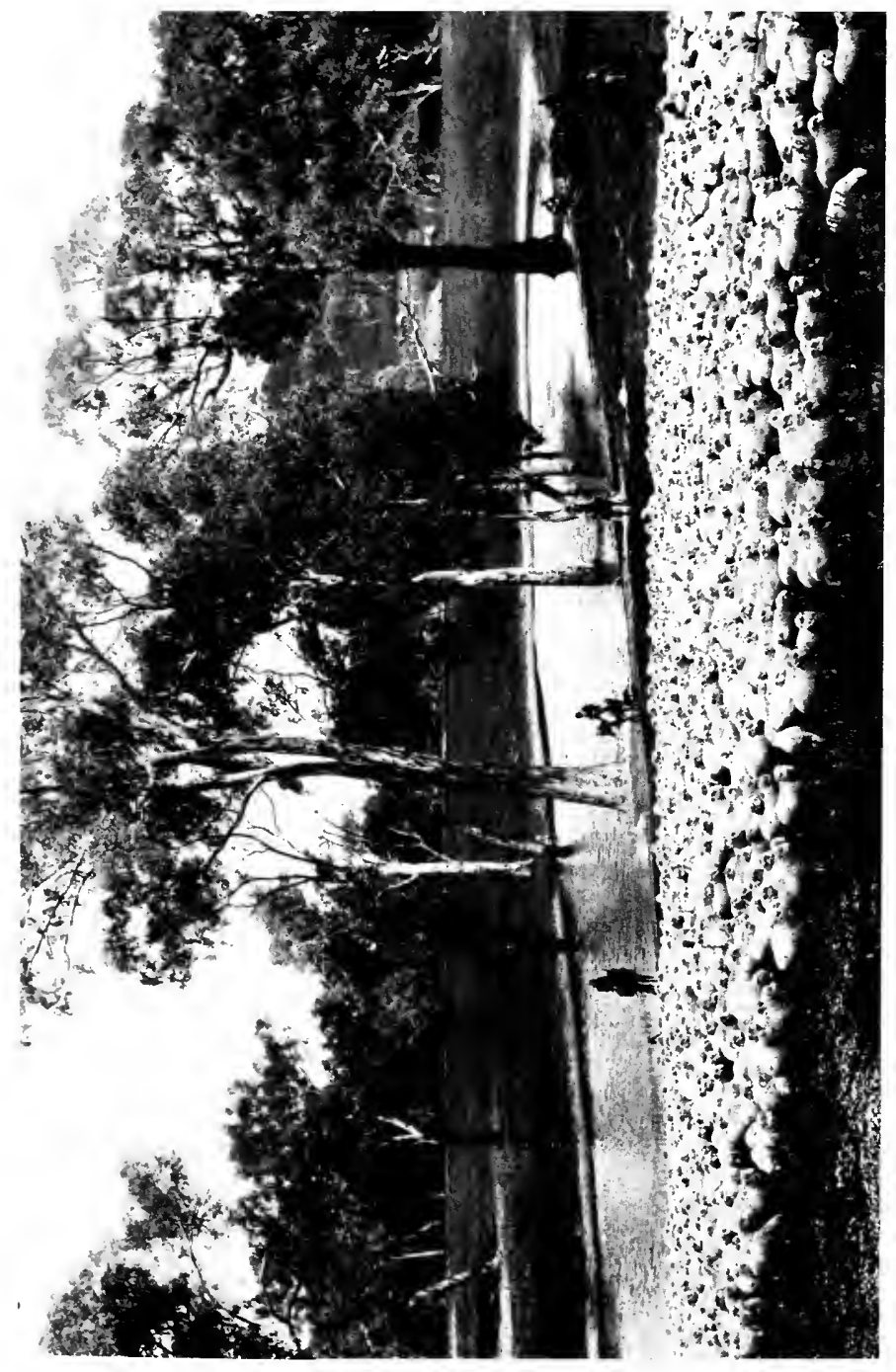



system, in which the flockmaster is as a rule a distinct type, something of a capitalist and not a general farmer, the characteristic English systems of comparatively small grazing farms and farms on which sheep rearing is only a part of a general scheme of farming? The conditions of surface, soil and climate will not allow of this change in every case ; but over a vast area in North America, South America and Australasia it is certainly possible. The States of New York, New Jersey and New England, for instance, are almost as large as Great Britain, and have a soil and climate well enough suited for the English type of farming. They contain, all told, about a million and a half sheep. Yet, if sheep farming were profitable and popular, they might be made to carry ten times that number at least. Again, the United Kingdom, in spite of its towns, still contains far more sheep than New Zealand. No doubt it will always be impossible to introduce English farming in the drier parts of Australia, in the dry Western States of the Union, or in the comparatively rainless tracts of the West Central Argentine; but when every doubtful acre has been subtracted from the available territory, thousands of square miles remain open and fit for the change. It is a change which certainly will not come to-day or to-morrow; and its ultimate arrival depends on such a complicated series of 
factors that no business calculations could safely be based on it. Among those factors are the rate at which population thickens in the new countries; the relative strength of the demands for wool, mutton and other forms of live stock, or agricultural produce; the level of general prices; the success with which substitutes for woollen clothing can be devised, and so on. Yet it is well to remember that the world does possess this great reserve power of sheep rearing. For the present, however, additions to the wool supplies are more likely to come from the revival and extension of pure sheep farming in Australia, round the Straits of Magellan, in Buenos Ayres, and elsewhere, than from the rapid spread of small and mixed farming on the young continents.

When first the Australian wools came to this country the commercial organisation for handling them was naturally clumsy and imperfect, and the trade was a slow and risky one. The squatters sent their wool by track or river to the ports-a process which in Australia might take several months - and consigned it to London dealers for sale, the voyage being a matter of another six months. Regular auctions for the colonial wools began in 1835 , and from that time onwards the trade assumed a more uniform course - a course which still continues. As commerce and banking developed in Australasia, the custom arose among 


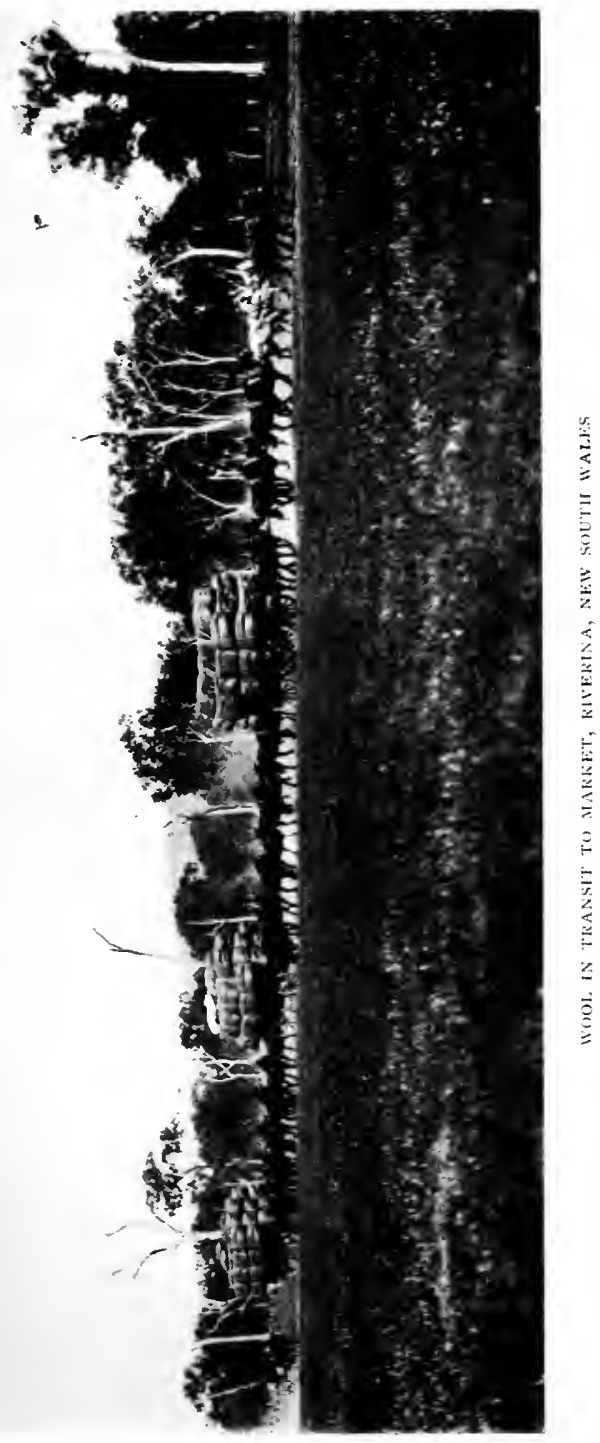



the squatters of entrusting all the technical work connected with the shipping, and insuring of the wool in transit, to mercantile firms or banking houses; these in their turn being prepared to advance to the owner 70 per cent. or 80 per cent. of the probable value of the wool, and thereby relieve him of the inordinately long wait for his money which the pure consignment system necessitated. Wool shipped in this way remains the property of the grower until knocked down at the London sales. For two generations those sales have been the centre of the international wool trade; and, though they are now to some extent losing that position, they remain one of its most important features. Very little colonial wool is disposed of by private contract in London; all, or almost all, comes under the hammer at the Wool Exchange, Coleman Street, E.C. Of the wool sold there, fully two-thirds now comes to this country "in the grease". A very small and declining quantity is of the type known as "washed fleece"- - wool carefully cleansed while yet on the sheep's back. The remainder is scoured wool and "slipe" or skin wool-that is, wool from the hide of the slaughtered sheep. The use of scouring is to save freight charges, especially when the bales come from a remote inland station; for the yield of pure wool from a greasy bale is not often more than 50 per cent. of the weight, and may be much 
less. The scouring process, however, reduces the value in England. The scoured wool often gets unpleasantly felted, when compressed in the bale, and in many of the scouring establishments the work is carelessly carried out. The skin wool has naturally increased in quantity with the growth of the frozen meat trade; but the greasy wool is much the most important class, the most popular with home dealers and users.

Australasian wool has always been the staple article at the London sales. For many years, however, wool from the Cape and the Falkland Islands has been sold together with that from Australia. Of late years consignments from Punta Arenas, the River Plate, and elsewhere, have also been disposed of at these "Colonial," or "Fine Wool" sales. The sales are divided into six series-January, March, May, July, September, and November. Generally, as has been said, the Australian wool is despatched to England by the financier, who has advanced part of its value to the owner; but a certain quantity has already been sold out and out to dealers in the colonies, who put it up for re-sale in London-"speculators' wool" it is sometimes called.

In the case of the growers' wool, shipping documents come to the financier's London office or bank, and the wool is warehoused to await sale. 
The selling brokers, a small group of old and eminent firms-not ten in all-are authorised to take samples of the consignments which they are to put up for auction, and they circulate catalogues as the sales draw near. Intending buyers select from these catalogues consignments of wool likely to meet their requirements, and inspect them in the warehouses, before going to the sale rooms. This inspection is of such vital importance that frequently the sales have to be postponed, in November and January, should a heavy fog settle over the city and the docks.

Corresponding to the selling brokers are the buying brokers, who do most of the actual bidding. They are, as a rule, connected with wooldealing firms and, through regular attendance, are familiar with the procedure at the sales and have good seats in the sale room. They have no monopoly of bidding, but buyers - especially those who do not buy in very large quantities-generally find it convenient to employ them. Members of selling firms often act as buying brokers. The selling brokers secure, as a rule, a commission of $\frac{1}{2}$ per cent., advanced by the importer on behalf of his client, the grower. They are further entitled to a fee of one shilling, "lot money," paid by the purchaser for each lot of wool knocked down. The buying brokers charge $\frac{1}{4}$ per cent., or thereabouts, in return for the loan of their ex- 
perience and the slight risk which they run, by becoming legally the owners of the wool for a short time.

Strict cash terms are the rule at the London sales - the buyer being required, under ordinary circumstances, to pay cash within seven days, and to remove his purchase from the warehouse within a fortnight. Should he fail to remove it, the selling broker is at liberty to resell the wool by auction or private contract, and charge all expenses and losses, incidental to the resale, to the defaulting buyer. The absence of credit thus renders it difficult for any but strong buyers, with a good supply of free capital, to make use of the sales extensively and as a regular thing.

Very early in the history of Australasia, small quantities of wool were sold by the growers before shipment, either to local firms-scouring firms in some cases - or to agents of English wool merchants; but this business remained an insignificant one until about twenty-five years ago. Its rapid growth of late, a growth that is registered by the increasing importance of the auctions at Melbourne, Geelong, Sydney, Adelaide, and in New Zealand, now seriously threatens the business in London. It is true that part of the wool disposed of at the local sales comes up again for auction at London, but it is a relatively small part. Every year the proportion of the total 
Australasian clip that misses the London market altogether becomes greater. The quantities sold at the various Australasian auctions grew from 205,000 bales in the season I88O-I, to 535,000 bales in the season I890-1, 770,000 in the season I900-I, and $1,056,000$ in the season 1904-5. The process continues steadily, so that now about three-quarters of the Australian and half of the New Zealand wool passes out of the growers hands before leaving the country.

Various causes have been at work to bring about this state of things. Provided good prices can be obtained, it is an obvious convenience to the grower thus to be able to complete his sale at home. And as a rule prices in Australia are fairly related to those in London, thanks, in the first place, to the rapid dissemination of market news, since the laying of the ocean cables, and, in the second place, to the eagerness of wool buyers from all the manufacturing nations to secure supplies at the fountain head. Before I 880 the direct buying that took place in Australia was entirely for English account. Almost all foreign users of colonial wools had to buy in London, though there was some direct trade between the Cape and Germany. Since I880 however the situation has changed completely.

According to the best Australian opinion, the international exhibitions at Sydney and Mel- 
bourne in 1879 and 1880 , by revealing the resources of the country, greatly stimulated direct trade. But there can be no doubt that many years earlier Frenchmen, Germans and Belgians had resented their dependence on the London market, and sought opportunities to do away with it. This was not easy, so long as there was no direct and regular steamship communication between Australian and continental ports. But that difficulty no longer exists. In I 883 the vessels of the Messageries Maritimes of Marseilles appeared in Australian waters. In 1887 they were followed by those of the Norddeutscher Lloyd of Bremen. In 1888 a line of German cargo boats started regular runnings between the Australian wool ports and three of the chief landing places for wool on the Continent-Dunkirk, the port of the Roubaix district, Antwerp, the port for Verviers and the Rhine, and Hamburg, the mouth of North Germany. A Belgian line followed shortly. Then British lines began to run direct to continental ports. Later still Japanese and United States lines made their appearance; so that now the facilities for direct trade are ample. This does not mean that foreign buyers are no longer to be found in London - merely that foreign as well as English firms have two strings to their bow; they can buy in the colonies or in London, as is most convenient. 


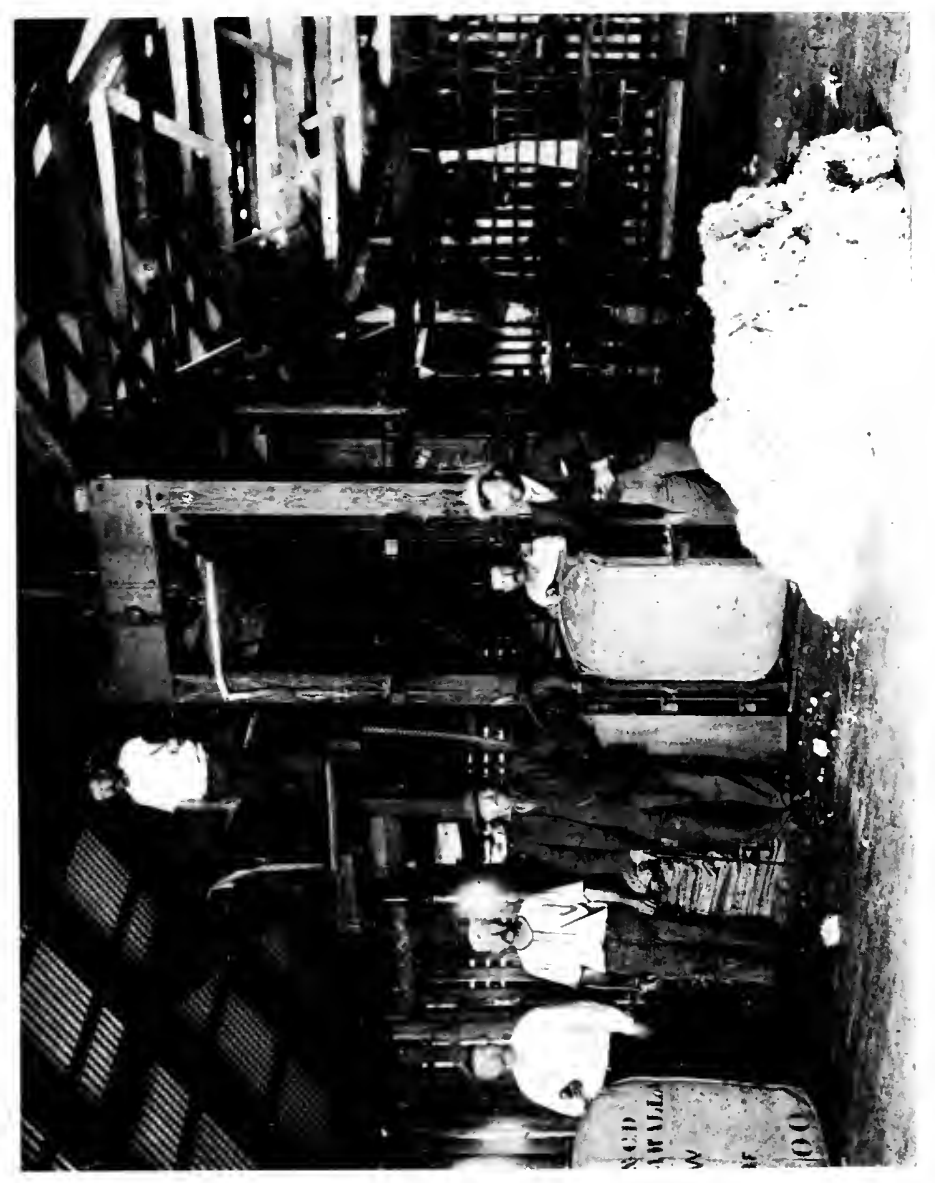

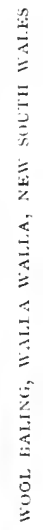



In fact the shares of the wool taken by the home and the foreign trade respectively, at the London sales, have not varied to any considerable extent for over thirty years. The foreigners, European and American, usually take half, or rather more than half, the quantity varying with the state of fashion and trade generally. Not infrequently the very best lots are thus bought for foreign account.

Purchases in Australia in the early days were made exclusively, and are still made very largely, on behalf of wool-dealing firms in Europe. But it is possible, and indeed frequent, for such purchases to be made on behalf of large spinners and manufacturers. In every case a professional buyer is employed. The buyers may belong to firms whose sole business is wool dealing on commission. More frequently they are connected with some large house, that does business in wool on its own account, but they are still free to execute buying commissions for others - its rivals, perhaps. They keep in touch with both the demand and supply sides of the market, by means of constant journeys to and fro, between England and Australia. Their commissions vary from I to 2 , or even $2 \frac{1}{2}$ per cent. As cash terms are the rule at the auctions, in the Commonwealth as well as in England, it is necessary for the actual purchaser to open a credit with an Australian 


\section{WOOLLEN AND WORSTED INDUSTRIES}

bank, upon which the professional buyer may draw, to an amount previously agreed upon.

Such, in outline, is the organisation for the purchase and sale of Australian wool. Much of what has been said in this connection applies to all classes of wool dealt in at the London sales; but there are some special customs and peculiarities, in other important branches of the trade, that deserve notice. The Cape wools, for instance, were never all consigned for sale to London, as the Australian wools were before the days of direct imports. The large squatters of Australia could afford to wait for the whole or part of their money; the smaller farmers at the Cape, especially the native flockmasters, very seldom could. Such growers have always sold their wool locally, in many cases to storekeepers. These in their turn dispose of it to buyers for European firms, or to export houses at the ports -houses which frequently do business of a very general character, in which wool dealing forms but a single item. A certain amount of Cape wool is knocked down in London, together with the consigned wool from Australasia; but about four-fifths of the clip is never catalogued at the sales. Purchases in South Africa are not made at auctions, but by private treaty, between the buyer and the grower, or the local middleman. England still buys River Plate wools so spar- 
ingly, that a detailed account of the history and organisation of this branch of the trade would be out of place here. It is enough to say that the bulk of the trade, more than nine-tenths it is believed, is direct; that purchases are made by buyers on commission, or by representatives of European firms, in open market at Buenos Ayres and Monte Video; that occasionally the buyers visit the ranches and make their purchases on the spot; and that only a small quantity of wool is consigned unsold to the auctions at Antwerp, Liverpool or London. It should be added that much wool sold out and out in America comes again under the hammer at Antwerp, and some at Liverpool. During the last few years-since 1900-the use of South American wools in this country has increased perceptibly; and it may well be that, before long, they will form an important section of the raw material for the British trade. It is however impossible to measure the growth in their use statistically; for the direct imports from Uruguay and the Argentine represent only a part of our purchases. Owing to the earlier and more perfect development of dealing in these wools on the Continent than in England, the English purchaser frequently applies at Antwerp, Roubaix or some other accessible foreign market, for any supplies of them that he may require. In 1904 rather less 
than $£ 600$,000 worth of wool came to us direct from the River Plate, while over $£ \mathrm{I}, 000,000$ worth came from France and Belgium; and there can be no doubt that a very large portion of the $\notin 1,000,000$ - probably a great deal more than half-was spent on South American wool.

Besides the colonial sales, there are also held in London the "low wool" sales, at which comparatively small quantities of inferior woolsmostly from the East - together with camels' hair, cashmere and mohair are put up to auction. At Liverpool the regular sales, like the London colonial sales, are held in six annual series, and the wools bought and sold at them are of an exceedingly miscellaneous character. Low grade, rough wool-that goes largely into the carpet, cheap blanket and rug trades-comes to Liverpool from the ends of the earth; above all, from Asia, all parts of Asia between China and the Levant. Every variety of South American wool, both from the east and west coasts of the continent, is landed there; and Liverpool is also the great landing place for two classes of raw material with which we have not yet dealtalpaca and mohair. The quantity of sheep and lambs wool brought into Liverpool, which is not of course the same thing as the quantity sold there, is now about one-fifth of that brought into London; but the imports by way of the Mersey 
show a steady growth of late years, whereas those by way of the Thames do not. There are few points of special interest in connection with the dealings at Liverpool. Sales by private treaty are common, in addition to the regular auction sales. Further, owing to the miscellaneous character of the wool and the nature of the countries from which much of it comes, only a small part remains the property of the grower on arrival; for sheep owners in Persia or India or East Africa, in Peru or Iceland or Syria, have not the credit facilities of a New South Wales squatter.

Owing to the decreasing importance of the London sales, and the long railway journey from London to the chief manufacturing districts, there is every reason to anticipate a steady-if slowdecline in the shipments of wool of all types by way of the Thames. There is no reason why direct imports from any country should pass through London, if a more convenient route can be found. And such routes exist. Already Hull, Goole and, to a small extent, Grimsby are used as landing places for wool going to Yorkshire; and efforts are now being made to regularise the traffic between Australia and the Humber. The quantity of wool landed at Hull increased greatly between 1904 and I 906. Liverpool is a natural terminus for the growing trade with the River Plate. Her import figures 


\section{WOOLLEN AND WORSTED INDUSTRIES}

have improved considerably since that trade began to expand. A little wool even goes up the canal to Manchester. It is just possible that a further curtailment of the London trade may result, in the near future, from the suspension of one or both the winter series of London sales. Those sales, in November and January, clash with the chief summer sales in Australasia ; and it is now being suggested from the Australian side that they should be dropped. It is a suggestion which the London brokers and the English trade generally are not likely to welcome; but as the Australian sales now rule the situation it may in time bear fruit.

So far nothing has been said about the home supplies of raw material. For it is right that the more important branch of the trade should be handled first ; and it is very many years since the home trade occupied that position. At the present time not much more than a fifth of the new wool spun and woven in the United Kingdom is home grown; though if no British wool were exported in the raw state the proportion might be greater. It so happens that during the ten years since 1895 the exports have been heavy, continuous and extensive purchases having been made, largely for the United States. On an average over a fifth of the home clip has been sent abroad every year. It has been stated already 
that the stock of sheep in the country has, on the whole, been well maintained, thanks to the joint demand for wool and mutton. The highest figure that the flocks of the United Kingdom have ever reached, in the last forty years, was $35,600,000$ in the year I 868 , at the time when the heavy demand for English wools started the cross-bred movement in the colonies. The lowest point was $27,400,000$ in I 882 . Since I 895 the figure has only varied between $29,000,000$ and 31,600,000. The present high prices of wool are certain, other things being equal, to lead to an increase; though reasons have already been given for the belief that that increase can only be slight. Even now, Great Britain and Ireland carry more sheep in proportion to their area than any other country ; and nothing short of a revolution in agriculture could add very greatly to the number.

The greatest sheep-rearing county is naturally Yorkshire, with nearly $\mathrm{I} \frac{3}{4}$ millions of sheep. Lincoln and Northumberland each contain over a million, Devon and Kent over 800,000. The flocks of Wales number about $3 \frac{1}{2}$ millions, those of Ireland nearly 4, and of Scotland nearly 7 millions. Very few counties, some seven in all, contain less than I00,000 sheep. The number of sheep is not, however, a sure indication of the wool-growing power of a county or country, owing 
to the very great variations in the weight of the fleece of different breeds and in different districts. The great Lincoln sheep, for instance, yield a fleece whose average weight is reckoned at from nine to ten pounds; while the fleece of the light Welsh breeds is little more than a third, that of the South Down sheep of Sussex about a half, of that weight.

Any full account of the breeds of British sheep and the characteristics of their fleeces would require a book to itself; for the matter is complicated by a great deal of cross-breeding, and by the fact that the sheep named after a particular district are rarely confined to that district. So it is necessary to be brief. Our flocks are roughly divided into the long and short wooled varieties, of which the former are the more important-not numerically, but owing to the unique characteristics of their wool, and the fact that, as has been seen, many of the flocks of the New World are descended from them. By far the most prominent of the long-wooled breeds are the Lincolns and the Leicesters, which have often been crossed with one another. Of less importance are the Cotswolds and the Romney Marsh, which have also been freely crossed with the Leicesters. The old pure Lincoln wool was the longest grown in the country; and the more or less cross-bred Lincolns of to-day frequently yield 


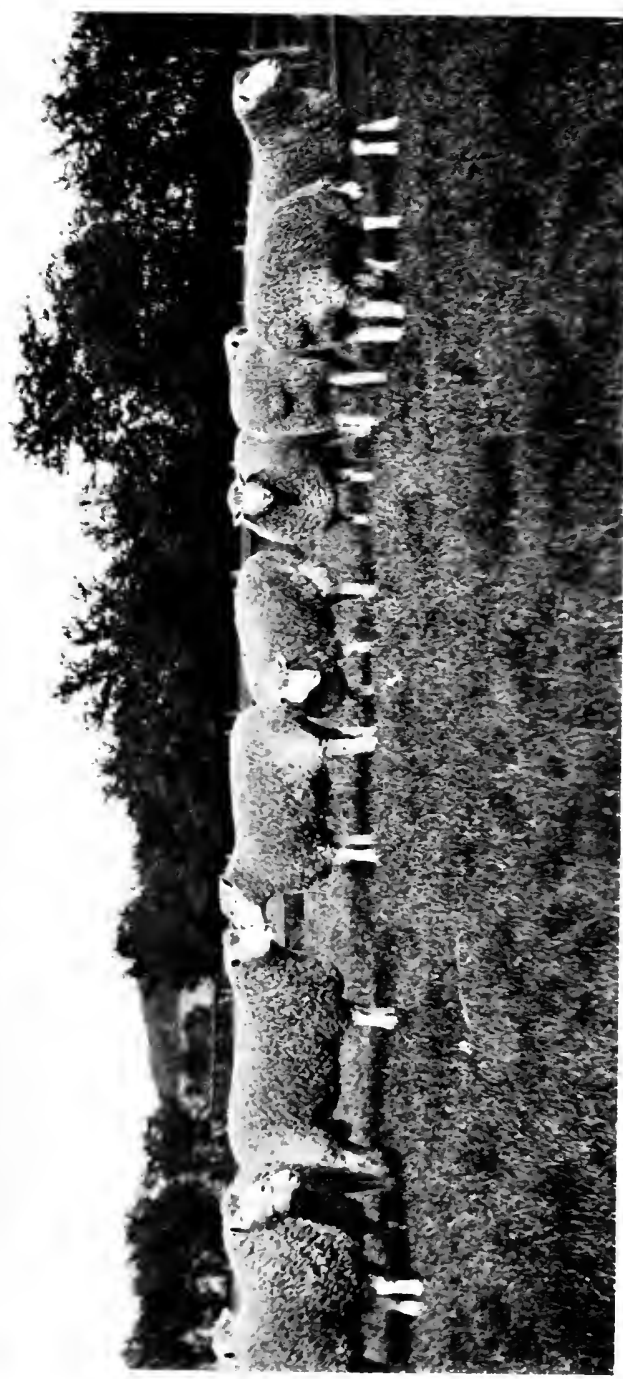

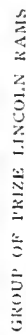



wool a foot or more in length. Long-wooled breeds are common in parts of Yorkshire, in many Midland counties, and in the south-western counties-particularly Cornwall-as well as in the districts from which the chief varieties take their names. The wool, besides being long, is relatively coarse, and always more or less lustrous; it is invariably combed and spun by the worsted process, and is mainly employed for women's fabrics which require a bright surface, for stout cloths of the serge type, and for braids.

The mountain sheep of Great Britain and Ireland, belonging to various breeds, yield wools of medium length, the classification and uses of which vary considerably. The roughest and most primitive of these wools are turned into carpet yarns, or stout Scotch and Irish tweeds, which are not spoiled, as more delicate fabrics would be, by the frequent occurrence in these coarse mountain fleeces of "kemps," that is to say, misgrown fibres, which will neither felt nor absorb dyes properly. The tendency to produce these "kemps" is a recognised test of a low breed; but fine breeds may produce them at times, though in the finest they are very rare. Of all the mountain breeds, the most valuable and important are the Cheviots and their various offshoots. They have in part displaced the rougher sheep of the Highlands and have spread over the English border 
counties. Crossed sometimes with the Leicesters, and sometimes with the short-wooled breeds, they yield a fleece which has in the past been largely employed both in woollen and worsted spinning, though it is now mainly used for woollens. The best breeds of Welsh and Irish mountain sheep bear a soft and fairly short wool, from which excellent flannels can be made.

Much the most important variety of the fine, short-wooled sheep is the South Down, a breed which stands in much the same relation to the other short-fleeced sheep as does the Leicester to the long-fleeced. Its offspring are spread all over the country, especially on the chalky uplands of the East and South, where they have in many cases either driven out or greatly modified the primitive stocks. The true South Down fleeces once upon a time supplied the material for the finest woollen cloth made in England; but fully 200 years ago they began to be displaced by the Spanish merino, which in its turn gave way to the Saxon merino, just as that has been almost entirely supplanted by the fine wool from Australia. As in the case of many other English breeds, the South Down wool suffered in quality owing to the attention paid to the carcase; but under no conditions, so far as one can tell, could Englishgrown wool have rivalled merino as a material for the best woollens and the softest worsteds. At 
the present time the various types of Down wool are not very freely used in the woollen trade, except in the manufacture of flannels; the greatest demand for them comes from the hosiery trade.

The trade in the home-grown wools varies considerably in its organisation from district to district. As in all trades, there is a tendency to keep down the number of hands through which the raw material passes; but the process of "getting rid of the middleman" is not so simple as it might appear, and is certainly not always economical. In some ways the dealer has gained rather than lost ground of late years. The most direct method of purchase, that in which the agent of the spinner goes round to the farms in person, is rare, though some of the wool grown near the manufacturing districts is still sold in this way. A much commoner method, the commonest of all in fact, is that of the local wool auction, to which the farmers of the country side bring their fleeces after the shearings of the spring and early summer. Such auctions are held all over the country, in the manufacturing districts - at Leicester, for instance, and at Bradford -as well as in the purely agricultural counties ; and the results of the earlier sales of the new season are anxiously awaited both by farmers and manufacturers as an index of the general trend of prices. At the present time (1906) such indications are of special interest, owing to the sharp rise in the 
prices of all grades of wool that has taken place in the last three years. The purchases at these sales may be made on behalf of spinners and manufacturers, or-and this is more usual at the rural sales-on behalf of dealers in the manufacturing districts at home and abroad. The buyer is at times a member of the firm on whose account the purchases are made; at times a travelling agent of the firm who goes round from sale to sale; and at times a man living on the spot who buys on commission, perhaps also doing a little dealing on his own account. All kinds of circumstances may determine the method of buying adopted in any particular case.

Besides purchasing at such sales, dealers or their agents buy largely by private treaty, either direct from the farmers or from some local middleman. The method adopted depends to a great extent on the size of the farms in the district concerned. In North Lincolnshire, for instance, where farms are normally large and the clip of a single farm forms in itself a considerable purchase, the buyer goes straight to the farmer, meeting him and arranging a price on a market or fair day in the nearest country town, and afterwards visiting the farm to see the wool packed in sheets for delivery. Where farms are small, such direct dealings would be neither easy nor economical, and in consequence of this there is room 
for a local dealer or collector, standing between the farmers and the buyers for the trade.

In the home trade, as in the import trade, there is an almost complete absence of dealings in anything but actual clipped wool, which can be carried away as soon as it is bought. Occasionally, however, a more speculative type of transaction is met with in sales by private contract-a farmer agreeing to dispose of his whole clip, before the flock has been shorn, at a given price per lb. or per todd. Such transactions arise either from the farmer's financial necessity, or from his desire to profit by what seems to him at the time a good offer, and so safeguard himself against the price fluctuations which usually accompany the regular selling season. They are exceptional in this country, though common in Germany.

There is another most important point of resemblance between the trade in British and that in imported wools-namely, the prompt terms of payment. The mass of the sales are made for cash down, or cash in a few days; and this is the dealer's opportunity. Few firms of spinners or manufacturers care to lay in a year's stock of wool in the sales season; for such an operation involves a long and costly locking up of capital. Quite apart from any consideration of this kind, spinners cannot often be certain in advance what grades of wool, and what quantities of each grade, 


\section{I}

their business will require. The dealer who is prepared to supply a great variety of grades, and with whom somewhat easier terms of payment can often be arranged, is therefore a necessity of the industry; and his functions have become more indispensable with the more frequent fluctuations of fashion and the decline in the practice of manufacturing standard yarns or fabrics from standard materials for stock.

The vague term dealer has been used deliberately to describe the whole class of business men, some of whom are known as wool merchants, some as wool staplers, some, in the worsted trade, as top makers. Both the composition and functions of this class are so interesting as to deserve special attention. Wool stapler is its oldest name; but it is a name that is dying out in the worsted trade, in favour of that of top maker, a change in terms which rightly indicates a change in function. The stapler of the old days bought in person from the farmer, and either sold the wool as he bought it, or-much more generally - had the fleeces sorted into their different qualities, and sold this sorted wool to spinners. Hence his name; for in the language of the trade a lock of wool is a "staple," and it was his business to have the wool sorted into the long and short, fine and coarse, locks. To him also fell the work of blending wools to meet his 
customers' needs, a delicate and responsible task. As the staplers extended their operations, with the general adoption of imported wools, some of them became merchants on a very large scalewith buyers at home and abroad, large staffs of sorters in their employ, clients in both the woollen and the worsted trade, and a financial position that enabled them to give long credit to manufacturers. But at the same time the ease with which manufacturers could buy at the sales took away part of the merchant's work; although it remained-and remains-convenient to employ the merchant as a buying broker and, from time to time, as a giver of credit. To-day, the merchants who merely buy, sort and sell have become scarce. There is but little room for them in the woollen trade, except in those branches of it which only employ pure, new wool in small quantities, and so get their supplies locally, instead of buying in London or at the rural auctions. And in the worsted trade, the custom among spinners of buying not wool but tops has grown steadily; so the stapler or merchant has generally added to his other work that of getting the wool combed; in short he has become a "top maker". He may own some combs himself, thus ceasing to be a mere dealer and taking part in the actual work of manufacture; but the bulk of the combing is done by one of the many commission firms, 


\section{2 WOOLLEN AND WORSTED INDUSTRIES}

the comber returning everything-top, noil and waste-to his client. The noil is then sold for use in some branch of the woollen trade-the finest qualities, combed out of merino wool, often going into fancy woollen cloths or superior blankets. The waste too may find its way into low woollens, or possibly into felts; and the top, labelled according to the fineness of the yarn into which it is expected to spin, as a 30's, 40's, 60 's, or whatever the number may be, is disposed of to the worsted spinner.

Top making forms a part at least of the business of almost every wool merchant who sells largely to the worsted trade and is in a position to avail himself of the work of the commission combers, though some staplers of the old type remain in the English wool trade. Worsted spinners who buy and sort their own wool are still numerous, but all spinners occasionally, and some invariably, buy tops. The great drawback to this division of functions is that the spinner who buys tops has no means of knowing their exact composition. Once the wool has been combed the most competent expert cannot distinguish the component parts of the blend; and friction is likely to arise should the top not draw and spin as its description and appearance have led the buyer to expect. To the dealer the arrangement is obviously convenient. He can blend freely; 
can, for instance, mix with colonial wool unpopular, but really sound, brands from South America, which might not find a ready market under their own name. But it is equally obvious that the system is liable to abuse. It is an outcome of specialisation whose value to the trade as a whole is at least doubtful.

Dealings in wool, tops and noils are carried on by firms of all sizes and descriptions. Many of the smaller dealers are agents rather than merchants. For as their lack of capital prevents them from holding large stocks, they sell from samplessecured perhaps from the London brokers or from the larger dealers-and only buy in when they have secured an order. Some specialise in noils and the various kinds of waste, a trade which offers greater opportunities to the small dealer than the wool trade proper, owing to its purely local character.

It has already been pointed out that one of the functions of the wool dealer is to ease for spinners and manufacturers the rigid cash terms of the first stage in the wool trade. Formerly he did so by giving very long credit freely; but of late the long credit system has been in part broken down. It dies hardest in the Scotch trade, presumably because the fine Scotch tweeds and cheviots eventually come into the hands of that type of tailor who is apt to wait a very long time for his 
cash, and this involves delay in payment all along the line. The old custom in this branch of the trade, a custom not yet quite extinct, was four clear months' credit, after which the manufacturer usually accepted a four or six months' bill, so that payment might be delayed for nearly a year. Generally speaking, the dealer now requires cash in fourteen days, but he may arrange to draw upon firms of unquestioned stability at four or even six months.

In the top market contracts for future delivery are common, the top maker undertaking to furnish so many packs of tops per month for a given period at a fixed price. It remains for him, if he has not wool enough in hand, either to cover his contract by prompt purchases of raw material-the safest course-or to take the risks of price fluctuations at the London sales and in the country, which may render the contract unprofitable. This is the only form of "future" dealings known to the English wool market, unless we are to include the selling of the wool of unclipped sheep already referred to. It does not come within the definition of "future" or "terminal" dealings properly so called, since those terms imply a highly organised trade-such as the "future" trade in cotton or corn-in which the qualities, standard units and periods and conditions of delivery are carefully defined. Proposals have recently been made before 
the Bradford Chamber of Commerce to imitate in England some of the regulations which already exist in the terminal top markets of the Continent ; but hitherto the scheme has met with no support, for there is a strong feeling in the English trade that such rules, by doing away with the necessity for expert knowledge on the part of buyer and seller, open the door to the outside speculator and exercise a disturbing influence on prices. Whether this be true or not is doubtful. Price fluctuations on the organised continental markets are not greater than those on the unorganised market at Bradford; it has, indeed, been argued that they are less, and there is a good deal of evidence in support of this view; but the strong feeling remains, and is not likely to decline as yet.

Before passing from the wool trade, to speak of the trades in alpaca, mohair and rags, reference should be made to the very extensive dealings in sheepskins and skin wools-dealings which have increased greatly since the establishment of the frozen mutton business. There is little that is remarkable about this branch of the wool trade, so it may be handled in a few words. Large quantities of Australian and South American skins are stripped of their wool by fellmongers before export. About one-twelfth of the Australasian wool that was put up at the London sales of 1905 was of this class. Besides these imported 
skin wools, skins come into the country from all parts of the world with the wool still on them ; and these, together with the skins of the sheep killed at home, provide work enough for the English fellmongers. The imported skins are put up to auction-mainly at London and Liverpool-and are largely bought by wool merchants, who have them stripped and then sell the skin to tanners. Some British skins are also sold by auction at various wool-dealing centres. The wool from others comes into the hands of the merchants by more round-about methods, through butchers and fellmongers. From the merchant's hands the skin wools find their way into all branches of the trade, according to the character of the fleece and the method by which it has been separated from the hide. Least damage is done to the wool when it is "sweated" off the skin. In this process the fell is soaked and carefully heated, until slight fermentation sets in on the face of the skin, when the wool can readily be detached. Such wool combs well and so is in considerable demand. The alternative method - a very common one-is to treat the fell with lime or some other chemical reagent. This is quick, cheap and effective. But wool removed in this way is generally not easy to comb or card; also the chemicals may interfere with the washing, and if carelessly applied they may damage the fibre. 
Nevertheless skin wools as a class form a valuable raw material, as well as an important item in the world's total supply of wool. It should be added that enormous quantities of them are handled on the Continent, the imports of wooled skins from the River Plate into France and Belgium being particularly heavy. The stripped wool is often sent across the Channel to this country.

Less than two generations ago, alpaca was added to the raw materials of the worsted trade, largely through the initiative of one man-the late Sir Titus Salt. It remains an interesting and valuable commodity, though the whole quantity used is trifling when compared with that of true wool. In 1904, for example, when the imports of wool into this country were worth upwards of $£ 20,000,000$, the whole stock of alpaca and kindred fibres was valued at less than $£ 300,000$. The alpaca, llama and vicuna are, as is well known, the American representatives of the camel tribe. Their wool, or rather their hair, was spun and woven by the Indians of the Central Andes, before ever Pizarro left Spain. To this day the imports come exclusively from Peru and Chili, whence they are shipped - vi $\hat{a}$ Liverpool - to the Bradford district. Outside this country the United States are the only considerable buyers. Everywhere the worsted trade is the sole user of 


\section{WOOLLEN AND WORSTED INDUSTRIES}

these long smooth fibres, which have little felting property, but possess that remarkable lustre which from time to time renders them a popular ingredient in certain fabrics for women's dress.

The hair of the Bactrian camel-coming to us almost entirely from the Chinese and Russian empires-also enters into some classes of goods ; but its use is limited and its importance small. Goat's hair, on the other hand, is a raw material of the first importance. The varieties used in this country are mohair - the long silky hair of the Angora goat of Asia Minor-and cashmere, the soft down that grows beneath the hair of the goats of Tibet and the Western Himalayas. Of these, mohair is by far the more important. Its name, by the way, is a corruption of the French form of an Arabic word for hair-cloth, and has nothing to do with the English word hair. Up to about the end of the first quarter of the nineteenth century, the spinning and weaving of mohair was confined to Asia Minor and Turkey. Then the raw material began to be imported into England; and from that day to this the combing and spinning of it have remained almost monopolies of the Bradford district. For mohair, like alpaca, is never used in the woollen trade. Mohair yarn is largely consumed abroad, and raw mohair is now being imported in considerable quantities into the United States. Between $185^{\circ}$ 
and 1870 the demand for mohair was so keen that the price was rarely below 3 s. a pound, whereas to-day fair average samples fetch about Is. $4 \mathrm{~d}$. In consequence of the high prices forty years ago, attempts were made, with the reluctant consent of the Turkish government, to acclimatise the Angora goat in British colonies. Between I 870 and r880 this task was successfully carried through at the Cape. Now, rather less than half the imports into Great Britain are Turkish, rather more than half South African-all other sources of supply being for practical purposes negligible.

The trade in mohair is beset with difficulties. Asia Minor still yields the very finest qualities, and Asia Minor is not a country with which trade runs smoothly. The Government levies a tax on the goats; the peasant owner does a good deal of false packing, and sometimes waters his goods generously to increase their weight, before delivering them to the exporting firms at Constantinople. Impurities of all sorts are common in the mohair bales, and the work of sorting them is both unpleasant and unwholesome. In the case of Cape mohair, the main difficulties are the relative inferiority of the breed and the habit of shearing twice instead of once a year, to which the South African farmers cling. First rate Turkish stock to breed from is hard to get; and nothing short of diplomatic representations suf- 
fices to secure it. With regard to the double clip, Cape farmers have generally maintained that the conditions of climate necessitate it. Its continuance is encouraged by the fact that, from time to time, a turn of fashion drives up the value of the short Cape fibres, as compared with that of the longer and generally better Turkish mohair.

Mohair yarns have a great variety of uses. They are a common material for shoe laces and braids; so much so that a fashion for braids sends a flutter through the whole mohair trade. They go into "Astrachans" and plushes, and, as fashion swings, into many other fabrics, whose names no one but a worsted-weaving expert could either enumerate or understand.

The rag trade remains to be considered. It is a trade of much greater importance than that in either alpaca or mohair, in its relation to the woolworking industries of the country as a whole. With the worsted industry it has little, if any, connection; but there is hardly a branch of the woollen industry that does not make use of rag wool. Nearly fifty years ago the local historian of the shoddy manufacture noted that the industries of Halifax, Huddersfield and Leeds-as well as those of Batley and Dewsbury, the headquarters of the rag trade-were being " in some 
measure inoculated with the materials, shoddy and mungo". The stage of inoculation has long been passed, and rag wool is now used even in the fine cloth districts of the west of England. In consequence, the quantity of rags consumed in the country is enormous, though no exact figures as to the relative proportions of rag wool and new wool can be given. The estimated annual consumption of the former is now (1905-6) over I $80,000,000$ lbs., an estimate that is certainly not excessive, seeing that about 90,000,000 lbs. of rags and rag wool are imported annually, in addition to which, account must be taken of the whole immense "home grown" supply. Against this estimate can be placed the ascertained average annual consumption of new wool, alpaca and mohair-rather more than 450,000,000 lbs. for the period 1900-5. It should be added that the scarcity of wool of late years has brought the two figures much nearer together than they were at the end of the nineteenth century. In I 899 , for instance, they were I 25,000,000 and 520,000,000 respectively.

It must not be thought that shoddy is necessarily an adulterant, in the bad sense of the word. In fact its use, which is now nearly a century old, was one of the first illustrations of the principle of the employment of waste products upon which much of the economy of manufactures depends. 


\section{22 WOOLLEN AND WORSTED INDUSTRIES}

Moreover the best qualities of the material are considerably more valuable than the lower grades of wool, and are employed not merely because of their relative cheapness, but also because they are believed to improve the surface of certain types of fine cloth. Generally speaking, rag wool is used because of its cheapness; but when judiciously blended with other materials it will make a cloth which, although not of first-rate quality, is good at its price. Rag wool also, of course, enters into cheap flashy cloths, whose production requires great ingenuity on the part of the manufacturer, but has no other merit worth considering. But that in no way justifies comprehensive denunciations of shoddy.

In the language of the trade, shoddy is a special type of rag wool, that which results from tearing up, or "pulling," soft woollen rags, stockings, underclothing and the like. Rags and tailors' clippings of cloth are made into a second type, known as "mungo". These two terms are sanctioned by official usage and to be found in Board of Trade publications. Two other terms are, however, now in regular use, though the uses vary somewhat, namely "merino"- - the rag wool made from women's dress goods and other soft worsted rags of good quality - and "worsted," the torn-up remnants of men's worsted clothing of a close texture. This worsted is really a variety 
of mungo, just as "merino" may be called a variety of shoddy. There is, no doubt, a natural tendency to extend the use of the polite word "merino"; for shoddy can never be made to sound well. "Merino" is indeed a popular term far beyond the rag trade; and the goods that bear it have often no very clear connection with the merino sheep, or with one another.

The rag trade is one from which the middleman cannot under any circumstances be excluded ; and as a rule the rags pass through several sets of hands before they come to the cloth mill. It is not practicable for the manufacturer, or even the wholesale rag dealer, to come into touch with the producers. These producers are too numerous and their products too miscellaneous. Ordinary domestic rags of all sorts go into the bags and carts of the humblest class of business men in the country. From them they often pass to that curiously named type of social scavengers, the marine store dealers. As these men usually carry on business of a very small and general type, they hand on their goods to larger dealers of the same class, in important centres, of which London is the chief; and it is from these large dealers that the woollen rag merchants generally buy. The domestic rags of the manufacturing districts, the tailors' and clothiers' clippings, and some other raw materials of the shoddy manufacturer pass through fewer hands. 


\section{I24 WOOLLEN AND WORSTED INDUSTRIES}

Abroad, the rags are collected in much the same fashion as at home, the trade, both on the Continent and in England, being to a great extent in Jewish hands. The chief sources of supply are France and Germany, which together send five-sevenths of the imports. Then come, and in the order named, Holland, Belgium, Denmark and Russia ; and then a long list of countries that send small consignments, including Portugal, Turkey and the United States. The rags on arrival in Yorkshire, whether from other parts of the country or from abroad, have usually been roughly sorted already according to qualities and shades. This used not to be the rule; but as the trade has extended and become more specialised, the practice has increased. They may be bought by private contract or at the Dewsbury auction sales, which are to the rag trade what the London colonial sales are to the wool trade-with this exception, that the woollen manufacturer who uses rag wool, seldom, if ever, buys his rags at this stage. In the first place, only a few manufacturers make their own rag wool; and secondly, the sorting of the rags is as yet far from complete. They are usually bought by specialist rag dealers, or by shoddy and mungo makers. These classes overlap to some extent; for the dealers often own rag-pulling machinery. In their hands the rags undergo a most thorough sorting, shades and 
qualities being elaborately matched, so that the dealer can supply rags, and the "puller" rag wool, of an almost endless variety of grades and colours, at prices varying from $\frac{1}{2} \mathrm{~d}$. to Is. a pound.

As a rule the manufacturer buys his rag wool dyed as well as pulled. Sometimes the original colour of the rags is good enough for the purpose ; and the puller may exercise very considerable skill in so blending his materials, as to yield a respectable tint. In other cases, the original colour is reinforced by dyeing, or an entirely new tint is produced, the dyestuffs being applied to the rags before they are torn up. The largest shoddy makers card the wool after pulling it; but about two-thirds of the shoddy factories contain no carding machinery. No section of the woollen industry is more strictly localised than the manufacture of rag wool. Out of 908 rag-grinding machines in the United Kingdom in 1904, 88I were in Yorkshire; and most of these $88 \mathrm{I}$ machines could be found inside a circle, with Dewsbury as a centre and a radius of six or seven miles. Into that circle come at last the rags of the Frenchman, the German, the Turk and the Yankee, to start again on their journey about the world in a new form. 


\section{CHAPTER IV}

INDUSTRIAL AND COMMERCIAL ORGANISATION

A NY industry the organisation of which is A simple and rigid has either arrived at an uncommon state of perfection or is in danger of decay. The wool industry is neither perfect nor decadent, hence its organisation is complex and is always undergoing slight alterations and readjustments. The variety and intricate structure of the goods produced, the constant changes in the character and cost of raw materials, the shiftings of fashion, and the openings and shuttings of markets serve to keep it flexible and adaptable, though maybe it is not flexible enough. Firms or districts that stiffen themselves against change, decay and disappear; the adaptable survive. There are not merely perpetual variations in the fabrics made - that goes without saying-but also frequent modifications in the character and functions of the manufacturing and distributing businesses. Every now and then some new branch of the trade sprouts from the main stem; though 
this is rare. Or again, functions at one time united, as for example, combing and spinning, may fall more and more into separate hands. And the relations between manufacturer ${ }^{1}$ and merchant, or rather between manufacturing and "merchanting," are particularly liable to change, as in the case of the top makers referred to in the last chapter.

The lines which divide the various sections of the trade are seldom quite clearly drawn. The most important division of all - that between woollen and worsted-is itself not absolute, thanks to fashion and the intricacy of manufactured fabrics. Very frequently a woollen manufacturer will employ worsted yarns and some worsted manufacturers regularly use woollen. In a weaving shed, pieces of cloth that are in one case all woollen and in another all worsted may sometimes be seen side by side on the looms. The user of shoddy, as we have seen, may be also a maker of shoddy, or he may not. The worsted spinner may comb all his own materials, which is rare, or some of them, which is common, or none at all, which is also common. In a few exceptional firms machinery is made on the premises, though the vast majority buy from tex-

${ }^{1}$ In the language of the trade a manufacturer is an employer who makes cloths or stuffs. The word is here used in its broader sense, to describe all who are not simply dealers. 
tile machinists. Dyeing, nominally a gigantic separate industry, is often found combined with woollen manufacturing, occasionally with worsted manufacturing, sometimes with rag-pulling.

These few illustrations are introduced at the outset, because in describing the organisation of any industry there is always a danger of producing a false impression of simplicity and uniformity. And the wool-working trades are most emphatically neither simple nor uniform.

The absence of simplicity and uniformity is in part due to the very gradual way in which the factory system has conquered the various branches of the industry. There is still well-known unconquered territory in the "Celtic fringe" of the United Kingdom-domestic spinning and weaving in remote Scotch and Irish and Welsh cottages. It is not so generally known that the hand-loom woollen weavers, working at home, formed a class, though a very tiny class, in the Yorkshire census of I90I. They may be extinct before the census of rgi i is taken. But five-and-twenty or thirty years ago, they were still an important body of men, in the small towns and villages about Leeds, Huddersfield and Dewsbury. In one large Yorkshire woollen manufacturing business, as I have been told, no weaving was ever done by power down to the year I 877 , when the business came to an end. Many manufacturers con- 


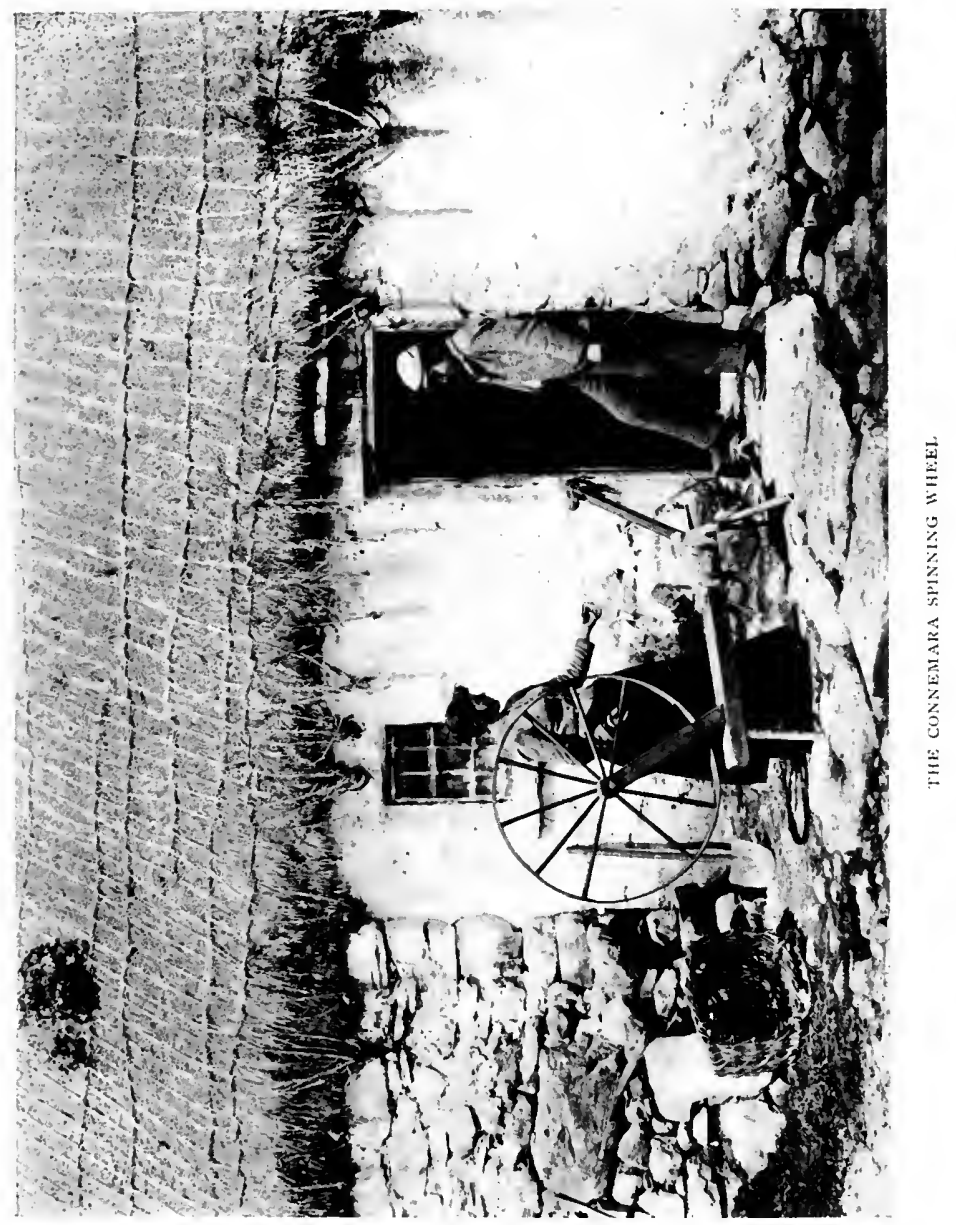



tinued to give out some classes of work to the domestic looms for long years after that date. To-day the hand-loom weavers are mainly to be found making patterns and sample lengths, in those mills which produce goods of the best quality. The two or three hundred who still work at home make a queer assortment of things -fancy waistcoats, rugs, flannels and what not.

In some branches of the industry the factory system has been well established for three full generations. Worsted spinning is a case in point. In other branches the factory had hardly begun its conquest two generations ago, and has only completed it in the generation which is now closing. Nor did the factory always spring into life complete, the property of "a capitalist millowner". Many of the early woollen factories were "company mills," owned by groups of small master clothiers, who clubbed together and bought machinery, which carried out for them on commission those manufacturing operations which it was no longer economical to perform by hand. And although this type of mill is now practically extinct, mills that accommodate more than one manufacturer and firms that start in a humble way by working on commission for their neighbours are still common enough. The small employer may rent a few rooms or a whole floor in a spinning mill. Looms belonging to two different manufacturers, 
driven by engines which belong to neither, can often be found running in one weaving shed.

Small masters of this class may be working quite independently or on commission. There are commission firms at every stage in both industries - commission combers, spinners, weavers, dyers and finishers - and they are by no means all small firms. The largest combers, dyers and finishers all work on commission. The commission spinners and weavers, on the other hand, are, as a rule, in rather a small way of business, though some of the commission firms in the worsted trade could not be called small. The small master, however, whether working on commission or not, exists more or less in all sections of the trade. The older the factory system in any particular section, the fewer chances are there for men of this class. A small-scale worsted spinner, for example, is a rare creature. It is in the trades subsidiary to spinning and weaving that the small firm best holds its own. Rag-pulling and the pulling of the tangled ends of waste from the spinning machinery and the looms are often carried on in buildings which would not be classed as factories in popular language, though they are factories "within the meaning of the Act". Small combing businesses, again, are not uncommon. There is, in short, still room for the small employer, although his sphere of action tends to get narrowed year by year. 
Side by side with these small businesses are to be found others of great size, each of which gives employment to one or two thousand people, possibly even more. Some of the large mills confine their attention to a single process, or, more strictly speaking, to a single group of processes such as combing, spinning or "manufacturing"; but several of the greatest are of a composite character; that is to say, they are in a position to carry on all, or almost all, the processes of the industry. But, as we shall see, disintegrating tendencies have been at work of recent years in the worsted trade, where these great concerns are most common. Cases in which a single employer or firm owns two or more mills of the same type are also not infrequent, and may, of course, be found in any branch of the industry.

When the woollen and worsted industries of the United Kingdom are compared with one another, two points of contrast are apparent in their general organisation-in the first place, the scale of operations in woollen is generally smaller than in worsted, and, secondly, specialisation has gone much further in worsted than in woollen. Taking the first point, one finds that in the year 1899 there were 1918 woollen and shoddy factories of all sorts in the United Kingdom, employing 1 53,232 persons; that is to say, as nearly as possible, 80 persons to a factory. At the same date there were 753 worsted factories, with 148,324 workpeople, which 


\section{I32 WOOLLEN AND WORSTED INDUSTRIES}

gives almost 200 to a factory. More recent and more exact figures yield similar results. For I90 I we have employment statistics not merely for factories "in bulk," but for the various departments in the different classes of factories. From these figures it appears that in the average woollen spinning factory or woollen spinning department only 22 persons were employed in spinning and all incidental processes. In the case of worsted spinning the corresponding figure is 140 . In weaving the difference is much less marked. The average woollen weaving shed, whether it is a separate business or a department, employs 50 workers in weaving and incidental processes; the average worsted weaving shed I06. It may be added that the employment figure for an average combing department or combing mill is 60 .

The machinery statistics of 1904 bear out the employment statistics of rgor. The average number of woollen spindles working together in one place is 2354, of worsted spindles 8000 . The average woollen weaving shed contains 49 looms, the average worsted weaving shed I $25 .^{1}$

Thus it appears that a woollen mill, which contains both spinning and weaving departments,

${ }^{1}$ The relation between machinery and employment statistics is too intricate to discuss here. The amount of machinery watched by one employee is the key to the difficulty. 
employs as a rule only about half as many hands as a worsted mill that only spins, and about twothirds as many as a worsted mill that only weaves. The figure for combing requires further consideration. Confining our attention for the moment to spinning and weaving, it should not be forgotten that the woollen industry, as was pointed out in the Introduction, is far more scattered than the worsted. Whereas in the case of worsted we are dealing with a trade that is carried on almost exclusively in active manufacturing districts, in that of woollen the figures include many small and many tiny mills in Wales and Ireland, Scotland and out-of-the-way parts of England. If the West Riding of Yorkshire and the woollen districts of Lancashire only were taken the disparity between the two sets of figures would be less marked. But even then a very great disparity would remain. It is not easy to illustrate this from the employment figures, but the machinery figures make the situation fairly clear. Whereas for the whole of the kingdom the average number of woollen spindles working together in one place is 2354 and of looms 49, in Yorkshire the spindle figure is $3 \mathrm{I} 82$, and the loom figure 63. In the case of worsted the Yorkshire figures are higher than those for the whole kingdom, but only by a small amount. The latter are 8000 spindles and 125 looms, the 


\section{WOOLLEN AND WORSTED INDUSTRIES}

former 8052 spindles and I 35 looms. Thus the situation is not greatly altered by narrowing the field of comparison.

A contrast has just been drawn between the woollen mill that both spins and weaves, and worsted mills that do one or the other, but not both. This contrast was drawn because the typical woollen mill does, as a matter of fact, contain both spinning and weaving departments. Its owner may not spin all the yarn that he uses; for some of that yarn perhaps is cotton and some worsted, and these he will naturally buy. But so far as it is woollen-which of course does not mean made of pure wool but made by the "woollen" processes - it will generally be spun at home. There are however important exceptions to this rule. In the Scotch tweed trade, for instance, the buying of yarn from specialist spinners is common. In Wales and Ireland there are many mills that sell yarn, and in England also weaving yarns are sometimes spun for sale in mills where there are no looms.

Carding normally goes with spinning. In a sense carding is the primary function of the woollen mill; for it was the process first taken over completely by modern machinery. The early company mills were mainly carding mills; and for many years after carding had entirely ceased to be done by hand, large quantities of 
yarn were spun in the weavers' cottages on the hand jenny. The introduction of mule spinning was almost as gradual as that of power weaving. It took place for the most part between I 820 and I 860, but was not completed, even in Yorkshire, in the latter year. And quite recently there were plenty of old hand mules at work, in which the carriage was pushed in by the weaver's knee. To this day the great carding machines are sometimes spoken of in the Leeds districts as "the engines," without further qualification or description-a reminder of the time when they were the chief if not the sole wool-working engines that the mill contained.

What is probably the commonest type of woollen mill, does not merely combine carding, spinning and weaving. It combines all processes, from opening the new wool or rag wool on a willey, to dyeing the cloth-when it is piece-dyed-and finishing it. In some cases, as we have seen, the rag wool itself is made on the premises. In others, wool dyeing also is done at home. At any point in the manufacturing process outside help may be required, either in emergency or as a regular thing. Rag wool is frequently bought dyed. If the shoddy or mungo maker owns "engines," he will card the rag wool before he disposes of it to the manufacturer. Wool and yarn dyeing may be done by a firm of profes- 
sional dyers. Woollen yarns, English or foreign, may be bought. At seasons of high pressure, a manufacturer who has difficulty in carrying out his orders to time, may give out spinning and weaving to be done by a neighbour whose machinery is less fully occupied than his own. Piece dyeing and finishing may also be done on commission, either for the manufacturer himself, or for a merchant to whom he has disposed of his unfinished cloth. But when all has been said, it remains true that combination of processes in the hands of a single firm is characteristic of the woollen industry.

The worsted industry, on the other hand, is marked by specialisation. At the bottom of the scale of processes comes the great specialised branch of wool combing, to which reference has already been made more than once. Combing was the last of the main processes in the worsted manufacture to be taken over by machinery. It was only between I 842 and I 853 that the inventions of Lister, Heilmann, Donisthorpe, Holden and Noble raised machine combing from the experimental stage to the stage of commercial success. At that time the combing of fine merino wool was in its infancy, and the task of organising the combing process, together with the associated processes of washing and carding, was heavy enough to occupy all the attention of a single 
firm. Moreover, in the early days, combing was an unusually profitable business, and the inventors, or some of them, were in a position to exploit their own patents, patents which were vigorously defended by much ligitation. So it came about that, although patented combs were sold at most remunerative prices, a large portion of the combing, both at home and abroad, was, from the outset, in the hands of firms which worked their own combs on commission for spinners. Now they work on commission for spinners and topmakers, more often the latter. Whenever possible, the combing mill runs day and night. Thanks to this and to the specialised knowledge of a very delicate and complicated series of processes that its managers and foremen acquire, it is able, if skilfully directed, to work more economically than a combing department in a spinning or general manufacturing mill can, as a rule, hope to do. The recent growth among spinners of the practice of buying tops instead of wool, has also tended to encourage the further organisation of combing as a distinct industry; while at the same time this practice owes its existence to the fact that combing was already in part so organised.

Yet a good deal of combing is still done in mills which also contain machinery for other processes, as the comparatively small number of workpeople employed in the average combing 
mill or department shows. The number, it will be remembered, is sixty - a figure which would be ridiculously low if it represented the average staff of a large number of specialised combing mills, the more so if we were to assume that those mills worked double shifts. It is the continued existence of combing departments in spinning mills or combined mills that keeps down the average; for only a large concern would itself consume all the wool that sixty pairs of hands, regularly employed, could pass through the preparing machinery and the combs. In many cases a mill will contain a small combing plant, while at the same time its owner has wool combed on commission and buys tops. He may be in a position to keep this small plant at work constantly, preparing certain classes of wool, although it would not be worth his while to lock up capital in combing machinery enough to meet all possible demands upon it in busy seasons; at such times he can always fall back on the cheap services of the commission combers. In the same way, a topmaker may run a few combs, but rely on the commission firms to deal with the bulk of his wool. The materials most frequently combed "at home" are long English wool, mohair and alpaca. Fine merino combing is the speciality of the greatest commission firms. Passing from combing to spinning, we come to a branch of the industry in 
which for many years small scale businesses, or even small departments, have been unknown. The average worsted spinning mill or department is very little inferior in size to the corresponding concern in the cotton industry, the former employing I 40 and the latter I45 workpeople. It should be pointed out that these figures-and all others of the same type quoted in the present chapter-refer strictly to the group of processes included under spinning, combing, or weaving, as the case may be, and to no others. They would not include, in the case of a spinning mill, the men employed about the engines, the office staff, packers, carters, or other miscellaneous employees.

The causes that have brought about the specialisation of worsted spinning into a separate industry are numerous; but the chief of them are fairly clear. Before dealing with them, however, I may repeat that spinning and manufacturing, as well as spinning and combing, are still often found in combination; but the specialised system may be regarded as the typical one, and it has been gaining ground of late at the expense of the combined system. The combined businesses, however, include some of the largest and bestknown firms in the trade. Yet at times they have, as it were, a bias towards one side or the other-that is to say, either spinning or weaving 
predominates. And sometimes when one firm controls two or three departments, they are really separate businesses, working independently of one another. Suppose, for instance, that spinning and weaving are combined, the spinning department need not confine itself to making yarns for the looms, nor need the weaving department consume only yarn spun on the premises. Such strict combination is opposed to the swift, varied, highly competitive and economical working of the worsted industry of to-day. It would tend to throw a good deal of machinery idle periodically and to lock up too much of the circulating capital of the business, in the form of wool waiting to be spun or yarn waiting to be woven-for heavy stocks would have to be kept on hand to meet the varying needs of the weaving department. The spinning section requires to be in a position to take any order that seems advantageous, and to specialise on those types of yarns for the production of which its machinery and the qualifications of its staff may fit it. Similarly the weaving section must buy its yarns where they are to be had best and cheapest for its immediate purposes, and not to be tied down to a single source of supply. When this stage of semi-independence has been reached, financial or other considerations may bring about the actual disruption of the business without its technical 
operations being appreciably interfered with. Just as spinning and weaving might in this way break apart, so might spinning and combing, and for similar reasons. Such things have happened in Yorkshire of late years, separations of spinning from combing having been fairly numerous owing to special circumstances. ${ }^{1}$

But the specialised worsted spinning mill is by no means the outcome of recent conditions only. It has always existed. In the early days of the factories it was found that worsted lent itself in a way that woollen did not to the process of frame spinning worked out by Arkwright. The early spinning frames, no doubt, left much to be desired, but they were at least more satisfactory than the early mules; so that twenty years before the latter machine had made any considerable progress in the woollen industry, and twenty years before the power loom had got a real footing in Yorkshire, water or steam-driven worsted spinning mills were fairly numerous. There was a steady demand for their yarns, independently of the local manufacture; and it is the continuance of this external demand in various forms which, more than anything else, has favoured specialisation. At the beginning of the nineteenth century

${ }^{1}$ When the woolcombers' combination was formed a number of spinning firms sold their combing plants to the new company. See p. 157, below. 


\section{WOOLLEN AND WORSTED INDUSTRIES}

the Yorkshire "mill yarn" went in considerable quantities into the old worsted manufacturing districts of East Anglia. As the manufacture in those districts decayed, in face of northern competition, the demands from the hosiery trade and from abroad sprang up-demands which, roughly speaking, have increased ever since. These demands are not, and never were, entirely met from Yorkshire; since worsted yarn for hosiery is largely spun in the mills of Leicester and Scotland. But spinning and knitting are such distinct processes that those mills are specialised, just as are so many in the West Riding. So far as the latter are concerned, the foreign yarn demand alone has given work enough to occupy many spinners for almost two generations. In 1905 our exports of worsted, alpaca and mohair yarns were valued at nearly five and three-quarter millions sterling; against which has to be set an import which probably does not exceed one million. Then again, the set of fashion, towards the end of the last century, favoured the worsted spinners. Fine broadcloths for men's wear went down before fine worsteds. Rougher types of woollen cloth to some extent gave way to worsted serges. Knitted underclothing, made of worsted yarn, gained ground; and so on. The effect of this substitution was twofold. In the first place, it caused a steady export of yarn from worsted 
into woollen districts, as the woollen manufacturers were obliged in many cases to turn their attention to weaving worsted fabrics. In the second place, it encouraged the foundation of worsted mills or worsted spinning departments, outside the boundaries to which they were at one time confined. The latter process has naturally not been very rapid; though its results are conspicuous in the West Riding, worsted being now of first-rate importance in the Leeds district, which was once almost entirely given over to woollen. In the West of England, on the other hand, worsted spinning has made very little progress, though there is a considerable demand for worsted yarns in weaving. These yarns must be drawn either from the West Riding or from abroad. There has been some reaction lately in favour of woollen, for years of dear wool are not favourable to the advance of worsted; but the ground lost by woollen has never been completely recovered. It does not necessarily follow that, because what might be called the external demand for worsted yarns is heavy, therefore spinning and weaving must be in separate hands in the worsted districts; but clearly the situation absolutely prevents, and always has prevented, spinning from being regarded as a mere subordinate process to weaving, and gives free play to all the forces which tend to encourage specialisa- 


\section{I44 WOOLLEN AND WORSTED INDUSTRIES}

tion. We shall see when we come to deal with the fluctuations in the export trade of the United Kingdom, how the check given to the expansion of our foreign trade in piece goods, by the development of manufacturing and of tariffs abroad, has further encouraged the tendency to treat spinning as an end in itself and not only as a step in the production of woven goods.

What has already been said throws a good deal of light on the reasons for the specialised character of weaving, or manufacturing, in the worsted industry. The existence of specialisation there is in part also due to the great variety of the yarns used, especially in the oldest branch of the trade, the "Bradford" trade in women's dress materials. Worsteds for men's wear, whether they are plain, like the modern dress coat, for instance, or fancy, like the modern "trousering," are made almost entirely of wool. The light women's dress goods on the other hand, have very generally a cotton warp and a worsted weft. They often approach cotton goods in character; and the quick, narrow looms on which they are mostly made can readily be used for the weaving of pure cotton fabrics, linings and so forth, and constantly are so used when wool is dear, or when, for any other reason, fashion turns towards cotton. There was, for instance, great activity in this line of business in 1905. Or again, the 
materials woven by the "worsted " manufacturer may be half silk ; and the use of silk in the best products of the West Riding is likely to become more common in the future, owing to recent improvements in the dyeing and finishing of mixed fabrics. It would therefore be no great exaggeration to say that the average dress goods manufacturer draws half his materials from outside the worsted industry; and this state of things is not a new one, for silk and worsted were woven together more than a century ago, and cotton warps have been a feature of the Bradford trade for seventy years.

These things being so, the separation of manufacturing from spinning is natural, and, from most points of view, desirable in the dress goods trade. The dress goods manufacturer is only one among many possible clients of the worsted spinner; and the spinner, in his turn, can at best only supply some of the manufacturer's needs. The case of the worsted "coating" manufacturer is rather different, as plain worsteds, at any rate, require no great variety of yarns. Combined businesses are in fact fairly common in this branch ; though as the manufacture of "coatings" and "trouserings" is very widely spread, and is mixed up with other classes of weaving, it is generally found separated from worsted spinning. As further reasons for the prevailing specialisation 
we may note, in the first place, that the variety and complexity of woven fabrics increases rapidly, and the direction of weaving operations becomes every year a more and more exacting occupation ; and, secondly, that the capital needed to start or carry on a manufacturing or spinning business, with fair chances of success, is obviously less than is needed for a combined business.

The comparative scarcity of specialised spinning and weaving businesses in the woollen industry requires some further explanation. There is clearly no room for a threefold division of the work, such as one finds in worsted ; for the preliminary processes in the manufacture of woollen yarn are short and relatively simple. The wool goes straight from the carding engines to the mule, and there is nothing that corresponds either to combing or drawing. But, at first sight, there seems no special reason why the separation of spinning and weaving should not be as usual in woollen as in worsted. It exists, more or less, in all the main manufacturing districts ; it is fairly common in Scotland; but, taking the country as a whole, it is the exception. Moreover it seems to be declining, and certainly it is not on the increase. Specialised spinning mills are far less numerous now than they were eighteen years ago ; though the decline in spindles is not nearly so great as the decline in the number of mills, the 
number of these mills having fallen 28 per cent. between 1889 and 1904, and the number of their spindles only I 2 per cent. This of course means that the great decline in mills is mainly due to the ordinary working of industrial concentration. Those that have gone out of use were, in the majority of cases, small and out-of-the-way concerns, of the type described in the Introduction. But there has also been some decline in the demand for the work of spinning mills, in the main manufacturing districts, except when that work consists in spinning yarns for other purposes than ordinary woollen weaving. Here we have the exact reverse of the worsted situation, and it claims attention.

The demand for woollen weaving yarns was never great in the West Riding, most manufacturers having always spun their own. Neither has there ever been a large export, nor have spinning mills in one district been called upon, to any great extent, to feed the looms of another. There is some "import" of Scotch woollen yarns into Yorkshire, for use in the coating trade of the worsted districts; and Bradford coating mills may buy from Huddersfield spinners-but such purchases are not very important. When woollen yarn is brought from a distance, it is generally of foreign origin-Belgian or German. Thus the absence of an export and the existence of an im- 
port discourage independent spinning, just as the reverse situation in the worsted industry encourages it. Why there should be an import at all, and why a large export has never grown up, are pertinent questions that could only be answered, if at all, in a long technical and historical discussion, for which there is no room here.

An important technical impediment to the spread of specialised spinning in the West Riding is the complex character of most of the woollen yarn. The manufacturer's success depends so largely on the skilful composition of his yarn, that it must as a rule be made under his own eye and not bought from a neighbour. He is perhaps scribbling new wool and rag wool, or wool and cotton together, in proportions nicely calculated so as to produce the maximum of effect in the finished cloth at the minimum cost. Or maybe he is twisting a tender coating of shoddy about a core of cotton yarn that will stand the tension of the loom and of subsequent wear. These are tasks which a Yorkshireman, least of all, would care to trust as a regular thing to an outside spinner. It is interesting to notice that most of the worsted and woollen weaving yarns, which are regularly bought and sold, are made of pure wool. Some risk, of course, is run in purchasing these ; the wool may be an inferior blend; and ignorance as to the exact composition of one's tops or yarn 
is rightly regarded as one of the drawbacks to specialisation in the worsted trade. But the risks would be far greater in the case of the cheaper, but more ingenious, yarns used in medium and low-grade woollens.

In my opinion the typical organisation of the woollen industry is partly due to tradition, as well as to commercial and technical causes. The master clothier or master manufacturer of the late eighteenth and early nineteenth centuries habitually supervised all the processes of the manufacture; though when he was in business on a large scale, he gave out wool to be spun, or yarn to be woven in the cottages, before machinery took over these processes. And just as the small masters of Yorkshire survived in considerable numbers some forty years ago, so the type of organisation which they represented survives to this day. But mere tradition would not have kept the combined businesses in existence, had technical and commercial considerations favoured subdivision.

So far we have been dealing with the case of woollen cloth and the relation of spinning to weaving in the various branches of the cloth trade. But woollen yarns are also used in the manufacture of hosiery and shawls and in all kinds of knitting and amateur wool work. Yarns of this class are regularly produced in specialised spinning 


\section{I5 WOOLLEN AND WORSTED INDUSTRIES}

mills; and these mills may also turn out weaving yarns. This combination is fairly common in Scotland. The reasons for specialisation in the case of knitting and hosiery yarns are obvious: there is no weaving process. Spinners of these yarns not infrequently own both woollen and worsted machinery; for while some of their yarns are carded and spun on a mule, others are drawn and spun in the worsted style, and, it may be, combed as well. A hybrid process, consisting of carding, drawing and frame spinning, is also constantly employed in the production of carpet yarns, which like the knitting yarns are often made in specialised mills. It is natural enough that the rather complex business of carpet weaving should have become separated in many cases from that of spinning the carpet yarns. The fact that carpets often have a foundation of tough jute, which forces the manufacturer to go into the market for some of his yarn, helps to account for the partial specialisation in this instance.

A few words may here be said as to the relation of dyeing and finishing to the other processes, on its business, as distinct from its technical side. In the case of worsted, spinners and manufacturers as a rule have nothing to do with dyeing. Whether the wool be dyed in the top, the yarn or the piece the dyeing is generally done on commission, either for the spinner, the 
manufacturer or the merchant. The chief exceptions to this rule are to be found in the worsted coating trade. Finishing also is often done at home by the coating manufacturer-particularly in Huddersfield - whereas dress goods are almost invariably finished on commission by the great dyeing firms of the Bradford district. These are the firms which were welded in 1898 into what is probably the most successful of British industrial "combines," the Bradford Dyers Association. The Bradford Dyers are primarily piece dyers and finishers. A second combination, which has had a less successful career, the British Cotton and Wool Dyers Association, is concerned mainly with the dyeing of raw material and yarns. Its constituent firms are scattered over Yorkshire, Lancashire and the Glasgow district.

In the woollen trade, as has been already mentioned, dyeing and finishing are frequently associated with the other manufacturing processes. There is, however, plenty of dyeing on commission here also, and the raw material often comes dyed into the manufacturers' hands. The fancy woollen manufacturer, whose goods are necessarily wool or yarn dyed in a great variety of shades, is less likely to include a dyeing department in his works, than is the manufacturer who is mainly concerned with self-coloured fabrics such as uniform cloths, and plain blue or 
black materials of all sorts. Manufacturers of this latter class almost always do some at least of their own dyeing, though indigo dyeing is generally done on commission. The finishing and dressing of woollen cloth and worsted coatings forms an important specialised business in the Leeds and still more in the Huddersfield district. Generally speaking, it is the finer cloths which are handed over to the specialist to go through these final processes, as would be expected; for cheap goods can as a rule be adequately prepared for market by the original producer. The part which merchants take in the task of getting both woollens and worsteds dyed and finished will be explained in connection with the commercial organisation of the industries.

Two important matters connected with the industrial organisation remain to be dealt with. These are joint stock enterprise and industrial combination. But a few years ago-in the early nineties of the last century-companies that issued reports and balance sheets, whose shares were regularly bought and sold, were rare in all branches of the woollen and worsted and associated industries; though private companies of course existed. Even now, after the outbreak of company promotion in the late nineties, the number of spinning and manufacturing companies, whose shares are quoted on the West 
Riding Stock Exchanges, is comparatively small. It is never possible, for example, to gauge the general prosperity of worsted spinning by comparing the balance sheets and dividends of scores of limited mills, whereas this is regularly done in the case of Lancashire cotton spinning. Worsted weaving and woollen manufacturing are in much the same situation as worsted spinning. Latterly, a number of large concerns have been turned into limited companies, and their shares have been taken by the public; but the family business, though it may have assumed the company form, is still the prevalent type.

Whether this state of things will last very much longer is doubtful. Joint stock companies are on the increase, and combination in various forms has been making steady, though not always noisy, progress during the last ten years. There is already vague talk of general combinations among both the Scotch and the West of England manufacturers. The cause which is said to render combination necessary is the same in both cases - the need to protect genuine West of England cloth and genuine Scotch tweed, by means of a stamp affixed by the associated manufacturers and by organised campaigns of advertisement, against imitations from Yorkshire. Although there has been one disastrous collapse of a large combination and a number of doubtful successes, 


\section{I54 WOOLLEN AND WORSTED INDUSTRIES}

only a man unable to read the signs of the times would maintain that we have heard the last of large textile amalgamations. It is true that in all branches of the trade the promoters of a combination have to deal with special obstacles, not the least of which is the strong local feeling and pronounced individualism of the manufacturer; but these things have been overcome before, and may be overcome again, when there is gain to be made or loss to be avoided. Another obstacle is the great variety of yarns and fabrics turned out by the various mills. For as a rule only the producers of articles that come into fairly direct competition with one another are easily moved to set bounds to the force of that competition by means of joint action.

Hitherto combinations have been commonest in the dyeing industry. Besides those already referred to-the Bradford Dyers and the British Cotton and Wool Dyers-there are others in Yorkshire of less importance, such as the Yorkshire Indigo Dyers and the Leeds Worsted Dyers. The Bradford Dyers' Association does an immense business, dealing not only with worsted and all sorts of mixed fabrics, but also very largely with pure cotton goods. So strong has the Association become, and so important is the maintenance of friendly relations between it and the manufacturers and merchants for whom it 
works, that the Bradford Chamber of Commerce, with the concurrence of the dyers, established in I9OI-02 a permanent committee, known as the Bradford Piece Dyeing Board, to discuss and, so far as possible, adjust all differences between the two parties. The Board is composed of twenty representatives of the Chamber, one of whom is chairman, and three representatives of the Association. There is also a standing arbitrator, but his services have been but little used. A few quotations from the printed reports of the Board will illustrate the general character of its work.

The Chamber of Commerce members protested against the appointment as manager of one of the branches of the Association of "a gentleman who is also a merchant and manufacturer," on the ground that he might make unfair use of the knowledge he would thus acquire of the styles of dyeing and finishing ordered by other merchants and manufacturer's. "The Association's representatives assured the Board that the styles of customers were not and would not be seen by the gentleman named, but that the views expressed by the Board with regard to the appointment should be borne in mind in the future."

The Association announced a surcharge of 3s. per shade "for dyeing travellers' pattern lengths". After discussion on the Board, "the 


\section{I56 WOOLLEN AND WORSTED INDUSTRIES}

representatives of the Association promised to reconsider the matter".

Attention was called to the cheap dyeing of cotton goods in Italy, which enabled Italians to compete successfully in the Levant trade. It was replied that the Association was alive to this competition, "and was taking what steps it could to meet it; further, that the great bulk of the goods were dyed by the manufacturers themselves, and that it was therefore impossible to say what rates were actually charged for dyeing".

"A complaint was made that the Association was competing with Bradford firms in the selling of piece goods." It was replied that, "with one exception, all the pieces sold by the Association were damaged- 'jobs' in fact,-and that the Association was compelled to dispose of them; but, as far as possible, the Association would endeavour to avoid competing or interfering with merchants".

These quotations have been given at length to show that the main work of the Board is to give opportunity for the explanation of misunderstandings and the checking of possible abuses at an early stage. It oils the wheels of commerce, and, to mix metaphors, acts as a safety valve for grievances. To pronounce it an unqualified success would be premature, for it is still young, but it marks an important step in the direction of that better and more rational organisation of industry 
and commerce towards which the manufacturing nations are feeling their way.

Outside the dyeing trade, combinations have been either unsuccessful or comparatively small; yet they are fairly numerous. It was natural that the amalgamation of the commission dyers should be followed by a combination among the commission combers, whose trade is very strictly localised. But the combers' combination has had a disastrous history. It never included the greatest firm in the trade; after a few years of precarious existence it had to reorganise with some discredit and great loss; and it is as yet too early too speak of the success or failure of the reorganised business. Proposals have from time to time been made for large scale combinations of manufacturers or spinners in Yorkshire, as well as in Scotland and the West of England; but the misfortunes of the combers, and the reaction against the exaggerated combination movement of the closing years of the nineteenth century, have effectually checked such ambitious schemes-for the time being, at any rate. There have been, however, important combinations of comparatively small groups of firms in certain specialised branches of spinning, such as the making of hosiery yarns and of carpet yarns; there has been one combination of considerable importance in the rag-wool produc- 
ing trade; and some few manufacturing (i.e., weaving) combinations. But manufacturing has not been seriously affected, there having been no amalgamations of any large number of firms, but merely fusions of a type that have long been familiar in English business. Combination is of course here taken to mean not a mere association of employers, with a view to watching the interests of the trade and dealing with organised labour, but either a close alliance of firms pursuing a common business policy or an actual financial amalgamation. All the important cases of combination just referred to are of the latter type.

Some account was given in the last chapter of the dealers and dealings in the raw materials of the woollen and worsted industries. It now remains to complete what was there said by examining briefly the organisation of the trade in yarns and piece goods. Before doing so, however, reference should be made to a very important public institution, that was called into existence to promote the smooth working of the trade in tops and worsted yarns - the Bradford Conditioning House. The Conditioning House was established by the City Corporation in I89I, and by a recent arrangement its working is supervised by a joint committee of the Council and the Chamber of Commerce. Its business is to 
test and certify authoritatively the "condition," that is to say the percentage of moisture, of tops or yarns submitted to it by members of the trade. Also it is prepared to certify the weight of consignments of tops or yarn, and the counts and lengths of yarns. Its certificates are recognised as final in cases where a dispute has been referred to it for decision. The standard condition for tops was explained on page 47 . For woollen and worsted yarns the standard condition, according to the practice of the Conditioning House, is between I 5 and 16 per cent. of moisture. In testing, the yarn is first completely dried and then allowed to regain moisture to the extent of I $8 \frac{1}{4}$ per cent. of its dry weight. Moisture thus represents I5-16 per cent. of the total weight of the marketable yarn. For cotton yarns the regain is $8 \frac{1}{2}$ and for silk yarns I I per cent. of the dry weight. During the last two years (1905-6) conferences have been held between the Bradford authorities and those of the similar Conditioning Houses in the great continental worsted centres of Roubaix, Verviers, Elberfeld and Leipzig; and an attempt is being made to secure uniformity of testing and measuring methods throughout Europe.

In the home yarn trade there is no regular class of merchants coming between the spinner and the manufacturer. Yarn is sometimes bought 
through dealers, for there is always room for middlemen in certain classes of transactions. But generally speaking, and especially in the Yorkshire worsted trade, where yarn buying is most frequent, spinners and manufacturers come into direct relations with one another. The independent yarn agent, who invariably appears as an intermediary between spinner and manufacturer in the cotton trade, is scarce in the wool trade; although sales in a comparatively remote district - say from Yorkshire to Scotland-may be conducted through an agent of this class. The manufacturer, when buying, can either stipulate for delivery on a given date or for "delivery as required". If he does the latter, or if no time for delivery is specified, it is understood in the Bradford district-according to the Yarn Contract Rules-that "at least two-thirds of the contract must be completed within six months, and the remainder within a further three months". Terms of payment vary considerably, even within single districts, but they are generally short and have a tendency to shorten. In Bradford monthly settlements-with a discount-are common.

The export of yarn lies mainly in the hands of a considerable group of firms in Bradford; for the bulk of our yarn exports come from the West Riding worsted district. The names of these 
firms frequently indicate a foreign origin. Some of them deal in pieces as well as in yarns, but more usually the yarn trade is specialised. Generally speaking, spinners in the near neighbourhood of Bradford have no direct relations with foreign purchasers, but sell to the merchants. Spinners for export in other parts of Yorkshire often deal direct with the foreign buyer; and there is a tendency for the largest and strongest businesses to see to their own " merchanting" both at home and abroad. When the spinner sells to an export merchant, the ordinary terms in the Yorkshire worsted district are that all yarns delivered in the course of any month are paid for with $2 \frac{1}{2}$ per cent. discount, on the second Thursday of the following month, in a fourteen days' draft on a London bank. No such custom is of course absolutely hard and fast. It is impossible to make any general statement as to the terms on which the merchant, in his turn, disposes of the yarn to foreign customers ; for credit periods and discount rates vary very greatly. But it may be pointed out that the yarn merchant, like the majority of English exporters, does not often draw bills on his foreign correspondent.

The organisation of the trade in finished goods, the piece trade, underwent considerable changes during the latter part of the nineteenth century, 
and is at present intricate and interesting. Formerly there existed an important class of specialised merchants, woollen merchants or worsted. merchants as the case might be, in the manufacturing districts-above all in Yorkshire-through whose hands all the goods passed, whether they were intended for the home or the foreign trade. This mercantile class was absolutely indispensable, so long as a large part of the manufacturing was carried on by the small master clothiers; for the clothiers laid no claim to commercial knowledge. They sold their goods to the merchants in the cloth halls of Halifax, Huddersfield, Bradford and Leeds, buildings erected at various dates in the eighteenth century for the convenience of the trade. The oldest of these halls, that at Halifax, was built in 1700 ; the second-the Leeds white cloth hall-in I7 Ir. An important feature of the old trade is recorded in the name of this latter building; for it was the place to which the clothiers brought their undyed cloth and disposed of it to the merchants, who either had it dyed and finished on commission or themselves controlled finishing establishments. There was a separate market place for coloured cloths in Leeds, known as the "mixed cloth hall". With the decline of the small clothiers the cloth hall business slackened. This was first noticeable in the worsted trade. Dealings in the cloth 
hall at Bradford came to an end in the early '5o's ; they lasted longer at Huddersfield, while - at Leeds they continued far into the last quarter of the nineteenth century. In the West of England, where really small manufacturers were scarce even in the eighteenth century, the relations between manufacturing and merchanting were of a different character. Many of those who controlled the industrial operations were in the first instance merchants, who bought wool, had it spun, woven, dyed and finished, and then sold the pieces. That is to say, the industrial organisation was capitalistic before the factory age began, and the industrial and commercial organisations were not quite clearly separated from one another; though clothiers not infrequently sold to merchants, particularly to London merchants.

As the factory system was adopted in the North, a somewhat similar state of things arose there. Many of the first mill-owners were men who had acquired capital as merchants; indeed for a considerable number of years they were regularly described as "merchant manufacturers". The old clothiers regarded them with jealousy as commercial men who were intruding into the manufacturing business; though as a matter of fact, before the days of machine spinning and steam, merchants had occasionally controlled full- 
ing and finishing mills, and so had had a hand in the true work of manufacture. All through the nineteenth century this transference of capital from commerce to industry continued, though not in so rapid and dramatic a fashion as in the early days, mercantile firms buying or building mills, or perhaps absorbing manufacturing businesses with which they had previously had close relations and which could no longer stand alone. In very few such cases, if any, was the commercial work abandoned. The firms remain "merchant manufacturers," though the name is no longer current ; while many other firms, which were not originally founded by merchants, now find it convenient to deal directly with large, and sometimes even with small consumers of their goods. This state of things is perhaps commonest in the Yorkshire woollen industry, but it is found in all branches of the woollen and worsted trades. There is not much work left for the old type of specialised merchant in the home market. For one thing, the rise of the great wholesale clothing industry in Yorkshire and elsewhere, during the second half of the nineteenth century, has provided for the manufacturers regular customers at their very doors, who can buy in large quantities. There is no room for a middleman between the mill-owner and the "clothier" in the modern sense of the word, that is to say, the maker of clothes. Then, 
too, small retailers, tailors, or drapers or "costumiers," like to deal with mercantile houses that handle a great variety of goods-worsteds, woollens, silks and cottons-rather than with a number of specialists. Large, miscellaneous retailers of the class that to-day controls so much of the clothing and furnishing trades can, if necessary, deal with the manufacturer. And the tailor who is in a large way of business may at times go direct to the mill. There is also, as is well known, a general tendency in modern business for very large retail firms to do some or all of their own manufacturing. But this tendency has as yet affected the wool textile industries but slightly. Its existence, however, shows clearly how little room is left for an intermediary between the manufacturer and the large retailer.

Thus, although there are many important mercantile firms in the manufacturing districts which do a considerable home trade, that trade is not usually of a specialised character. The woollen merchant and the worsted merchant as separate types have become scarce. Most firms combine home with foreign business; for in the foreign trade the sphere of the merchant is far less liable to invasion. Much of the large scale, miscellaneous, mercantile business for the home trade gravitates to London. The London houses keep in touch with all the manufacturing districts, and 
they stand at the centre of the world's greatest consumption of clothing. They play a specially important part in the work of distributing the best classes of woollens and worsteds, such as the Scotch tweeds, the West of England cloths, and the finest goods from Yorkshire. These fabrics for the most part pass into the hands of the "West End" type of tailor in England, or in those foreign countries - and they are manywhere English materials and what claims to be English tailoring are popular among the wellto-do. There are few important commercial firms, either in the West Country or in the Scotch tweed manufacturing districts; though there are, of course, a number in Glasgow.

Not many manufacturers regularly manage their own export business. Here, at least, the British merchant is usually employed as intermediary in all branches of the trade. In some cases foreign import houses deal direct with the British millowner, sending round buyers to the mills at regular intervals to choose among the new season's goods. A considerable amount of the trade between the Scotch tweed districts and Germany, for instance, is carried on in this fashion. Or again, manufacturing done on contract for colonial or foreign Governments, such as the making of uniform and army cloths, may be arranged for directly between the agent of the purchasing 
Government and the manufacturer. But, as a rule, there is room for the merchant.

The bulk of the export trade, in the nature of the case, is with civilised and temperate lands or their colonies and dependencies. Your savage easily acquires a taste for cotton; he soon becomes a purchaser of cheap blankets; as he unlearns his old habits he may begin to use readymade clothing, though it will probably not come to him at firsthand; but he rarely becomes a good customer of the woollen and worsted piece merchant. The chief buying countries are, like ourselves, subject to fashion. There is little of that class of business in which the merchant steadily buys standard qualities of goods, for distribution among uncivilised peoples or peoples with conservative tastes. Such business is not unknown; but it is rare and it grows rarer. There is nothing in the woollen or worsted trade comparable to the demand for plain cotton goods from India and the tropics. The thing that most nearly resembled it was the American demand in the old days for what were known as slave cloths ; but that has been dead these forty years.

A great deal of export work is in the hands of houses in London and the North that do a varied trade in many types of textiles; but there are also a number of firms whose business is entirely in woollen and worsted goods; and others which 
confine themselves, generally speaking, to either woollen or worsted after the old fashion. But as the public taste abroad, as well as at home, runs at times towards worsteds, and at other times towards woollens, strict specialisation on the part of merchants has long been declining.

A distinction is sometimes drawn in Yorkshire between the export merchant, properly so-called, and the shipper, who does merchant's work, but not quite in the merchant's way. Shipper and merchant stand in different relations to the manufacturer and perform rather different functions in the task of distribution. The latter takes greater risks and requires more capital. He receives the manufacturer's patterns season by season, makes his selection and orders his pieces, trusting to his knowledge of the markets with which he deals to insure him against loss. The shipper, on the other hand, gives no orders to the manufacturer until he himself is provided with orders from abroad. He sends the patterns to his customers and places his orders in this country according to the results of this canvass of the foreign market. Naturally he is somewhat behind the fair, as far as patterns are concerned; for before his orders come in, the merchant who has a stock of new materials may be selling them in competition with him. On the other hand, as he takes few risks and has not to keep much money locked 
up in goods, he can afford to quote low prices to the foreign buyer; and in markets where it is not necessary to offer the very latest English patterns this is an important consideration. All this applies chiefly to fancy goods, or at any rate to goods which are not of standard types. But a very large proportion of our exports now belongs to the class which is made from fresh patterns year by year. In the case of standard goods and repeat orders, the shipper's position is but little different from that of the merchant. $\mathrm{He}$ is sure to be able to get the former at short notice, and the latter can be executed as quickly for him as for any one else.

From what has just been said, it will have been gathered that making to order rather than making to stock prevails in the woollen and worsted industries to-day. There are, of course, in each section of the trade some classes of goods which could be made to stock to a limited extent without too great risk. Plain and self-coloured materials of all kinds are cases in point. Blankets or blue serge or billiard table cloth might be made to stock more safely than worsted trouserings or Scotch tweeds. But it is not safe to go far with such work, so that, generally speaking, it is avoided. Twenty years ago a Scotch tweed manufacturer mentioned in evidence before a Royal Commission that "all the goods made 


\section{WOOLLEN AND WORSTED INDUSTRIES}

in the South of Scotland trade were made to order"; and a mill-owner from the Yorkshire heavy woollen district told the Commissioners that in his neighbourhood, owing to the frequent changes of fashion, they were "cautious not to overstock, ... hence the difficulty of keeping themselves going with orders that came in a retail way, instead of in the large wholesale way which characterised the business when all the goods were plain; and this hand-to-mouth style of business ... produced a good deal of cautiousness". The state of things described by these two representative manufacturers has become more pronounced since I 886-faster shiftings of fashion and an increased taste for fancy materials of all sorts; hence less and less opportunity of making for stock; more and more small orders, and greater demands on the technical skill and organising capacity of the employer.

It has already been mentioned that the work of the old type of Yorkshire woollen and worsted merchants included the purchase of undyed materials-goods "in the grey," as they are called in the worsted trade, or "in the balk," as the woollen phrase is. These were dyed and finished, and sold both at home and abroad. This class of business has never ceased, but it is not as important as it once was. Certainly the old custom of handling large stocks of material in this way is 
on the decline. The pure shipper does not undertake this work, as his business is more that of an agent than that of a risk-taking capitalist, and the merchants do less of it than they did. But it should not be forgotten that, though the pure merchant may be disposed to avoid this particular form of risk, there are some important manufacturing firms that, besides undertaking it cheerfully, do their own merchanting at home and abroad into the bargain.

The terms on which manufacturers sell to merchants and others vary very greatly; but some account of them cannot be omitted, although it is impossible to make such an account complete. Long credits were a feature of the old-fashioned business, and they still survive in certain branches. Where the tailor has to wait for his money, he is apt to make the merchant wait too, the merchant in his turn exacting generous treatment from the manufacturer; and a custom of long credit once established, whether on this or on less reasonable grounds, is not easily got rid of. In the Scotch tweed trade one hears of six months' credit, with a four months' bill on top of that and a discount of $2 \frac{1}{2}$ per cent. at the finish, as a regular custom. The manufacturers, not unnaturally, grumble at such terms, but have not yet broken them down. In Yorkshire things are managed differently, and when a clothier not a merchant is the buyer, busi- 


\section{I72 WOOLLEN AND WORSTED INDUSTRIES}

ness is often exceedingly prompt. It is a common arrangement, especially in the Bradford district, for the clothier to pay cash within seven days, with a substantial discount of course. Monthly payments, also with a discount, are very common in all parts of the West Riding. A member of a clothing firm outside Yorkshire once spoke to me almost plaintively of the Yorkshireman's persistence in this monthly demand for cash. Another arrangement, frequent in the Leeds and Huddersfield districts, is for the clothier to pay for spring goods in May and winter goods in November, in each case with a small discount. As the former would be delivered about the beginning of the year and the latter about July, this amounts to some four months' credit. This method of payment by seasons is also common as between merchant and manufacturer, but in this case the periods may be rather longer. Spring goods are delivered by the manufacturer between, say, September and February, and are paid for, again with a small discount, in April ; winter goods being paid for in similar fashion about October. Two payments yearly and a $2 \frac{1}{2}$ per cent. discount may be considered a normal arrangement, but customs vary from firm to firm and in the different branches of the trade. Some mercantile firms prefer monthly payments and heavier discounts; while repeat orders that do not fall fairly into either 
of the two seasons will be paid for under some arrangement different from that which applies to regular season goods. Lastly, the terms between manufacturer and shipper differ from those between manufacturer and merchant, as would be expected, for the shipper neither waits so long for his money nor takes so much risk as the merchant who carries large stocks of goods. In this case the monthly payment with a small discount is the ordinary arrangement. 


\section{CHAPTER V}

\section{LABOUR IN THE INDUSTRIES}

ПHE difficulties connected with any attempt $\perp$ to determine quite accurately with our existing statistical material, the number of persons employed in the woollen and worsted industries were pointed out in the Introduction to this book. As to the indirect employment which these or any industries give-that is a thing which can never be put into figures. A great staple trade draws into the circle of its dependents railwaymen and miners, landowners and farmers, makers of machinery and makers of houses, bankers, lawyers, accountants, and professional football players, besides the large commercial class that is engaged directly in the work of collecting its raw material and distributing its products. The figure of 259,909 which represents the total number of persons employed in the year igor, according to the returns made to the factory inspectors, is no doubt somewhat inexact. It certainly does not include all those employed about the mills, though not in the 
actual manufacturing processes; it only includes those dyers, bleachers and printers--some 3,000 all told-who serve in the mills and not in separate works; but it is as accurate a return as we are likely to get of those engaged in the primary processes described in Chapter II.

The West Riding of Yorkshire is the only county area in which a really considerable section of the people is occupied in these processes. Of all the men and boys in regular work in the Riding, one in every twelve, and of all the wageearning women and girls rather more than one in every four, is so occupied. At Bradford the figures are naturally far higher-more than one working boy or man in five, and nearly one working woman or girl in two, being employed in the actual task of manufacture in the worsted mills. Those indirectly dependent on the trade must form almost the whole of the population of a town like Bradford, and maybe a quarter or a third of the population of the Riding.

The total body of wool workers is composed of men and women in the proportion of two-fifths to three-fifths, almost exactly. Of the 106,598 men more than 83,000 and of the 153,3 II women more than I I 4,000 are (or were) eighteen years old and upwards-full grown according to the standard of the factory acts. Some 54,000 boys and girls between twelve and eighteen were 
working full time; while 7475 children between twelve and fourteen were serving as half-timers. This latter class, the ignorant subject of so much controversy and of two generations of factory acts, is now on the high road to extinction, perhaps soon to be legislated out of existence altogether. More stringent education and factory laws, combined with other circumstances, reduced its numbers very rapidly during the last decade of the nineteenth century. From nearly 23,000 in I 889-9o they had fallen in I90 I to the figure just quoted, and there has no doubt been a further fall since that date. What half-timers remain are employed almost entirely in the Yorkshire worsted spinning mills, where their services and those of the other young children whom the raising of the school age keeps from work, have long been valued, and where their loss is sometimes regretted-the more so as it is not always easy to get their simple tasks performed by the older boys and girls, who naturally aim at better paid work.

Another section of the mill-workers, whose numbers deserve special attention, is that of the married women. In Yorkshire-the typical county-wives and widows make up about a sixth of the women workers, that is to say some 19,000 . How many are wives and how many widows the census returns do not state, but it may be as- 
sumed that the percentage of widows is high; for a woman who loses her husband naturally goes back to the mill in which she worked before marriage. There can be no doubt, however, that many thousands of wives are in regular work, to the detriment of their health and that of the next generation. According to an apparently well-founded opinion, their number has declined considerably of late years, but the question has not been tested statistically. Their continued presence in the mills, even in reduced numbers, is a source of disquiet to the best employers; but in existing circumstances it is not easily avoided. Legislation alone could effectually bar the mill doors against the wife of the idler, the out-o'-work, or the under-paid; and what the effect of such legislation would be cannot be discussed here. Only one more point of interest can be indicated, namely, that although two-thirds of the married women are weavers, yet the highest percentage of married women is found in the combing mills. The reason for this seems to be that heavy tasks in these mills, of a kind not usually given to women, are frequently undertaken by sturdy Irish women; and among the poor Irish the wife more often goes to work than among the English.

Except at certain points, the line between men's and women's work is fairly well marked, although not with absolute precision. Broadly 
speaking, a woman neither sorts nor washes the raw wool, at one end of the scale, neither dyes nor finishes the pieces, at the other. She may serve as a back washer or fill some subordinate post connected with the first washing. About the carding rooms few women are to be seen; though in the woollen trade they are fairly often employed to feed the engines. This is a light and simple task, particularly when an automatic feeding mechanism is introduced. All that the human feeder then has to do is to heap wool into a trough. The machine does the rest. Women regularly tend preparing boxes and combs. At this stage men fill only the few more responsible posts, except of course on the night shift. Women constantly handle and sort rags; but they are not likely to be in charge of rag-grinding machines or to have anything to do with the task of blending raw materials. Worsted spinning rooms are full of young women and girls, with only a sprinkling of male overlookers; whereas woollen mules always give a good deal of employment to men, though girls and women may be engaged about them. Weaving is curiously mixed. The Bradford trade, in the technical sense, is the home of the girl weaver; men have been well-nigh forced out of it. In the worsted coating trade, and in most branches of woollen weaving, the sexes work side by side; 
but there is a tendency for the heaviest and most complex looms to be tended by men. In Huddersfield and district, for example, the percentage of male workers is unusually high, just as in Bradford it is unusually low. Everywhere the general oversight and direction of weaving, as of all operations, is in the hands of men.

Without entering into the statistical controversy that has raged rather bitterly of late years, it may be stated definitely that, since about the year 1890 , there has been a decline in the number of persons employed directly in the woollen and worsted manufacturing processes; although this decline has been accompanied by increased employment in some of the associated trades, such as dyeing, and in the commercial pursuits connected with the industry. The bald figures of the factory inspectors are: I890, 301,556; I896, 284,44I ; I90I, 259,909. The census figures tell much the same story; and the slow growth of those towns which are most completely given up to the industries, during the last decade of the nineteenth century, is a further bit of evidence in support. It is, however, most important to note that there has been no appreciable reduction in the demand for adult labour. For England and Wales, the number of persons over twenty employed in the trade was in I 89 I, I 61,394 and in $1901,160,999$. The decline is there- 
fore mainly a decline in the employment of halftimers and young persons. That there has been no counterbalancing growth may be traced in part to the steadily growing efficiency of machinery; in part to the increased use of cotton yarns and cotton materials; in part to the rise of factories and of tariffs abroad. These last points will be dealt with in later chapters. Here I am only concerned to make it clear that actual mill work in this great branch of the textile industry does not demand an increasing number of hands year by year ; rather the reverse. "It's a good thing," as a working spinner from the heavy woollen district once said to me, "that these electric trams have come to give the lads work." Fortunately other things have developed besides trams.

Employment in almost all branches of the industries is apt to be somewhat irregular, and the present industrial, commercial and political situation in some ways tends to increase irregularity. Seasons, fashions, fluctuations in the price of raw materials and foreign tariffs are the special causes of irregularity, that operate in addition to those ordinary alternations of good and bad trade which affect all industries alike. There is a normal fluctuation of employment, due to the alternate demands for summer and winter goods; and there are abnormal fluctuations, due 
to mild winters or cold summers and the resulting changes in the demand for the different types of materials.

Fluctuations of employment due to fashion are of frequent occurrence. They affect whole districts and even whole countries. "When crinolines went out," said the late Sir Jacob Behrens to the Commissioners on the Depression of Trade and Industry in I884, "the fashion set in for very soft and nicely draping goods, which the French were far better able to supply than we were; and as many of our mills were not prepared to follow the fashion, there was an enormous competition for the reduced home and foreign demand for Bradford mixed goods." "Wher the taste for mantle cloth is in smoothfaced goods," said a witness before Mr. Chamberlain's Tariff Commission in 1905, "then this cloth is largely made on the Continent, but when the taste. . . is for tweeds, then the Huddersfield cheap tweeds come in and hold their own." Or to quote another of Mr. Chamberlain's witnesses-" "The West Country people... suffered when the worsted cloth came in. We Yorkshiremen are really the culprits, because we introduced a new kind of cloth that knocked out the West of England people." These are merely illustrations of the working of fashion inside the industry itself, given in the words of men who 
know. There is also room for fashion to work between wool and other materials. Cases in point are the recent popularity of cellular underclothing, which has in part superseded wool fabrics, and the immense use of mercerised cotton in place of some of the mixed products from the Bradford stuff looms.

Fashion is not always mere whim. It may have a simple economic origin; the fluctuations of employment which at first sight seem due to fashion, may be seen to depend on fluctuations in the price of raw material. For the public at large becomes more and more accustomed to dressing at a price; and if "our half-guinea skirt" or "two guinea suit" cannot be made of the old materials at that price, so much the worse for the materials and for the fashion which dictated them. A few years ago, when Australian cross-bred wool was abnormally cheap, light "allwool" worsteds for women's wear, made in Bradford, were beating out the cheaper and flimsier varieties of those soft, but not always honest, French materials that came in after the crinoline days. These light serges and such like were sent largely to the colonies and South America, as well as to the home market. But the rise in wool, 1903-6, altered the situation. The price of the all-wool worsteds became prohibitive. Their place began to be taken by 
"woollen" serges of varied materials, from Leeds and Morley. With dear wool also has come the prosperity of the Colne valley tweed maker, and of manufacturers of all those various cotton materials, which may on occasion be substituted for worsted or mixed fabrics. There is thus no sort of certainty that employment will be all good or all bad at one time throughout the wool industries; and there is every probability that in any given branch it will be subject to frequent changes.

The tariffs make things worse. Markets upon which the activity, if not actually the existence, of the trade of whole districts depended have at times been shut as it were in a night. Where the closing of a market is due to the growth of a local industry, the process is likely to be slow, and the adjustment in this country need give no great trouble; but dramatic fiscal events, such as the McKinley tariff, are bound to have disorganising effects, although those effects are not necessarily permanent. And wool textiles have been experimented on by protective tariff makers more freely than most commodities, perhaps more freely than any except silks.

There is as yet no trustworthy means of testing whether or not irregularity of employment is on the increase. Confident assertions have been made on both sides in the course of recent controversy, but they cannot be put to the test of 
statistics. An exact average of truth for the whole trade cannot be struck out from the conflicting assertions of experts from different towns and different political parties; and there are no comprehensive Trade Union figures, such as some industries can show. But the fact that the total amount of employment has ceased to grow is some argument in favour of increased irregularity, at any rate locally; for a population accustomed to enter a certain trade does not lose the habit all at once; and if employment in the trade is not expanding, there are likely to be more people qualified to earn a living in it than there are posts for them to fill.

That a surplus body of reasonably qualified workers exists is shown by the comparative ease with which night work can be resorted to in an emergency, in some branches of the trade. As the factory acts forbid such work for women the night shift must be all men. This is a bar to night work in worsted spinning and stuff weaving. But in the Yorkshire woollen and worsted coating districts-about Batley, for instance, and about Huddersfield - there has, as a rule, been no great difficulty in arranging for night work of late years; for mule spinners are men and a large number of male weavers is still available. The simplest method of organising night weaving is to turn all the male weavers on 
at nights, giving them extra pay, and take on more women for the day. These are more likely to be married women, who are tempted back to the mills for a time in the hope of extra earnings, than regular working women who, but for the double shift, would be seeking places in vain. But these complete night and day shifts, when they are not a regular institution, must contain some who in normal times would be otherwise occupied, or not occupied at all.

Work outside factory hours may of course be done by men at any season and in any trade. Looms are mounted, carding engines "fettled," repairs executed and other jobs performed in this way, in all branches of the industries. In one branch only is night work a regular institutionin the combing mills. A regular institution but very far from a regular trade; for the fluctuations of the whole industry are, as it were, handed on with interest to those who comb at night. There are first the ordinary fluctuations, which affect combing as well as spinning and weaving. Then too, any temporary shortage of combing work is felt most acutely in the commission mills, for the spinner who runs combs naturally works his own machinery to the utmost in slack times, and dispenses with commission work so far as he can. The comber, when work is slack, keeps it up by day and cuts down the night work, though he 
never suspends night work altogether if he can help it. When the sales are on in London or on market days at Bradford he may not know up to the last moment how much wool he will have to handle during the next few days. There may or may not be full work for the night shift. Hence it often happens that the night comber, like the docker, comes to see if there is work in the evening, and, finding none, returns. This is a great hardship and a great grievance ; but the attempts made by combers to regularise employment have not yet got rid of it. Without some fundamental change in the character of the trade it is hard to see how it could be entirely got rid of, for at present the employer cannot always tell his men in advance when they will or will not be wanted.

What the average amount of employment for a night comber is has never been authoritatively determined. In the course of an inquiry carried out in $1897-8$ by the Bradford labour organisations, three and a half nights a week was given as about the average throughout the trade. This may have been an under-statement, as in all industries there is a tendency for the men's organisations to exaggerate and for the masters to minimise irregularity, in the absence of accurate statistics. But it is certain that the night comber's position is an unsatisfactory one. And it is not surprising that the question of 
night combing is a storm centre in Bradford labour politics.

The night comber, it may be added, is not necessarily a comber in the narrowest technical sense. Women make excellent comb minders, and are often preferred for that task. Also the carding and back washing of a given quantity of wool take longer than the actual combing-in some cases twice as long. So it is possible to do all the combing by day and confine the night work to the preliminary processes, though this practice is not universal. Work in the combing mills has another drawback-it is exacting, owing to the high temperature at which the operations are always carried on. This is, of course, especially trying to the night shift, who are exposed to extremes of heat and cold, but it renders all combing rather unwholesome, though not definitely dangerous. Profuse perspiration is almost inevitable, so that both men and women work lightly clad. Scandalous allegations as to the conditions of work were made during the controversy of ten years ago; but they proved to be grossly exaggerated, although the sanitation and conveniences of some of the older mills left much to be desired.

Taken as a whole, wool working in all its departments is a reasonably healthy occupation. But at some points dangers exist which require 
special precautions, and at others dirt and discomfort, if nothing worse, are almost inevitable. One very horrible danger hangs over the wool sorter and the "willeyer," when dealing with certain classes of material - the risk of anthrax, "wool sorter's disease" as it was called when first it made its appearance in the industry, some seventy years ago. The need for special precautionary measures in dealing with dangerous wools was recognised in Bradford long ago, and suggestions for the guidance of masters and men were drawn up locally in $\mathrm{ISS}_{4}$. These rules were taken over by the Home Office and turned into legal enactments in ISS9, and have since been revised and expanded. They affect the Bradford district almost exclusively; for the chief materials scheduled as dangerous are Van mohair, alpaca, East Indian cashmere, and camel hair, all of which go primarily into the Bradford trade. Bales of Van mohair and "Persian locks," the most dangerous substances of all, may not even be opened until they have been thoroughly steeped in water. The less dangerous wools on the list must be opened over a wirework screen "with mechanical exhaust draft, in a room set apart for the purpose". The willeying machine must also have an efficient exhaust draft. All the details of the operations, the dress of the operatives, the conditions under which they take 
their meals, the very nail brushes in the lavatories, come within the scope of the law-so completely has the State become the official guardian of those whose daily occupations involve risk.

Rags like wool have their dangers, but the rag sorter's task is offensive and laborious rather than risky; though, as much of the work is done by women, cases of internal injury resulting from the handling of heavy bales are more common than one could wish. Unless disinfected, rags may carry disease, and are certain to carry parasites ; but there is no definite ailment to which those who deal with them are specially liable. While being ground in the "devil," however, the rags fill the air with an unpleasant dust, half wool, half dirt, which is intensely irritating to the throat and often brings on "shoddy fever," a disease not unlike epidemic influenza in its symptoms and course. Yet, provided the mills are reasonably well looked after, the rag worker's life need not be unhealthy. I never saw a more wholesome-looking set of factory girls than the sorters and seamers in a certain halfrural Yorkshire "merino" mill of my acquaintance-in spite of its sickly, sweaty smell and the incrustation of unwholesome-looking grey fluff on beams and brick work, beyond the reach of the broom. 
For the rest, there is little to say. All factory work has its monotony, its noise, its dangers to the health of girls and especially of married women, due to long standing and unremitting if not serious strain. No trade is without defects of sanitation and construction in mills and workshops, or without numerous processes involving some slight degree of risk. Such things are found neither less nor more in the woollen and worsted industries than in others. The conditions of work for spinners, weavers and indeed for most types of operatives are normally good, and in the best of the mills they leave nothing to be desired. Only a small group of worsted and a very few woollen spinners are subject to the inconvenience of an artificially produced humidity, so common in flax and cotton spinning. There are few heavy tasks that demand great strength and endurance, such as are found so often in the iron and steel industries. One such task, that of "blanket stoving," has sometimes been reckoned risky, but was definitely left out of the list of dangerous trades, after careful inquiry, some few years"ago. The heavy part of the work consists in carrying great bundles of blankets to and from the stoving houses, where they are bleached and dried by exposure to sulphur fumes, and in stretching them between posts on the "tenter fields". 


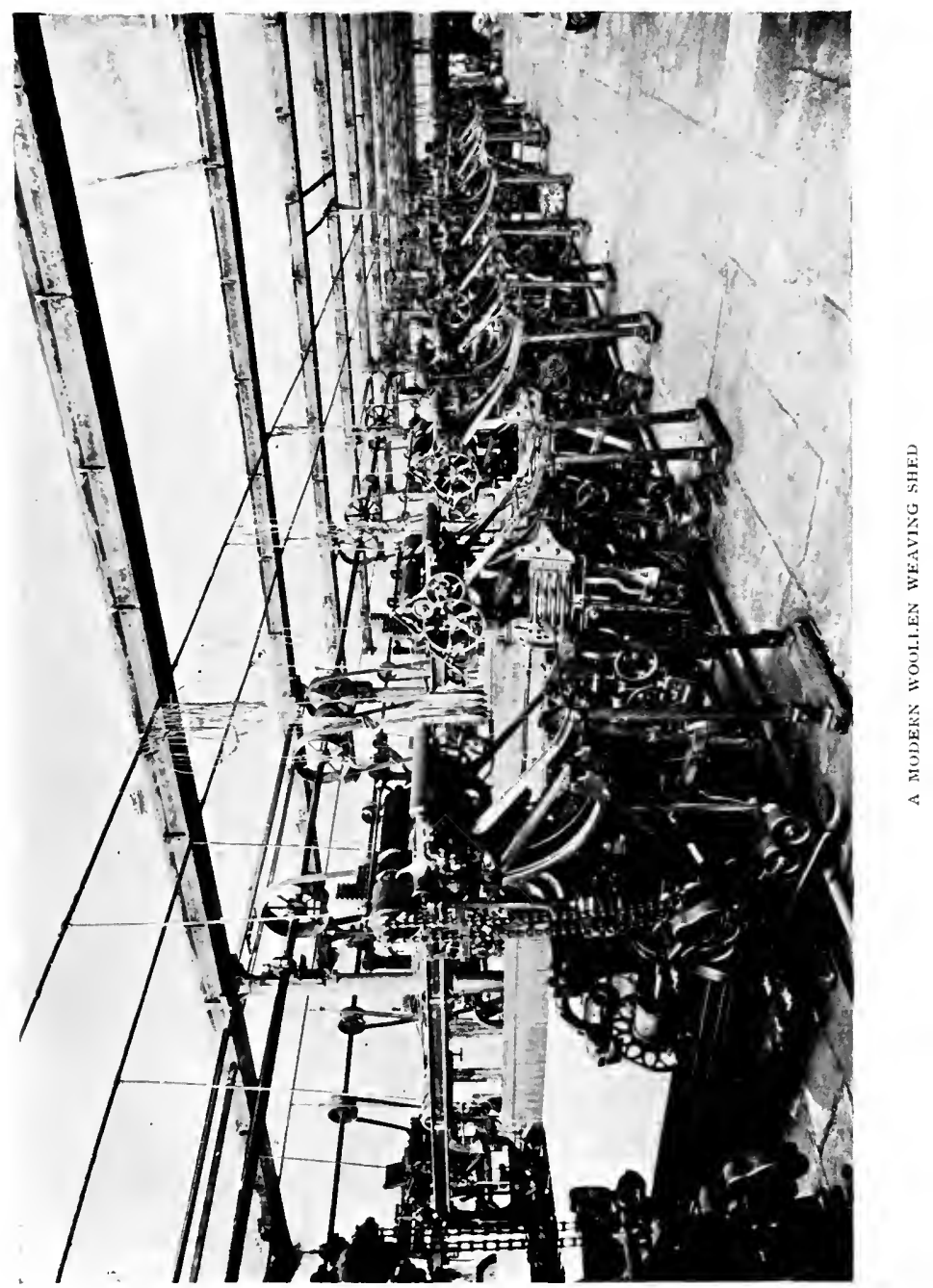



In spite of exposure to alternations of sulphurous heat and damp cold, the stovers are a healthy and hardy set-better developed and less anæmic-looking than many textile operatives. For it must certainly be admitted that the mill hands of the towns, as a class, are not a fine race physically. Those who remember well the old type of cottage weavers and their half-rural life, sometimes speak bitterly of the deterioration that the mills have brought about. But probably any deterioration that there may have been -and its existence, one must remember, is asserted rather than proved-is due more to the towns than to the mills. The merit of the old order was not that work was done at home, but that the workers' houses usually lay-as many of them fortunately still lie-in small towns and big villages on the windy flanks of the Yorkshire and Scottish moorlands. When the hand-loom weaver, bent over his loom sixteen hours a day, or the hand comber with his brazier and charcoal fumes, chanced to be a real townsman, his lot was unenviable enough - as the reports of the Handloom Weavers' Commission in the thirties of the last century bear witness.

In dealing with wages among the wool workers, generalisation is absolutely impossible, unless each district is treated separately; and even then it is far from easy. Within the limits of the pre- 
sent chapter such an exhaustive treatment of all the manufacturing districts would be both impossible and undesirable. Attention will be concentrated on the West Riding, the headquarters of the trade; and it will be hard enough to get at the whole truth even there.

Woollen and worsted wages are neither very high nor very regularly earned. Of the irregularity something has already been said. It introduces an element of the greatest uncertainty into wage calculations. There is often difficulty enough even in finding out what is a full week's wage for an average weaver or spinner, comber, sorter, fuller, or warper; but what is the average number of weeks worked per year? That is a question the answer to which varies from year to year, as well as from mill to mill, and with which no statistician has been able to deal in a satisfactory fashion. One can sometimes get rough estimates from the workers themselves; but they do not claim to be more than estimates. It is stated in Bradford labour circles, for instance, as has been already mentioned, that night combers as a class cannot get work more than two-thirds of their time. Employers admit considerable irregularity, but point out that some combers at any rate will not take full work when it is to be had. What the inevitable amount of unemployment for an average comber under present conditions is we 
cannot know with any certainty. The discrepancies which constantly occur between the wage estimates of masters and men are usually connected with this question of irregularity. The masters generally quote the wage for a full week's work; the men often quote what they believe to be the wage for an average week's work. When estimates from both sides agree, we are on safe ground. Such concordant estimates usually relate to a full week's work.

This is not the place to grapple with the difficulties of a wage census. Twenty years ago, in 1886 , such a census was taken. Though far from complete, it has formed the starting point for all later inquiries. The figures and facts given here may be taken as some slight contribution to the question. They were collected from employers and representative members of trades societies during the years 1904-6. These figures have been checked by comparison with all other available statistics, especially with those quoted in the report of an inquiry into the conditions of work in combing mills, carried out by Bradford labour organisations in 1897-8. Only the larger groups of workers can be dealt with; for to follow the trade in all its ramifications is impossible. Unless otherwise stated, the figures refer to a full week's work. Taking first men's wages in the worsted trade of the Bradford district we find that the 
wool sorter earns from $28 \mathrm{~s}$. to $32 \mathrm{~s}$. a week, the higher rates being secured when working by the piece, the lower being the standard rate. Washers, who, are subdivided into steepers, feeders and washbowl minders, make from 20s. to $26 \mathrm{~s}$. 6d., the upper rate being rare. Night washers are paid more than day washers, $24 \mathrm{~s}$. by night and 22s. 6d. by day, being the respective average rates in one case. The average rates for the whole trade are probably rather lower than these. Overlookers in carding, drawing, spinning and weaving usually make upwards of 30s., but not often more than $35 \mathrm{~s}$. or $36 \mathrm{~s}$., though an overlooker in a position of special trust, in any branch of the trade, may at times earn very high wages. Among the overlookers the spinners are generally the worst paid, their wages in some cases falling below 30 s.

Ordinary night workers in the combing mills make from $18 \mathrm{~s}$. 6d. or 19s. to 23s. a week, according to the nature of their tasks. During the day the work is done at lower rates; but much of it then falls to women and boys. The average earnings of the night workers-always be it remembered for a full week's work-are not much above 20s. ; the best paid classes being the back washers and "card jobbers" with 22 s. or $23 \mathrm{~s}$. This does not include the washers, but does include their assistants and auxiliaries, who 
do what in the daytime is women's or boys' work. $^{1}$

Two small, but fairly well-paid classes are the twisters and warp dressers. They usually work by the piece so that their earnings are not very easily reckoned; but the normal standing wage, i.e. the time rate, for both classes is 30 . When on piece work their earnings may run up to $36 \mathrm{~s}$., or in single weeks, a good deal higher. In this case much depends on the class of materials to be handled, and of course on the skill of the men. There is also a common practice of assigning warp dressers their jobs by lot, which leads to considerable inequality, but presumably works out with tolerable fairness in the long run.

Women at work in the combing mills, picking impurities and lumps from the washed wool, back washing and minding combs or boxes, earn from IIs. to I 4 s. The former figure is a low wage for an adult ; and the average probably lies between I 2s. and I3s. Girls may be employed at Ios. or less. The average earnings of women and girls in the spinning mills are harder to ascertain than in most departments ; for the number of "sides"-sides of frames that is-which one

${ }^{1}$ A number of the largest combing firms have agreed to raise the wages of all those who earn over 15 s. by Is., and of all those who earn less than 15 s. by 6 d. a week, from July, 1907 . 
person minds varies, and the wage naturally varies with it. Perhaps the most satisfactory method of illustrating the wage levels will be to quote the average figures of a single representative mill for the leading classes of women workers. They are-drawers, Ios. $2 \frac{1}{2} \mathrm{~d}$. ; spinners, 9s. $3 \frac{1}{2} \mathrm{~d}$. ; half-timers from $2 \mathrm{~s}$. $9 \mathrm{~d}$. to $4 \mathrm{~s}$. according to skill. The odd figures are arrived at by averaging together different sub-classes of workers, with different rates of wages. Thus the figure for drawing is made up from the following list-two girls at IIs. 6d. ; two at I Is. ; six at Ios. 3 d. ; and six at 9s. 6d. In this particular mill all, or almost all, the drawing and spinning "hands" are "young persons"-and this is the general custom. For warping and reeling women are employed, at rates of pay varying from I $2 \mathrm{~s}$. to I6s. $6 \mathrm{~d}$.

In dealing with weavers, too, it may be well to start from a single mill. It is a mill doing a high class of work in the dress goods trade, so that its figures may be taken as typical of the best Bradford earnings in this branch. For twelve weeks in 1904, including minor stoppages but no slack work, the weekly takings of the weavers averaged I4s. $8 \frac{1}{2} \mathrm{~d}$. This figure covers a great variety of individual earnings, from the I $2 \mathrm{~s}$. Or so of the worst weavers to the I $7 \mathrm{~s}$. or more of the best. For the power loom 
by no means reduces all to one level of skill and wage, and weaving is always paid by the piece. From the side of labour it is maintained that 1 $2 \mathrm{~s} .6 \mathrm{~d}$. is about the average for the whole trade, but, seeing that the best paying firms are generally also the largest, it is almost certain that this is an under-statement. Yet the average for full work is not likely to exceed I4S., and is probably nearer I3s. 6d. A return from Iog Bradford firms, quoted before the Labour Commission by Mr. E. P. Arnold Foster in I892, gave an average actual wage of $13 \mathrm{~s}$. $5 \mathrm{~d}$. for nearly i 2,000 weavers during the years I 890 and I 89I. It was estimated that had they been fully employed the wage would have been nearly 8 per cent. higher, or say I 4 s. $6 \mathrm{~d}$. These figures, however, did not refer only to dress goods weavers, but included some at least of the better paid class of "coating" weavers. The "coating" weavers in Bradford and district are often men, and their work and pay approach those of the worsted weavers of Huddersfield and the best woollen weavers of Yorkshire and Scotland. Weavers of dress goods always mind two looms, and if the looms are very narrow they may mind even more. The worsted coating weaver, on the other hand, when he is engaged on fine or fancy work usually minds but one. In the higher branches of woollen weaving, also, one loom to a weaver is the rule, and throughout the woollen 
industry the practice is prevalent; for the yarn used in low-grade work may be so tender as to require a world of care, and the woollen loom, as we have seen, is normally very wide. But plain or cheap worsteds and some of the simpler woollens can be produced successfully on the twoloom system.

It is the custom in the Bradford district to pay the same rates for weaving coatings to both men and women-rates which vary from $14 \mathrm{~s}$. or $15 \mathrm{~s}$. to 2 IS. or $22 \mathrm{~s}$. - - for the full week's work. The average is probably not far from $18 \mathrm{~s}$., though in labour circles it is believed to be considerably lower. But in the present state of our statistical information average weaving rates are extraordinarily hard to ascertain; since the payment varies with almost every variation in the goods produced, and these variations are infinite. The highclass worsted weavers of the Huddersfield district -mostly men-make from i 8 s. to 24 s. a week. In a worsted weaving mill, where only women are employed, in the Leeds district the average is I9s. 6d. It may be added that pattern weavers in mills, that turn out the finer fabrics, can earn considerably more than the rates here quoted for ordinary weavers, but they are a very small class.

Worsted dyers are employed almost exclusively by the great dyeing firms, and so their wages are, strictly speaking, outside the scope of this book. 
But they may fairly be put on record here. In their case there is little room for uncertainty or conjecture. By contract between the Bradford Dyers' Association and the Unions of the working dyers, the average standard wage for thirteen separate tasks in 1905 was-as nearly as possible -24s. 6d. at Bradford, 23s. $6 \frac{1}{2}$ d. at Leeds and Halifax, and 22s. $7 \frac{1}{2} \mathrm{~d}$. in country districts. The actual rates ranged only from $22 \mathrm{~s}$. to $26 \mathrm{~s}$., and in Bradford only from 24s. to $26 \mathrm{~s}$. There are, however, a number of unscheduled tasks, which are sometimes paid for at lower rates. At the beginning of 1907 a Io per cent. rise all round was agreed upon.

As reference has already been made to woollen weaving, it will be convenient to take weaving wages first in dealing with that branch of the industry. Here men and women often work together, though the higher branches mainly employ men. In some districts men and women are paid on different scales for the same work; in others the sexes are on an equal footing. About Huddersfield, for example, men are paid i 5 per cent. more than women both in woollen and worsted; but in places where the male weaver is rare such a privilege cannot be maintained. As the fabrics range from the simplest and cheapest shoddy cloths up to the best "dress faced" plain materials and most complicated fancy ones, there 
is naturally a most varied wage scale. Before the Tariff Commission a Huddersfield tweed maker said that his firm "expected" their weavers -all women- " to earn $£ \mathrm{I}$ a week each on the average when fully employed". A witness from Galashiels gave the weaving wage for his district as 2 Is. Five important mills, all within six miles of Leeds, yield this list-I2s. 9d., I 3 s. 6d., I6s. Io $\frac{1}{2}$ d., I7s. 9 d., 2 Is. It may be worth while to mention, as an illustration of the difficulties of an amateur wage census, that on making inquiries from the side of labour, I was told that wages in the fourth of these mills - in the case of which my information from the employer's side happens to be particularly full and trustworthy-would not average above 14 s., even for good weavers. The earnings of the worst paid and least competent weavers are said to fall to $7 \mathrm{~s}$. $6 \mathrm{~d}$. and less; and it is claimed in Trade Union circles that an average of $\mathrm{r} 3 \mathrm{~s}$. $6 \mathrm{~d}$. for Leeds and its neighbourhood, together with the heavy woollen district, would be, if anything, rather too high. Unfortunately, those employers who pay the lowest wages are the least likely to aid inquirers with figures; so that the definite figures quoted are generally too high for the whole trade. Nothing short of a stringent official wage census would get at the absolute truth and rid us once for all of guess work. 
Outside weaving there is fortunately less room for error, though wages vary from place to place, and work is not arranged on a uniform plan in all mills. The figures given here apply to "good" mills in the Leeds district. Rates in other districts, except Huddersfield, are usually somewhat lower. Much the best paid class are the carding foremen. For them $£_{3}$ is no uncommon wage. When not in a position of great responsibility they may be only given 35 s. to 40 s. ; but for picked men in responsible posts three pounds need not be the limit. The weaving overlooker or tuner earns from 35 s. to 40 s., perhaps rather more, the foreman spinner from 40s. to 5os. Spinners' wages depend on the character of their work. For a man who minds one pair of mules 30 . is the rule, or rather more when the work is paid by the piece. Two pairs of mules bring the spinner from $35 \mathrm{~s}$. to $40 \mathrm{~s}$. Sometimes, though not actually in Leeds, the spinner has a male assistant known as a mule-head minder; at other times all his assistants are girls, "chain minders" and "piecers".

The willeyers and fettlers, that is to say, men who "fettle" the carding engines, are classed together and have a common Trade Union. Their Union rate in Leeds is $5 \frac{1}{2} \mathrm{~d}$. an hour, or $6 \mathrm{~d}$. when working overtime, and their earnings run from 23s., with an average of about 26s. Where 
much overtime is worked they may make upwards of 3 os.

There remain sorting, washing, dyeing, and the various finishing processes. Owing to the extensive use of rag wool, noils and other materials, sorting is not carried on at all the woollen mills by any means. Where sorters are employed they receive about 3 os. Ordinary washing and dyeing jobs bring in $23 \mathrm{~s}$. on an average. This is the Union rate, but rather less is paid in some cases, and for certain jobs rather more. For the finishing processes pay varies considerably with the quality of the cloth. In the case of ordinary materials that call for no special skill, scourers, raisers, steamers and the like will not make more than from 20s. to $22 \mathrm{~S}$. With more delicate tasks wages rise towards 30 s. There are always some highly paid men in the finishing departmentforemen fullers and press setters for instance, who earn from 3 Is. to $37 \mathrm{~s}$.; but the staff and the distribution of work among the staff is hardly the same in any two mills, owing to the variety of materials produced. This would render the task of averaging exceptionally difficult. The finishing of fine cloth is a trade in which wages are good, but it is a small trade, and with small trades and exceptional circumstances we are not here concerned.

In the absence of really satisfactory statistics, 
it is not surprising that a somewhat inconclusive strife has been waged over the question of the rise or fall of woollen and worsted wages in recent years. It is clear enough that there has been no general fall, though it is possible that here and there, owing to special circumstances, some group of wage-earners may have suffered. But it has been maintained that there is no conclusive evidence of a general rise since 1886 . The figures just given, when compared with those of 1886 , do, however, point to a slight general rise, and to a very definite rise in certain cases. Weavers are the most doubtful class, and, as weavers form the largest group, this is important. But if it is hard to prove a definite rise in their average earnings, it would be impossible to prove a fall. Neither the figures of twenty years ago, however, nor the figures available to-day will bear the weight of confident inferences. The change in the ratio of men to women weavers and the changes in the character of the work done introduce further difficulties. On the whole, bearing in mind the fact that the demand for weavers has certainly not increased, it is safe to accept the opinion that their wages have at best advanced by but a small fraction. It is evident, too, that there has been no rise in the cash earnings of the average wool worker comparable to the rise in the earnings of the average coal miner or bricklayer, let us say. 
To discuss the causes of this contrast would take us too far afield; it must suffice to have called attention to it. Nor is it possible to touch on the question of the growth of real wages; that is to say, the increase in the purchasing power of cash earnings. What improvement there has been here is, of course, common to all trades.

The woollen and worsted industries properly so called have never been strongholds of Trades Unionism. There is, indeed, no great branch of industry of equal importance, except agriculture, in which the Unions have made less headway. Out of the 260,000 operatives-nearly 200,000 of whom are eighteen years old and upwards - a mere 7673 are entered as Union members in the latest official figures (1904). This excludes dyeing, pressing and warehousing, but covers all the true manufacturing operations. In the West of England there is not a single Union, large or small. In Scotland there is one at Galashiels, containing 40 men and 74 women; another at Alva - north of Alloa-with 70 members, all women; a third at Glasgow, numbering I 64 men. These last are warpers, some of whom handle cotton yarns. And this completes the list for Scotland.

The list for Yorkshire is longer and more varied; but its very variety is a weakness from the point of view of the labour strategist. There 
are a few fairly strong Unions in specialised branches of the trade, such as the National Union of Wool Sorters, with over 900 members; the Bradford and District Warp Dressers, with upwards of 600 ; and the Yorkshire Twisters and Drawers-in, with rather less. Among the weaving overlookers there are several small compact Unions, with an aggregate membership of about 1250. The warp dressers have other societies besides that at Bradford, and there is more than one society of twisters. If only for the sake of its long life, the Amicable Society of Woolstaplers also deserves mention. Its officially recognised existence dates from $\mathrm{I} 785$, and it has 45 members.

Few of these Unions can show more than one branch. Even the Yorkshire Twisters and the National Woolsorters have only three each. But the General Union of Weavers and Textile Workers is exceptional in this and in other respects. It has six branches and a membership of over 1500 , of whom 631 are women. As in the whole of the United Kingdom there are barely 1000 women Unionists in the woollen and worsted industries, this society is of some importance, but it is not really powerful, and its membership fell off markedly between 1902 and 1904. It has some trouble in keeping up the number of its male members, as might have been expected, seeing that it is primarily a weavers' 
society. Further proof of the weakness of Unionism would be superfluous. The reasons for that weakness have long been under discussion, but have hardly yet been fully explained. No observer has ever failed to notice the striking contrast between wool and cotton in this respect, and it is natural to seek an explanation by the use of the comparative method. The map which shows the distribution of the wool industries partly explains the contrast. Widely-scattered trades are seldom highly organised; and the woollen and worsted industries are far less concentrated than the cotton industry. There is concentration enough in the West Riding, however, and yet it has not begotten a vigorous Unionism. Other causes must be at work. One of these is the great cleavage between woollen and worsted, to which there is no parallel in Lancashire. Woollen and worsted men, whether employers or employed, are often unconscious of common interests; and, indeed, their interests are very frequently not common, but diametrically opposed one to another. This cleavage of interests and sympathies is repeated within the trades. The outsider does well to avoid confusing the woollen trade of Huddersfield with that of Batley. He must understand that the Leeds trade is not as the trade of Morley, which is five miles away, or as that of Guisely, which is nine miles away. The 
worsted stuff trade of Bradford is distinct from the worsted coating trade of Huddersfield, and Halifax carpet making has little in common with either. Real and important lines of cleavage, due to differences in processes and products, are accentuated by that local feeling which is perhaps the strongest force in the life of the West Riding, and, thanks to which, places but a few miles apart each work out their own salvation in their own way. That which is done in Bradford is no precedent for Leeds. Pudsey does not learn of Cleckheaton, nor Ossett of Wakefield.

But the endless subdivisions of the industries and the intensity of local life do not explain everything. Weight must be given to the frequent survival of what are commonly called patriarchal relations between masters and men. In some of the old family businesses strikes are unknown. Two of the largest employers in the worsted trade stated in evidence before the Labour Commission, in the nineties, that there had never been a strike at their mills, and that so far as they were concerned Unions might have been nonexistent. Nor has the situation altered greatly since their evidence was given. In the country mills especially, the old relations of employer and employed survive, and the Unions make little headway.

Combination generally develops its most strik- 
ing features in places where not only are there concentrated many men of one craft, but where the men work together in large bodies. Now, owing to the decline in the number of male weavers, this last condition is not often realised in the West Riding. It is realised least where there is most concentration, that is to say, in worsted. At Bradford, the point of greatest concentration, the men in spinning and weaving mills are largely, though not exclusively, employed in positions of trust and authority. The rank and file of the workers are women and girls.

It is very significant that the only Spinning Union in the Bradford district is the Overlookers' Provident Society. The Union of Weavers and Textile Workers is represented in Bradford, but it includes only a small minority of the weavers; whereas the Weaving Overlookers' Society is a strong and compact body, with between 700 and 800 members from this small and "aristocratic" group of workpeople. The Warpdressers and the Twisters, who also have unions of some strength, carry on the responsible business of preparing the warp and mounting the loom. So one might go on enumerating highly-skilled trades of this kind whose members never represent any considerable proportion of the staff of any particular mill. Their Unions are not large popular organisations. They are, as a rule, 
unlikely to initiate strikes. They seldom cover the whole trade. Often their main concern is friendly society work. And their members are separated by occupation, position and sex from the rank and file.

In combing mills and dyeworks men of the same grade of skill work together in large numbers, and the division of sex does not coincide with the division between the overlookers and the "overlooked". There are practically no female dyers. In the combing mills there are, roughly, three men to every two women. Bradford alone contains over 3000 male combers. Yet of these but 2 Io were members of the Bradford Machine Woolcombers Society in 1904. The dyers, on the other hand, are strongly organised. The Huddersfield, Bradford and District Dyers and Finishers Union has some I 300 members. The Amalgamated Dyersone of the great Unions of the country-are well represented in the worsted trade; while some of the less skilled men in the dyeworks belong to the Gasworkers and General Labourers Union, a far greater society even than the Dyers. The local Dyers Union-the Huddersfield and Bradford-has been in existence over fifty years. In short, dyeing is a typical organised trade in which, during the last ten years, collective bargains have taken the place of the 
individual wage contract between master and man, and in which the associated employers and the men's Unions may meet in pitched battle. Such a battle was only just avoided by concessions on both sides, at the end of 1906 . The small and exclusive craft of stuff pressing is even more highly organised than dyeing. Like dyeing it is a man's trade; and the pressers, like the working dyers, treat almost as equals with the powerful Bradford Dyers' Association.

That the labour organiser has met with so little success in the combing trade may in part be explained by reference to the very low position that the combers hold in the scale of textile operatives. It is notoriously difficult to form permanent organisations among bodies of ill-paid and half-casual labourers ; and such, unfortunately, the combers are, especially the night men. More difficult tasks than the organising of such a class have, no doubt, been solved by labour leaders in the last eighteen years. The failure must not be ascribed altogether to overmastering economic circumstances. It is due in part to the absence of any strong tradition of Trade Unionism in the woollen and worsted trades; in part, one may fairly assume, to personal, and what may be called accidental, causes. But the purely economic factors dominate the situation.

Turning to the woollen industry, one finds 
that here also men of the same grade rarely work together in large numbers, but that men form a greater proportion of the rank and file than in worsted spinning and weaving. Yet the Unions are few, and with one exception unimportant; some purely local, some composed of overlookers and other picked men. There is no very obvious reason why this should be so. Mule spinning is a man's task, and there is no more efficient organisation in the Trade Union world than that of the Lancashire Cotton Mule Spinners, with I 8,000 or I9,000 members. It is true that owing to the smaller size of the woollen mills, the spinners are more isolated than their colleagues in Bolton and Oldham. But none of these things suffice to account for the fact that there is no regular Woollen Spinners' Union. Local circumstances and local character have to be called in to explain the matter. It is a case of economic backwardness, pure and simple, not the result of some specific economic cause. To account for this backwardness would require a treatise - which might be made interesting enough - on the economics and psychology of the West Riding.

The Weavers and Textile Workers is in part a "woollen" society; but its importance is relative, not absolute. In woollen, as in worsted, it includes but a small fraction of workpeople; 


\section{I2 WOOLLEN AND WORSTED INDUSTRIES}

its position is not very strong, and it cannot be said to exercise a decisive influence on the course of affairs.

A few words must be given to the noteworthy failure of Trade Unionism to take root among the women of the Yorkshire mills. There are nearly ten times as many women Unionists among the linen and jute workers as there are in all the wool industries. And the contrast between wool and cotton is of course even more striking; for there are nearly 100,000 women in the cotton Unions, whereas in woollen and worsted there are barely a thousand all told. No doubt girls, who do not expect to spend their whole lives in the mills, are always less attracted by such advantages as a Union can offer, than men are. But that does not explain the curious contrast between Lancashire and Yorkshire. The explanation must be sought in those general circumstances, briefly referred to already, which have hindered the growth of Unionism of all sorts eastward of the Pennine Hills; since it may be taken as an axiom that the organisation of women is never likely to be complete where that of men is defective. A rate of wages that is relatively low, as compared with the cotton trade, has also acted as a hindrance to Unionism in Yorkshire; for, although Unions certainly sometimes help 
to make high wages, it is even more certain that high wages in their turn favour the growth of Unions. And as the effective organisation of women is almost confined to the cotton trade, which contains nearly 97,000 out of 125,000 women Unionists in the country, perhaps the real problem for solution is not why the organised women in other industries are so few, but why in that particular industry they are so many. For such a discussion this is not the place.

The weakness of Unionism, among both men and women, carries with it as a matter of course a lack of uniformity both in wage rates and methods of paying wages. Time and piece rates, different time rates, and different piece rates for similar jobs exist side by side. In part this is due, not to the weakness of the Unions but to the variety of raw materials, of manufacturing processes, and of finished goods. There are so many similar but not identical tasks in weaving, for instance, that it is no easy matter to draw up standard lists of piece wages. When an attempt of this kind was made some years ago in Bradford, there were first of all five separate rates of pay for dress goods weavers, and then no less than seventeen headings under which additional payments might be made-such as the use of mohair weft, of extra shafts, extra 
shuttle boxes, extra beams, of the Jacquard shedding motion, and so forth. Each of the numerous classes of wool has its special difficulties for sorters, combers and spinners. It would be no light matter even for the most capable Trade Unionists to come to an agreement among themselves and with the employers as to piece rates in all these varying cases. And as piece payment is well established in most branches of the trade, any attempt to force employers to adopt time wages would be equally difficult. Nor are such attempts either desirable or likely to be made. The piece list difficulty is no doubt one that could be got over; it has actually been got over in some cases; but the work is very far from easy.

Time and piece work exist side by side, as has already been mentioned. Most Leeds woollen spinners are paid by time, but some by the piece. Exactly the reverse is the case with the Bradford warp dressers. Weaving is normally paid by the piece; but there are cases in which the weaver is paid a "standing" or time wage. This is likely to occur when some new material is being produced. In such a case perhaps neither the weaver nor the employer know at first exactly how a piece rate will work out. Here, again, it would not be easy to standardise such time rates; for they are based on the class of work usually 
done in that particular mill, and these classes vary almost indefinitely.

There is naturally, in each district, a rough approximation to equality in the wages earned by men or women of any given level of skill, when in full work. "In every shop there is a different level for piece-workers," writes the secretary of a certain Union. "There are not two exactly alike." But, he adds, "In comparing some of the lists, which I often do, I find they work out within coppers of each other". "There is no regular scale," says an employer in another branch of the trade, "but the mills work more or less together; we know what others are giving for any particular class of work." Striking differences in earnings are due, generally speaking, rather to differences in the level of skill required in the various mills, and to differences in the regularity of work, than to actual discrepancies in the rates of pay for tasks of a given type-whether those rates are time or piece rates. There are such discrepancies. Labour is not absolutely mobile because the workers are not perfectly intelligent. It does not flow quite automatically, as some old economists held, to the towns or the mills where its remuneration is the best; but it is easy to make too much of the resulting inequalities in earnings.

A weavers' piece list has been in existence in 
the Huddersfield trade for over twenty years, since I883. It appears not to be followed strictly in all cases; but it forms the basis of payment throughout the trade, and is regarded as a satisfactory arrangement by Labour leaders in the neighbouring districts. Its main principles are fairly simple, and may be summarised thus: for weaving a piece of cloth with a warp sixty yards long, the weaver receives $3 \mathrm{~d}$. multiplied by the number of picks per inch, when the material is fancy, and $2 \mathrm{~d}$. multiplied by the number of picks per inch, when it is plain. The picks vary from about twenty to sixty or seventy, and even more in some cases. A low number of picks to the inch means a thick weft yarn and a rapidly growing piece: so that the discrepancy is far less than appears at first sight, when these rates are translated into weekly earnings. Extra payments for complicated work form part of the scheme, as in the case of the Bradford list quoted above.

This Bradford list was the result of prolonged discussion between two committees, representing the Chamber of Commerce and the other the Trades Council. It was drawn up in I895, and is divided into two parts, one dealing with dress goods, the other with coatings. But it never met with general acceptance; for neither the Chamber nor the Council was in a position to 
force manufacturers to adopt it. The men took the view that it was unnecessarily complex; and one of their leaders told me that a simpler and in every way better scale, which was at the time in operation in one of the chief Bradford mills, might well have been adopted as a basis. However this may be, the lists as finally drafted were not agreeable to the trade as a whole; and to this day each firm arranges its weaving payments in its own way, although there is of course a general resemblance in methods. Similarly in spinning both woollen and worsted, there is no officially recognised system according to which piece rates are reckoned.

Throughout the West Riding one meets with surprisingly little indirect payment of wages. Woollen mule spinning is the chief exception. When this work is paid by the piece, it is common for all payments to be made to the spinner. He will hire what piecers he wants, though there may be a general understanding between the spinner and his employer as to the earnings of the piecers. In worsted spinning, on the other hand, the overlooker is not a small employer after this fashion, and the women and girls are paid directly by the firms. In some branches of woollen weaving the weaver may hire a lad or girl to act as "nipper," that is to say, to do odd jobs about the loom; but this is 
by no means common. Practically all sorting, washing, combing, preparing, carding, dyeing, and other jobs are paid for directly. Here and there exceptions might be found; but direct payment is the rule of the trade. In no case, so far as I know, is an adult paid indirectly.

There has never existed any organised system of apprenticeship or training for the rank and file of the woollen and worsted workers, since the advent of the factories. Nor was apprenticeship universal even in the pre-factory days. Domestic spinning was naturally never under regular apprenticeship rules. In weaving, such rules had to a large extent broken down before the rise of the mills. "I don't know of any workmen who have served a regular apprenticeship," was the testimony of Nathan Murgatroyd, a small Bradford stuff manufacturer, before a House of Commons Committee in 1803 . He himself had learnt to weave in three months and had "supported himself from twelve years of age". Combing he had learnt "in less than three months," and he saw no reáson why others should not do the same. From that day to this things have not greatly changed. In some cases boys and girls pick up their knowledge, while engaged about the mills in inferior capacitieshalf-timers, "nippers," or underlings of some sort. In other cases ! they are put straight to 
work, of course making but small earnings at the outset. Thus a girl weaver, who is leaving the mill to marry, may secure the vacant loom for a sister or friend, who has perhaps watched her at work and so is in a position to learn easily. If fortunate, the capable weaver may make her way up the trade, passing from simple to more difficult tasks, or from a low grade to a higher grade mill, as her skill advances. In worsted spinning, a girl learns to take more and more sides; in a combing mill, she may be promoted from minding a preparing box at ros., to minding a comb at $\mathrm{r} 3 \mathrm{~s}$. ; and so forth. So too, boys work their way from simple and relatively unskilled to more remunerative jobs. Even in the higher walks of the industry there is little or no formal, though a good deal of informal, apprenticeship. The weaving overlookers, for example, form a distinct trade, into which lads generally enter as overlookers' assistants; though where male weavers are common, a man may be promoted from the ranks. At Bradford, where such promotion is practically impossible, the Overlookers Union is in a position to enforce fairly strict conditions of apprenticeship. The situation of the weaving overlookers corresponds with that of most of the more highly skilled sections of woolworkers. Their crafts must be regularly learned and can hardly be picked up anyhow. But 
formal entrance rules to these crafts are seldom to be found, and it is nearly always possible for a man of sufficient ability to rise in them, whether or no he has learned them as a lad in the recognised way. Sorting, until very recent years, was an industry guarded by strict entrance rules, including the old seven years of learning, at Leicester. Yorkshire has long been more lax in this respect; but even there at least three or four years were invariably required, though neither in Yorkshire nor in Leicester was there any system of indenturing apprentices. Latterly, with the decline in careful sorting and so in the demand for highly trained sorters, the entry to the trade has become easier; and complaints are heard from the side of the men that its old position as a skilled craft, relatively difficult of access, is passing away. 


\section{CHAPTER VI}

\section{THE INDUSTRIES ABROAD}

A $S$ there is no single civilised or half-civilised A country without wool manufactures, a full account of the industries abroad would be inordinately long. They must be described only in part and that briefly. Three groups of nations claim attention. First there is a group of the chief manufacturing nations, our neighbours, clients and competitors. These deserve special attention. In their case it is particularly interesting to contrast foreign types of industrial organisation with those of this country and to estimate, so far as possible, the factors of competing strength. Secondly, there is a group of nations that have recently developed manufactures on modern lines and are pushing forward towards the first rank. These countries are, in some cases, not such good clients of the English manufacturers as they were. It is natural to ask whether they are destined to become competitors at home or abroad. Thirdly, there are the wool-growing nations of the South, obviously 
and not unnaturally discontented with an economic system, whereby the wool that they grow goes half-way round the earth to be turned into the clothes that they wear. They mean in course of time to do their own manufacturing. Are there any signs that the day when they will do so is at hand? That also is a question worth asking.

Among the nations of the first group France has long held the foremost place. Her industry, like ours, is organised largely with a view to export. Specially important as articles of export are the women's dress materials, in the manufacture of which the French excel. It has recently been estimated that France sells 30 per cent. of her total output of this class of goods abroad. We in Great Britain have always imported far more wool manufactures from France than from any other country. In the past our industry has been indebted to the French more than to any nation, except the old Flemings. And it can still learn from them. Although the French industry has not expanded of late years so remarkably as have the industries of Germany and America, yet it maintains its reputation as the most finished and artistic section of the wool manufactures of Europe.

Exact statistics of employment and machinery in France are not to be had, and those given in the present chapter are estimates, to be accepted 
with a certain amount of reserve. For employment, the figure adopted by our Board of Trade is 199,400 for the year 1896 - the last date at which inquiry was made. This excludes dyeing and finishing, which are estimated to occupy another I4,500 men. The number returned in I 896 as actually employed in the "industrie lainière" was I77,270. The Board of Trade figure is arrived at by adding to this an estimate of those returned under some other heading-say "textile industries not further specified"-who were really wool workers. For machinery there are no recent official statistics; but we have some figures given in evidence before the French Parliamentary committee that inquired into the state of the textile industries in 1904. They are avowedly only rough estimates, and they seem remarkably low, as a comparison with the English figures given on page 7 will make clear; but they are useful for certain purposes and so are worth quoting. ${ }^{1}$ They run thus-combs,

${ }^{1}$ The English industry employs about 30 per cent. more workpeople than the French, and yet-if these figures are correct-it runs more than twice as many spindles and nearly three times as many looms. The spindle figure is very likely accurate; for spinning forms a great part of our industry, and the English spinner minds more machinery than the French. The figure for looms probably does not include the hand looms. 
I600; worsted spindles, 2,000,000; woollen spindles, 390,000; looms (some of which are used for cotton as well as wool), 35,000. The very great importance of worsted is the most obvious fact here indicated. It is in the manufacture of worsted fabrics, and fabrics into which worsted enters, that France excels ; and so it is to her worsted industry that most attention will here be given.

The French worsted manufacture is concentrated to a high degree; not to so high a degree as the English, it is true, but conspicuously enough nevertheless. Its headquarters lie in the allied towns of Roubaix-Tourcoing, near to Lille, on the extreme edge of the Department of the North. Of combing, that Department has an almost complete monopoly. It contains 87 per cent. of the combing operatives, and in I9OI Roubaix-Tourcoing alone turned out fifty-two out of a total for the whole country of sixty-one million kilos. of tops. The greater part of the remainder came from the two half-English firms of Isaac Holden \& Sons and Jonathan Holden at Reims, and some from Fourmies, sixty miles S.E. of Roubaix but in the same Department. Both Fourmies and Reims are declining as combing centres, and Roubaix absorbs the business that they lose.

For spinning and weaving it is impossible to 
give such precise figures. The Department of the North contains $5^{I}$ per cent. of all the working spinners (both worsted and woollen) and about 50 per cent. of all the weavers in France. These are for the most part worsted workers, but there are some woollen firms at Roubaix and elsewhere in the Department. The Reims district is second in importance to the Roubaix district as a worsted producer. The majority of the mills are in and about Reims itself, but some are scattered far and wide over the Departments of the Marne, the Aisne and the Ardennes. All told, these Reims worsted mills have I 55,000 spinning spindles. Both they and the mills of Fourmies have been suffering of late from Roubaix competition, largely because the two former towns are accustomed to work pure merino wools, and have not easily adapted themselves to use cross-breds and to turn out the more quickly made and cheaper materials that popular taste demands. Complaints of stagnation, the shutting of mills, and the loss of trade, were freely made before the Committee in I904.

The general organisation of the Reims and Roubaix trades resembles that of Bradford in many ways. Combing is a distinct industry and the work is almost always done on commission. Few spinners ever did their own combing, and there is at present, as with us, a tendency for the 
two trades to become absolutely distinct. In the Reims area, for example, there is now only a single firm that both combs and spins. As in England again, spinning and weaving are to a large extent specialised businesses. Taking the Reims district once more-for which exact figures happen to be available-it appears that, out of thirty worsted firms, five do nothing but spin, twelve do nothing but weave, thirteen both spin and weave. At Roubaix the proportion of specialised firms is probably even higher.

Both in spinning and weaving, commission work is at least as common in France as in this country. The trade of Fourmies and the neighbouring town of Le Cateau is largely dependent on this class of work; there is a certain amount of it at Roubaix; but in and around Reims it is not found. The "manufacturer" who gives the commission is, in many cases, a man in a very small way of business, who owns no machinery himself but buys wool and sells yarn or pieces. It is said that the spinners of Fourmies have done harm to themselves and the French trade by trying to spin too fine yarns, from the inferior wools furnished them by these small men.

Closely connected with this commission spinning and weaving in factories, is the practice of getting yarn woven on the rural hand looms -the extensive survival of which further dif- 
ferentiates the French from the English industry. The hand loom has been almost completely driven out of the great manufacturing towns and the old staple trades. But it still survives in the villages round about Cambrai and Le Cateau, southward towards St. Quentin. and in other parts of the departments of the North, the Aisne and the Somme. The skilled hand-loom weavers mainly produce novelties for women's wear, of the type that are made only in small quantities and of ever-varying pattern. Thanks to these constant changes, to the economy of life on the land and to their capacity for giving character and individuality to their work, the hand-loom weavers hold their own in competition with power-driven machinery; though their sphere of action is being narrowed by the taste for "tailor-made" clothes among women, and the increasing popularity of moderate-priced and serviceable machine-made goods. Yet villages with two, three and four hundred weavers are still to be found. There can be no doubt that the cheap skill and taste of these village craftsmen is a valuable aid to the French industry : for the goods that they make are very largely exported to meet the demand de luxe on the London and other metropolitan markets. Sometimes the cottage weaver works directly for the manufacturer-or perhaps one should say the merchant 
-of Fourmies, St. Quentin, Reims or Roubaix. $\mathrm{His}$ loom is his own; but of course the yarn and very often also the Jacquard harness, or some part of it, are furnished by his employer, a custom which had its parallel in this country in the handloom days. Much of the business is done through a class of middlemen-known as contremaittres, facteurs or coureurs - who get the yarn and agree on a price with the export houses and then make their own bargains with the weavers. In his spare time the weaver works on the land, as for that matter do some of the Roubaix combers, when trade is slack-a curious contrast with Bradford.

In most branches, both of the worsted and woollen trades, in France, hand-loom weaving and domestic work generally have been rapidly disappearing in the last five-and-twenty years. There are few hand looms left about Reims or in the Ardennes. At Elbœuf in Normandy, an ancient centre of the woollen trade, the whole industry has been going through a rapid process of concentration. There are still hand looms, water-driven fulling mills in the valleys near the town, and other small concerns; but there has been an extraordinary change in the general character of the industry since about I 880. "Twenty-five years ago," said the president of the Chamber of Commerce of Elbouf before the Committee of 1904, "we were 250 
manufacturers. . . . We have been forced either to start large establishments or vanish. Those who had not the necessary capital have vanished. ... To-day there are but thirty-five concerns." Moreover, worsted thread from Roubaix has largely replaced the local woollen yarn; and the Elbœuf district, instead of turning out special classes of woollens as it once did, now does a miscellaneous trade somewhat after the style of Leeds.

The same story of the disappearance of the small concerns and the "family workshop" comes from Vienne on the Rhone, a centre of what the Englishman would call the shoddy trade, but what the more tactful Frenchman has very gracefully named "the manufacture of Renaissance cloth". In this class of work and in the production of lowgrade woollens generally, Vienne has to compete with other southern towns, such as Castres, Mazamet and Lodève, as well as with some of the northern centres. Complaints are also made, and that loudly, of the pressure of competition from Germany and from the rising industry of Italy, despite the tariff.

These and other complaints made before the Committee throw useful light on the competitive strength of the French industry as a whole. Grievances brought forward by manufacturers, before legislators who are held to have interfered 
unduly with trade, must be taken with reserve; and this was the situation in I904. But they show how the wind blows. Complaints of decadence are remarkably common. Sedan, the old seat of the fine woollen cloth manufacture, is now forced to take a very humble place. It might be called the French "West of England," and it led the whole trade of the country a century ago. But times have changed. Reims, Fourmies, Elbœuf, all complain of growing difficulties ; and even at Roubaix it is alleged that there has been a decline of 70,000 spindles, and a slackening in the employment of those that remain, of recent years. Complaints of heavy taxes and of the factory acts, that have reduced the working day, are universal. Recent legislation has indeed cut down the working hours in France nearly to the English level, and there is not a difference between the two countries in the matter of wages. ${ }^{1}$

${ }^{1}$ For working hours see the table at the end of this chapter. The following wage estimates are extracted from figures given in evidence before the 1904 Committee, and may be compared with the English figures in Chapter V. Of course a mere comparison of wage rates does not tell the cost of labour to the employer, unless we know also the amount of work done in each case for a given wage. It is not possible to give any exact statistical comparisons of work done; but it is probable that, in spite of rather shorter hours and wages that are in some cases higher, British factory 
On the other hand, in Belgium, Italy and Germany hours are longer, and in Belgium and Italy, at any rate, wages are lower than in France.

The French trade has two grave hardships to face in dear coal and dear machinery. The coal question is of the greatest importance for places like Reims and Vienne, that lie off the coal

labour is not really dearer than French. This however is a point that needs further examination.

In the table below, the wages are given in francs per week. For combing, the week is reckoned at 60 hours, which has been the legal factory week in France since 1904. The other figures refer to 1903 , and are in some cases for a 63 , in others for a 66 hours' week. The cheapness of some classes of labour at Roubaix-Tourcoing is due to the fact that Belgians, from across the frontier, are very largely employed there. They are cheaper than Frenchmen. Except where otherwise stated, the wages are those of grown men. In combing they are day rates; night rates are somewhat higher.

Roubaix-Tourcoing.-Sorters, $3^{\circ}$ to $3^{6}$; head spinners (mule), 36 ; washers, 177 to 204 ; weavers, men, 24 to 33 , women, 18 to 24 , learners, I 5 to $2 \mathrm{I}$; carders, 18 to r 9.65 ; comb minders (men and women), i 8 . These are employers' figures. The Weavers' Union gives a different series, namely: coating weavers, 15 to 25 ; dress-goods weavers, 9 to 16 ; furniture-materials weavers, 12 to 25 . The Roubaix weaver minds two looms.

Elbouf.-Washers, dyers, etc., 19.50; carders, 24 ; spinners, 27 to 30 ; weavers, men, 27 , women, 18 ; fullers and pressers, $2 \mathrm{I}$ to 24 . The Elbœuf weaver minds one loom. 


\section{WOOLLEN AND WORSTED INDUSTRIES}

measures ; but even in places on or near the coalfields, the French purchasers do not get such good value for their money as the Englishmen, the Germans or Belgians. The machinery question is vital to all. In spite of her manufacturing skill, and mainly in consequence of the relative dearness of coal, iron and steel, France imports textile machinery over her tariff fence in great quantities. Alsace was the chief seat of textile engineering up to 1870 ; and from Alsace mules and other machines still come. English looms and some English spinning frames are also imported, and purchases are likewise made in Belgium. It was maintained before the Committee by manufacturers from Elbœuf, that the Frenchman pays 20 or 30 per cent. more for his machinery than his foreign competitors. This may be an exaggeration, but there must be some fire where there is so much smoke.

With an almost stationary population, the home demand is not very expansive. While it expands slowly the foreign market for French manufactures contracts. The causes are the familiar ones-tariffs and growing foreign industries. The story of recent years can best be told in a short table of figures:- 
ANNUAL

AVERAGE.

$$
\text { I 893-5 }
$$

I 896-8

I 899-I 90 I

I $902-4$
VALUE OF YARN EXPORTED.

26.9 million francs

$27 \%$

$31^{\circ} 9$

$34 \%$

$7 \circ 7 \quad " \quad$

The modest

VALUE OF PIECES

EXPORTED.

$28 I^{\prime} 7$ million francs $260 \cdot 8$

$234^{\circ} 9$

$219^{\circ} 3$

$\begin{array}{ll}" & \quad " \\ \prime & ,\end{array}$

"

",

yarn The modest rise in the value of exported yarn goes but a little way to balance the decline in fully manufactured goods. ${ }^{1}$ With the export and re-export of raw wool, and with the very considerable export of tops from Roubaix, we are not here concerned. But it may be mentioned that the German demand for French tops, once considerable, has greatly declined of late years; although Belgium, Austria and Italy are still good customers. Seeing that England is the chief buyer of finished goods, there is no need to prove that the French manufacturer fears Tariff Reform.

In the matter of access to raw material, the French industry has nothing of which to complain. Wool is admitted free of duty, except when it comes by way of some non-French continental port, in which case it pays the so-called surtaxe d'entrepot. This fiscal device, started in 1892 , is responsible for the diversion of a large part of the trade once done vi $\hat{a}$ Antwerp.

${ }^{1}$ It should be noted that the movement in the prices of raw materials was on the whole upward during this period. See the diagram facing page 276 . 
Roubaix now buys direct from South America and elsewhere, and also on the London market. Its situation is excellent. It is actually nearer to London than Bradford is, and it has in Dunkirk an accessible and handy harbour. Whether the possession of a great future market in tops is or is not a gain to Roubaix-Tourcoing, considered as a manufacturing centre, is a matter for argument; but there can be no doubt that the top market has added to the commercial importance of the sister towns. The supply of home-grown wool is considerable; and although France, like every other nation, depends mainly on imported materials, her 20,000,000 sheep-many of them yielding fine wool-are a valuable asset to the manufacturer. The best of the flocks are in the north-east Departments, within reach of Sedan and Reims, the old headquarters of the woollen and worsted industries respectively.

Another important factor affecting the supply of raw material is the existence at Mazamet, in the hilly Department of the Tarn, of a highly specialised, localised and efficient fellmongering industry (Industrie de delainage). Out of the fifty-eight French firms which, in the year 1903, were engaged in this business of stripping sheepskins of their wool, no less than fifty-four were at Mazamet. The work is done entirely without the use of chemicals, by soaking and heating 
the fells, so as to make them part readily with their wool, without damage either to wool or leather. For the most part the fells treated come from South America, by way of Bordeaux, Cette, or Marseilles; but Australasian and other skins are also handled at Mazamet. As a consequence of the skill and care of the Mazamet strippers, and the excellent chemical properties of their water supply, the export of skin wools from France to England, Belgium, Germany and elsewhere has become an important branch of the international wool trade.

There are certain conspicuous technical distinctions between the French and English worsted industries which demand a brief reference. In Chapter I. it was pointed out that "French drawing" is a process widely different from English, in that it gives no twist whatever to the roving. Like the woollen yarn, the French-one might almost say the continental-worsted yarn comes to be spun in the form of a soft, untwisted band of wool fibres. Then, too, the combing process is in many cases carried out on the Heilmann comb, or some one of its derivatives, although the Holden comb does a vast amount of work at Roubaix and Reims, and the Lister and Noble combs are not unknown. Further, much of the combing is "dry," that is to say, oil is not used at all or is used only to be washed thoroughly 
out of the top after combing and before a final gilling. Lastly, the great majority of French worsted yarns are mule spun and always have been. These combined processes put less strain on the wool than do the typical English worsted processes; so that short and relatively inferior wools can often be spun to finer counts in France than in England. Moreover, the resultant yarn is normally softer than frame spun yarns, and is excellently fitted for use in dress materials that are wanted to hang in smooth folds. In coatings it is of less value; and in this branch of the trade England has, as yet, no serious competitor, whereas for many years Bradford has been exercised in its mind about the competition of the dress goods, made by the skilled French weavers from these soft mule-spun yarns, and dyed and finished by the equally skilled Frenchmen engaged in those industries. For the reputation of the French dyers stands high.

The wool-working industries of Belgium are in close touch and keen competition with those of France. They gave employment in $1896-$ the latest date for which complete figures are available-to 23,000 factory workers and 7900 domestic workers, besides 2200 employers, managers, clerks, and so forth. Verviers is the headquarters for most branches of manufacture, the Province of Liège, in which Verviers lies, 
containing 14,300 out of the 23,000 factory hands. The rest are widely scattered-near Brussels and Antwerp, at Dinant, Tournai and in East Flanders. Flanders is also the home of the hand-loom weavers, who form the bulk of the domestic workers to whom reference has just been made. Belgium owes her high position as a wool-manufacturing nation mainly to her success in the preparatory process, and in the spinning both of woollen and worsted yarns. Lying between England, France and Germany, she is in a position to do work for all three, and she does it. Her raw material is almost all imported, for she has no flocks worth mentioning, and it comes to her through Antwerp. Near Antwerp-at Hoboken - stands her only combing mill, which provides the material for the Antwerp top market, a market where future dealings in River Plate tops play an important part. It should be added that the Hoboken mill is not a purely Belgian concern, but practically a branch of the great Leipziger Wollkammerei, and that it works largely for the German trade-an instance of the close connection of the industries of Belgium with those of its continental neighbours. Combing is also carried on in worsted mills, chiefly in Verviers. Almost all the combs are of the Heilmann type. Two-thirds of the wool combed in Belgium is exported, very largely into Germany and the inner parts of the Continent generally. 


\section{${ }_{23} 8$ WOOLLEN AND WORSTED INDUSTRIES}

More important and characteristic than the combing trade is the washing and carbonising industry of Verviers. ${ }^{1}$ This industry may be said to take the place occupied in other countries by specialised combing. It owes its existence and its success to commercial and chemical enterprise, good water, and the fact that Belgium lies across important trade routes from the sea into Europe. The cleansing of the wool is done with the greatest care and thoroughness, by processes differing considerably from those employed in England. All the "washeries" work on commission, and their clients are as often foreigners as Belgians. Merchants and spinners in Germany, Austria and even Russia import large quantities of wool through Belgium. When doing so they often find it convenient to hand the greasy bales over to the washers of Verviers. They receive their wool back carefully cleansed and 30 to 60 per cent. lighter than it was in the grease. Appreciable economies in the cost of carriage on the long overland journey are the result.

The Verviers district is the headquarters of the spinning as well as of the washing trade. In both woollen and worsted, spinning is largely a

${ }^{1}$ See page 27 for the process of carbonising, which is one of the methods of disposing of vegetable impurities in wool. 
specialised business. Owing to the heavy exports of yarn-rarely falling below $£ \mathrm{I}, 500,000$, and sometimes rising to $£ 2,000,000$ per annum-it is of more importance than weaving, for the export of finished goods does not exceed $f_{5}-600$,ooo. Belgium contains 242,000 worsted spinning, 340,000 woollen spinning, and 87,000 twisting spindles, the last mostly for worsted. As the worsted mills are not in a position to do all their own combing, and as a great part of the wool combed in Belgium is exported, tops have to be drawn from Roubaix, or wool combed there on its way into Belgium. It is said that two-thirds of the tops used in Belgium are the product of the Roubaix mills; while at the same time twothirds of the tops made in Belgium are exported - a curious situation.

The Belgian worsted yarn is generally made by the "French" processes, though frame spinning is not unknown. Between 35 and 40 per cent. of the yarn spun is for export, and England is the best customer. The exports of woollen yarn are even greater, amounting to 50 or 60 per cent. of the total output. Here, again, England is the chief buyer, the Belgian yarns going both into the weaving and the hosiery industries. The manufacture of "Vigogne" yarns, that is to say, yarns of mixed cotton and wool, forms an important section of the Verviers trade. Some of 
these come to England with the rest. A couple of figures will serve to illustrate the importance of the English market for the Belgian spinners. In I904 yarns were consigned from Belgium to this country to the value of $£ \mathrm{I}, 3 \mathrm{I} 4,946$. Our total import of yarns in that year from all sources was $£ 2,352,482$.

Weaving, as has been pointed out already, is more widely spread than spinning, and is still in part domestic. There is, however, nothing of special interest connected with this branch of the industry, although the Belgians carry it on with considerable success.

At the present time the manufacturers of Roubaix-Tourcoing are in some anxiety about the possible transference of a part at least of their industry to Belgian soil, owing to the special economic advantages presented by such towns as Mouscron and Tournai, which lie but a few miles distant from them across the plain. Land, building materials, coal and labour are all considerably cheaper than in Roubaix. Transport facilities by land and water are excellent and not expensive. The cost of living is lower than on the French side of the frontier, hence the lower wages. Lastly, the duties on imported textile machinery are not so high in Belgium as in France, and the State takes less care of the factory workers. Hours are longer, and night work is common in 
all sections of the Belgian trade, ${ }^{1}$ whereas in France it is usual only in combing. It is not surprising that the easy movement across a frontier that is only a "conventional sign" has already begun, or that the President of the Tourcoing Chamber of Commerce threatened the Parliamentary Committee with further migration, should the French Government go too far ahead of the Belgian in imposing regulations on textile factories.

Like most things German, the German woollen and worsted industries have developed and thriven astonishingly since the foundation of the Empire. Although of late years the export trade has increased comparatively little, owing to those difficulties which all manufacturing nations now have to face in the international market, the home trade continues to expand, for the population has grown steadily both in numbers and in average purchasing capacity. Protective tariffs keep down foreign competition, and the mass of the new demand must be met from the produce of the German mills. The growth is most conspicuous in the case of worsted, where the figures tell a remarkable story. In 1885 there were 35 large spinning concerns engaged in the production of worsted weaving yarns. They turned out between

${ }^{1}$ See the table at the end of the chapter. 
them the bulk of the yarns of that type spun in the Empire. They employed i I,00o workpeople, and ran 668 combs and 573,000 spinning spindles. In 1902 the number of firms of the same class had grown to 47 , with 28,000 workpeople, I 425 combs and 1,634,000 spindles. Taking woollen and worsted together, it appears that the number of power looms grew from 30,500 in 1875 to 77,000 in 1895 . It should be added, however, that the hand looms during the same period fell from 47,000 to 23,000 . At the later date there were $3,335,000$ spinning spindles of all sorts in the country.

With regard to employment, the size of businesses and the like, very full accounts are given periodically in the elaborate German census figures. Unfortunately, the last such account at present available dates from I895, since when many things have happened. And it does not properly distinguish woollen from worsted. Still it is instructive; it shows that in the year named, there were 262,000 men, women and masters in the industries, including dyeing and finishing. Of these, in round figures, I6,000 were washers, combers and others engaged in the preparatory processes; 63,000 were woollen and worsted spinners; 7000 were makers of mungo and shoddy; I 53,000 were weavers; 23,000 were dyers and finishers. About four-fifths of the 
spinners and nearly two-thirds of the weavers were employed in mills containing fifty workpeople and upwards-in large scale modern factories, that is to say. But nearly 28,000 weavers were working at home. Domestic weaving has declined considerably since $\mathbf{1 8 9 5}$; yet the hand-loom weavers are still a large army, scattered more or less over the Empire and to be found in nearly every manufacturing district, but concentrated especially in Western Saxony, round about the twin towns of GlauchauMeerane, where they do work of much the same class as their French colleagues of the Cambrai and St. Quentin neighbourhood. They are specially numerous also about Solingen and in Northern Bavaria.

This scattering of the hand-loom weavers is typical of the whole German wool industry. It has so many "centres" that it has no true centre; every State has a hand in it. There is only one of the ninety administrative districts of the Empire in which absolutely nobody is engaged either in spinning or weaving wool. Commission combing, to take a striking example, which in England and France is one of the most localised of all industries, has five headquarters, each with a single great mill of outstanding importance. They are Blumenthal near Bremen, Hamburg, Leipzig, Döhren near Hanover, and Mylau 
near Reichenbach. Worsted spinning again is anything but concentrated. Leipzig, Zwickau, Plauen in the Saxon Vogtland and Mühlhausen in Alsace each have a number of important mills ; but there are others spread far and wide over the country, some at great distances from any other textile factory whatsoever, others in comparatively small groups in the neighbourhood of kindred trades, as in the Rhenish textile districts.

Nor are woollen and worsted districts sharply divided. Saxony and Alsace are prominent worsted producers, but they are also known for their woollens. Westward of Saxony, the little territories of the house of Reuss, with their capitals Gera and Greiz, are mainly given over to weaving of the Bradford type; yet they too do some woollen weaving. Aachen and its neighbourhood are best known for their woollens, but they do not neglect worsted. Berlin and its suburbs do a most miscellaneous business. So do the towns and villages eastward and southward, in Brandenburg and Silesia; but there woollens predominate, though Liegnitz and Breslau spin worsted yarns. At the other end of the Empire, most branches of the trade are represented in the great industrial area within a twenty-five mile radius from Düsseldorf-about Cologne, Solingen, Elberfeld, Barmen, MunchenGladbach and Rheydt. The overlapping of 
woollen and worsted weaving, to be found now in all countries, still further increases the diffculty of describing accurately the distribution of the industries in Germany.

Besides domestic weaving there is still a good deal of small scale manufacturing of different kinds, to be found up and down the country. In the district of Upper Franconia-round about Bayreuth-there were in I 895 thirty-one houses, one cannot say mills, where spinning of sorts was carried on, and there were I07 spinners; in Saxe-Coburg-Gotha there were five such establishments with 52 spinners; in the district of Magdeburg 58, employing 2 I 9 workers; and so on. On the other hand, the average spinning mill in Upper Alsace contained $38_{3}$ operatives; at Gera, thirteen worsted weaving mills together employed more than 6400 hands; and the Bremen Wollkammerei at Blumenthal now employs over 3000. Such contrasts render generalisations about German industrial organisation particularly difficult. The statements made below must be taken as applying to those sections of the trade that are organised on modern lines, which after all form the vast majority.

The worsted industry is the most completely modernised, and is specially interesting to us, for it is a great purchaser of English yarns. This shows that it is not yet full-grown, as has already 
been pointed out, but it is growing fast. Its growth began with the acquisition of Alsace; for in the sixties it was of no account. The Alsatian spinning firms generally do their own combing, and so do many of the largest "spinneries" elsewhere. But they also buy tops, sometimes from abroad, or have part of their wool combed on commission. The five great commission firms already referred to do almost half the washing and combing work for the trade; some washing of both combing and carding wools is done in separate "washeries," like those of Verviers. The remainder of the preliminary work falls to the large spinners. Small and medium-sized firms rarely either wash or comb, but buy from topmakers (Kammzugmacher), as in England. Before the great commercial depression of 1900-2 the big combing firms had done business extensively on their own account, buying wool, combing it and holding it for the rise. But they suffered severely during the price collapse of 1900-I, and latterly they have been confining themselves more strictly, though not yet entirely, to commission business. When they sell their own tops, they now do so through the regular dealers.

Combined spinning and weaving businesses are rare in the German worsted industry, ${ }^{1}$ rarer

1 The Germans have a convenient name for such a business-Spinnweberei, a "spin weavery". 
than in any other European country. There are various reasons for this peculiar to Germany, over and above the general causes that make for specialisation. With us the combined businesses are generally the older ones; in Germany really old businesses are scarce. Moreover the spinners have never been able to supply all the needs of the weaving firms, so that in many cases combination has been quite impracticable. At one time, mule-spun merino yarn came largely from France. This trade has now declined, but our frame-spun yarns of long English and crossbred wool, alpaca or mohair, are imported yearly in immense quantities. As there is every year a greater demand for yarn of this class, the German spinners are now hard at work putting in frames, ring frames for the most part.

Formerly the equipment was of the French type, specially adapted for handling merino wool and turning out soft yarns. For some time the Germans have sent considerable quantities of these yarns to England, largely for use in the hosiery trade. But now a few firms have adopted frame spinning exclusively, and they hope in time to dispense with our yarns altogether. Whether they will do so or not remains to be seen. As yet the signs hardly point that way, but the tariff may be called in to hasten the process.

The German combing and worsted spinning 
mills are generally companies, not family businesses; and there has developed of late a good deal of common action among them, though regular Kartells have not been formed. As long ago as 1889 the leading spinners agreed on uniform terms of payment and delivery. They collect and publish statistics of stocks and output for their mutual guidance. Since I 897 they have more than once agreed to work short time, as our cotton spinners do when trade is slack. The large commission combers have fixed uniform scales of charges and appear to be tending towards a Kartell organisation. But the spinners have made no attempt to fix prices; and among the weaving firms there is no regular and organised co-operation whatever.

Woollen as usual shows less specialisation than worsted. Half the woollen yarn spun in Germany in 1897 was for use "on the premises," as in the English woollen mills. The rest came from specialised mills. Both here and in the worsted trade, some considerable portion of the yarn from mills of this latter class goes to feed the hand looms; for in Germany simple woollen materials as well as fancy worsteds and mixed fabrics are extensively woven by hand. For the rest, the German woollen industry has taken very kindly to mungo and shoddy-adopting the names as well as the things-and succeeds 
in sending into this country quantities of cheap cloths of the type known as "mantle cloths" and other miscellaneous goods. It is not in a position to compete successfully with the higher branches of the English industry. Nor for that matter are the German worsted manufacturers. German dress materials come into England, it is true; sometimes they are made of English yarn ; but the quantity is as yet comparatively small, although the quality is often very good and the dyeing excellent. In the manufacture of worsteds for men, England's position is undisputed.

Sixty years ago, Germany exported quantities of raw wool. To-day no important manufacturing country except Belgium is so completely dependent on imports. The wool grown at home does not supply a tenth of her needs, and the old wool fairs have lost much of their importance. South American wool is the staple raw material, but Australasian is also extensively used. Direct buying is now the rule, though large purchases are still made in London, and tops are imported from England, France and Belgium. Bremen, Leipzig and Berlin are the leading markets. Until I899 Leipzig had an organised future market for tops; but the Government has suppressed it at the request of a majority of those engaged in the industry. As many of the spinning districts lie far from the 


\section{$25^{\circ}$

coast, railway carriage adds something to the cost of materials, though through rates are generally moderate. Coal is good and tolerably cheap. All classes of textile machinery are made at home, combing and mule-spinning machinery coming mainly from Alsace. But for spinning worsted after the English fashion, it is customary to use English machines.

And what of wages? This is a question to be answered with caution. A high German authority is of opinion that, although some English wool workers are better paid than any in Germany, "the centre of gravity in Germany" is somewhat higher than in England." Factory wages rose greatly during the last two decades of the nineteenth century. In Alsace between I 885 and I 902 mule spinners' wages, in a representative mill of this representative district, rose from 2448 to 3 I 08 marks per week, and the wages of women doublers from 14.50 to I 548 , and that in spite of the fact that working hours were reduced from twelve to a little over ten hours a day during the interval. It is at least certain that the money wages of German factory workers are not conspicuously lower than ours.

1 Professor Hasbach, who knows England well. Quoted in Ashley's Progress of the German Working Classes, page Io. 
The fourth country that will be dealt with here in some detail is the United States. Holland, Switzerland and Austria must be passed by, although they are competitors in certain branches of the trade. The Americans do not compete with us in the home market, and their competition in other markets is not yet of any great account ; but they must certainly be classed among the great manufacturing nations, rather than among the nations who have but recently developed manufactures on modern lines, though of course the boundary between the two groups cannot be sharply drawn.

The American wool industries are concentrated in the states of the north-eastern seaboard. A few factories are to be found in the central and western cities. The ranching states and territories have some wool-scouring establishments. In out-of-the-way corners of such states as Kentucky, West Virginia and Tennessee, old-fashioned woollen mills still make cloth, flannel and blankets for the local farmers from the local wool. There is even a little domestic spinning and weaving in these up-country districts, where the mills card the farmers' wool on commission and return it to them to be spun. But fully 90 per cent. of all the capital invested in the industries is in the New England States, together with New York, New Jersey 


\section{WOOLLEN AND WORSTED INDUSTRIES}

and Pennsylvania. Pennsylvania and Massachusetts united produce more than half the wool manufactures of the Union. Philadelphia alone was responsible for nearly a fifth of the national output in I900. In I 890 its position was even stronger than this. Lawrence, Massachusetts, comes second, and Providence, Rhode Island, third. But the trade of Philadelphia in 1900 was more than twice as great as that of Lawrence, and three times greater than that of Providence.

The woollen and worsted industries properly so called, including shoddy making but excluding the carpet and hosiery manufactures, employed just over I35,000 workpeople at the census of I900. There were I45 I combs, I,939,709 woollen spindles, I, I9 I,406 worsted spindles, and 6I,253 power looms, of which $34,88 \mathrm{I}$ were in woollen and the remainder in worsted mills. The figures for spindles include both spinning and doubling. ${ }^{1}$ These are not

1 There were $3^{15} 5,000$ hosiery yarn spindles, reckoned separately in the census. Of these all but $2 \mathrm{I}, 000$ were for woollen yarn. There were also 225,000 spindles in carpet and felt mills. Machinery statistics for 1905 are now available; but it seemed best to use the complete figures of employment and machinery for 1900 . The 1905 figures show a total increase of 14 to 15 per cent. in spindles and of nearly 5 per cent. in looms. 
very high figures for a nation of about seventysix millions, with a stiff tariff; but it must be remembered that the climate sets limits to the demand for such things as overcoats and blankets in the South, that there is no serious export trade and that the tariff, though high, is still often crossed by $£ 4,000,000$ worth of wool goods in a year. Relatively low the figures may be, but they are uncommonly high when compared with those of 1890 or of 1880 . The main growth, as in Germany, has been in worsted. There were nearly six times as many worsted spindles and nearly three times as many combs in the country in 1900 as in 1880 . During the same period the number of worsted operatives rose from I 8,000 to 57,000 . In woollen, however, the number of spindles increased only by about $\delta$ per cent. ; the number of looms declined slightly; and the number of wage earners fell by 18,000 , owing to the concentration of the industry and the disappearance of the primitive local mills. ${ }^{1}$

Characteristically enough, the American worsted mills are now larger than those of any other country. On an average each establishment dealt with in the census employed over 300 hands, a figure which England certainly cannot equal.

${ }^{1}$ In 1880 there were $199^{\circ}$ separate woollen establishments of all sorts; in I 900 only 1035 . 
This is in part due to that absence of specialisation, which differentiates America from the whole of Europe. The familiar division of combing from spinning, and spinning from weaving, is the exception, not the rule. Combing as a distinct trade does not exist. "I do not know that a single establishment in the country makes only tops," writes a high authority in answer to a question on this point. ${ }^{1}$ He proceeds to mention mills which make tops for sale, but notes that they all do something more than that. One "makes tops for sale and also yarns for sale, . . . but the largest part of their business is the weaving of fabrics for women's wear". Another "makes tops and spins yarns for sale, but weaves no cloth". Here we have the division of spinning and weaving; but combination is the rule, a combination that even includes dyeing, "but very few piece goods being dyed by special establishments". During the last ten years a tendency to division has shown itself, but it has not yet altered the general character of the industry. Such being the situation in worsted, it is in no way surprising that the large woollen mills are almost, if not quite, invariably of the combined type that buys raw wool and sells dyed and finished cloth. Shoddy making however is a distinct

${ }^{1}$ Mr. J. B. McPherson, Secretary of the National Association of Wool Manufacturers. 
trade with ro5 establishments and nearly 2000 workpeople; although some of the woollen mills make what shoddy they require on the premises. There is no territorial distribution of the industries in woollen and worsted districts. The three great combing states, Pennsylvania, Massachusetts and Rhode Island, are also the chief woollen producers. For the worsted industry, which is substantially a growth of the last thirty years, has simply established itself wherever woolworking was previously well developed. Worsted mills were built in the old manufacturing localities, and woollen mills were sometimes converted to meet the growing demands for worsted goods, caused by the change of fashion and the increasingly rigid exclusion of European manufactures.

The combination or Trust movement touched the wool industries in March, I899, when the American Woollen Company was formed, with an authorised capital of $\$ 65,000,000$, to take over twenty-six woollen and worsted businesses, for the most part in Massachusetts and Rhode Island. Many of the combining firms had suffered severely during the period of relatively low tariffs, from I 894 to I 897 , and were glad to sell to the promoters. The company is not and never has been in a position of monopoly in any line of production, although it is interested in most lines, from broadcloth to French-spun 
worsted yarns. In I901 the various mills contained 2 I 2 combs, 426,000 spindles and 6500 looms, and they employed from 20,000 to 21,000 workpeople. The company maintains its own selling agency in New York and imports its own wool when necessary. In the early days its financial methods were sounder and more cautious than those of some of the great combinations. Its preference shares have in consequence always been a paying investment; though the same cannot be said of the ordinary shares. The scope of its operations has widened somewhat in the last few years; but it still only controls a part of the trade.

As a competitor in the international market the American industry suffers from dear labour, dear raw material and an inability to produce the finest classes of goods. The tariff alone protects the manufacturers from destructive foreign competition at home. The tariff is also responsible for the dearness of raw material, owing to the wool duty, reimposed in 1897 , after a three years' experiment with free wool. Merino and other fine wools pay $5 \frac{1}{2} \mathrm{~d}$. per $\mathrm{lb}$. ; long combing wools $6 \mathrm{~d}$.; low grade carpet wools $2 \mathrm{~d}$. if worth less than $6 \mathrm{~d}$. a lb., $3 \frac{1}{2} \mathrm{~d}$. if worth more. America, as we know, herself produces a great variety of wools; but they do not meet her needs. Since I 897 she has on several occasions imported over 
a third of her total consumption, and the present tendency is for imports to increase. In the free wool years the imports rose from 40 to 57 per cent. of the consumption. At this point the complaints of the wool growers secured the high rates of the Dingley Tariff.

The following short list illustrates the level of wages in New England woollen mills in I900:-

(a) Males above sixteen years of age.-Bobbin hands and doffers, $\$ 5$ per week; card tenders, $\$ 6$; beamers, $\$ 8$; dyehouse hands, $\$ 7$; loomfixers, $\$ 13.50$; head foremen, $\$ 19.50$; spinners, $\$ 9.50$; weavers, $\$ 9$; sorters, \$1 2.50. (b) Females above sixteen years of age.-Bobbin hands and doffers, $\$ 4$; drawers-in, $\$ 8$; general hands, $\$ 5^{\circ} 5^{\circ}$; spinners, $\$ 6$; weavers, $\$ 85^{\circ} \mathrm{O}^{1}$

The occupations are not in all cases quite comparable with those in English mills, but the table brings out the general level of wages clearly enough. It must be repeated that the amount and character of the work done for the weekly wage are of course not identical in the two countries. The American workman probably produces

${ }^{1}$ These figures, taken from the 1900 wage census, are not averages, but "medians"; i.e., $\$ 8.50$ for women weavers means that there were as many women earning more than $\$ 8.50$ as there were earning less, in the wage lists submitted to the census officials, 
more than the English; how much more has not been accurately determined.

It is not possible to deal with the second group of nations, to which reference was made at the beginning of the chapter, in anything but the most summary fashion. All over the civilised world textile industries of the West European type were being developed at the close of the nineteenth century, in some cases with striking rapidity. In Europe, Italy furnishes a remarkable instance of an old and famous country who has thrown herself into the work with vigour. Textile progress has played a great part in her recent economic revival; and although that progress is most conspicuous in the case of the cotton industry, wool manufacturing has shared it in no small degree. The headquarters of the industry are in the north, in the cities of Lombardy and Piedmont and along the foothills of the Alps. There water power is available in abundance, and the mills round about Biella make extensive use of it, both as a direct motor and as a generator of electricity. The goods which they produce are mainly of a simple character, plain cloths, flannels and so forth, suited to the demand of the people. Already, as has been seen, they have come into competition with the similar products of the mills of the south of France; and an examination of the import and 
export figures shows that Italy is ceasing to be dependent on her neighbours and is in a fair way to become an equal. With modern equipment, such as she now possesses, her chances of success are great; for the labour of the northern Italians is not only cheap, but good. And the Italian, of whatever class, has an artistic sense denied to the Teuton and the Slav.

Other statistics than those of foreign trade are available, but they are not very satisfactory. Figures of employment for 1894 and $190 \mathrm{I}^{1}$ point to a great increase at the close of the century; but the two series are of such a kind as to render close comparisons impossible. In 1894 there were I 28,000 spindles - mostly woollen-in small spinning mills, 2700 looms in ${ }_{10} 3$ little weaving mills, 2 I 7,000 spindles and 7600 looms in combined mills, and I 8,500 domestic looms. Of the looms in the mills, over a third were worked by hand. At the same date more machinery was driven by water than by steam. Things have been changing fast since 1894 ; but these figures give some indication of the character of the industry at the time when Italy began to rank as a considerable manufacturing nation.

${ }^{1}$ The latter from the I90I census; the former from an inquiry of which the results are given in the Annuario Statistico Italiano, 1904. 
Statistics of foreign trade yield the following interesting results :

Imports.-Average VALUe PER anNum in Millions of Lire, ${ }^{1}$ I891-3. I894-6. I897-9. I900-2, 1903.

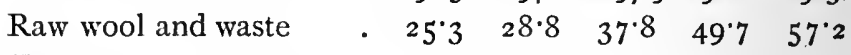
Yarns . . . . . $\begin{array}{llllll}7.6 & 7.3 & 4.7 & 2.8 & 2.6\end{array}$

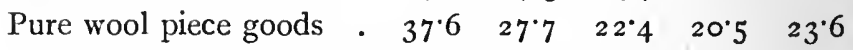

The quantity of manufactures exported annually---measured by weight - increased very little between 1886 and I 895 , but rose sharply in 1896-7; and for the period 1898-1903 was between two and three times what it had been in 1886-95. How far these changes are due to tariffs, and how far to increased industrial efficiency cannot well be determined. But the growth of the exports clearly proves the existence of increased efficiency, though as yet the value of these growing exports is inconsiderable.

Recent events have interfered with the economic development of Russia; but before the beginning of the present troubles, her manufactures were growing fast, in the hot-house atmosphere of an exaggerated tariff system; and although neither the growth nor the tariff prevented an increase of imports, they succeeded in confining the imports within very narrow limits. So far as woollens are concerned, Russia has

${ }^{1}$ It should be noted that the exchange value of the lira rose during the later years covered by this table. 
long been practically self-sufficing; although some of the finer sorts have always been imported in small quantities for use among the well-to-do. Her flocks, which are far greater than those of any European country, supply most of the raw material, which is still worked up to some extent by the peasants themselves for their own use. But the factories of Poland and the Moscow neighbourhood, nursed by Government, have killed this primitive system in many districts ; though the peasant still makes his own felt boots and gloves as a rule. The worsted manufacture is new. It has grown up during the last five-and-twenty years, tariff-fed, of course. For the most part it is a Polish industry, with its seat round about Lodz and Warsaw; but most of the manufacturers are Germans and Austrians, with a few Englishmen. In the early days of its growth, large quantities of yarn had to be imported, and the yarn imports are still considerable. But spinning and combing made great progress towards the end of the nineteenth century, although Russia remains a good customer of foreign top makers and commission combers. In 1903, for example, she bought nearly $£ 374,000$ worth of prepared wool, mostly tops, from this country. Her purchases of raw wool in the international market have also increased. Her imports of piece goods are 
small, though the tariff has failed to stop the slow growth which has been noticeable for some years past. She is not formidable as a competitor in neutral markets, except in some of the inaccessible parts of Central Asia ; for her fiscal system and the relative incompetence of her workmen make the cost of production high.

The main features of the Russian import trade are shown in the following table, which gives both the annual average value and the annual average weight of the raw wool, and the value of the woollen and worsted yarns and piece goods imported :-

1891-3. 1894-6. I897-9. 1900-2. I903.

Raw wool-

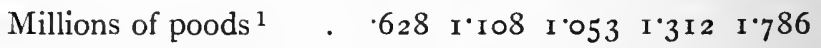

Millions of roubles.$\quad 9^{\circ} 3 \quad 15^{\circ} \circ \quad 14^{\circ} 7 \quad$ I $7^{\circ}$ I $\quad 22^{\circ}$ I

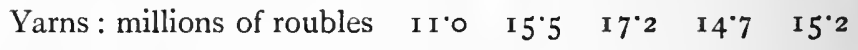
$\begin{array}{lllllll}\text { Piece goods } \quad & 3.5 & 5.7 & 6.5 & 7.7 & 9^{\cdot} \mathbf{I}\end{array}$

It is natural to pass from the trade of Russia to that of Japan. The fact that they have no wool of their own has not diminished the determination of the Japanese to master the art of wool-working, together with the rest of the useful Western arts. They can buy in the best of all markets far more easily than any other nation, for there is now regular steamship communication

${ }^{1}$ The pood is $36 \mathrm{lbs}$; ; the rouble up to 1897 was worth $2 \mathrm{~s}$., and after 18972 s. $3^{\frac{1}{2}} \mathrm{~d}$. 
between Yokohama and the Australian ports. It is only a few years since the Japanese buyers first came to the Australian sales, but their purchases are already considerable. At the outset they always bought scoured wool. But in 1906, for the first time, they extended their operations to "wool in the grease". "If this is to be permanent," wrote the Sydney correspondent of the Yorkshire Observer, then the scourers must say good-bye to the lucrative business which they have for some time done with Japan." Probably it will be permanent. When Japan learns an art she practises it; and the purchases indicate that some of her manufacturers at any rate are confident that they have learnt to scour. They are securing first-rate equipment. Government assistance is freely given. Japanese students are making prolonged studies in the textile schools of Europe and America. In short, an industry is being created with that method and deliberation which have made the Japanese army and the navy what they are.

For the present, however, Japan imports manufactured goods in large quantities. Of late years the Tokio War Office has been one of the best customers of the West Riding manufacturer. Both in 1905 and I906 Japan bought more English woollen cloth than any other country, and she also took blankets and a good stock of 
worsteds. In what is commonly called the course of nature, this state of things might be expected to continue for many years to come. That is perhaps a good reason for thinking that it will shortly terminate, since the Far East now habitually upsets all comfortable generalisations based on either western or eastern experience. But so far as it is possible to weigh the matter, it certainly seems that Japan is not likely to be in a position to supply all her own needs, much less to export, during the next decade or two.

Canada should certainly be reckoned among the nations who have recently developed manufactures on modern lines. But the development has not been very rapid during the last five-andtwenty years. The old-fashioned carding and fulling mills in the long-settled provinces of the East have been dying out, and are now practically extinct; there has been a great concentration of the industry in mills of considerable size; but the growth in productive power has not been comparable with that in the United States, so far as one can judge from available figures. The average woollen mill appears to contain only about forty workpeople. The estimated value of the goods turned out from all the mills, excluding hosiery, was about $£ 3,000,000$ in 1901 , and about $£ 2,000,000$ in $188 \mathrm{r}$. These estimates of production, which are popular in Canada and the 
States, must not be taken too seriously; but they serve as rough indicators of the growth of an industry. It is interesting to compare with them the figures of imports, in order to contrast the relative importance of the home-made and the imported wool goods. The latter, including hosiery in this case, came to nearly $£ 2,000,000$ in I90I, and just about $£ 3,000,000$ in 1905 . The output of Canadian hosiery was valued in I 90 I at about $£ 750,000$.

The industry is widespread and varied in character. Montreal and Toronto each contain a number of mills. Others are to be found scattered among the towns of the Ontario peninsulaPeterborough, Brantford, Guelph, Chatham and elsewhere. There are a few in the provinces of Quebec and Nova Scotia, and a very few in the western provinces. Most classes of woollens are produced, but not many worsteds. There is no such thing as a specialised worsted mill, so far as one can ascertain; all those that make worsteds, and they are but seven or eight, also making other things. Spinning mills are scarce, the combined mill being the regular type. A few specialised dyeing and finishing works exist, and there are three firms at least which make textile machinery -one at Hespeler in Ontario and two in Toronto. In short, an industry with most of the necessary branches and allied trades. 
Yet an industry which, in spite of generous protection, has not been able to cope with the immense expansion of the home demand of recent years. Imports increased 50 per cent. between I 900-I and I904-5, and they are not likely to fall again. Some say that Canada's dry, hot summers and dry, cold winters unfit her for the practice of the textile trades, and certainly these things are not favourable to spinning. Still she has her humid provinces on the eastern seaboard, and there seems no reason why they should not in time rival New England. But the time is not yet.

The last group of nations to be dealt with here are the pastoral lands of the Southern Seas. Only a small fraction of the wool that they raise for the world's use comes back to them in the form of cloth or clothing; yet, if they were to supply all their own needs, a valuable outlet for the manufactures of the North would be stopped once for all. In I906 Great Britain sent just over $f_{3}, 000,000$ worth of woollen and worsted tissues -not to mention yarn, hosiery, blankets, and clothes-to Australasia, South Africa, and the shores of the River Plate. This is the trade which Great Britain stands to lose in proportion as manufactures develop in the South. The risk, from the British point of view, is not yet very great. It is no easy thing to start textile trades 
where machinery and plant have to be brought from the other side of the earth, and where, as in Australia, there is not that rapid rise in population which drives nations to explore new fields of economic activity.

But in some cases the start has been successfully made, and in all the great pastoral lands the governments are fully prepared to give what assistance they can. Australia and New Zealand, whilst admitting machinery free or at nominal rates, levy protective duties varying from I 5 to 25 per cent. on all but certain selected types of woollen and worsted fabrics, such for instance as bunting. In New Zealand there is something serious to protect;-her woollen mills in 1904 gave employment to I692 workpeople, and turned out goods whose value was estimated at between $£ 300,000$ and $£ 400,000{ }^{1}$ Nor were the goods lacking in variety. Tweeds, woollen cloth, flannel, blankets, rugs and shawls -some of excellent quality-were all included in the list; and the consumption of wool by the mills was over $3,000,000$ lbs. For a population of some 800,000 in a new country, this is already a considerable achievement. But it has not as yet stopped the steady growth of the im-

1 The value of the woollen and worsted piece goods exported from this country to New Zealand in 1906 was

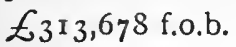


ports, which more than doubled between 1892-4 and 1902-4. The Australian Commonwealth cannot match this sturdy "infant industry" of New Zealand. It is true her woollen mills contain some I 900 workers; but then her population is nearly five times that of New Zealand. Only in Victoria are there any mills of importance. New South Wales, the foremost woolgrowing State in the world, had in 1902 but four mills, each employing about sixty hands. Moreover, although the produce of the Australian mills is as varied as that of the New Zealand mills, it is not so evenly divided among the different branches. Flannels are the staple goods; rugs, tweeds and cloths are comparatively unimportant. In several cases the woollen mills are combined with clothing factories, showing that the textile industry proper is not yet strong enough and specialised enough to stand alone. Probably the difference in climate is in part responsible for the relatively greater success of the New Zealand manufacture; but there is no reason to suppose that the Commonwealth might not conceivably be able to do her own spinning and weaving in the long run. To-day she supplies only a small part of her needs, and her textile trade grows very slowly.

South Africa has hardly yet begun to think of herself as a manufacturing nation in the true 
sense of the word. And as the agricultural and metallurgical industries are likely to occupy all her attention for many years to come, there is no reason to anticipate any textile progress comparable with that of New Zealand. There has always been some domestic wool manufacture among the Boers and other up-country farmers; but there have been singularly few attempts to start woollen mills. One or two unsuccessful enterprises of this kind are on record. It may be that some have succeeded and survive, or that fresh starts have been made since the war. If so the work is being done very quietly. I myself do not at present know of any working mill in South Africa. No doubt fresh attempts will be made. A country full of sheep is not likely to forget the value of spindles and looms. There is an excellent market among the natives for the plain goods that a young industry can most easily turn out, such as blankets; and the object lesson of the Rand should keep South African statesmen alive to the value of a diversified national industry. But labour of the right sort will be hard to find for many years to come; so that one can prophesy with some confidence that, of all the greater wool-producing lands, South Africa will be the last to develop a manufacturing industry of international importance.

The Argentine Republic, like Australasia, 
already possesses a few woollen and other textile mills. For the most part they employ foreign yarn, and the whole textile industry is still weak and raw. Stock-rearing and agriculture absorb the best strength of the country; and hitherto the chief industrial developments have been connected with milling, meat-freezing, sugar-refining and the like. But government, here as elsewhere, is ready to foster promising branches of manufacture. Quite recently special rewards have been held out to induce some competent foreigner to introduce the worsted manufacture into the country. With a population that grows rapidly and is full of enterprise, there should be no difficulty in developing a respectable manufacturing industry as time goes on. But for the present Argentina, like her fellow pastoral nations, affords a widening market rather than a dangerous competitor for the produce of the European mills to which she sends her wool. 


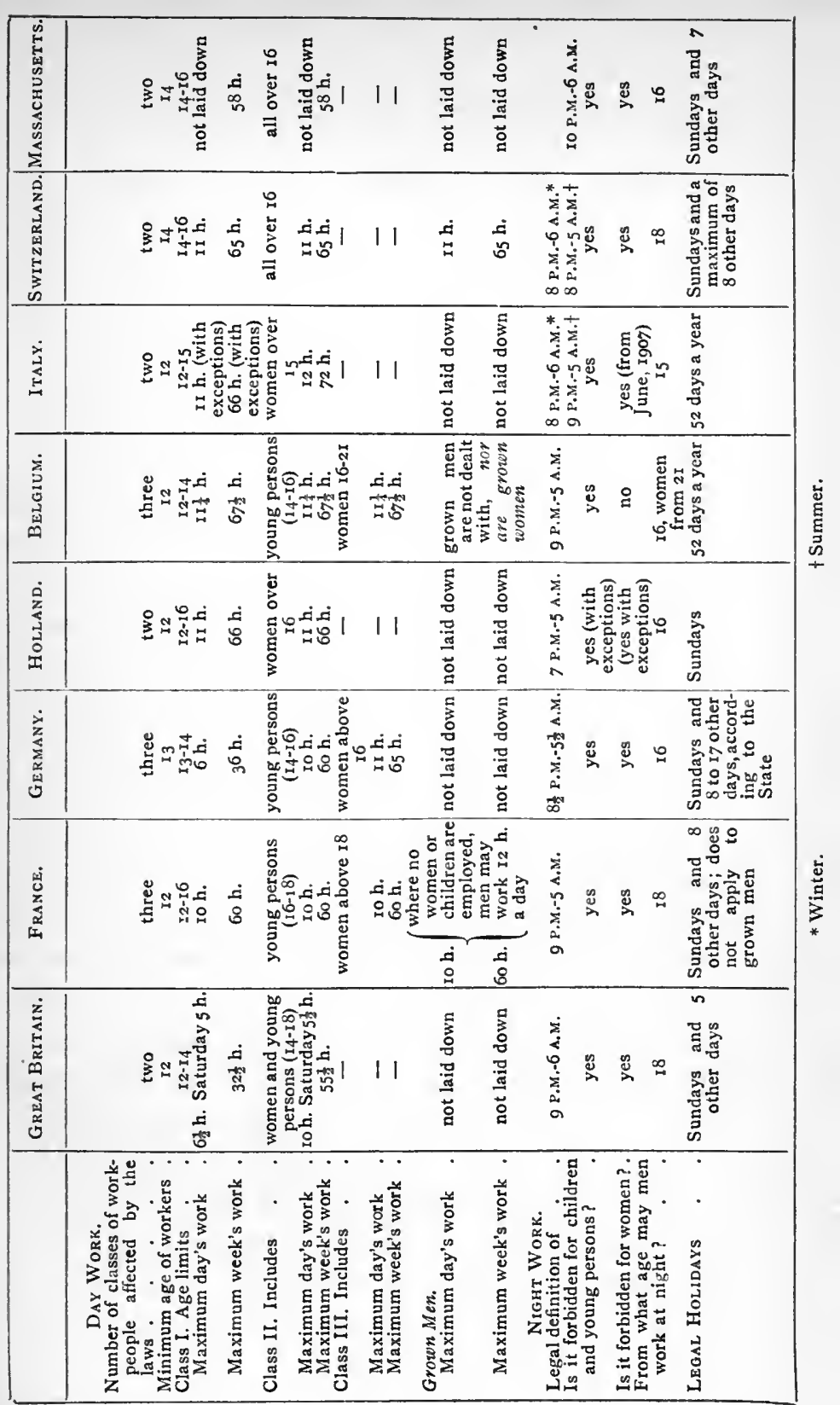




\section{CHAPTER VII}

\section{IMPORTS AND EXPORTS}

\section{REFORE the rise of the modern cotton}

industry, during the last thirty years of the eighteenth century, the export of wool manufactures was by far the most important branch of Great Britain's foreign trade. In I770 it was valued at $£ \mathrm{I}, 000,000$ out of a total export of some $£ 4,000,000$. This state of things came to an end during the years of the first great industrial revolution. Not that the wool industry declined-very far from it-but cotton grew with incredible rapidity and soon pushed its way to the place which it now holds at the head of the list of exports. Iron, steel and machinery followed hard after cotton, as the means of transporting bulky goods improved. In the second half of the nineteenth century came the vast extension of the export trade in coal. Meanwhile miscellaneous exports of every conceivable type were increasing in importance, as compared with the old staple commodities. As a result of these changes the export of wool manufactures 
has become a secondary branch of our oversea trade, although it has never lost its importance. At present these manufactures, including yarns and partially worked wool, make up from a twelfth to a fourteenth of the total exports of British and Irish produce. For example, in 1906 the total exports were worth $£ 375,000,000$, and the woollen and worsted exports $\ell_{3} 1,745,000$.

What proportion this figure of $\ell_{3} \mathrm{~J}, 745,000$ bears to the whole value of the woollen goods produced in the United Kingdom, no one as yet knows with certainty. It is clear enough that in the wool trades the home market, and in the cotton trade the foreign market, is the more important; but the relative importance in either case will remain a matter for estimation, or in other words intelligent guessing, until England has her census of production. An estimate that is probably not far from the truth makes the United Kingdom consume two-thirds and export one-third of the annual output of its woollen and worsted mills. But of course the proportions vary from year to year and have varied from decade to decade. It is fairly certain that, during the last five-and-twenty years, the home demand has increased in relative importance, owing to the growth of population and of spending power at home and of mills and tariffs abroad. For the total quantity of wool, mohair, rag wool and so. 


\section{WOOLLEN AND WORSTED INDUSTRIES}

on, annually used in the United Kingdom during the period I880-4 was just under $500,000,000$ lbs. ; from $\mathrm{r} 895$ to $\mathrm{r} 899$ it was $685,000,000$ lbs. ; from 1900 to $1904,659,000,000$ lbs.; in 1905 , $685,000,000$ once more. Meanwhile the number of yards of woollen and worsted exported had fallen, and the increased exports of ready-made clothing, yarns and tops had not been nearly great enough to absorb the huge balance of raw material. ${ }^{1}$ The bulk of this balance must have gone into the home market in the form of finished goods.

The difficulties of testing with perfect accuracy increases or decreases of exports are now well known. In some industries, such as coal and iron, quantities as well as values may easily be measured. For the textile industries figures of quantity are misleading, unless they are calculated with a nicety to which no customs house has yet attained. Before 1890 the quantity figures for piece goods were simply given in yards; since I 890 woollens are classed as light and heavy, and sub-classed as broad and narrow. Worsted coatings and trouserings are also divided into broad and narrow. Stuffs are still only returned in yards. Even with this improved classification

${ }^{1}$ See F. Hooper, Statistics of the Woollen and Worsted Trades, 1906; and a note by A. L. Bowley, Economic Journal, Dec., 1905 . 
a yard is rather a vague thing. It is known, for instance, that Bradford stuffs are generally wider than they used to be, so that a given number of yards will on an average contain more raw material and have involved more labour than they did, say, twenty years ago. The widening of the average yard of exports in part explains the fall in the actual number of yards already referred to. This fall is shown in the following table-based on calculations made by Mr. Bowley - which deals only with piece goods:-

\section{YARDS Exported ANNUAlly.}

I 865-9, 255 millions I890-4, 190 millions

$1870-4,324$," I895-9, I79 ",

$1875-9,253$ ", I900-4, I54 ", 1880-4, 244 ", I905-6, I79 ", I $885-6,246$ ",

For the purpose of the present chapter it is impossible to discuss all the statistical issues which are raised by the quantity figures of the Board of Trade. Moreover, for some classes of goods there are no quantity figures. The diagram of exports that faces page 276 has therefore been based on values. Separate curves show the course of trade during forty years in its three main lines-piece goods and other finished manufactures, ${ }^{1}$ yarns, tops and prepared wool generally.

1 This includes carpets, tapestry, hosiery of wool and miscellaneous manufactures. 
Besides showing the course of exports the diagram indicates, in broad outline, the fluctuations in the prices of raw materials. These raw material curves are of the greatest assistance in estimating the real significance of movements in the export trade. ${ }^{1}$ It will be seen, for example, that the abnormally high figures of I 87 I- 3 were to some extent the result of dear wool. The increase in the value of tops and yarns exported since I9OI is mainly, and the increase in the values of manufactures is partly, due to the same cause. On the other hand the state of the export trade from I 882 to I 890 was more satisfactory than the curve of manufactures taken alone would lead one to suppose; for while that curve shows an intermittent rise the raw material curves show a decided fall.

As is noted on the diagram, the export of readymade clothes has not been taken into account. If it had the manufactures curve would show a slight improvement in its later course. There is no question that the bulk of the clothing exported

1 They are not of course absolutely accurate. As was pointed out in the Introduction, there was relatively more clean wool imported twenty or thirty years ago than there is to-day. Clean wool being dearer than greasy wool, the actual fall in the price of wool generally was slightly less than the apparent fall shown in the diagram. But the curves register the broad movements in prices accurately enough. 

is either woollen or worsted; but we have no exact figures which distinguish clothing made of wool from that made of other materials, and therefore this branch of the trade has been omitted. Mr. Hooper of the Bradford Chamber of Commerce estimates that up to 1872 the value of the woollen clothing exported never reached $£ \mathrm{I}, 000,000 . \quad$ From $\mathrm{I} 872$ to $\mathrm{I} 879$ it averaged about $\mathcal{E} \mathrm{I}, 000,000$; in the eighties the average was $£ \mathrm{I}, 400,000 ;$ in the nineties nearly $£_{1}, 600,000$; from I 900 to I 905 just over $£ 2,000,000$. These figures are the nearest approach that we possess to an official valuation of this branch of the trade.

The diagram brings out very clearly the great importance of yarns and prepared wool and their increased relative importance since about the year I 886. Right through the period the yarn exports have been heavy. The staple articles are yarns of worsted, alpaca and mohair. Woollen yarns have never been shipped in great quantities from this country. Only once, during the fifty years covered by the diagram, has their value risen above $£ 500,000$ and it has fallen below $£$ I00,000 several times. Of late the annual exports of true worsted yarn have varied between $£ 3,400,000$ and $£ 5,000,000$, those of mohair and alpaca between $£ 1,500,000$ and $£ 2,000,000$. The total value of yarns exported towards the end of the period is seen 


\section{WOOLLEN AND WORSTED INDUSTRIES}

to have been frequently greater than it was in the fat years of the early seventies, when wool was considerably dearer than it is to-day. This implies an export trade of much greater bulk than that of I 87 I-5. In fact the average weight of yarns exported in those five years was $40,100,000 \mathrm{lbs}$. as compared with $74,600,000$ for the five years I 902-6.

There are special points of interest connected with the prepared wool trade. Until some twentyfive years ago it was of no importance, a few hundred thousand pounds' worth of rag wool and flocks being the chief item. About I 886 the rapid growth of the trade in tops and noils began to make itself felt; but figures by which that growth could be tested were not available before 1890 . Then it appeared that about $£ 600,000$ worth of each of these products of the combing mills had left our ports in the year. During the last sixteen years the export of noils has grown but little, either in value or quantity. The highest value figure is $\mathbb{Z}_{809,000}$ in 1906 , the highest quantity figure I $3,756,000$ lbs. in I 885 . The corresponding figures for tops, on the other hand, are $£_{3}, 095$, 000 in 1906 and 42,513,000 lbs. in 1903. Even in years of cheap wool, the export of tops is now a great business, and at the present high level of wool prices it bulks very large indeed.

From some points of view, however, it is not 
satisfactory. It. means, at any rate in certain cases, that foreign nations, who perhaps once bought from us yarn or even manufactures, are now themselves in a position to spin, leaving to us only the work of combing. Germany is the chief buyer, and we have seen that Germany is determined to render herself independent of supplies of English yarn-if she can. It is true that her increased takings of tops have not as yet been accompanied by any shrinkage in the German yarn trade; but it is clearly possible that such a shrinkage may in time set in. On the other hand, so long as foreign manufacturing nations buy any wool-whether British or colonial-in this country, there is always a considerable probability that they may prefer to buy it already combed.

A stiff tariff on tops, such as the United States now levy, would be the only effectual means of killing the trade. There is of course no guarantee that the buying nations will refrain indefinitely from imposing such a tariff. At present tops are on the free list in Germany. Sweden, Belgium and Japan, all considerable buyers, also admit them free. Italy, who in recent years has been the greatest buyer after Germany, levies a duty amounting to about twothirds of a penny per lb., not a very serious obstacle to trade at the existing high level of prices; for the average value of the tops ex- 
ported in 1906 was nearly 20d. per lb. Russia has at times been an excellent customer, in spite of a duty that works out at nearly $5 \mathrm{~d}$. a $\mathrm{lb}$. The fact that France is only a small buyer is to be explained more by the excellence of her own combing mills than by her duty of Ios. $2 \mathrm{~d}$. a cwt.

Within the Empire, Canada is the only important purchaser of combed or carded wool. She is a new customer and hitherto her purchases have not been heavy; but for the three years I 903-5 they averaged over $£ 40$,000. All other British possessions put together spend less than $£ 2000$ with the English top makers. It should be added that Canada levies a small duty on tops. Indeed she taxes all Lincoln, Leicester and other combing wools, whether combed or not.

The destinations of the yarn exports do not differ widely from those of the exports of tops and prepared wool. These forty years and more Germany has been the principal purchaser. Some account of her yarn buyings was given in the last chapter. It only remains to examine the trade from the English side and to refer to the tariffs that affect it. Originally the staple export was worsted yarn made of English lustre wool. To this were added yarns of alpaca and mohair. Latterly large quantities of combed 
yarn spun from the coarser cross-bred wools and other yarns not quite of the lustre type, have been shipped on German account. So the old contention that the trade was based on a natural division of labour, by which England span and sold yarns from the lustre wool which she alone could raise, no longer holds good. German advocates of an increased duty point to these facts in support of their demands, arguing that Germany is now as well fitted by nature as Great Britain for the production of most of these yarns, and that only a little more protection is required to make her self-sufficing.

The new German tariff of 1903 gave some encouragement to this party. Many of the yarn duties were unaltered ; those on alpaca and mohair were actually reduced; but those on the ordinary "hard combed yarn of lustrous wool, over twenty centimetres in length" - to quote the tariff schedule-were slightly raised. Yet even the raised duties are very moderate. Single unbleached yarns pay Is. $9 \frac{1}{4} \mathrm{~d}$. per cwt., double or treble yarns 2s. o $\frac{1}{2} \mathrm{~d}$. When the yarns are bleached, dyed or printed the rates are 3 s. $0 \frac{1}{2} \mathrm{~d}$. and 7 s. $I \frac{1}{2} \mathrm{~d}$. respectively. These charges work out at from about one-fifth of a penny to four-fifths of a penny per lb., whereas the average value of the yarns sent to Germany in 1903-a year of moderate wool prices-was about $16 \mathrm{~d}$. and in 1906 nearly 
23d. per lb. The rates on alpaca and mohair are lower still.

So far there have been no signs of a check in the German demand for worsted. In the case of alpaca and mohair no check was to be expected. For the three years 1904-6 Germany took just over two-thirds of all the worsted yarn exported, reckoned by weight. Her proportion of the alpaca and mohair was as nearly as possible the same- $-30,000,000$ out of $44,000,000$ lbs. The values of course ran up very high, owing to the rise in wool prices, so that in 1906 Germany owed this country all but $£ 5,000,000$ for yarns.

Those yarns which Germany does not take go all over the world, so far as tariffs will permit. France has an exceedingly complicated tariff schedule, under which the yarns are taxed in proportion to their fineness, dyed paying more than undyed and twisted yarns more than single. The very lowest duty on combed yarns is I Is. $5 \mathrm{~d}$. per cwt. ; from that level the duties run up to upwards of $£ 2$. In spite of this she buys alpaca and mohair freely, her purchases at present amounting to about a quarter of the quantity taken by Germany. This leaves but little alpaca and mohair over for all other nations. Worsted yarns she buys sparingly, rarely taking more than $£$ i 50,000 to $£ 200,000$ worth of special qualities that she cannot easily produce herself. Russia 
in normal times buys a good deal more than this, in spite of duties ranging from $\ell_{4} 3 \mathrm{~s}$. 9d. to $E_{5}$ i 2s. 4d. per cwt. The Scandinavians, the Dutch and the Belgians all do some trade with us; but we have no other foreign customers of importance. The United States has extinguished the trade very effectually by means of a characteristic minimum duty of $27 \frac{1}{2}$ cents a pound and 40 per cent. ad valorem. 'This applies to all yarns valued at not more than 30 cents a pound. Further details are unnecessary.

The Canadian yarn duties do not approach the exaggerated imposts of the United States, but they are fairly stiff nevertheless. Under the latest revision of the tariff, certain classes of yarn imported by braid, cord and hosiery manufacturers, together with alpaca and mohair yarns, are admitted free. Most other yarns pay either 20 or 30 per cent.; but when British spun the rates are reduced to $\mathrm{I} 2 \frac{1}{2}$ and 20 per cent. respectively. As yet Canada is not a large buyer, but her purchases have increased rapidly since I 899 and are now of some importance. Besides importing English worsted to the value of from $£$ I 00,000 to EI 50,000 she is one of the few countries that takes any appreciable quantity of woollen yarns from this country. She buys from the States and the Continent as well as from England; but the bulk of the trade is with us. 
Small quantities of yarn are exported to Australia, New Zealand and other British dominions beyond the seas. There is, however, no need to trace all the minor channels of the trade, or to call attention to the duties by which those channels are impeded.

There are no broad, simple features in the distribution of the finished manufactures, no country or group of countries which holds a place at all resembling that of Germany in relation to the yarn trade, or of India in relation to the trade in cotton cloth. Literally every country on the face of the earth-every country at least which possesses trade statistics-is a customer of ours. Nearly all buy piece goods; one or two are satisfied with ready-made clothes. Korea used to belong to this latter class; so did Siam; but both may have left it in the last three years. Of these innumerable purchasers, the majority buy in relatively small quantities. Take, for example, the year I905. The total exports of wool manufactures were valued at $£ \mathrm{I} 9,600,000$. Only one country, the Dominion of Canada, took more than $£ 2,000,000$ worth. Two others spent more than $\mathcal{E}_{1,500,000}$ but less than $£ 2,000,000$. They were the United States and Australia. Five more came between $\mathcal{E}_{\mathrm{I}, 500,000}$ and $\mathscr{E}_{\mathrm{I}, 000,000}$ - Germany, Belgium, ${ }^{1}$ France, China and Japan.

${ }^{1}$ It is often stated that a great part of the goods shipped to Belgium eventually go to Germany. This may be so in 
Next in order of importance were the Argentine Republic and the British East Indies. Then British South Africa. Some way behind her, Turkey. Below that Holland and New Zealand -these two between $£ 400,000$ and $£ 500,000$. And so on and so forth. It is a complex trade -a trade which is always being forced to compensate itself for partial or total loss of markets in one direction by energetic opening out of markets in another. How dependent it is upon the young and rising nations the catalogue just quoted shows clearly enough. But it also shows that a good business is still done even with our full-grown and protectionist neighbours.

The most dramatic vicissitudes of the last sixteen years have occurred in the trade with the United States. In I 890 the exports of manufactures to the States amounted to $£ 5$, I 48, ooo. Of these, by far the greater part were worsteds - Huddersfield and Bradford goods. Then came the $\mathrm{M}$ 'Kinley Tariff, and next year the exports stood at $£_{3}, 178$, ooo. This precipitate fall was not all due to the new duties. Heavy consignments had been hurried into the country in I 890 before the tariff came into operation, as is

the long run; but the figures showing the countries of consignment, as well as the countries of immediate destination, first published for the year 1904, make it clear that most of the goods now sent to Belgium are sent on Belgian account. 
always the case under such circumstances ; moreover, the price of wool was falling, and trade in general was slackening. Yet the tariff was responsible for much, very much. It fell on the worsted manufacturers with crushing force; for the $\mathrm{M}$ 'Kinley Act was framed with a special view to the trade in stuffs and worsted coatings, goods which had never hitherto been produced with much success in the United States. The shock to Bradford was so great that prophets of evil talked of the impossibility of her ever recovering. But recovery soon set in. Even the trade with America expanded once more under the more favourable Wilson Tariff of 1894 . In I 897 came the Dingley Bill, a reversion to the policy of 1890 , and once more there was a calamitous fall in the exports of worsted-a fall of upwards of $£ \mathrm{r}, 000,000$. There has been recovery again in the new century. Since 1903 the export of worsteds of all sorts to the States has averaged just over $£ \mathrm{I}, 000,000$ a year, and the exports of worsteds and woollens together have latterly exceeded $£ \mathrm{I}, 500,000$; but there is no prospect that the figures of 1890 will ever again be approached, for the Americans are rapidly learning to make their own worsteds, although for the finest qualities they must still come to England or to France. Under the existing tariff woollen or worsted cloths pay duties 
that vary from Is. $4 \frac{1}{2} \mathrm{~d}$. per lb. and 50 per cent. ad valorem to is. Iod. per $\mathrm{lb}$. and 55 per cent. ad valorem. Flannels and blankets are admitted rather more easily. Dress goods and the like pay from $3 \frac{1}{2} \mathrm{~d}$. per square yard and 50 per cent. ad valorem upwards; and any such materials that weigh more than four ounces to the square yard pay duty as cloths. This is the tariff through which $£ \mathrm{I}, 000,000$ worth of worsteds break their way yearly. It is no small achievement.

The export trade in finished goods to France sprang into life with the Cobden Treaty of 1860 , and grew in satisfactory fashion during the next decade. After the war of I870-I it expanded in the Free Trade air of the seventies. In 1880 , a year of but moderate commercial activity, it was still over $£ 3,000,000$. There was no serious decline in the eighties, for the French tariff of I88 I was not highly protective. For the three years $1890-2$, a time of cheap raw material, the annual value stood at $£ 2,540,000$, in spite of the fact that in 1892 the Méline Tariff raised the rates on all textiles. Subsequently, however, the increased duties began to tell. In combination with a slight fall in the price of wool, and-it may be - some influences from the South African war, they reduced the annual average to $£ \mathrm{r}, 440,000$ for 1900-2. There was a further slight fall to $£ 1,340,000$ in $1903-5$, due almost entirely to 
a decline in the export of worsteds during the two latter years. Considerably more than half the present export consists of woollens, the preponderance of woollens having increased during the dear wool years since I903-years which have, to a certain extent, been unfavourable to the worsted manufacture.

It is impossible to summarise accurately the history of the German trade, owing to the difficulties already referred to in connection with the shipping of goods viâ Dutch and Belgian ports. The direct exports of manufactures to Germany, like those to France, were at their maximum in the early seventies, when they reached $£ 5,000,000$ and upwards. With the late seventies came trade depression and tariffs, accompanied and followed by the great extension and improvement of the German manufacturing industry. Already in 1880 the direct trade had dwindled to a little over $£ \mathrm{I}, 200,000$, and there was no recovery in the following decade. Between I 890 and 1904 both the direct trade and the total trade with Germany, Belgium and Hollandwhich it is convenient for some purposes to treat as a single item in our exports - remained remarkably stationary in value. During the period I 890-2 the former stood at $£ 866,000$ per annum, and the latter at $£ 2,367,000$ per annum. For the years 1902-4 the corresponding figures were 
$£ 897,000$ and $£ 2,229,000$. In 1905 the direct trade rose above $£ \mathrm{I}, \infty 00,000$, and the total rose to $£ 2,603,000$. These increases seem to have been more than maintained in 1906.

To trace the history of each of the numberless sections of the export trade would be tedious and unprofitable. It is enough to mention here that the foreign markets whose recent histories have been most satisfactory, from the point of view of the British manufacturer and merchant, are the Japanese, the Chinese and the Argentine. Some further reference to the colonial markets is however necessary. With Canada there has been a considerable trade for a generation and more. It amounted to just about $£ \mathrm{I}, 000,000$ in 1870 and to over $£ \mathrm{I}, 000,000$ in $\mathrm{I} 880$, while wool was still rather dear. In I890-2, when wool prices had fallen far below the level of the seventies, it had grown to $£ 1,315,000$. Five years later the preferential tariff came to help the British exporter against his foreign competitor, though it by no means threw the Canadian market open to him. The tariff for most classes of finished goods was fixed at 35 per cent., ad valorem, with a reduction of a third on Britishmade goods. There was not a very rapid expansion of trade with this country immediately after the introduction of the preferential system. But if not rapid the extension was steady enough 
to rob the system of some of its popularity. Whether it was caused by the preference rather than by the increase of Canadian demand, due to a rapidly growing population, is a question too delicate for off-hand solution. Our annual average export to Canada for I900-2 was $£$ I,618,000; for 1903-5 it stood at $£ 2,287,000$. The sharp rise after 1902 led to complaints from the Canadian mill-owners and a raising of the rate on the most important classes of British goods to 30 per cent. instead of $23 \frac{1}{2}$ per cent. Finally the tariff resolutions of November, 1906, introduced an intricate system of parallel tariffs, the preferential, the intermediate, and the general. The intermediate is intended for friends who treat Canadian produce with consideration, the preferential is for blood relations, the general for the world at large. The chief British exports-tweeds, coatings, woollen cloths and so on-are still to pay 30 per cent., the general tariff on the same classes of goods being 35 per cent. British flannels, blankets, hosiery, "Italian linings," alpacas and mohairs pay $22 \frac{1}{2}$ per cent. ; carpets, 25 per cent. ; undyed or unfinished dress goods and the like, I $7 \frac{1}{2}$ per cent. In all these cases except the last the general tariff is again 35 per cent.

The trade with Canada has to face the competition of an important local manufacturing in- 
dustry, tha with Australia has not. But owing to the slow growth of Australia's population, her many economic vicissitudes and a little foreign competition, ${ }^{1}$ this branch of the export trade is somewhat stunted, though strong. It was rather larger than the Canadian branch in the early seventies and again in the early eighties. For the years $1890-2$ the annual average stood at $£ \mathrm{I}, 549,000$; for $1900-2$ at $£ \mathrm{I}, 768,000$; for 1903-5 at $£ \mathrm{r}, 545,000$. The year 1903, the last of the drought, proved a particularly bad one in the Australian trade, as might have been expected. Seeing that the Commonwealth has now almost recovered from the effects of the drought, the quickened growth of 1904-6 may be expected to continue.

All the remaining colonial markets except the West Indies, have been markedly better outlets for British manufactures in the opening years of the twentieth century than they were at the beginning of the previous decade or at any earlier date. Of foreign countries, some as we have seen have fallen off while others have improved. During the three years 1903-5, out of an average annual export of finished goods valued at $£$ i $7,828,000, £ 6,393,000$ worth-or rather more than a third-went to markets within

${ }^{1}$ Foreign competition is, however, keener in Canada than in Australia. 
the Empire. The ratio of Irn sales had never been quite so high wefore. Oddly enough it coincided almost exactly with the ratio between the total Imperial and the total foreign exports of all classes of British and Irish produce, a ratio which, as is well known, has altered surprisingly little for a long series of years. In the case of wool manufactures, however, there seems at least a prospect, one cannot say more, that the Imperial trade will assume greater relative as well as absolute proportions in the near future. The yarn trade, as we have seen, has not yet entered the Imperial phase.

Before turning from exports to imports it is interesting to compare the export trade of the United Kingdom with those of her two greatest rivals, France and Germany. Such a comparison is made in the diagram opposite. The notes on the diagram itself explain the principles upon which it has been constructed. It would be interesting, were it possible, to trace the fluctuations over a much longer period; but statistical difficulties - which need not be explained here stand in the way. Although it only deals with a relatively short period, the diagram brings out a number of interesting points. Much the most interesting is the similarity of the curves for the three countries and the extraordinary similarity of the French and English curves up to 1902. 


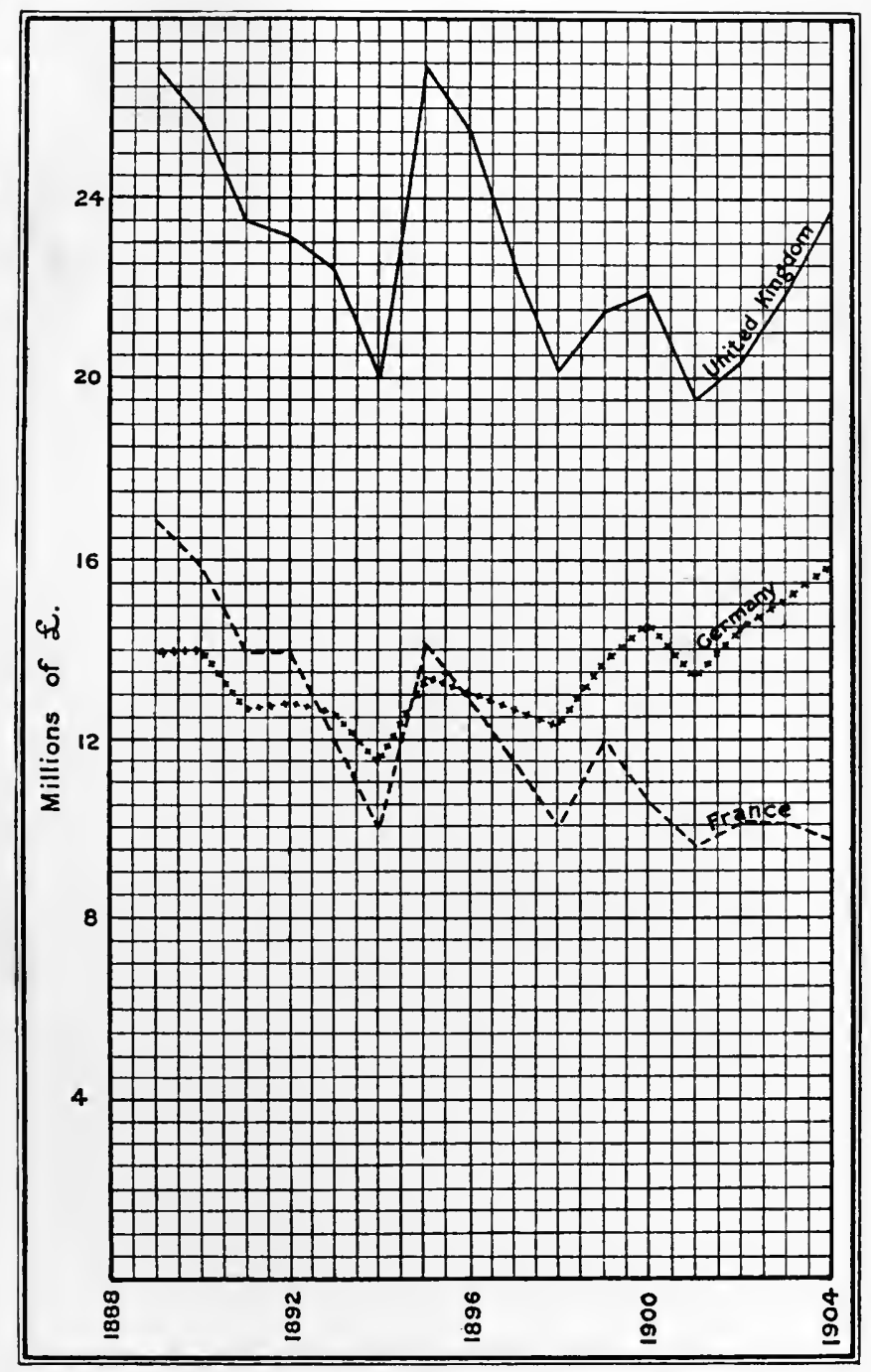

EXPORTS OF YARNS AND MANUFACTURES FROM THE UNITEN KINGDOM, FRANCE AND GERMANY, 1889-1904

Note.-The figures cover yarns, woollen and worsteds, hosiery, carpets, etc., but not tops, etc., or ready made clothing. Francs have been translated into pounds at 25 and marks at 20 to the $\delta \mathrm{x}$. An exact iranslation would slightly reduce the total value of both French and (ierman trade, reckoned in pounds, but to an extent which would hardly be noticeable on the diagram. 

All three are, of course, subject to certain influences in common-fluctuations in the world prices of raw materials, expansions and contractions of the whole volume of international commerce, and decisive fiscal or other changes in important markets with which all deal. The M'Kinley, Wilson, and Dingley Tariffs, for instance, have left their marks on all. Those marks are deepest on the English and French curves, because France and England are specially interested in the worsted trade, which was the chief target for the American tariff-makers in the nineties. The almost absolute coincidence of years of maximum and minimum exports for the three countries, during the period covered by the diagram, is a conclusive proof-if proof were needed - that in matters of foreign trade one country's prosperity is not another's adversity.

France's failure to recover her position at the close of the period, at a time when German and English trade were both on the up-grade, is not altogether easy to explain. It is in part connected with her rather dangerous dependence on a single market, the market of this country, to which she sends from a half to two-thirds of all her goods. Should the demand of this single market contract or not expand satisfactorily, the effect on total exports is very conspicuous; whereas in the case of England, with her long 


\section{WOOLLEN AND WORSTED INDUSTRIES}

list of important customers, failure in one quarter can be balanced by successes elsewhere.

Of the three curves the German is certainly the best and the French the worst. The former, in spite of vicissitudes, shows a general upward trend, the latter a trend downwards. ${ }^{1}$ The English curve occupies an intermediate position; its slight decline is accompanied by great recuperative power. A comparison with the diagram facing page 276 will show that, if the figures had been brought up to date, the recovery registered would have been complete, partly as a consequence of dearer raw material. But that is a circumstance which affects all parties alike. It might be pointed out in this connection that the yarn element is of course greater in the English curve. Germany and France are, however, both considerable yarn exporters. Taking the five years I900-4, it appears that, in the case of the United Kingdom, the value of the yarns was 26.6 per cent. of the total value of the exports with which the diagram deals. For Germany the percentage, reckoned on the same basis, was 20.4 per cent., and for France I 2.4 per cent. This shows that our dependence on the yarn

${ }^{1}$ In 1905 England and Germany rose again, France fell again. But as figures strictly comparable with those for the earlier years were not available at the time of writing, this year was not included in the diagram. 
trade is not so exceptional as is sometimes supposed. Germany at any rate is in much the same position as ourselves.

That Germany has on the whole the most satisfactory record of the three great exporting nations is in no way surprising. During the period under review her population was growing faster than that of the United Kingdom and very much faster than that of France. But far more important than this is the fact that only since the seventies has she succeeded in establishing a manufacturing industry, so organised and equipped as to be able to compete successfully with the older industries of England and France.

On the effect of a nation's fiscal policy upon its own exports the diagram throws but little direct light. France, although free to retaliate and bargain with tariffs, has not managed to force her goods upon other protectionist nations, who have shown an increasing disinclination to take them. In Germany protection is associated with rising, in France with falling, exports. If any fiscal moral were to be extracted from the facts, it might run somewhat as follows: that at times of fiscal controversy there is a tendency to exaggerate the importance of Government action, both positive and negative, and to underrate the effects of those deep-working economic forces over which Acts of Parliament have but a limited 
and an indirect control. That this is a moral distasteful to the controversialist cannot be helped.

The total imports of woollen and worsted yarns and manufactures into the United Kingdom, for the forty years covered by the export diagram, are shown in the curve facing this page.

A comparison between the two is interesting. There are naturally no great jolts and jerks in the course of the imports, for neither wars nor tariffs have impeded it. From I 866 to 1889 there was a very steady upward movement, with one marked irregularity in 1880 and a second, less marked, in I886. Since 1889 there has been astonishingly little variation throughout a period of eighteen years. Reference to the wool prices facing page 276 shows that this stagnation in the value of imports cannot be explained by any marked fall in the cost of raw material. There was a fall, on the whole, up to 1902 ; but it was slight, and even the swollen wool prices of the last few years have not had that stimulating effect on the value of the imports, which is so conspicuous in the case of the exports. Indeed it is clear at a glance that the imports of the years 1904-6 were at least as low as those of any other triennial period since 1893 . There is thus no sort of evidence to support the belief that the close of the nineteenth and the opening of the twentieth centuries witnessed a disastrous "in- 


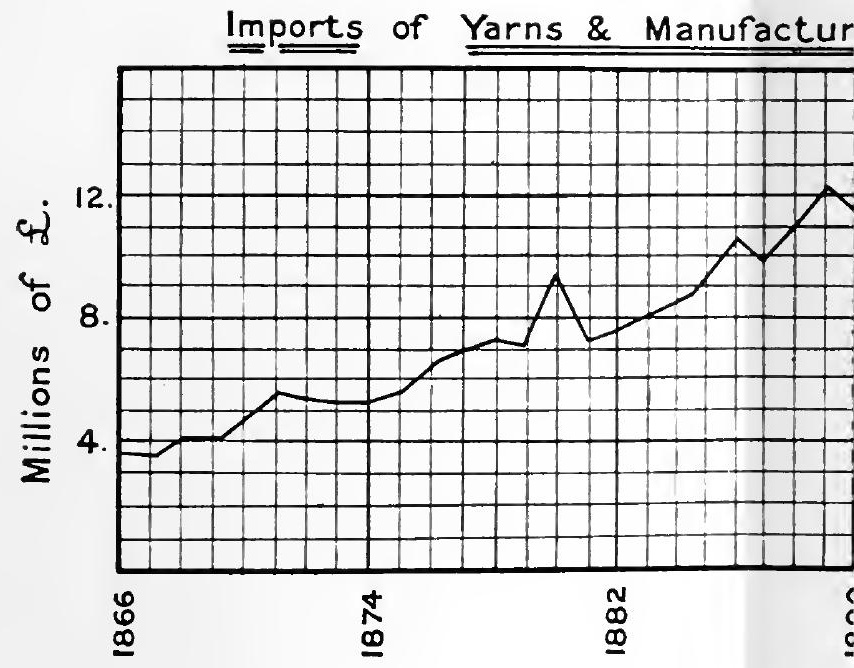





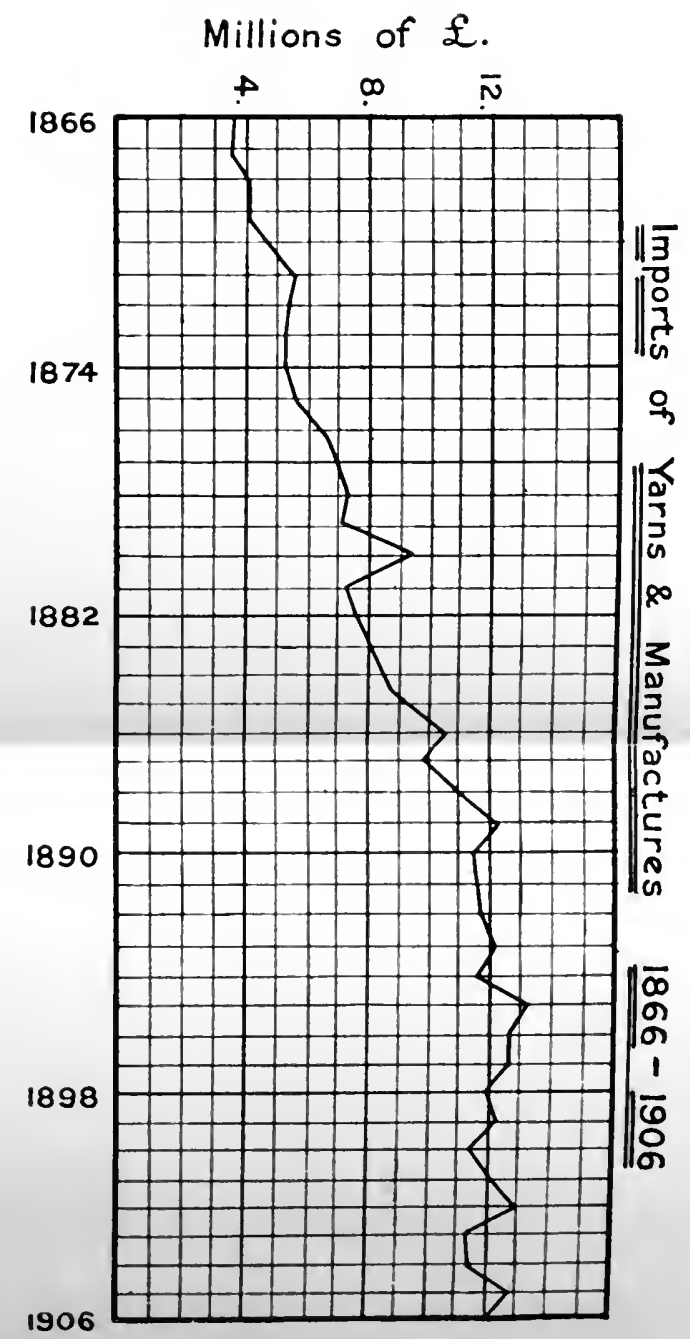



vasion" of our market from abroad. For eighteen years at least all the increase in the home consumption of wool textiles must have been met by the produce of the home mills. And during those eighteen years the national income -in the economist's not the statesman's senseincreased by something between a quarter and a third, carrying with it a proportionate increase of purchasing power throughout the country.

Before these import figures are further analysed, one modification or correction of them should be made. They cover each year a considerable quantity of goods which are not consumed in this country but are re-exported by English merchants. This re-export trade fluctuates a good deal. Before 1880 it was comparatively insignificant. Except in one single year-187 I -it never rose above $\mathcal{E}_{3-400,000}$. A short table of quinquennial averages will best illustrate its movement since that date :-

$\begin{array}{llll}\text { 1880-4, } & £ 552,000 & 1895-9, & £ 762,000 \\ \text { 1 885-9, } & £ 611,000 & 1900-4, & £ 883,000 \\ \text { 1890-4, } & £ 1,208,000 & 1905-6, & £ 1,098,000\end{array}$

The period I $890-4$ is seen to have been one of abnormally high re-exports. In 1890 the figure reached a million and a half, the highest of any year on record. It remained over a million during the three following years, but never touched that figure again till I 905. For certain statistical 
purposes it might be well to subtract these reexports from the imports, so securing a "net" import. This operation would slightly increase the fluctuations in the import curve; it would also somewhat lower the general level of the curve since I880, as compared with the sixties and seventies, thus showing the rise in the imports for domestic consumption to have been even more gradual than the rise in total imports. But although these re-exports do not enter into competition with British goods in the home market, they do, or at least may, compete with British exports, and therefore it seems better on the whole not to construct a "net" import curve which would ignore their existence altogether. A brisk re-export trade indicates a pressing need of some sort for foreign-made goods, in markets served by English merchants; and it is relatively immaterial that those markets happen also to be foreign.

The present sources of our imported yarns were described in Chapter VI. More than a half of those yarns are Belgian. In 1905, out of a total yarn import of $£ 2,697,000$, Belgium was credited with $£ \mathrm{I}, 579,000$; France came next with $£ 679,000$; then Germany with $£ 4$ I4,000. No other country sent any appreciable quantity. Both the weight and the value of the yarns imported in 1905, and again in 1906, 
were greater than they had ever been before; but the development of the trade has been very gradual indeed. So long ago as 1863 the imports were already over $£ \mathrm{I}, 000,000$. In the late sixties they were about $\mathscr{E} \mathrm{I}, 500,000$. Since $\mathrm{I} 883$ they have seldom fallen much below $£ 2,000,000$. The annual fluctuations do not merit a more careful examination.

Officially the imports are now nearly all classed as weaving yarns, though the knitting machines use them as well as the looms. The imports of yarn for hand-knitting and wool-work were considerable for some twenty years, say, I878-98. Those were the palmy days of the true Berlin woolshop. The trade has now dwindled to about a third of its former size. It is not worth more than $£ 70,000$ to $£ 80,000$ a year, and its place has been taken, so far as Germany is concerned, by the export of weaving yarns. $U p$ to 1890 , Belgium and France supplied us with almost all the mule-spun worsted and foreign woollen yarn that we required. In the early nineties Germany was sending over some $£ \mathrm{I} 80$,000 worth of the "Berlin" class of yarns and only $£ 60,000$ to $£ 70,000$ worth of weaving yarn. Since 1900 her exports of weaving yarn to us have never fallen below $£ 300,000$ and have once risen above $£ 470,000$. Occasionally she has run France close for the second place, and it is likely 
enough that she will outstrip her in the near future.

In the matter of finished goods France still holds her own. It is from her that we have always drawn the bulk of our imports. Her share of the trade fluctuates of course, but roughly speaking it forms two-thirds, or nearly two-thirds of the whole. Its character has for many years been very much what it now is-immense consignments of stuffs of every grade, the finest and most workmanlike, the flimsiest and most specious, all attractive and many beautifully dyed and finished; no cloths worth mentioning; and a list of miscellaneous fabrics, sometimes long and sometimes short, including carpets, shawls, furniture materials, tapestries, damasks and what not. The trade ebbs and flows with the ebb and flow of fashion; but France who makes so many of the fashions can generally profit by them, although at times their movements get beyond her control.

It is not possible to apportion exactly the remainder of the trade among the nations, over any long period, owing to statistical difficulties caused by the import of German, Austrian, Swiss and other goods through Belgium and Holland and France. The official return of the actual as distinguished from the apparent sources of supply for the year 1904, published 
in 1906 , enables us for the first time to measure with some accuracy the importance of certain sections of the trade, whose existence was well known to business men, but whose size was not known to any one. What follows is necessarily based on the figures of this single year and must be valued accordingly. It should be borne in mind too that in 1904 the manufactures imported were worth less than they had been in any year since 1888, except 1903. Yet no doubt the figures give a good, rough, general impression of the present state of trade.

The total is $£ 9,076,000$. The subdivisions, to the nearest thousand, are-cloths, $£ 634,000$; stuffs, $£ 5,64 \mathrm{r}, 000$; flannels, $£ \mathrm{r} 3,000$; hosiery, $£ 307,000$; carpets and rugs, $£_{46}, 000$; mohair braids and laces, $\ell_{102,000 ;}$ and unenumerated manufactures, $E_{1}, 910,000$. Of the stuffs $£ 4,922,000$ were consigned from France and $£_{514,000}$ from Germany. Four-fifths of the German goods and about $£ 75$,000 worth of the French were shipped from Belgian and Dutch ports. Third in the list of exporters of stuffs came Switzerland with $£$ I 24,000. This is an interesting trade, the existence of which was first officially revealed in the 1906 return. Possibly some of the Swiss stuffs were really English made; for cases have been known in which goods were sent all the way from Yorkshire to Switzer- 
land to be dyed-a curious instance of international division of labour.

The other foreign countries from which stuffs were consigned were, in the order named, Belgium $\left(\AA_{4} 6,000\right)$, Austria-Hungary, Holland and Italy $(£ 4000)$. British possessions sent $£$ I45 worth. One would like to know what part of the Empire was responsible for this lonely figure; but that is not revealed.

The cloths were mainly German $(£ 455,000)$

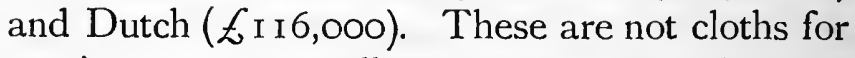
men's wear, generally speaking, but what are known as mantle cloths, bought by wholesale clothiers to be turned into women's golf capes, and so forth. Belgium sent $£ 34$, 000 worth of cloth, probably of the same class as that from Holland and Germany. Lastly, Austria-Hungary was credited with $£ 30,000$. This sum represents, in part at any rate, fine cloth from Brünn in Moravia, that competes with the goods from the West of England mills. France ends the list with $£ 2000$.

The mohair braids and laces are practically all Belgian, the flannel is all German, and so are five-sixths of the woollen hosiery. Switzerland is the second hosiery exporter $\left(£_{4} \mathrm{I}, 000\right)$, and France the third ( $£ 9000)$. Just half the carpets are from the Turkish Empire and Persia, as one would expect. Nearly a fifth $(£ 90,000)$ are from 
British India. The only exporters of importance in the West are Germany $(£ 60,000)$, France $(£ 37, \infty 00)$, and Austria-Hungary $(£$ I 2,000$)$. The United States appears under this heading, but her $£ 4000$ worth of rugs could hardly raise the bogey of an American Invasion.

The unenumerated manufactures are-Ger-

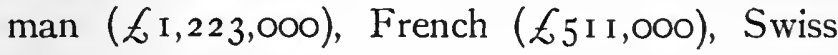
( $£ 61,000)$, Belgian $(£ 47,000)$, Austrian $(£ 32,000)$, Dutch $\left(£_{25}, 000\right)$, American $(£ 4000)$, and Danish, with $£$ iooo worth from British possessions. Fortunately the export figures from Germany enable us to break up her immense share into some of its component parts. There were over $£ 200,000$ worth of fringes and trimmings, over $£ 100,000$ of feltings, some furniture plushes, embroideries, shawls and mixed fabrics of worsted and silk. What else there may have been only the merchants know. Such are the imports. Except for the French stuffs they are a motley crew. No wonder that there is perpetual striving and inquiry in Bradford after the best methods of meeting and overcoming French competition; for if the French were once beaten out of the field there would be little left to conquer. We have seen that the home manufacture has held its own well of late years in the home market, and that pessimistic statements to the contrary are not borne out by the facts. But 
304 WOOLLEN AND WORSTED INDUSTRIES

greater familiarity with French methods of manufacture and more of the French artistic spirit are still to be desired. The first need can be met by education, scientific inquiry and perseverance. Unfortunately, there is more difficulty about the acquisition of so intangible a thing as the French spirit. 


\section{INDEX}

AlpaCA, I00, I15, II7, I21, I38, Distribution of industries, I2 sqq. $I_{42}, 280,282$.

Argentine wools, 78, 82, $8 \mathrm{~g}$.

Auctions-

Australian, 94 -98, ro2.

Dewsbury (rag), 124.

Liverpool, 99-Ior.

Local, ro7, ro8.

London, 90-94, 98-102.

Australian wools, $79,80,84,87-$ 90, 92-95.

BackWashing machine, 39 .

Bradford Chamber of Commerce, I 5 , I55, I $_{5}^{8}$.

Bradford Conditioning House, 158.

Bradford Dyers' Association, I5 I, I54.

Bradford Piece Dyeing Board, r55, 156.

Burr extraction, 32, 33 .

Carding, 33-36, 38, 39, I34, I35.

Camel's hair, roo, II 8 , I88.

Cashmere, I00, II8.

Cheviot sheep, 83, 105.

Combers' combinations, 157 .

Combing, 40-47, 130, 136, 137, I4I.

Combing mills, $136-38$.

Combs-

Heilmann, 4r.

Holden, 4I, 43, 45, 46.

Lister, 4I, 43-45.

Noble, 4r-43, 45 .

Commission firms, I30, $_{3} 37, \mathrm{I}_{3} 8$.

Condensing, 35 .

Consumption of wool, ro.

Cotswold sheep, 86, I04.

Drawing, 47-49.

Dyeing, 57, I28, I35, I36, I 50-52,

x54.

Dyeing combinations, I54.

EASTERN wools, roo, ror.

Employment statistics--

Great Britain, 5, 7, 132, r39, r74-8r sqq.

France, 223.

Germany, 242.

New Zealand, 267.

United States, 252.

English wools, 102-104, I06-108, 138.

Export trade-

Great Britain, 272-77, 284 sqq., 292.

Piece goods, $167-70,284 s q q$.

Yarns, I6r, 277 sqq., 294.

Tops, etc., 278.

To Australia, $29 x$.

To Canada, 289, 290.

To France, 287, 288.

To Germany, 288, 289.

To United States, 285,287 .

Canadian, 265.

French, 233, 292, 296.

German, 292, 296.

Comparison of export trade of Great Britain, France and Germany, 292-96.

FACtories, 129 sqq., I4I, I46, I47.

Factory laws, table of, $27 x$.

Fellmongery, I I6, I I 7, 234, 235.

Finishing processes, 70-75, I50, I5I.

Fulling, 70 sqq. 


\section{WOOLLEN AND WORSTED INDUSTRIES}

HAND looms, 58, 63, 67, I28, 129.

Hand looms (France), 226-28.

Hand looms (Germany), 243.

Hand mules, 135 .

Healding, 6r sqq.

Health of workers, $187 s q q$.

\section{IMPORT trade-}

General statistics, Great Britain, 296, 30I-4.

From Belgium, 298, 299, 301.

From France, 298-30r.

From Germany, 298, 299, 301.

Piece goods, 300 sqq.

Yarns, 298, 299.

Canadian, 265, 266.

German, 249, 280-82.

Italian, 26o.

Russian, 262.

Industrial organisation abroad, 221.

America, 251 sqq.

Argentine, 269, 270.

Australia, 267, 268.

Belgium, 236 sqq.

Canada, 264-66.

France, 222 sqq.

Germany, 24I $s q q$.

Italy, 258-6o.

Japan, 262-64.

New Zealand, 267, 268.

South Africa, 268, 269.

Ireland, I3, I4, I34.

JoINT stock companies, I52, I53.

LANCASHIRE, I3, 21, 22, I33, I5I.

Leicester sheep, 28, 37, 78, I04, I06. Lincoln sheep, $37,78,82,86$, ro4. Looms-

"Dobbie," 64.

Hand, See Hand looms.

Jacquard, 62, 63 .

Power, $5^{8}$ sqq.

Tappet, 63, 64.

MACHINERY statistics -

Great Britain, 7, 9, 132-34.
France, 223, 224.

Germany, 242.

Italy, 259.

United States, 252, 253.

Merino, $37,38,77,78,81,82,86$, Io6.

Milling. See Fulling.

Mixing, 36.

Mohair, 45, I00, II5, II8-21, I38, I $42,188,280,282$.

Mungo, I21, I22, 135 .

New Zealand wool, $8 \mathrm{r}, 84,88,89$. Noils, 40, 46, II2, II3, 278.

Norfolk sheep, 83 .

Physique of workers, Igr.

Piece trade (home), I6r sqq., I7o sqq.

Preparing boxes, 39.

RAGS, 27, II5, I20, I2I, I25, I89.

Rag-grinder, 26.

Rag wool. See Shoddy.

Raising, 72, 73.

Re-export trade, 297, 298.

Romney Marsh sheep, I04, I05.

SAXONY wool, 28.

Scotland, $I_{3}, 22,56, I_{33}, I_{34}, I_{4} 6$, I5I, I 53, I59, I67, I70, I7 I, I97, 204.

Scoured wool, 91, 92.

Scouring, 71 .

Shoddy, 26, 27, I 20 sqq.

Skin wool, 91, 92, II5-I7.

Sleying, 65, 66.

South African wool, $79,80,84$.

South American wool, 80 sqq., 90 $s q q$.

South Down sheep, Io6.

Sorting, 29.

Specialised businesses, I 44 sqq.

Spinning-

Cap, 51, 52.

Flyer, 50.

Mule, 53-55, I50.

Ring, 52, 53.

Woollen, 134, I35, r46-48.

Worsted, 50 sqq., I39 sqq.

Spinning combinations, I57. 
TARIFFS-

Canada, 280, 283.

France, 282, 287 .

Germany, 280 .

Italy, 279.

Russia, 280, 283.

United States, 256, 279, 283, $285-87,293$.

Tops, 40, 46, 47, 112, I13, 137, $158,159,278,279$.

Top makers, I Io sqq.

Trades Unions, 204 sqq., 213.

Training and apprenticeship, $2 \times 8$. 20.

Twisting, 56, 57 .

WAGES, methods of paying, 213, 218.

Wage statistics-

Great Britain, IgI sqq.

France, 231.

Germany, 250.

United States, 257.

Wales, 13, 14, I33, 134, 142.

Washed and greasy wool, $9 \mathrm{I}$.
Washing, 3r, 32, 233.

Warping, 59 .

Weaving, 57 sqq., I40, I4I.

Welsh sheep, ro5, xo6.

West of England, 56, I43, 153 , 157, 163, I67, 181 .

Willey, 3I.

Women's dress goods, $\mathrm{r}_{44}, \mathrm{I} 45$, I5I.

Wool staplers and merchants, xIo $s q q$.

Woollen, 3, 26, 33-37, 53, 69, 70 $s q q ., 127$ sqq.

Worsted, 2, 3, 37 sqq., IIo, I27 sqq., 142 sqq.

Worsted coatings, $x_{45}, I_{5}$.

YARNS, 55 sqq., 69, 71, 134, 136, I42, I43, I47 sqq., I57 sqq., 277$80,298$.

Yarn trade (home), 160, I6r.

Yorkshire, 18, 20, 56, 128, 133, 142, 143, I47-49, I5 I, I57, I62-64, I67. I 70, I 72, I75, I84, 197-99, 205. 
THE ABERDEEN UNIVERSITY PRESS LIMITED 


\section{A SELECTION OF BOOKS}

PUBLISHED BY METHUEN AND CO. LTD., LONDON 36 ESSEX STREET W.C.

CONTENTS

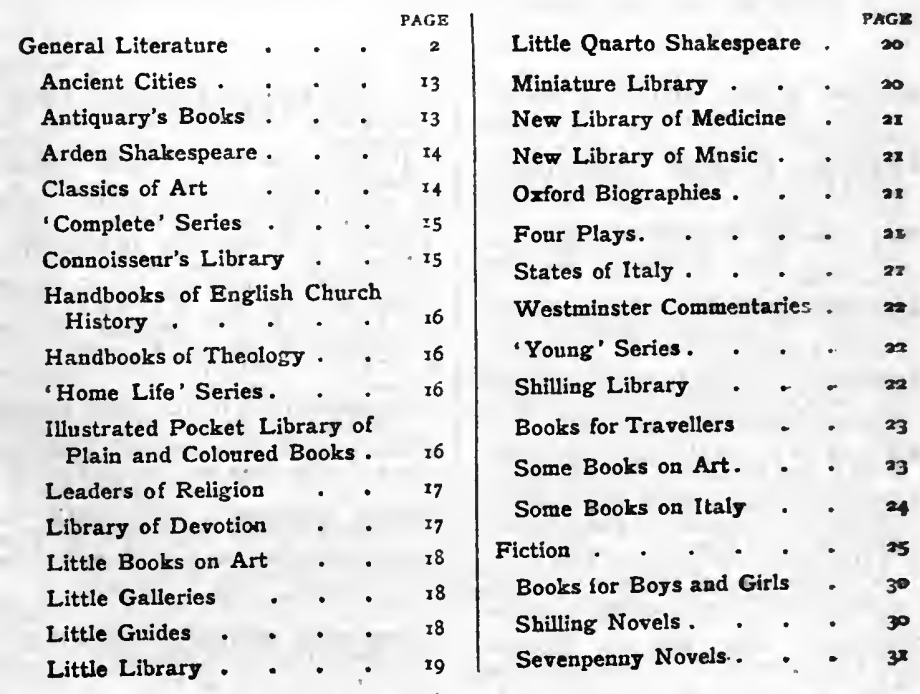

\section{September I9I 3}




\section{A SELECTION OF}

\section{MessRs. MethuEN'S PUBLICATIONS}

IN this Catalogue the order is according to authors. An asterisk denotes that the book is in the press.

Colonial Editions are published of all Messrs. Methuen's Novels issued at a price above $2 s .6 \%$. and similar editions are published of some works of General Literature. Colonial Editions are only for circulation in the British Colonies and India.

All books marked net are not subject to discount, and cannot be bought at less than the published price. Books not marked net are suljject to the discount which the bookseller allows.

Messrs. Methuen's books are kept in stock by all good booksellers. If there is any difficulty in seeing copies, Messrs. Methuen will be very glad to have early information, and specimen copies of any books will be sent on receipt of the published price plus postage for net books, and of the published price for ordinary books.

This Catalogue contains only a selection of the more important books published by Messrs. Methuen. A complete and illustrated catalogue of their publications may be obtained on application.

Abraham (G. D.). MOTOR WAYS IN LAKELAND. Illustrated. Demy 800 . 7s. 6 d. net.

Adcock (A. St. John), THE BOOKLOVER'S LONDON, Illustrated. $C r$. 8vo. 6s. net.

* Ady (Cecllia M.). PIUS II. : Tue Humanist Pope. Illustrated. Demy 8vo. ros. $6 d$. net.

Andrewes (Lancelot). PRECES PRIVATAE. Translated and edited, wirb Notes, by F. E. Brightman. Cr. 8vo. 6s.

Aristotle. THE ETHICS. Elited, with an Introduction and Notes, by Jorn Burnet. Demy 800. ros. fd. net.

Athinson (C. T.). A HISTORY OF GER. MANY, 17 15-1815. Demy 8vo. 12s. 6d. net.

Atkinson (T. D.). ENGLISH ARCHITECTURE. Illustrated. Third Edition. Fcap. 8ro. 3s. 6d. net.

A GLOSSARY OF TERMS USED IN ENGLISH ARCHITECTURE. Illustrated. Second Eidition. Fcap. 8vo. 3s. 6il. net.

ENGLISH AND WELSH CATHEDRAL.S. Il!ustrated. Demy 8zo. Ios. 6a. net.

Bain (ק. W.). A DIGIT OF THE MOON: A Hindoo Love Story. Tenth Edition. Facp. 8oo. 3s. 6d. net.
THE DESCENT OF THE SUN : A CYCLE oF BIRTh. Fifth Edition. Fipp. 8vo. 3s. 6 d. net.

A HEIFER OF THE DAWN. Seventh Edition. Fcap. 8vo. 2s. td. net.

IN THE GREAT GOD'S HAIR. Fifth Edition. Fcap. 8vo. 2s. 6d. net.

A DRAUGHT OF THE BLUE. Fifth Edition Fcas. 8vo. 2s. 6d. net.

AN ESSENCE OF THE DUSK. Third Edition. Fcap. 8vo. 2s. 6d, net.

AN INCARNATION OF THE SNOW. Third Edition. Fcap. 8vo. 3s. 6d. net.

A MINE OF FAULTS. Third Edition. Fass. 8vo. 3 s. 6d. net.

THE ASIIES OF A GOD. Second Edition. Fcap. 8zo. 3s. 6al. net.

BUBBLES OF THE FOAM. Fcap. 4 to. 5s. net. Also Fcap. 8vo. $3^{s}$. 6 d. net.

Balfour (Graham). THE LIFE OF ROBERT LOUIS STEVENSON. IlluStrated. Elcventh Edition. In one Volume. Cr. 8vo. Buckram, 6s.

Also Fcap. 8vo. is, net.

Baring (Hon. Maurice). LANDMARKS IN RUSSIAN LITERATURE. Second Edition. Cr. 8vo. 6s. net.

RUSSIAN ESSAYS AND STORIES. Second Edition. Cr. 8vo. 5s. net.

THE RUSSIAN PEOPLE. Derry 800. 15s. *et. 


\section{General Literature}

Baring-Goula (8.). THE LIFE OF NAPOLEON BONAPARTE. Illustrated. Second Edition. Royal 8vo. Ios. 6d. net.

THE TRAGEDY OF THE CASARS : A Study OP THE Characters OF THE Chesars of the Jullan and Claudian Houses. Illustrated. Seoenth Edition. Rog al 8vo. ros. 6d. net.

THE VICAR OF MORWENSTOW. With a Portrait. Third Edition. Cr.8vo. 3s.6d. Also Fcap. 8vo. is. net.

OLD COUNTRY LIFE. Illustrated. Fifth Edition. Large Cr. 8vo. 6s. Also Fcap. $8 v 0$. is. net.

A BOOK OF CORNWALL. Illustrated. Third Edition. Cr. 8vo. 6s.

A BOOK OF DARTMOOR. Illustrated. Second Edition. Cr. 8vo. 6s.

A BOOK OF DEVON. Illustrated. Third Edition. Cr. 8vo. 6s.

Baring-Gould (S.) and Sheppard (H. Fleetmood). A GARLAND OF COUNTRY SONG. English Folk Songs with their Traditional Melories. Dcmy 4 to. $6 s$.

SONGS OF THE WEST. Folk Songs of Devon and Cornwall. Collected from the Mouths of the People. New and Revised Edition, under the musical editorship of Cecil. J. Sharp. Large Imperial 8vo. 5s. net.

Barker (E.). THE POLI T I CA L THOUGHT OF PLATO AND ARIS. TOTLE. Demy 8vo. zos. 6d. net.

Eastable (C. F.). THE COMMERCE OF NATIONS. Sixth Edition. Cr. 800 . 2s. 6.1 .

Beckford (Peter). THOUGHTS ON HUNTING. Edited by J. Otho Paget. Illuştrated. Third Edition. Demy 8vo. 6s.

Belloc (H.). PARIS. Illustrated Third Edition. Cr. 800 . 6s.

HILLS AND THE SEA. Fourth Edition. Fcap. 8vo. 55. Also Fcap. 8vo. is. net.

ON NOTHING AND KINDRED SUBJECTS. Third Fdition. Fcap. 8'0. 55. ON EVERYTHING. Thind Edition. Fcap. 800. 5 s.

ON SOMETHING. Second Edition. Fcap. 800. 55.

FIRST AND LAST. Second Edition. Fcap. 8vo. $5^{5}$

THIS AND THAT AND THE OTHER. Second Edition. Fcap. 8vo. 5 s.

MARIE ANTOINETTE. Illustrated. Third Edition. Demy 8zo. iss. net.

THE PYRENEES. Illustrated. 'Second Edition. Denty 87'0. 75. 6d. net.

Bennett (Arnold). THE TRUTH ABOUT AN AUTHOR. Crown 8vo. 6s:

Bennett (K. H.). A PRIMER OF THE BIBLE. Fifth Edition. Cr. 8vo. 2s, $\epsilon d$.
Bennett (W. H.) aed Ideney (W. F.). A BIBLICAL INTRODUCTION. With a concise Bibliography. Sixth Edition. Cr. 8vo. 7s. 6d. Also in Two Volumes. Cr. 8vo. Each $35.6 d$, net.

Benson (X̃rchblshop). GOD'S BOARD. Communion Addresses. Second Edition. Fcap. 8v0. 35. 6d. net.

* Berriman (IIgernon E.). AVIATION. Illustrated. Cr. 800. ros. $6 d$. net.

Blcknell (Ethel E.). PARIS AND HER TREASURES. Il]ustrated. Fcap. 800 . Round corners. 55. nct.

Blake (WIIIlam). ILLUSTRATIONS OF THE BOOK OF JOB. With a Genera! Introduction by LAURence Pinyon. Illus. trated. Quarto. 2rs. met.

Bloemfontcln (Bishop of). ARA CALI: AN Essay in Mrstical Theology. Fifth Edition. Cr. 800. 3s. td. net.

FAITH AND EXPERIENCE. Second Edition. Cr. 8vo. 3s. $6 d$, ret.

* Boulenger (G. A.). THE SNAKES OF EUROPE. Illustrated. $C r .8 v 0.6 s$.

Bowden (E. M.). THE IMITTATION OF BUDDHA. Quotations from Buddhist Literature for each. Day in the Year. Sixth Edition. Cr. $16 \mathrm{mo}$. 2s. 6 d.

Brabant (F. G.). RAMBLES IN SUSSEX. Illustrated. Cr. 8vo. $6 s$.

Bradley (A. G.). THE ROMANCF, OF NORTHUMBERLAND. Illustrated. Third Edition. Demy 8vo. 7s. 6d. net.

Braid (James). ADVANCED GOLF. Illustrated. Seventh Edition. Demy Ero. Ios. 6d. net.

Bridger (A. E.). MINDS IN DISTRESS. A Psychological Study of the Masculine and Feminine Minds in Health and in Disorder. Cr. 800. 2s. 6d. net.

Brodrick (Mary) and Morton (A. Inder. son). A CONCISE DICTIONARY OF EGYPTIAN ARCHAOLOGY. A Hand. book for Students and Travellers. Illustrated. Cr. 8vo. 3s. $6 d$.

Browning (Robert). PARACELSUS. Edited with an Introduction, Notes, and Bibliograplyy by MARGARET L. LEF and Katharine B. Locock. Fcap. 8vo. 3s.6d. net.

Buckton (A. M.). EAGER HEART: A Christmas Mrstery-Play. Elezenih Edition. Cr. 8vo. rs. net.

Bull (Paul). GOD AND OUR SOLDIERS. Second Edition. Cr. 8vo. $6 \mathrm{s.}$

Burns (Robert). THE POEMS AND SONGS. Edited by ANDREW LANG and W. A. CRAsGie. With Portrait. Third Edition. Wide Demy 800 6s. 
Calman (W. T.). T I E LIFE OF CRUSTACEA. Illustrated. Cr. 8vo. 6s.

Carlyle (Thomas). THE FRENCH REVOLUTION. Edited by C. R. L. F1.ETCHER. Three tolumes. Cr. $8 v o$. I $8 \mathrm{~s}$. THE LETTERS AND SPEECHES OF OLIVER CROMWEI, With an Introduction by C. H. FirTh, and Notes and Appendices by S. C. Lomas. Three Volume's. Demy 8io. Ifs. ntt.

Chambers (Mrs. Lambert). LA W N TENNIS FOR LADIES. Illustrated. Second Edition. Cr. 8ro. 2s. 6d, net.

Chesscr (Elliabeth Sloan). PERFECT HEAITH FOR WOMEN AND CHILDREN. Cr. 8vo. 3s. td. net.

Chesterfield (Lord). THE LETTERS OF THE EARL OF CHESTERFIELD TO HIS SON. Edited, with an Introduction by C. Strachey, and Notes by A. Calthrop. Two Volumes. Cr. 8vo. 12s.

Chesterton (G. K.). CHARLES DICKENS With two Portraits in Photogravure. Eighth Edition. Cr. 8vo. $6 s$. Also Farp. 8vo. is. net.

THE BAILAD OF THE WHITE HORSE. Fourth Edition. Fcap. 800. 5 s.

ALL THINGS CONSIDERED. Seorth Edition. Feap. 8vo. 5 s.

TREMENDOUS TRIFLES. Fifth Edition. Faap. 800. 5s.

ALARMS AND DISCURSIONS. Second Edition. Fcap. 8vo. $5^{s}$.

A MISCELI.ANY OF MEN. Second Edition. Fcap. 8vo. 5s.

*Clausen (George). ROYAL ACADEMY LECTURES ON PAINTING. Illustrated. Cr. 800. 5s. net.

Conrad (Joseph). THE MIRROR OF THE SFA: Memories and Impressions. Fourth Edition. Ficap. 8vo. $5^{5}$.

Coolidgs (W. A. B.). THE AL.PS: IN NATURE AND HISTORY. Illustrated. Demy 8vo. 7s. 6d. nct.

Correyon (H.). ALPINE FLORA. Translated and enlarged by E. W. Clavforth. lllustrated. Square Demy 8vo. 16s, net.

Goulton (G. G.). CHAUCER AND HIS ENGLAND. Illustrated. Second Edition. Demy 8vo. 1os. Cd. net.

Cowper (Wlllam), POEMS. Edited, with an Introduction and Notes, by J. C. BAtLev. Illustrated. Demy 800 . ro. Gd. net.
Cox (J. C.) RAMBLES IN SURREY. Illustrated. Second Edition. Cr. 8zo. $6 s$.

RAMBLES IN KENT. Illustrated. $C r$. 800. $6 s$.

Crawley (A. E.). THE $3 O O K$ OF THE BALL: AN ACCOUNT OF What IT DOES AND WHY. Illustrated. Cr. $800.3^{s .6 d}$ net.

Crowley (H. Ralph). THE HYGIENE OF SCHOOL LIFE. Illustrated. Cr. 8\%o. 3s. 6d. net.

Davis (H. W. C.). ENGLAND UNDER THE NORMANS AND ANGEVINS: ro66-1272. Thiri Edition. Demy 800 . ros. 6 d. net.

Dawbarn (Clarles). FRANCE AND THE FRENCH. Illustrated. Demy $3 v 0$. 1os. $6 d$. net.

Dearmer (Mabel). A CIILD'S LIFE OF CHRIST. Illustrated. Large Cr. 8vo. 6s.

Defiand (Madame du). LETTRES DE LA MARQUISE DU DEFFAND A HORACE WALPOLE. Edited, with Introduction, Notes, and Index, bv Mrs. Paget ToynbeE. Three Volumes. Demy 8vo. $\ell_{3} 3^{\text {s. net. }}$

Dickinson (G. L.). THE GREEK VIEIV OF LIFE. Eighth Edition. Cr. Swo. 2s. $6 d$. ret.

Ditchfleld (P. H.). T H E O L D.T I M E PARSON. Illustrated. Second Edition. Demy 8vo. 7s. 6d. net.

THE OLD ENGLISH COUNTRY SQUIRE. Illustrated. Demy 8vo. Ios. $6 d$. net.

Dowden (J.). FURTHER STUDIES IN THE PRAYER BOOK. Cr. 8 . 6 .

Driver (S. R.). SERMONS ON SUB. JECTS CONNECTED WITH THE OLD TESTAMENT. Cr. 8vo. 6 s.

Dumas (Alexandre). THE CRIMES OF THE BORGIAS AND OTHERS. With an Introduction by R. S. GARNETT. Illustrated. Second Edition. Cr. 8vo. 6s.

THE CRIMES OF URBAIN GRANDIER AND OTHERS. Illustrated. $C r$. 8v0. 6 s.

THE CRIMES OF THE MARQUISE DE BRINVILLIERS AND OTHERS. lllustrated. $C r .800$. $6 s$.

THE CRIMES OF ALI PACHA AND OTHERS. Illustrated. Cr. 8vo. $6 s$.

MY PETS. Newly translated by A. R. ALLINSON. Illustrated. $C r .800$. $6 s$.

Dunn-Pattison (R. P.). NAPOLEON'S MARSHALS. Illustrated. Second Edition. Demy 800. I2s. 6d, net. 
THE BLACK PRINCE. Illustrated. Second Edition. Demy 80o. 7s. 6d. net.

Durham (The Earl of, THE REPORT ON CANADA. With an Introductory Note. Demy 8vo. 45. 6d. net.

Egerton (H. E.). A SHORT HISTORY OF BRITISH COLONIAL POLICY. Third Edition. Demy 8vo. 7s. 6d. net.

Eyans (Herbert A.). CASTLES OF ENGLAND AND WALES. Illustrated. Demy 8vo. 125. 6d. net.

Exoter (Bishop of. REGNUM DEI. (The Bampton Lectures of 19oz.) A Cheafer Edition. Demy 8vo. 7x. 6\%. net.

Ewald (Garl). MY LITTLE BOY. Translated by Alexander TeIXeira DE Matros. Illustrated. Fcap. 8vo. $5^{s}$.

Falrbrother (W. H.) THE PHILOSOPHY OF T. H. GREEN. Second Edition. Cr. 8vo. 3s. 6d.

ffoulkes (Charles). THE ARMOURER AND HIS CRAFT. Illustrated. Royal 4tc. t2 2s. net.

*DECORATIVE IRONWORK. From the xith to the xvisth Century. Illustrated. Royal 4 to. $\&_{2} 2 s$. net.

Firth (C. H.). CROMWELL'S ARMY. A History of the English Soldier during the Civil Wars, the Commonwealth, and the Protectorate. Illustrated. Second Edition. Cr. 8zo. 6s.

Flsher (H. A. L.). THE REPUBLICAN TRADITION IN EUROPE. Cr. 800 . 6s. net.

FitzGerald (Edward). THE RUBAIYA'T OF OMAR KHAYYAM. Printed from the Fifth and last Edition. With a Commentary by H. M. BATson, and a Biographical Introduction by E. D. Ross. Cr. 820 . 6s.

* Also Illustrated by E. J. Sut.Livan. Cr. 4to. 55 s. net.

Plux (ג. W.). ECONOMIC PRINCIPLES. Deing 8vo. 7s. 6d. net.

Fraser (E.). THE SOLDIERS WHOM WELLINGTON LED. Deeds of Daring, Chivalry, and Renown. Illustrated. Cr. svo. 5s. net.

*THE SAILORS WHOM NELSON LED. Their Doings Described by Themselves. Illustrated. Cr. 8vo. 5s. net.

Fraser (J. F.) ROUND THE WORLD ON A WHEEL. Illustrated. Fifth Edition. Cr. 800. 6.
Galton (BIr Francis). MEMIORIES OF MIY LIFE. Illustrated. Third Edition. Demy 800. ros. 6d. net.

Qlbbins (H. de B.). INDUSTRY IN ENGLAND: HISTOR ICAL OUT. LINES. With Maps and Plans. Seventh Edition, Rerised. Demy 8vo. 1os. 6 d.

THE INDUSTRIAL HISTORY OF ENGLAND. With 5 Maps and a Plan. Nineteenth Edition. Cr. 820.3 s.

ENGLISH SOCIAL REFORMERS. Third Edition. Cr. 8vo. 2s. 6d.

Gibbon (Edward), THE MEMIOIRS OF THE LIFE OF EDWARD GIBBON. Edited by G. Birkbeck Hill. Cr. 8vo. $6 s$. THE DECLINE AND FALL OF THE ROMAN EMPIRE. Edited, with Notes, Appendices, and Maps, by J. B. BURY, Illustrated. Seven Volsmes. Demy 8zo. Illustrated. Each ics. 6d. net. filso in Seven Volumes. Cr. 8vo. 6s. cach.

Glorer (T. R.). THE CONFIICT OF RELIGIONS IN THE EARLY TOMAN EMPIRE. Fourth Edition. Demy 800 . 75. 6 d. net.

VIRGIL. Second Edition. Demy 800. 7s. 6d. net.

THE CHRISTIAN TRADITION AND ITS VERIFICATION. (The Angus Lec. ture for 1922.) Cr. 820. 35. 6d. ntt.

Godley (A. D.). LYRA FRIVOLA. Fourth Edition. Ficap. Sio. 2s. $6 d$.

VERSES TO ORDER. Second Edition. Fcap. 800. 2s. $6 d$.

SECOND STRINGS. Fcap. 8vo. 2s. 6\%.

costling (Frances M.). AUVERGNE AND ITS PEOPLE. Illustrated. Demy 800. ros. 64. net.

Gray (Arthur). CAMBRIDGE. Illustrated. Demy 800. 10r. 6 d. net.

Grabame (Kenneth). THE WIND IN THE WILLOWS. Seoenth Edition. Cr. $8 v 0$. 65 .

*Also Illustrated. Cr. 4to. 7s. 6d. net.

Granger (Frank). HISTORICAL SOCIOLOGY: A TEXT.BOOK OF POLITICS. Cr. 8vo. 3s. 6d. net.

*Gretton (W. Sturge). A CORNER OF THE COTSWOLDS. Illustrated. DCmy 8vo. 7s. 6r. net.

Grew (EdwIn Sharpe). THE GROWTH OF A PLANET. Illustrated. Cr. 8vo. $6 s$.

Griffin (W. Hall) and MInchIn (H, C.), THE LIFE OF ROBERT BROWNING. Illustrated. Second Edition. Demy 800. 12s. 6 d. net. 
HaIf (K. G.). HEALTH THROUGH DIET. Second Edition. Cr. 8vo. 3s. $6 d$. net.

Hale (J. R.). FAMOUS SEA FIGHTS: From Salamis to TSU-Shima. Illustrated. Second Edition. Cr. 8vo. 6s. net.

Hall (H. R.). THE ANCIENT HISTORY OF THE NEAR EAST FROM THE EARLIEST TIMIES TO THE BATTLE OF SALAMIS Illustrated. Second Edition. Demy 8vo. 15s. net.

Hannay (D.). A SHORT HISTORY OE THE ROYAL NAVY. Vol. I., 1217-x688. Vol. II., 1689-18i5. Demy 8vo. Each 75. $6 d$.

Hare (B.). THE GOLFING SWINT SIMPLIFIED AND ITS MECHANISII CORRECTLY EXPLALNED. Third Edition. Fcap. 8vo. is. net.

Harper (Charles G.). THE AUTOCAR ROAD-BOOK. With Maps. Four Volumes. Cr. 8vo. Each 7s. 6d. net.

Vol. I.-South of the Thames.

Vol. II.-North and South Wales aND West Midlands.

Vol. III.-EAst Anglia and EAst MiDLANDS.

* Vol. IV.-The North of England and SOUTH OF SCOTLAND.

Harris (Frank). THE WOMEN OF SHAKESPEARE. Demy 8vo. 7s. 6d. net.

Hassall (Arthur). THE LIFE OF NAPOLEON. Illustrated. Demy $8 v 0$. 7s. 6d. net.

Headley (F. W.). DARWINISM AND MODERN SOCIALISM. Second Edition. Cr. 8vo. 5s. net.

Henderson (M. Sturge). GEORGE MEREDITH : NOVELIST, POET, REFORMER. With a Portrait. Second Edition. Cr. 8vo. 6s.

Henley (W. E.). ENGLISH LYRICS: CHAUCER TO POE. Second Edition. Cr. 8vo. 2s. 6d. net.

Hill (George Francis). ONE HUN DRED MASTERPIECES OF SCULPTURE. Illustrated. Demy $8 v 0$. ros. $6 d$. net.

Hind (C. Lewis). DAYS IN CORNWALI. Illustrated. Third Edition. Cr. 8vo. $6 s$.

Hobhouse (L. T.). THE THEORY OF KNOWLEDGE. Demy 8vo. ros. 6d. net.

Hobson (J. A.). INTERNATIONAL TRADE: AN APPLICATION OF ECONOMIC THEORY. Cr. 8vo. 2s. $6 d^{\prime}$. net.
PROBLEMS OF POVERTY : AN INQUIRY INTO THE INDUSTRIAL CONDITION OF THE Poor. Eighth Eation. Cr. 800 . 2s. $6 d$.

THE PROBLEM OF THE UN. EAPLOYED: AN INQUIRY AND AN Economic Policy. Fifth Edition. Cr. 800 . 2s. $6 d$.

GOLD, PRICLS AND WAGES: WITH AN Examination of thF QUanTITy Theory. Second Edition. Cr. 8vo. 3s. 6d. net.

Hodgson (Mrs. W.). HOW TO IDENTIFY OLD CHINESE PORCELAIN. Illus. trated. Third Edition. Post 8vo. Gs.

Holdich (SIr T. H.). THE INDIAN BORDERLAND, I880-rgo0. Illustrated. Second Edition. Demy 8vo. 10s. 6d. net.

HoIdsworth (W. S.). A HISTORY OF ENGLISH LAW. Four Volumes. Vols. I., II., III. Demy 8v0. Each ros. $6 d$. net.

Holland (Clive). TYROL AND ITS PEOPLE. Illustrated. Demiy 8vo. ros. $6 d$. net.

Horsburgh (E. L. S.). WATERLOO: A Narrative and a Criticism. With Plans. Second Edition. Cr. 8vo. 5s.

THE LIFE OF SAVONAROLA. Illustrated. Cr. 8vo. 5s. net.

Hosle (Alexander), MANCHURIA. Illustrated. Second Edition. Denny 8vo. 7s. $6 d$. net.

*Howell (A. G. Ferrers). ST. EERNARDINO OF SIENA. Illustrated. Demy 820. ros. $6 d$. net.

Hudson (W. H.). A SHEPHERD'S LIFE : IMPRESSIONS OF THE SOUTH WILTSHIRE DOWNS. Illustrated. Third Edition. Demy 8vo. 7s. Ed. net.

Humphreys (John H.). PROPORTIONAL REPRESENTATION. Cr. 8vo. 5s. net.

Hutton (Edward). THE CITIES OF SPAIN. Illustrated. Fourth Edition. Cr. 8vo. 6s.

THE CITIES OF UMBRIA. Illustrated. Fifth Edition. Cr. 8vo. 6s.

THE CITIES OF LOMBARDY. Illustrated. Cr. $8 v$. $6 s$.

*THE CITIES OF ROMAGNA AND THE MARCHES. Illustrated. $C r .820 .6 s$.

FLORENCE AND NORTHERN TUS. CANY WITH GENOA. Illustrated Second Edition. Cr. 8vo. 6 s.

SIENA AND SOUTHERN TUSCANY. lllustrated. Second Edition. Cr. 820. 6 . 
VENICE AND VENETIA. Illustrated: C. 800 . 6s.

ROME. Illustrated. Third Edition, $C r$. 8vo. 65.

COUNTRY WALKS ABOUT FLORENCE. Illustrated. Second Edition. Fcap. 820. 5s. net.

A BOOK OF THE WYE. Illustrated. Demy 800. 75. 6d. Het.

Ibsen (Henrik). BRAND. A Dramatic Poem, translated by William WilsoN. Fourth Edition. Cr. 8vo. 3s. $6 d$.

Inge(W. R.). CHRISTIAN MYSTICISM. (The Bampton Lectures of 1899.) Third Edition. Cr. 8v0. 55, net.

Innes (A. D.). A HISTORY OF THE BRITISH IN INDIA. With Maps and Plans. $C r .800$. $6 s$.

ENGLAND UNDER THE TUDORS. With Maps. Fonrth Edition. Demy 800 . ros. 6 d. net.

Innes (Mary). SCHOOLS OF PAINT. ING. Illustrated. Second Edition. Cr. 8v0. 5s. net.

Jenks (B.). AN OUTLINE OF ENGLISH LOCAL GOVERNMIENT. Secona Edition. Revised by R. C. K. Ensor Cr. 800. 2s. 6d. net.

A SHORT HISTORY OF ENGLISH LAW: FROSI THE EARLIEST TIMES TO THE END OF the YeAR 193. Demy 8vo. 1os. $6 d$. ret.

Jerningham (Charles Edward). THE MAXIMS OF MARMADUKE. Second Edition. Fcap. 8vo. 55 .

Jerons (F. B.). PERSONALITY. cr. 8vo. 25. 6d. ret.

Johnston (SIr H. H.) BRITISH CEN. TRAL AFRICA. Illustrated. Third Edition. Cr. 4 to. 18s. net.

THE NEGRO IN THE NEW WORLD. Illustrated. Demy 8vo. 225. net.

Jullan (Lady) of Norwlch. REVELA. TIONS OF DIVINE LOVE. Edited by Grace Warrack. Fourth Edition. Cr. 800. 35. 6d.

Keats (John). POEMS. Edited, with Intro* duction and Notes, by E. de SÉlincourt. With a Frontispiece in Photogravure. Third Edition. Demy 8vo. 7s. 6d. net.

Keble (John). THE CHRISTIAN YEAR. With an Introduction and Notes by W. Lock. Illustrated. Third Edition. Fcap. 8vo. 3s. $6 d$.
Kempis (Thomas \&). THE IMITATION OF CHRIST. From the Latin, with an Introduction by DEAN FARRAR. Illustrated. Fourth Edition. Fcap. 800. 3s. 6d.

THOMAE HEMERKEN A KEMPIS DE IMITATIONE CHRIST1. Edited by Adrian Fortescue. Cr. 4 to. 62 is. net.

Klpllng (Rudyard). BARRACK.ROOMI - BALLADS. 'rith Thousand. Thirty. fourth Edition. Cr. 8zo. Buckram, 6s. Also Fcap. 8vo. Cloth, 45. 6d. met; leather, 5s. net.

THE SEVEN SEAS. 97th Thousard. Twenty-first Edition. Cr. 8vo. Buckram, 6s. Also Fcap. 8vo. Cloth, 4s. 6d. ret; leather, 5s. net.

THE FIVE N.ATIONS. 8Ist Thousand. Eleventh Edition. Cr. 8'o. Buckram, 6s. Also Fcap. 8vo. Cloth, 4s. 6d. net; keather, 5s. net.

DEPARTMENTAL DITTIES. TrentyThird Edtition. Cr. 8v0. Bucklam, 6s. Also Fcap. 8vo. Cloth, 4s. Ed. net; leather 5s. net.

Lamb (Charles and Mary). THE COM. PLETE WORKS. Edited, with an Intro. duction and Notes, by E. V. Lucas. $A$ New and Revised Edition in Six Volumes. With Frontispicce. Fcap. 8v0. 5s. eacl. The volumes are :-

1. Miscellaneous Prose. 11. Elia and the Last Essays of Elia. IIt. Books for Children. IV. Plays and Porms. $v$. and vi. LETTERS.

Lane-Poole (Stanley.). A HISTORY OF EGYPT IN THE MIDDLE AGES. Illustrated. Cr. 8vo. 6s.

Lankester (8lr Ray). SCIENCE FROM AN EASY CHAIR. Illustrated. Scoenth Edition. Cr. 8vo. 6s.

Lee (Gera]d Stanley). INSPIRED MILLIONAIRES. Cr. 800. 3s. 6.1. net.

CROWDS : A STUDY OF THE GENivs of Demockacy, and of the FeARs, DEsires, AND EXYECTATIONS OF THE PEOPI.E. Cr. 8200. 6s.

Lock (Walter). ST, PAUL, THF MASTER BUILDER. Thind Edition. Cr. 8v0. 35. 6rt.

THE BIBLE AND CHRISTIAN LIFE. Cr. 800. 6s.

Lodge (SIr Ollyer). THF SUBSTANCE OF FAITH, ALLIED WITH SCIENCE : A CATEChism for PARENTSAND TeAchers. Eleventh Eitition. Cr. 800. 25. net.

MAN AND THE UNIVERSE: A STUDY OF THE INFLUENCE OF THE ADVANCE IN SCIENTtFIC KNOWLEDGE UPON OUR U'NDER. STANDING OF CHRISTIANity. Ninth Edition. Demy 8v0. 5s. Het.

Also Fcap. 800. 25. net. 
THE SURVIVAL OF MAN : A STUDY IN UNRECOGNISED HUMAN FAcULTy. Fifth Edition. Wide Cr. 8vo. 5s. net.

REASON AND BELIEF. Fifth Edition. Cr. 8vo. 3s. 6d. net.

MODERN PROBLEMS. Cr. 8vo. 5s, net.

Lorebnrn (Earl). CAPTURE AT SEA. Cr. 8vo. 2s. 6d. net.

LorImer (George Horace). LETTERS FROM A SELF-MADE MERCHANT TO HIS SON. Illusirated. Twentyfourth Edition. Cr. 8vo. 3s. 6 d.

Also Fcap. 8vo. Is. net.

OLD GORGON GRAHAM. Illustrated. Second Edition. Cr. 8vo. 6s. Also Cr. 8vo. 2s. net.

Lucas (B. Y.).THE LIFE OF CHARLES LAMB. Illustrated. Fifth Edition. Demy 8v0. 7s. 6d. net.

A WANDERER IN HOLLAND. Illustrated. Fourteenth Edition. Cr. 8vo. 6 s.

A WANDEERER IN LONDON. Illustrated. Fiftecnth Edition, Recised. Cr. 8vo. 6s.

A WANDERER IN PARIS. Illustrated. Tenth Edition. Cr. 8vo. 6s. Also Fcap. $8 \% 0.5 s$.

A WANDERER IN FLORENCE. Illustrated. Fourth Edition. Cr. 8vo. 6s.

THE OPEN ROAD: A LITTLE BOoK FOR WAYFARERs. Twenty-first Edition. Fcap. 8vo. 5s. India Paper, 7s. 6d. Also Illustrated. Cr. 4to. I5s. net.

THE FRIENDLY TOWN : A LitTLE BOOK FOR THE URBANE. Seventh Eidition. Fcap. 8vo. 5 s.

FIRESIDE AND SUNSHINE. Seventh Edition. Fcap \&vo. 5s.

CHARACTER AND COMEDY. Sixth Edition. Fcap. 8vo. 5s.

THE GENTLEST ART: A CHOICE OP LETTERS BY ENTERTAINiNg HANDS. Sezenth Edition. Fcap. 8vo. 5 s.

THE SECOND POST. Third Edition. Fcap. 8zo. 5s.

HER INFINITE VARIETY : A FEMININE Portrait Gallery. Sirth Edition. Fcap. 8vo. 5s.

GOOD COMPANY: A Rally of MEN. Second Edition. Fcap. $8 v 0$. 5s.

ONE DAY AND ANOTHER. Fifth Edition. Fcap. 800 . 5s.

OLD LAMPS FOR NEW. Fourth Edition. Fcap. 8vo. 5 s.

*LOITERER'S HARVEST. Fcap. 800.

LISTENER'S LURE : AN Oblique NARRATION. Winth Edition. Fcap. 8vo. 5 s.

OVER BEMERTON'S: AN EASY-GOING Chronicle. Tenth Edition. Feap. $8 v 0$. 5 s.
MR. INGLESIDE. Tenth Edition. Fcap. 8 80. 55.

* LONDON LAVENDER. Fcap. 8v0. 55.

THE BRITISH SCHOOL : AN ANECDOTAL Guide to THE BrITISH Patsters aNd Paintings in the National Gallery. Fcap. 8vo. 2s. 6d. net.

HARVEST HOME. Fcap. 8vo. is. net.

A LITTLE OF EVERYTHING. 'Third' Edition. Fcap. 8vo. Is. net.

See also Lamb (Charles).

Lydekker (R.). THE OX AND ITS KINDRED. Illustrated. Cr. 8vo. 65 .

Lydekker (R.) and Others. REPTILES, AMPHIBIA, FISHES, AND LOWER CHORDATA. Edited by J. C. CUNNingHAM. Illustrated. Demy 8vo. ros. $6 d$. net.

Macaulay (Lord). CRITICAL AND HISTORICAL ESSAYS. Edired by F. C. Montague. Three Volumes. Cr. $8 v 0$. 185.

McCabe (Joseph). THE EMPRESSES OF ROME. Illustrated. Demy 8vo. 12s. $6 d$. net.

THE EMPRESSES OF CONSTANTINOPLE. Illustrated. Demy 8vo. IOS. 64 . net.

HacCarthy (Desmond) and Russell (Agatha), LADY JOHN RUSSELL: A MEMotr. Illustrated. Fourth Edition. Demy 8vo. ros. 6d. net.

McDongall (Willam). AN INTRODUC. TION TO SOCIAL PSYCHOLOGY Seventh Edition. Cr. 8vo. 5s. net.

BODY AND MIND: A HISTORY AND A DEFENCE of AnIMISM. Second Edition. Deny 8vo. tos. 6d. net.

Maeterlinck (Maurice). THE BLUE BIRD: A FaIRY Play in Six ACTs. Translated by ALEXANDER TEIXEIRA DE Matros. Fcap. 8vo. Deckle Edges. 3s. Ed. net. Also Fcap. 8v0. Is. net. An Edition, illustrated in colour by F. CAYLEY RoBiNson, is also published. Cr. 4 to. $21 s$. net. Of the above book Thirty-three Editions in all have been issued.

MARY MAGDALENE: A PLAY IN ThREE Acts. Translated by Alexander Teixeira DE Matros. 7hird Edition. Fcap. 800. Deckle Edges. 3s. 6d. ret. Also Fcap.8vo. is. net.

*OUR ETERNITY. Translated by Alex. ander Tetxeira de Matros. Fcap. 8vo. 5s. net.

* Maeterllnck (Mme. M.) (Georgette Leblanc). THE CHILDREN'S BLUE. BIRD. Translated by ALEXANDER Teixeira de Matros. Illustrated, Fcap. 8vo. 55. net. 
Mahaffy (J. P.). A HISTORY OF EGYPT UNDER THE PTOLEMAIC DYNASTY. Illustrated. $C r .800$. $6 s$.

Waltiand (F, W.). ROMAN CANON LAW IN THE CHURCH OF ENGLAND. Royal 8vo. 7s. $6 d$.

Marett (R. R.). THE THRESHOLD OF RELIGION. New and Revised Edition. Cr. 8vo. 55. net.

Marrlott (Charles), A SPANISH HOLIDAY. Illustrated. Demy 8vo. 7s.6d. net.

THE ROMANCE OF THE RHINE. Illustrated. Demy 8vo. ras. 6d. net.

Marriott (J. A. R.). ENGLAND SINCE WATERLOO. With Maps. Demy 8vo. ros. $6 d$. net.

Masefield (John), SEA LIFE IN NELSON'S TIME. Illustrated. Cr. $8 v 0$. 3s. $6 d$. net.

A SAILOR'S GARLAND. Selected and Edited. Second Edition. Cr. 8zo. 3s. $6 d$. net.

Masterman (C. F. C.). TENNYSON AS A RELIGIOUS TEACHER. Second Edition. Cr. 800. 6s.

THE CONDITION OF ENGLAND. Fourth Edition. Cr. 8vo. 6s. Also Fcap. $8 v o$. Is net.

Also Fcap. 8vo. 1s. net.

Mayne (Ethel Colburn). BYRON. Illustrated. Two Volumes. Deniy 8vo. 215. net.

Medley (D. Jo). ORIGINAL ILLUSTRATIONS OF ENGLISH CONSTITU. TIONAL HISTORY. Cr. 8vo. 7s, $6 d$. net.

Methuen (A.M. S.). ENGLAND'S RUIN : Discussed in FOURTEEN LetTers to A Protectronist, Ninth Edition. Cr. $8 v 0$. 3 d. net.

Mlles (Eustace). LIFE AFTER LIFE; OR, THE TheORY OF ReINCARnation. Cr. 800 . 2s. $6 d$. net.

THE POWER OF CONCENTRATION: How To ACQUIR: IT. Fourth Edition. Cr. 8vo. 3s. 6d. net.

MIIIals (J. G.). THE LIFE AND LET. TERS OF SIR JOHN EVERET' MILLAIS. Illustrated. New Edition. Demy 800. 7s. 6d. net.

MIIne (J. G.). A HISTORY OF EGYPT UNDER ROMAN RULE. Illustrated. Cr. 8vo. 6s.

Mitchell (P.Chaimers), THOMAS HENRY HUXLEY. Fcap. 8vo. 1s. net.

Moffat (Mary M.). QUEEN LOUISA OF PRUSSIA. Illustrated. Fourth Edition. Cr. 800. 6s.

MARIA THERESA. Illustrated. Dcmy 8v0. 10s. 6d. net.
Money (L. G. Cblozza). RICHES AND POVERTY. New and Revised Isswe. Cr. 8v0. 15. net.

MONEY'S FISCAL DICTIONARY, 1910 Second Edition. Demy 8vo. 5s, net.

THINGS THAT MATTER: PAPERS ON SUBJECTS WHICH ARE, OR OUGHT TO BE, Under Discussion. Demy 8zo. 5s. net.

Montague (C. E.). DRAMATIC VALUES. Second Edition. Fcap. 8vo. 5 s.

Moorhouse (E. Hallam). NELSON'S LADY HAMILTON. Illustrated. Third Edition. Demy 8vo. 7s.6d. net.

florgan (C. Lloyd). INSTINCT AND EXPERIENCE. Second Edition. Cr. 8vo. 5s. net.

Nevill (Lady Dorothy). MYY OWN TIMES. Edited by ber Son. Second Edition. Demy 8vo. 15s, net.

O'Donnell (Ellot), WERWOLVES. $C r$. 8vo. 5s. net.

Oman (C. W. C.). A HISTORY OF THE ART OF WAR IN THE MIDDLE AGES. Illustrated. Demy 8vo. Ios. 6d. net.

ENGLAND BEFORE THE NORMAN CONQUEST. With Maps. Third Edition, Revised. Demy 800 . ros. 6d. net.

Oxford (M. N.). A HANDBOOK OF NURSING. Sixth Edition, Revised. Cr. 8vo. 3s. 6d. net.

Pakes (W. C. C.). THE SCIENCE OF HYGIENE. Illustrated. Secont and Cheaper Edition. Revised by A. I'. Nankivel.t. Cr. 800. 5s, net.

Parker (Eric), A BOOK OF THE ZOO. Illustrated. Second Edition. Cr. 8vo. 6s.

Pears (SIr Edwin). TURKEY AND ITS PEOPLE. Second Edition. Demy $8 v 0$. 12s. $6 d$. net.

Petrle (W. M. FIInders.) A HISTORY OF EGYPT. lllustrated. Six Volumes. Cr. 820. 6s. each.

Vol. I. FroN THE IST TO THE XVITh DrNastr. Serenth Edition.

Vol. II. ThE XVIITH AND XVIIITH DvNASTIEs. Fifth Edition.

Vol. III. XIXth to XXXth Dynasties. Vol. IV. EGYPT UNDER THB Ptolemaic DYNASTY. J. P. MAHAFFY.

Vol V. Egypt under Roman Rule. J. G. MiL.Ne.

Vol. VI. Egypt iN The Middle Ages. Stanley Lane.Pcole. 
RELIGION AND CONSCIENCE IN ANCIENT EGYPT. Illustrated. Cr.8vo. 2s. $6 d$.

SYRIA AND EGYPT, FROM THE TELL EL AMARNA LETTERS. Cr. 800 . 25. $6 d$.

EGYPTIAN TALES. Translated from the Papyri. First Series, Ivth to Xilth Dynasty. Illustrated. Second Edition. Cr. 800. 35. $6 d$.

EGYPTIAN TALES. Translated from the Papyri. Second Series, xvilth to xixth Dynasty. Illustrated. Second Edition. Cr. 8vo. 3s. 6d.

EGYPTIAN DECORATIVE ART. Illus. trated. $\mathrm{Cr} .820$ 3s. $6 d$.

Pollard (Alfred W.). SHAKESPEARE FOLIOS AND QUARTOS. A Study in the Bibliography of Shakespeare's Plays, r 594-1685. Illustrated. Folio. EI rs. net.

Porter (G. R.). THE PROGRESS OF THE NATION. A New Edition. Edited by F. W. HiRst. Demy 8vo. EI Is. net.

Power (J. O'Connor). THE MAKING OF AN ORATOR. Cr. 8vo. $6 s$.

Price (L. L.). A SHORT HISTORY OF POLITICAL ECONOMY IN ENGLAND FROM ADAM SMITH TO ARNOLD TOYNBEE. Seventh Edition. Cr. 8vo. 2s. $6 d$.

Pycraft (W. P.). A HISTORY OF BIRDS. Illustrated. Demy 800 . ros. 6d. met.

Rawlings (Gertrude B.). COINS AND HOW TO KNOW THEM. Illustrated. Third Edition. Cr. 820. 6s.

Regan (C. Talt). THE FRESHWATER FISHES OF THE BRITISH ISLES. Illustrated. Cr. 8*0. 6 .

Reld (Archdall), THE LAWS OF HEREDITY. Second Edition. Demy $8 v 0$. tI Is. net.

Robertson (C. Grant). SELECT STATUTES, CASES, AND DOCUMENTS, 1660-1832. Second, Revised and Erlarged Edition. Demy 8vo. ros. 6d. net.

ENGLAND UNDER THE HANOVERIANS. Illustrated. Second Edition. Demy 8v0. ras. 6 d. net.

Roe (Fred). OLD OAK FURNITURE. Illustrated. Second Edition. Demy 800.
- Rolle (Richard). THE FIRE OF IOVE and THE MENDING OF LIFE. Edited by Frances M. Comper. Cr. 800 . 3s. 6 d. net.

Ryan (P. F. W.). STUART LIFE AND MANNERS: A Social History. Illustrated. Demy 800. ros. 6d. net.

* Ryley (A. Beresford). OLD PASTE. Illustrated. Royal 800. $\ell_{2} 25$. net.

Bt. Francis of Assis1. THE LITTLE FLOWERS OF THE GLORIOUS MESSER, AND OF HIS FRIARS. Done into English, with Notes by WILLIAM Heywood. Illustrated. Demy 8vo. 5s, net.

'Saki' (H. H. Mnnro), REGINALD. Third Edition. Fcap. Svo. 2s. 6d. net.

REGINALD IN RUSSIA. Fcap. $8 v 0$. 2s. 6d. net.

Sandeman (G. A. C.). METTERNICH. Illustrated. Demy 8vo. 10s. 6d, net.

Schidrowitz (Philip). RUBBER. Illustrated. Demy 8vo. Ios. 6d. net.

Schloesser (H. H.) TRADE UNIONISM. Cr. 8vo. 2s. 6d.

Belous (Edmand). TOMMY SMITH'S ANIMIALS. Illustrated. Twelfth Edi. tion. Fcap. 8vo. 2s, 6d.

TOMMY SMITH'S OTHER ANIMALS. Illustrated. "Sixth Edition. Fcap. 8v0. 25. $6 d$.

JACK'S INSECTS. Illustrated. Cr.800. 6 s.

Shakespeare (Willam).

THE FOUR FOLIOS, 1623; 1632; 1664; 1685. Each $\ell_{4} 4 \mathrm{~s}$, net, or a complete set, EI 2 I2s. net.

THE POEMS OF WILLIAM SHAKE. SPEARE. With an Introduction and Notes by George WYNDHAM. Demy 8vo. Buckram, ros. $6 d$.

Shay (Stanley). WILLIAM OF GERMANY. Denty 8vo. 7s. 6d. net.

Shelley (Percy Bysshe), POEMS. With an Introduction by A. Clutron-BRock and notes by C. D. Locock. Two Volumes. Demy 800. EI is. net.

Smith (Idam). THE WEALTH OF NATIONS. Edited by EDwin Cannan. Two Volumes. Demy 8vo. EI is. net.

BmIth (G. F. Herbert). GEM-STONES AND THEIR DISTINCTIVE CHARACTERS. Illustrated. Second Edition. $C r$. 800. 6s. net. 
Snell (F. J.), A BOOK OF EXMIOOR. Illustrated. $C r .820 .6 s$. THE CUSTOMS OF OLD ENGLAND. lliustrated. Cr. 800 . 6 s.

'Stanclifre.' GOLF DO'S AND DONT'S. Fifth Edition. Ficap. 800. 15. net.

Sterenson (R. L.). THE LETTERS OF ROBERT LOUIS STEVENSON. Edited by Sir Sinney Colvis. $A$ New and Enlanged Edition in four volumes. Fourth Edition. Fcap. 800. Each 55. Leather, each 55. net.

Stor Cernon F.). DEVELOPMENT AND DIVINE PURPOSE. Cr. 8vo. 5 s. net.

Streatfelld (R. A.). MODERN MUSIC AND MUSICIANS. Illustrated. Second Edition. Demy 800. 7s. 6d. net.

Surtees (R. S.). HANDLEY CROSS. Illustrated. Fcap. 800. Gilt top. 35. 6d. net.

MR. SPONGE'S SPORTING TOUR. Illustrated. Fcap. 8vo. Gilt top. 3s. $6 d$. net.

ASK MAMMA; OR, THE RICHEST COMMONER IN ENGLAND. Illustrated. Fcap. 800. Gilt top. 35. 6d. nct.

JORROCKS'S JAUNTS AND JOLLITIES. Illustrated. Fouth Edition. Fcap. 800. Gilt top. 35. 6d. net.

MR. FACEY ROMFORD'S HOUNDS. Illustrated. Fcap. 8vo. Gilt top. $35.6 d$. net.

HAWBUCK GRANGE; OR, THE SPORTING ADVENTURES OF THOMAS SCOTT, EsQ Illustrated. Fcap. \$vo. Gilt top. 35. 6.t. net.

* Snso (Henry). THE LIFE OF THE BLESSED HENRY'SUSO. By Hisasel. Translated by T. F. Knox. With an Introduction by Dean INGe. Cr. 8vo. 3s. $6 d^{\circ}$. net.

Swanton (E. W.). FUNGI AND HOW TO KNOW THEM. Illustrated. Cr. 8v0. 6s. net.

BRITISH PLANT-GALLS. Cr. 800. 75. 6d, net.

Symes (J. E.) THE FRENCH REVO. LUTION. Second Edition. Cr. 800. 2s.6d.

Tabor (Hargaret E.), THE SAINTS IN ART. With their Attributes and Symbols Alphabetically Arranged. Illustrated. Third Edition. Fcap. 800 . 35. 6d. net.

Taylor (A. E.). ELEMENTS OF METAPHYSICS. Second Edition. Demy 800. ros. $6 d$. net.
Taylor (Mrs. Basil) (Harrlet Osgood). JAPANESE GARDENS. Illustrated. Cr. 4to. EI 15. net.

Thlbaudeau (A. C.). BONAPARTE AND THE CONSULATE. Translated and Edited by G. K. Fortescue. Illustrated. Demy 800. Ios. 6d. net.

Thomas (Edward). MAURICE MAE TERLINCK. Illustrated. Second Edition. Cr. 800 . 5s. net.

Thompson (Francls). SELECTED POEMS OF FRANCIS THOMPSON. With a Biographical Note by WiLfrid Mevnell. With a Portrait in Photogravure Twentieth Thousand. Fcap. 800. 5s. net.

Tileston (Mary W.). DAILY STRENGTH FOR DAILY NEEDS. Ticenticth Edition. Medium 16mo. 2s. 6d. net. Also an edition in superior binding, 6 s.

THE STRONGHOLD OF HOFE Medium I6mo. 2s. 6 d. net.

Toynbee (Paget). DANTE ALIGHIERI. His Life AND Works. With 16 Illustra. tions. Fourth and Enlarged Edition. Cr. 800. 5s. ret.

Treyelyan (G. M.). ENGLAND UNDER THE STUARTS. With Maps and Plans. Fifth Edition. Demy 8vo. I0s. 6d. net.

Trlg8s (H. Inlgo). TOWN PLANNING Past, Present, and Possible. Illustra. ted. Second Edition. Wide Royal 800 . I5s. net.

Turner (SIr Alfred E.), SIXTY YEARS OF A SOLDIER'S LIFE. Demy 800 . I25. 6d. net.

Underhill (Eyelyn). MYSTICISM. A Study in the Nature and Development of Man's Spiritual Consciousness. Fourth Edition. Demy 800 . 15s, net.

Urwick (E. J.), A PHILOSOPHY OF SOCIAL PROGRESS. Cr. 800. 6 s.

Yardon (Harry). HOW TO PLAY GOLF. Illustrated. Fifth Edition. Cr. 800. 25. $6 d$. net.

Yernon (Hon. W. Warren), READINGS ON THE INFERNO OF DANTE. With an Introduction by the Rev. Dr. MOORE. Trwo Volumes. Second Edition. Cr. $8{ }^{20}$. I5s. net.

READINGS ON THE PURGATORIO OF DANTE. With an Introduction by the late DEAN ChurCh. Two Volwmes. Third Edition. Cr. 800 . 15s. net. 
READINGS ON THE PARADISO OF DANTE. With an Introduction by the Bishop of Ripon. Two Volumes. Second Edition. Cr. 8vo. 15s. net.

Yickers (Kenneth H.). ENGLAND IN THE LATER MIDDLE AGES. With Maps. Demy 8vo. 1os. 6d. net.

Wade (G. W. and J. H.). RAMBLES IN SOMERSET. Illustrated. Cr. 8v0. 6 s.

Waddell (L. A.) LHASA AND ITS MYSTERIES. With a Record of the Ex. pedition of 1903-1904. Illustrated. Third and Cheaper Edition. Medium 8v0. 75. 6d. net.

Wagner (Rlchard), RICHARD WAGNER'S MUSIC DRAMAS. Interpretations, embodying Wagner's own explanations. By Alice Leighton Cleather and Basil Crump. Fcap. 8vo. 25. 6d. each. The Ring of the Nibelung. Fifth Edition.

LoheNGrin aNd Parsifal. Second Edition, rewritten ard enlarged. Tristan AND IsOLDE.

Tannhäuser and the Mastersingers of Nureaiburg.

Waterhouse (Elizabeth), WITH THE SI IPLE-HEARTED. Little Homilies to Women in Country Places. Third Edition. Small Poit 8vo. 2s. net.

THE HOUSE BY THE CHERRY TREE. A Second Series of Little Homilies to Women in Country Places. Small Pot 18 vo. $^{\circ}$ 2s. net.

COMPANIONS OF THE WAY. Being Selections for Morning and Evening Read. ing. Chosen and arranged by ElizABETH Waterhouse. Lange Cr. 8vo. 5s. net.

THOUGHTS OF A TERTIARY. Small Pott 800. is. net.

VERSES. A New Edition. Fcap. 800. 2s. net.

Waters (W. G.). ITALIAN SCULPTORS. Illustrated. Cr. 8vo. 7s. 6 d. net.

Watt (Francis). EDINBURGH AND THE LOTHIANS. Illustrated. Second Edition. Cr. 8vo. ros. Cd. net.

*R. L. S. Cr. 8 vo. 6s.

Wedmore (SIr Frederick), MEMORIES. Second Edition Demy 800. 75. 6d. net.

Weigali (Arthur E. P.). A GUIDE TO THE ANTIQUITIES OF UPPER EGYPT: From ABYdos to the SUDAN Frontier. Illustrated. Second Edition. Cr. 800. 7s. $6 d$ net.
Wells (J.). OXFORD AND OXFORD LIFE. Third Edition. Cr. 800. 3s. $6 d$.

A SHORT HISTORY OF ROME. Twelfth Edition. With 3 Maps. Cr. 820 . 3s. $6 d$.

Whitten (Wilfred). A LONDONER'S LONDON. Illustrated. Second Edition. Cr. 800. 6s.

Wllde(Oscar). THE WORKS OF OSCAR WILDE. Twelve Volumes. Fcap. 8v0. 5s. net each volume.

I. Lord Arthur Savile's Crime and THE PORTRAit of Mr. W. H. It. The Duchess of Padua. II. Poems. IV. LADV WINDERMERE'S FAN. v. A WOMAN OF No IMPORTANCE. vi. Av IDEAL HusBAND. VII. THE IMPORTANCE OF BEING EARNest. VIII. A HOUSE OF POMEgranates. ix. Intentions. $x$. De ProFUNDIS AND PRISON LetTERS. XI. Essays. Xi1. Salomé, A Florentine Tragedv, and La Sainte Courtisane.

Williams (H. Noel)。 A ROSE OF SAVOY : Marie Adélaide of Savov, Duchesse de Bourgogne, MOTHER of Louis Xv. Illus. trated. Second Edition. Demy 8vo. Iss. net.

THE FASCINATING DUC DE RICHE. LIEU: Louis François ARMand DU Plessis (1696-1788). Illustrated. Demy 820. 15s. net.

A PRINCESS OF ADVENTURE : MARIE Caroline, Duchesse de BerRy (17981870). Illustrated. Demy 8vo. i5s. net.

THE LOVE AFFAIRS OF THE CONDÉS (1530-1740). Illustrated. Demy 800. 155. ret.

-Wilson (Ernest H.). A NATURALIST IN WESTERN CHINA. Illustrated. Demy 8vo. EI 105. nct.

Wood (Sir Evelyn), FROM MIDSHIP. MAN TO FIELD-MARSHAL. Illus. trated. Fifth Edition. Demy 8vo. 75. 6d. net. Also Fcap. 8vo. is. net.

THE REVOLT IN HINDUSTAN (185759). Illustrated. Second Edition. Cr.800. $6 s$.

Wood (W. Birkbeck) and Edmonds (Col. J. E.). A HISTORY OF THE CIVIL WAR IN THE UNITED STATES (186r-65). With an Introduction by SPENSER Wilkinson. With 24 Maps and Plans. Third Edition. Demy 8vo. 12s. Ed. net.

Wordsworth (W.). POEMS. With an Introduction and Notes by NoweLL C. Smith. Three Volumes. Demy 8vo. Iss. net.

Yeats (W. B.), A BOOK OF IRISH VERSE. Third Edition. Cr. $800.35 .6 d$. 


\section{Part II.-A Selection of Series}

\section{Ancient Cities}

General Editor, SIR B. C. A. WINDLE

Cr. 8vo. 4s. 6d. net each volume

With Illustrations by E. H. New, and other Artists

Bristol. Alfred Harvey.

Canterbury. J. C. Cox.

Chester. Sir B. C. A. Windle.

Dublin. S. A. O. Fitzpatrick.
Edinburgh. M. G. Williamson.

Lincoln. E. Mansel Sympson.

Shrewsbury. T. Auden.

Wells and Glastonbury. T S. Hoine:

\section{The Antiquary's Books}

\section{General Editor, J. CHARLES COX}

Demy 8vo. 7s. 6d. net each volume

With Numerous Illustrations

\begin{abstract}
*Ancirnt Painted Glass in England. Philip Nelson.

Archeology and False Antiquities. R. Munro.
\end{abstract}

Bells of England, The. Canon J. J. Raven. Second Edition.

Brasses of England, The. Herbert IV. Macklin. Third Edition.

Celtic Art in Pagan and Christian TIMES. J. Romilly Allen. Second Edition.

Castles and Walled Towns of England, ThE. A. Harvey.

Churchwarden's AcCOUNTS From the Fourteenth Century to the Close of the Seyenteenth Century.

Domesday Inquest, The. Adolphus Eallard.

Enghish Church Furntture. J. C. Cox and A. Harvey. Second Edition.
English Costume. From Prehistoric Times to the End of the Eighteenth Century: George Clinch.

English Monastic Life. Abbot Gasquet. Fourth Edition.

English Seals. J. Harvey Bloom.

Folk-Lore as an Historical Sciency. Sir G. L. Gomme.

Gilds and Companies of London, ThE. George Unwin.

*Hermits and Anchorites of England, The. Rotha Mary Clay.

Manor and Manorial Records, The. Nathaniel J. Hone. Second Edition.

Medieyal, Hospitals of England, ThE. Rotha Mary Clay.

Old English Instruments of Music. F. W. Galpin. Secund Edition. 


\section{The Antiquary's Books-continued}

Ol.d English Libraries. James Hutt.

Old Service Books of the English Church. Christopher Wordsworth, and Henry Littiehales. Second Edition.

Parish Life in Medieval. England. Abbot Gasquet. Third Edition.

Parish Registers of England, The. J. C. Cox.
Remains of the Prehistoric Age in ENGLand. Sir B. C. A. Windle. Second Edition.

Roman Era in Britain, The. J. Ward. Romano-British Butldings and Earthworks. J. Ward.

Roval Forests of England, The. J. C. Cox.

Shrines of British Saints. J. C. Wall.

\section{The Arden Shakespeare.}

\section{Demy Svo. 2s. 6d. net each volume}

An edition of Shakespeare in Single Plays; each edited with a full Introduction, Textual Notes, and a Commentary at the foot of the page

All's Well That Ends Whlt.

Antony and Cleopatra. Second Edition. As You LiKe IT.

Cymbeline.

COMEdY OP ERRORS, THE HAMLET. Third Edition.

Julius Caesar.

*King Henry iv. PT, I.

King Henry $v$.

King Henkv vi. Pr. .

King HenRY vi. PT. II.

King Henry vi. Pr. IIt.

KiNG LEAR.

KING RICHARD 11.

KING RICHARD IIT.

Life and Death of King John, The.

LOve's LABOUR's Lost. Second Editien.
Macbeth.

Measure for Measure.

Merchant of Venice, The. Second Edition. MerRY Wives of Windsor, The.

Midsummer Night's Dream, A.

OTHELLO.

Pericles.

RoNEO AND JULIET.

TAMING OF THE SHREW, THE.

TEMPEST, The.

Timon of Athens.

Titus ANdronicus.

Troilus and Cressida.

Two Gentlemen of Verona, The.

Thelfth Night.

Venus and ADOnis.

Winter's TAle, The.

\section{Classics of Art}

\section{Edited by DR. J. H. W. LAING}

\section{With numerous Illustrations. Wide Royal 8vo}

Art of The GReEks, The. H. B. Walters. 12s. 6d. net.

Art of the Romans, The. H. B. Walters. 15s. net.

Chardin. H. E. A. Furst. 12s. Gd. net.
Donatello. Maud Cruttwell. 15.5. net. FLORENTINE SCULPTORS OF THE RENAISsance. Wilhelm Bode. Translated by Jessie Haynes. 12s. $6 d$. net.

GEORGE ROMNEY. Arthur B. Chamberlain. 12s. 6 d. net. 


\section{Classics of Art-continued}

Ghirlandaio. Gerald S. Davies. Second Edition. 10s. 6d. net.

LAWRENCE. Sir Walter Armstrong. $\ell_{\text {I }}$ is, net.

Michelangelo. Gera!d S. Davies. 12s. $6 d$. net.

Raphael. A. P. Oppé. 12s. 6 d. net.

Remarandts Etchingis. Two Volumes. 21s. net.

A. M. Hind.
Rubens. Edward Dillon. 25s, net.

Tintoretro. Evelyn March Phillipps. 15s. net.

Titian. Charles Ricketts. 15s. net.

Turner's Sketches axd Drawisgs. A. J. Finberg. Second Edition. т2s. 6d. net.

Velazquez. A. de Beruete. zos. 6ul. net.

\section{The 'Complete' Series.}

\section{Fully Illustrated. Demy 8vo}

The Complete Assoclation Footballer.

B. S. Evers and C. E. Hugbes-Davies. 5.s. net.

The Complete Athletic Trainer, S. A. Mussabini. 55. net.

The Complete Bulliard Player. Charles Roberts. ros. 6d. net.

The Complete Boxer. J. G. Bohun Lynch. 5s. net.

The Completr Cook. Lilian Whitling. 75. 6d. net.

The Complete Cricketer. Albert E. KNigir. 7s, 6u. net. Second Edition.

The Complete Foxhunter. Charles Richardson. 125. 6d. net. Second Edition.

The Complete Golfer. Harty Vardon. 105. 6d. net. Thirteenth Edition.

The Complet Hockey-Player. Eustace E. White. 5s. net. Second Edition.

The Complete Horseman. W. Scarth Dixon. Second Edition. ros. 6d. net.
Thr Complete Lawn Tennis Playez, A. Wallis Myers. 205, 6d. net. Thixd Edition, Revised.

The Conplete Motorist. Filson Young. I25. 6d, net. New Edition (Secen!h).

Thв Complete Mountaineer. G. D. Abraham. 15s. net. Second Edtition.

The Complete Oarsman. R. C. Lehmann. ros. $6 d$. net.

The Complete Photographer. R. Child Bayley. 10s. 6d. net. Fourth Edition.

The Complete Rugby Footballer, on the New Zealand System. D. Gallaher and W. J. Stead. ros. 6d. net, Second Edition.

Thв Complete Shот. G. T. TeasdaleBuckell. 12s, 6d. net. Third Edition.

Тне Сомplete Swim mer. F. Sachs. 7s. $6 d$. net.

The Complete Yachtsman. B. HeckstallSinith and E. du Boulay. Second Edition, Revised." iss. net.

\section{The Connoisseur's Library}

\section{With numerous Illustrations. Wide Royal 8vo. 25s. net each volume}

Exglish Furntture. F. S. Robinson.

English Coloured Books. Martin Hardie. Etchings. Sir F. Wedmote Second Edition. Eurotean Enasiels. Henty H. Cunyng. hame.

Glass. Edward Dillon.

Gozdsmiths' and StLversmiths' Work. Nelson Dawson. Second Edition.

illuminated Manuscripts. J. A. Hezbert. Second Edition.
IYorizs. Alfred Maskell.

Jzwellery. H. Clifford Smith. Second Edition.

Mezzotints. Cyril Davenport.

Miniatures. Dudley Heath.

Porcerain. Edward Dillon.

Fine Books. A. W. Pollard.

Seals. Walter de Gray Birch.

Wood Sculpture. Alfred Maskell. Second Edition. 


\section{Handbooks of English Charch History}

\section{Edited by J. H. BURN. Crown 8vo. 2s. 6d. net each volume}

The Foundations of the ENGLish ChURCh. J. H. Maude.

The Saxon Church and the Norman Conquest. C. T. Cruttwell.

The Medieval Church and the Papacy. A. C. Jennings.
The Reformation Period. Henty Gee.

The Struggle with Puritanisar. Bruce Blaxland.

The Church of England in the Eighteenth Century. Alfred Plummer.

\section{Handbooks of Theology}

The Doctrine of the Incarnation. R. L. Ottley. Fifth Edition, Revised. Demy 8vo. 12s. 6\%.

A History of Early Christian Doctrine. J. F. Bethune-Baker. Demy 8vo. ros. $6 d$.

AN IntRODUCTION TO THE History of Religton. F. B. Jevons. Fifth Edition. Demy 8vo. ros. 6 .
AN INTRODUCtion to the History OF the Creeds. A. E. Burn. Demy 8vo. ros. $6 d$.

The Philosophy of Religion in England and America. Alfred Caldecott. Demy 800 . Ios. $6 d$.

The XXXIX ARTicles OF ThE Church of England. Edited by E. C. S. Gibson. Seventh Edition. Demy 800. 12s. 6d.

\section{The 'Home Life' Series}

\section{Illustrated. Demy 8vo. 6s. to 10s. 6d. net}

Home Life in AMerica. Katherine G. Busbey. Sicond Edition.

Hone Life in France. Miss BethamEdwards. Sixth Edition.

Hone Life in Germany. Mrs. A. Sidgwick. Second Edition.

Home Life in Holland. D. S. Meldrum. Second Edition.
Home Life in Italy. Lina Duff Gordon. Second Edition.

Hose Life in Norway. H. K. Danjels. Second Edition.

Hone Life in Russia. A. S. Rappoport.

Homs Life in Spain. S. L. Bensusan. Second Edition.

\section{The Illustrated Pocket Library of Plain and Coloured Books}

\section{Fcap. 8vo. 3s. 6d. net each volume}

\section{WITH COLOURED ILLUSTRATIONS}

The Iffe AND Death of John Mytron, EsQ. Nimrod. Fifih Edition.

The Life of a Sportsman. Nimrod.

Handegy Cross. R. S. Surtees. Fourth Edition.

Mr. Sponge's Sporting Tour. R. S. Surtees. Second Edition.

JORROCKS'S JAUNTS AND JOI.LITIES. R. S. Surtees. Third Edition.

Ask Maman. R. S. Surtees.

\section{WITH PLAIN}

The Grave: A Poem. Robert Blair.
The Analysis of the Hunting Field. R. S. Surtees.

The Tour of Dr. Syntax in Search of the Picturesque. William Combe.

The Tour of Dr. Stntax in Search of Consolation. William Combe.

The Third Tour of Dr. Syntax in Search OF A WIFE. William Combe.

Life in London. Pierce Egan. 


\section{Leaders of Religion}

\section{Edited by H. C. BEECHING. With Portraits}

\section{Crozin Svo. 2s. net each volume}

Cardinal Newman. R. H. Hutton.

John WesLey. J. H. Overton.

Bishop Wit.berforce. G. W. Daniell.

Cardinal Manning. A. W. Hutton.

Charles Simeon. H. C. G. Moule.

John Knox. F. MacCunn. Second Edition.

JонN Howe. R. F. Horton.

Thomas Ken. F. A. Clarke.

George Fox, THE QuAKer. T. Hodgkin.
Third Edition.

ЈоHN KEBLE. Walter Lock. Thomas Chalmers. Mrs. Oliphant. Second
Edition. LANCELot ANdrewes. R. L. Ottley. Secont
Edition.

Augustine of Cantereury. E. L. Cutts. WILliaM Laud. W. H. Hutton. Fourth
Edition.

John Donne. Augustus Jessop.

Thomas Cranmer. A. J. Mason.

LAtimer. R. M. and A. J. Carlyle.

Bishop Butzer. W. A. Spooner.

\section{The Library of Devotion}

\section{With Introductions and (where necessary) Notes \\ Smalt Pott 8vo, cloth, 2s.; leather, 2s. 6d. net each volume}

The Confessions of St. Augustine. Eighth Edition.

The ImtTatron of ChR1st, Sixth Edition. The Christian Year. Fifth Edition.

LVRA INNOCENTIUM. Third Edition.

The Temple. Second Edition.

A Book of Devotions. Second Edition.

a Serious Call to a Deyout and Holy LiFE. Fifth Edition.

A Guide to Eternitv.

The InNer Wav. Second Edition.

ON THE LOVB OF God.

Thr Psalms of Dayid.

Lyra Apostolica.

The Song of Songs.

The Thoughts of Pascal. Second Edition.

a Manual of Consolation from the SAINTS AND Fathers.

Devotions from the Afocrypha.

The Spiritual Combat.
The Devotions of St. Anselm.

Bishop Wilson's Sacra Privata.

Grace abounding to the Chief of Sin. NERS.

LYRA SACRA. A Book of Sacred Verse. Second Edition.

A Day Book prom the Saints ant FATHERS.

A Little Book of Heavenzy Wisdom. A Selection from the English Mystics.

Light, Life, and Love. A Selection from the German Mystics.

Ax Introduction to the Devout Life.

The Little Flowers of the Glorious Messer St. Francis and of his Friars.

DEATI AND IMMORTALITY.

The Spiritual Guide. Second Edition.

DEYOTIONS FOR EVEKY DAY IN THE WEEK AND tIIE GrFat Festivals.

Preces Privatae.

Horae Mrsticae. A Day Book from the Writings of Mystics of Many Nations. 


\section{Little Books on Art}

With many Illustrations. Demy 16mo. 25. 6d. net each zolume

Each volume consists of about 200 pages, and contains from 30 to 40 Illustrations, including a Frontispiece in Photogravure

Albrecht DÜrer. L. J. Allen.

Arts of Japan, The. E. Dillon. Third Edition.

Bookplates. E. Almack.

BotTicelli. Mary L. Bonnor.

Burne-Jones. F. de Lisle.

Cellini. R. H. H. Cust.

Christian Symbolism. Mrs. H. Jenner.

Christ in ARt. Mrs. H. Jenner.

Claude. E. Dillon.

Constabte. H. W. Tompkins. Second Edition.

Corot. A. Pollard and E. Birnstingl.

Early English Water-Colour. C. E. Hughes.

Enamels. Mrs. N. Dawson. Second Edition. Frederic Leighton. A. Corkran.

George Romney. G. Paston.

Greek ART. H. B. Walters. Fourth Edition.
Greuze and Boucher. E. F. Pollard.

Holbein. Mrs. G. Fortescue.

Illuminated Manuscripts. J. W. Bradley. Jewellery. C. Davenport. Second Edition. JoHn Hoppner. H. P. K. Skipton.

Sir Joshua Reynolds. J. Sime. Second Edition.

Millet. N. Peacock. Second Edition.

Miniatures. C. Davenport. Second Edition. Ovr Lady in ART. MIrs. H. Jennet.

RAPHAEL. A. R. Dryburst.

Rodin. Muriel Ciolkowska.

Turner. F. Tyrrell-Gill.

VANDYCK. M. G. Smallwood.

Velazquez. W. Wilberforce and A. R. Gilbert.

WATts. R. E. D. Sketchley. Second Edition.

\section{The Little Galleries}

\section{Demy r6mo. 2s. $6 d$. net each volume}

Each volume contains 20 plates in Photogravure, together with a short outline of the life and work of the master to whom the book is devoted

A little Galleky of Reynolds.

A Little Gallery of Romney.
- A little Gallery of Hoppner.

A Little Gallery of Millais.

\section{The Little Guides}

With many Illustrations by E. H. New and other artists, and from photographs Small Pout 8vo. Cloth, 2s. 6d. net; leather, 3s. 6d. net each volume

The main features of these Guides are ( 1 ) a handy and charming form ; (2) illustrations from photographs and by well-known artists; (3) good plans and maps; (4) an adequate but compact presentation of everything that is interesting in the natural features, history, archæology, and architecture of the town or district treated

Cambridge and its Colleges. A. $H$.

Thompson. Third Edition, Revised.

Channel Islands, The. E. E. Bicknell.

ENGLish Lakes, The. F. G. Brabant.
Isle of Wight, The. G. Clinch.

London. G. Clinch.

Malvern Country, The. Sir B.C.A. Windle.

North Wales. A. T. Story. 


\section{The Little Guides-continued}

OxFord and its Colleges. J. Wells. Ninth Edition.

St. Paul's Cathedral. G. Clinch.

Shakespeare's Country. Sir B. C. A. Windle. Fifth Edition.

South Wal.es. G. W. and J. H. Wade.

Westminster Abbey. G. E. Troutbeck. Second Edition.

BERKSHIRE. F. G. Brabant.

Blckinghamshirz. E. S. Roscoe.

Cheshire. W. M. Gallichan.

Cornwallo A. L. Salmon. Second Edition.

Derbyshire. J. C. Cox.

Deyon. S. Baring-Gould. Third Edition.

Torset. F. R. Heath. Second Edition.

Durham. J. E. Hodgkin.

Essex. J. C. Cox.

HAMPSHIRE. J. C. Cox. Second Edition.

HeRTFORdshiRe. H. W. Tompkins.

Kent. G. Clincb.

KERRY. C. P. Crane. Second Edition.

Leicestershire and Rutland. A. Harvey and V. B. Crowther-Beynon.

Middesex. J. B. Firth.

Monмouthshire. G. W. and J. H. Wade.
NoRroLk. W. A. Dutt. Third Edition,
Revised.

Northamptonshire. W. Dry. Second Edition, Revised.

Northumberland. J. E. Mortis.

Nottinghamshire. L. Guilford.

OXFORDSHiRE. F. G. Brabant.

Shropshire. J. E. Auden.

Somerset. G. W. and J. H. Wade. Second Edition.

Staffordshire. C. Masefield.

Suffolk. W. A. Dutt.

Surrey. J. C. Cox.

Sussex. F. G. Brabant. Third Edition.

WILTSHIRE. F. R. Heatb.

YorkshiRe, The EAst Riding. J. E. Morris.

Yorkshire, The North RidiNg. J. E. Morris.

YorkshiRe, The West Rinisg. J. E. Morris. Cloth, 3s. 6d. net; leather, 4s. 6d. net.

Brittany. S. Baring-Gould.

NoRmandy. C. Scudamore.

Rome. C. G. Ellaby.

SicıLy. F. H. Jackson.

\section{The Little Library}

With Introduction, Notes, and Photogravure Frontispieces

Small Pott 8vo. Each Volume, cloth, 1s. 6d. net

Anon. A LITTLE BOOK OF ENGLISH LYRICS. Second Edition.

Austen (Jane). PRIDE AND PREJU. DICE. Two Volumes.

NORTHANGER ABBEY.

Bacon (Francls). THE ESSAYS OF LORD BACON.

Barham (R. H.). THE INGOLDSBY LEGENDS. Two Volumes.

Barnett (Annie). A LITTLE BOOK OF ENGLISH PROSE.

Beckford (WIllam). THE HISTORY OF THE CALIPH VATHEK.
Blake (William), SELECTIONS FROM THE WORKS OF WILLIAM BLAKE.

Borrox (George). LAVENGRO. Two Volumes.

THE ROMANY RYE.

Browning (Robert). SELECTIONS FROM THE EARLY POEMS OF ROBERT BROWNING.

Canning (George). SELFCTIONS FROM THE ANTI-JACOBIN : With some later Poems by George Canning.

Comley (Abraham), THE ESSAYS OF ABRAHAM COWLEY. 
The Little Library-continued

Crabbe (George). SELECTIONS FROM THE POEMIS OF GEORGE CRABBE.

Craik (Mrs.). JOH N H L I F A X, GENTLEMAN. Two Volumes.

Crashaw (Richard). THE ENGLISH POEMS OF RICHARD CRASHAW.

Dante Allghlerl. THE INFERNO OF DANTE. Translated by H. F. CARY.

THE PURGATORIO OF DANTE. Translated by H. F. CARY.

THE PARADISO OF DANTE. Translated by H. F. CARY.

Darley (George). SEIECTIONS FROM THE POEMS OF GEORGE DARLEY.

Dlckens(Charles). CHRISTMAS BOOKS. Tuo Volumes.

Ferrier (Susan). MARRIAGE. Two Volumes.

THE INHERITANCE. Tzo Volumes.

Gaskell (Mrs.). CRANFORD, Second Edition.

Haw thorne (Nathaniel). THE SCARI.ET LETTER.

Henderson (T. F.). A LITTLE BOOK OF SCOTTISH VERSE.

Klnglake (A. W.). EOTHEN. Second Edition.

Lamb (Charles). ELIA, AND THE LAST ESSAYS OF ELIA.

Locker (F.). LONDON LYRICS.
Maryell (Andrew). THE POEMS OF ANDREW MARVELL.

Milton (John). THE MINOR POEMS OF JOHN MILTON.

Molr (D. M.). MANSIE WAUCH.

Nichols (Bowyer). A LITTLE BOOK OF ENGLISH SONNETS.

Smith (Horace and James). REJECTED ADDRESSES.

Sterne (Laurence). A SENTIMENTAL JOURNEY.

Tennyson (Alfred, Lord). THE EARLY POEMS OF ALFRED, LORD TENNY. SON.

IN MEMORIAM.

THE PRINCESS.

MAUD.

Thackeray (W. M.). VANITY FAIR. Three Volumes.

PENDENNIS. Three Volumes.

HENRY ESMOND.

CHRISTMAS BOOKS.

Vaughan (Henry). THE POEMS OF HENRY VAUGHAN.

Waterhouse (Elizabeth). A LITTLE BOOK OF LIFE AND DEATH. Fourteenth Edition.

Wordsworth (W.). SELECTIONS FROM THE POEMS OF WILLIAM IVORDS. WORTH.

Wordsworth (W.) and Colerldge (S. T.). LYRICAL BALLADS. Second Edition.

\section{The Little Quarto Shakespeare}

Edited by W. J. CRAIG. With Introductions and Notes Pott I6mo. 40 Volumes. Leather, price is. net each volume Mahogany Revolving Book Case. Ios. net

\section{Miniature Library}

\section{Deny 32 mo. Leather, Is. net each volume}

Euptranor: A Dialogue on Youth. Edward | Poronius; or, Wise Saws and Modern InFitzGerald.

THE LIFE OF EDWARD, LORD HERBERT OF Chereury. Written by bimself. stances. Edward FitzGerald.

The RuBAjykt OF OMar KhayvkM. Edward FitzGerald. Fourth Edition. 


\section{The New Library of Medicine}

CARE of the Body, THE. by C. W. SALEEBy. Demy Svo

Second Edition. 7s. 6d net F. Cavanagh.

Childoren of thr Nation, The. The Right Hon. Sir John Gorst. Second Edition. 7s. 6d, net.

Diseases of Occupation. Sir Thos. Olivet. zos. 6d. net. Second Edition.

Drink Pronlem, in its Medico-Sociological Aspects, The. Edited by T. N. Kelynack. 7s. $\in$ d. net.

Drtgs and the Drug Habit. H. Sainsbuty.
Functronal Nerve Diseases. A. T. Scho* field. 7s. $6 d$, net.

Hygiene of Mind, THE. T. S. Clouston. Sixth Edition. 7s. 6d. net.

Infant Mortality. Sir George Newman. 7s. 6d. net.

Prevention of Tuberculosis (Consump. IION), The. Arthur Newsholme. Ios. $6 d$. net. Second Edition.

Air and Health. Ronald C. Macfie. 7s. $6 d$. net. Second Edition.

\section{The Ner Library of Music}

Edited by ERNEST NEWMAN. Illustrated. Demy 8vo. 75. 6d. net Brahsis.
Edition. J. A. Fuller-Mailland. Second HANDEL R. A. Strearfeild. Second Edition

\section{Oxford Biographies}

1llustrated. Fcap. 8vo. Each volume, cloth, 2s. 6d. net; leather, 3s. 6d. net

Dantr Alighizrl. Paget Toynbee. Third ERasmus. E. F. H. Capey. Edition.

Girolamo Sayonarola. E. L. S. Horsburgh. Sixth Edition.

JoH Howard. E. C. S. Gibson.

Alfred Texisyson. A. C. Benson. Second Edition.

Sir Walter Raleigh. I. A. Taylor.

Robert Burns. T. F. Hencetson.

Chatham. A. S. McDowall.

Canning. W. Alison Phillips.

Beaconsfield. Walter Siche!.

Johasn Wolfgang Goethe. H. G. Atkins.

François de Fénelon. Viscount St. Cyres.

\section{Four Plays}

Fcap. 8vo. 25. net

Thz Honermoon. A Comedy in Three Acts. Arnold Bennett. Second Edition.

The Great Adventure. A Play of Fancy in Four Acts. Arnold Bennett. Second Edition.

Mrlestones. Arnold Bennett and Edward Knoblauch. Sixth Edition.
Kismet. Edward Knoblauch. Second Edi. tion.

Typhoon. A Play in Four Acts. Melchior Lengyel. English Version by Laurence Irving. Second Edition.

\section{The States of Italy}

\section{Edited by E. ARMSTRONG and R. LANGTON DOUGLAS}

\section{Illustrated. Demy 8vo}
A History of Milan under the Sforza Cecilia M. Ady. 10s. 6d. net.
A History of Vekona. 12s. 6 d. net.
A. M. Allen. A History of Perugia.
W. Heywood. 12s. 6 d. net. 


\section{The Westminster Commentaries}

\section{General Editor, WALTER LOCK}

Demy $8 v 0$

The Acts of The Apostles. Edited by R. B. Rackham. Sixth Edition. ras. 6d.

The First Eristle of Paul the Apostle to THE Cokinthians. Edited by H. L. Goudge. Third Edition. 6s.

TuE Book of Exodus. Edited by A. H. I'Neile. With a Map and 3 Plans. ros, $6 d$.

THE Book OF Ezekiel. Edited by H. A. Redpatb. Ios. $6 d$.

The Book of Genesis. Edited, with Introduction and Notes, by S. R. Driver. Ninth Edition. 10s. 6 .
ADDitions AND CORRECTIONS IN THE Seventh and Eighth Editions op the Book of Genesis. S. R. Driver. Is.

The Book of THE Prophet IsAlah. Edited by G. W. Wade. ros. $6 d$.

THE Book of JoB. Edited by E. C. S. Gib. son. Second Edition. 6 s.

The Eristle of St. Janes. Edited, with Introduction and Notes, by R. J. Knowling. Second Edition. 6s.

\section{The 'Young' Series}

\section{Illustrated. Crown 8vo}

The Young Botanist. W. P. Westell and C. S. Cooper. 35. 6d. net.

The Young Carpenter. Cyril Hall. 5 s. The Young Electrician. Hammond Hall. 5 s.
The Young Enginere. Hammond Hall. Third Edition. 5 .

The Young Naturalist. W. P. Westell. Second Edition. 6 s.

The Young ORnithologist. W. P. Westell. 5s.

\section{Methuen's Shilling Library}

\section{Fcap. 8vo. Is, net}

Blue BrRd, ThE. Maurice Maeterlinck.

${ }^{*}$ Charles Dickens. G. K. Chesterton.

* Charmides, and other Poems. Oscar Wilde.

Chitrdl: The Story of a Minor Siege. Sir G. S. Robertson.

Conpition of England, The. G. F. G. Masterman.

De Profundis. Oscar Wilde.

From Minshipman to Field-Marshal. Sir Evelyn Wood, F.M., V.C.

Harvest Home. E. V. Lucas.

Hills aNd the SEa. Hilaire Belloc.

Huxley, Thomas Henry. P. ChalmersMitchell.

Ineal Husband, An. Oscar Wilde.

Intentions. Oscar Wilde.

Jimmy Glover, wis Book. James M. Glover.

JOHN BOYes, KiNG OF THE WA-KikUYU. Jobn Boyes.

Lady Windermere's Fan. Oscar Wilde.

LetTers from a Self-made MERchant TO HIS Son. George Horace Lorimer.
Life of John Ruskin, The. W. G. Colling. wood.

Life of Robert Louis Stevenson, The. Graham Balfour.

Life of Tennyson, The. A. C. Benson.

Little of Everything, A. E. V. Lucas.

Lord Arthur Savile's Crime. Oscar Wilde.

LORE OF THE Honey-BEe, The. Tickner Edwardes.

Man and the Universe. Sir Oliver Lodge. Mary Magdalene. Maurice Maeterlinck.

Old Country Life. S. Baring-Gould.

Oscar Wilde: A Critical Study. Artbur Ransome.

Parish Clerk, The. P. H. Ditchfield.

Selected Poems. Oscar Wilde.

SEvastopol, and other Storizs. Leo Tolstoy.

Two Admirals. Admiral John Moresby.

UNder Five Reigns. Lady Dorotby Nevill.

Vallima LetTers. Robert Louis Stevenson.

Vicar of Morwenstow, The. S. Baring. Gould. 


\section{Books for Trayellers}

\section{Crown 8vo. 6s. each}

Each volume contain's a number of Illustrations in Colour

Avon and Shakespeare's Country, The. A. G. Bradley.

Black Forest, A Book of the. C. E. Hughes.

Bretons at Home, The. F. M. Gostling. Cities of Lombardy, The. Edward Hutton. Cities of Romagna ano the Marches, THE. Edward Hutton.

Cities of Spain, The. Edward Hutton. Cities of Umbria, The. Edward Hutton. Days in Coknwall. C. Lewis Hind.

Florence and Nortiern Tuscany, with Genoa. Edivard Hutton.

Land of Pardons, The (Brittany). Anatole Le Braz.

Naples. Arthur H. Norway.

Naples Riviera, The. H. M. Vaughan.

New Forest, ThE. Horace G. Hutchinson.
Norfolk Broads, Thr. W. A. Dutt.

Norway and its Fjords. M.A. Wyllie.

RHINE, A BoOK OF THE. S. Baring-Gould.

Rome. Edward Hutton.

Round about Wiltshire. A. G. Bradley.

Scotland of To-DAy. T. F. Henderson and Francis Watt.

Siena and Southern Tuscany. Edward Hutton.

Skirts of the Great City, The. Mrs. A. G. Bell.

Throvgh East Anglia in a Motor Car. J. E. Vincent.

VRnice and Venetia. Edward Hution.

WANDerer in Florence, A. E. V. Lucas.

Wanderer in Paris, A. E. V. Lucas.

Wanderer in Holland, A. E. V. Lucas.

Wanderer in London, A. E. V. Lucas.

\section{Some Books on Art}

Armourer and his Craft, The. Charles froulkes. Illustrated. Royal 4 to. $\ell_{2} 25$. net.

Art AND Life. T. Sturge Moore. Illustrated. Cr. 8vo. 5s. net.

British School, The. An Anecdotal Guide to the British Painters and Paintings in the National Gallery. E. V. Lucas. Illustrated. Fcap. 8vo. 2s. 6d. net.

* Drcorative IroN Work. From the xith to the xvinth Century. Charles ffoulkes.

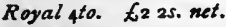

Francrsco Guardi, 1712-1793. G. A. Simonson. Illustrated. Imperial 4 to.

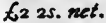

Illustrations OF THE BoOK OF Јов. William Blake. Quarto. EI 1s. net.

John Lucas, Portrait Paintre, 1828-1874. Arthur I.ucas. Illustrated. Imperial ${ }_{4} t o$. 633 net.

Old Paste. A. Beresford Ryley. Illustrated. Royal 4 to. $\ell_{2}$ 2s. net.

One Hundred Masterpieces of Painting. With an Introduction by R. C. Witt. Illustrated. Second Edition. Demy 800. Ios. 6 d. net.
ONE HUNdREd Masterpteces of Sculpture. With an Introduction by G. F. Hill. Illus. trated. Demy 8vo. 10. 6d. net.

Romney Folio, A. With an Essay by A. B. Chamberlain. Imperial Folio. $\boldsymbol{X}_{15}$ i5s. net.

* Royal academy Lectures on Painting. George Clausen. Illustrated. Crown 820. 5s, net.

SAints In ARt, The. Margaret E. Tabor. Illustrated. Second Edition, Revised. Ficap. 8vo. 35. 6d. met.

Schools of Painting. Mary Innes. Illus. trated. Cr. 800. 5s. met.

Chltic art in Pagan and Christian Times. J. R. Allen. Illustrated. Second Bdition. Demy 8vo. 7s. 6d. net.

'Classics of Art.' See page 14.

'The Connoisseur's Library.' See page 15.

'Little Books on Art.' See page 18.

'The Little Galleries.' See page 18. 


\section{Some Books on Italy}

Etruria and Modern Tuscany, Old. Mary L. Cameron. Illustrated. Second Edition. Cr. 8vo. 6s, net.

Florence: Her History and Art to the Fall of the Republic. F. A. Hyett. Demy $8 v 0$. 7s. 6d. net.

Florence, A Wanderer in. E. V. Lucas. lllustrated. Fourth Edition. Cr. 8vo. 6.

Florence and her Treasures. H. M. Vaughan. Illustrated. Fcap. 8vo. 5s. nct.

Florfice, Country Walks about. Edward Hutton. Illustrated. Second Edition. Fcap. 8vo. 5s. net.

Florence and the Cities of Northern Tuscany, with GenoA. Edward Hutton. Illustrated. Second Edition. Cr. 8vo. $6 s$.

Lombardy, The Cities of. Edward Hution. Illustrated. Cr. 8vo. 6s.

Milan under the Sfokza, A History of. Cecilia M. Ady. Illustrated. Demy 8vo. ros. $6 d$. net.

NAples: Past and Present. A. H. Norway. Illustrated. Third Edition. Cr. 8vo. 6s.

Naples Riviera, The. H. M. Vaughan. Iilustrated. Second Edition. Cr. 8vo. 6s.

Perugia, A History of. William Heywood. Illustrated. Demy 8vo. 12s. 6d. net.

Rome. Edward Hutton. Illustrated. Third Edition. Cr. 8*o. 6 s.

Romagna and the Marches, The Cities of. Edward Hutton. Cr. 8vo. $6 s$.

Roman Pilgrimage, A. R. E. Roberts. Illustrated. Demy 8vo. sas, 6d. net.

ROME OF THE PILGRIMS AND MARTYRs. Ethel Ross Barker. Demy 8vo. 12s. $6 a$. net.

Rome. C. G. Ellaby. Illustrated. Small Pott 8vo. Cloth, 2s. 6d. net; leather, $3 s .6 d$. net.

Sicily. F. H. Jackson. Illustrated. Smalt Pott 8vo. Cloth, 25. 6d. net; leather, $3^{s .6 d .}$ net.

Sic1ly: The New Winter Resort. Douglas Sladen. Illustrated. Second Edition. Cr. 8vo. 5s. net.

Siena and Southern Tuscany. Edward Hutton. Illustrated. Second Edition. Cr. 820. 6s.
Umbria, ThB Cities of. Edward Hutton. Illustrated. Fifth Edition. Cr. 8vo. 6s.

Venice and Venetia. Edward Hutton. Illustrated. Cr. 8ro. $6 s$.

VEN1CE ON FoOT. H. A. Douglas. Illustrated. Second Edition. Fcap. 8vo. 5s. net.

Venice AND HER Treasures. H. $A$. Douglas. Illustrated. Fcap. 8vo. 5s. net.

Verona, A History of. A. M. Allen. Illustrated. Demy 8vo. 125. 6d. net.

DANTE AND his ITALY. Lonsdale Ragg. Illustrated. Demy 8vo. 12s. 6d. net.

Dante Alighteri: His Life and Works. Paget Toynbee. Illustrated. $C r .820 .5 s$. net.

Home Life in Italy. Lina Duff Gordon. Illustrated. Third Edition. Demy 800 . ros. 6d. net.

LAKes of Northern Italy, The. Richard Bagot. Illustrated. Fcap. 8vo. 5s. net.

Lorenzo the Magnificent. E. L. S. Horshurgh. Illustrated. Second Edition. Demy 820. 15s. net.

Medici Popes, THE. H. M. Vaughan. Illustrated. Demy 8vo. 15s. net.

St. Catherine of Siena and ner Times. By the Author of 'Mdlle. Mori.' Illustrated. Second Edition. Demy 8v0. 7s. 6d. net.

S. Francis of Assisi, The Lives of. Brother Thomas of Celano. Cr. 8zio. 5s. net.

Sayonarola, Girolamo. E. L. S. Horsburgh. Illustrated. Cr. 8vo. ss. net.

Shelley ANd his Friends in Italy. Helen R. Angeli. Illustrated. Demy 8vo. ros. $6 d$. net.

Skies Italian: A Little Breviary for Tra. vellers in Italy. Ruth S. Phelps. Fcap. 800. 5s. net.

United Italy. F. M. Underwood. Dems 8vo. 10s. 6d. net.

WomaN in Italy. W. Boulting. Illustrated. Demy 800. ros. 6a. met. 


\section{PART III.-A Selection of Works of Fiction}

Albanesi (E. Maria). SUSANNAH AND ONE OTHER. Fourth Edition Cr. 820. 6s.

THE BROWN EYES OF MARY. Third Edition. Cr. 8vo. 6 s.

1 KNOW A MAIDEN. Third Edition. Cr. 8vo. $6 s$.

THE INVINCIBLE AMELIA; oR, THE Polite Advexturess. Third Edition. Cr. 8vo. 35. 6.t.

THE GLAD HEART. Fifh Edition. Cr. 8zo. Gs.

OLIVIA MARY. Fourth Edition. $\mathrm{Cr}$. 820. 65.

THE BELOVED EXEMY. Second Edition. Cr. 800. 6s.

Bagot (Richard), A ROMAN MYSTERY. Third Edition Cr. 8vo. 6s.

THE PASSPORT. Fourth Edition. $C r$. 8*0. 65.

AN THONY CUTHBERT. Fourth Edition. Cr. 8vo. 6s.

LOVE'S PROXI. Cr. 80o. 6s.

DONNA DIANA. Second Edition. Cr. 8ะ0. 6s.

CASTING OF NETS. Trulfth Edition Cr. 8vo. 6 .

THE HOUSE OF SERRAVALLE. Third Edition. Cr. 800. 6 s.

DARNELEY PLACE. Second Edition. Cr. 8vo. 6s.

Bailey (H. C.), STORM AND TREASURE. Third Edition. Cr. 880. 6r.

THE LONELY QUEEN. Thind Edition. Cr. 800. 6r.

THE SEA CAPTAIN. Cr. 800. 6.

Baring-Gould (\$.), IN THE ROAR OF THE SEA. Eighth Edition. Cr. 8v0. 6s. MIARGERY OF QUETHER. Second Edi. tion. Cr. 800. 6s.

THE QUEEN OF LOVE. Fifth Edition. Cr. 800. 6s.

JACQUETTA. Third Edition, Cr. 800 ." 6s. KITTY ALONE. Fifth Edition. Cr. 800. 6s. NOEMII. Illustrated. Fourth Edition Cr. 800. 6s.

THE BROOM-SQUIRE. Illustrated. Fift: Edition. Cr. 800. 6s.
BLADYS OF THE STEWPONEY. Illustrated. Second Edition. Cr. 800. 6s. PABO THE PRIEST. Cr. $800.6 s$.

WINEFRED. Illustrated. Second Edition. Cr. 800. 65.

ROYAL GEORGIE. Illustrated. Cr.800. 6s. IN DEWISLAND. Second Edition. $C$ r. 800. $6 s$.

MRS CURGENVEN OF CURGENVEN. Fifth Edition. Cr. 800. 6s.

BarT (Robert), IN THE MIDST OF ALARMS. Third Edition. Cr. 800 . 6s.

THE COUNTESS TEKLA. Fifth Edition Cr. 800. 6 s.

THE MUTABLE MANY. Third Edition. Cr. 800. 6s.

Begble (Harold), THE CURIOUS AND DIVERTING ADVENTURES OF SIK JOHN SPARKOW, BART.; OR, THE Progress of an Open Mind. Second Edition. Cr. 800. 6s.

Balloc (H.) EMMANUEL BURDEN, MERCHANT. Illustrated. Second Edition Cr. 820. 6s.

A CHANGE IN THE CABINET. Third Edition Cr. 8vo. 6s.

Bennett (Arnold), CLAYHANGER. Eleocnth Edition. Cr. 8\%o. 6s.

THE CARD." Sixth Edition. Cr. 800. "6s. HILDA LESSWAYS, Seocuth Edition. Cr. 800. 6s.

BURIED ALIVE. Third Edition $C r$. 800. 65.

A MAN FROM THE NORTH. Thind Edition. Cr. 800, 6s.

THE MATADOR OF THE FIVE TOWNS. Second Edition, Cr, 820 . Gs.

THE REGENT: A FIVE TOws STORV of ADVENTURR iN LONDON. Third Edition. Cr. 800. 6s.

ANNA OF THE FIVE TOWNS. Fcap. 800. Is. net.

TERESA OF WATLING STREET. Fcap. 800. Is. net.

Benson (E. E.) DODO: A DETatL of THa DAT. Sistecnth Edition. Cr. 800. 6s. 
Birmingham (George A.). S P A N I S H GOLD. Sixth Edition. Cr. 8vo. 6s. Also Fcap. 8vo. is. net.

THE SEARCH PARTY. Sixth Edition. Cr. 800 . 6s.

Also Fcap. 8vo. is. net.

LALAGE'S LOVERS. Third Edition. $\mathrm{Cr}$. $8 v 0$. 6s.

THE ADVENTURES OF DR. WHITTY. Fourth Edition. Cr. 8vo. 6s.

Bowen (Warjorie). I WIL L MAINTAIN Eighth Edition. Cr. 8vo. 6 s.

DEFENDER OF THE FAITH. Seventh Edition. Cr. 8vo. 6 s.

A KNIGHT OF SPAIN. Third Edition. Cr. 8vo. 6s.

THE QUEST OF GLORY. Third Edition. Cr. 8vo. 6s.

GOD AND THE KING. Fifth Edition. Cr. 8vo. 6s.

THE GOVERNOR OF ENGLAND. Second Edition. Cr. 8vo. 6s.

Castle (Agnes and Egerton). THE GOLDEN BARRIER. Cr. 8vo. $6 s$.

*Chesterton (G. K.). THE FLYING INN. Cr. 800. 6s.

clifford (Mrs. W. K.). THE GETTING WELL OF DOROTHY. Illustrated. 7hird Edition. Cr. 8vo. 3s. 6d.

Conrad (Joseph). THE SECRET AGENT: A Simple TAle. Fourth Edition. Cr. 8vo. $6 s$.

A SET OF SIX. Fourth Edition. Cr. 8vo. 6s. UNDER WESTERN EYES. Second Edi. tion. Cr. 8vo. 6s.

CHANCE. Cr. 8vo. 6s.

Conyers (Dorothea). SALLY. Fourth Edition. Cr. 8vo. 6s.

SANDY MARRIED. Third Edition. Cr. 8vo. 6s.

Corelli (Marie). A ROMANCE OF TWO WORLDS. Thirty-Second Edition. Cr. $8 v 0$. $6 s$.

VENDETTA; OR, THE STORY OF ONE FORGOTTEN. Thirtieth Edition. Cr.8vo. $6 s$.

THELMA: A Norwegian Princess. Forty-third Edition. Cr. 8vo. 6s.

ARDATH: The Story of A DEAD Selp. Twenty-first Edition. Cr. 8vo. 6 s.

THE SOUL OF LILITH. Seventecnth Edition. Cr. 8vo. 6 s.

WORMWOOD : A DRAMA OF PARIS. Nineteenth Edition. Cr. 8vo. $6 s$.

BARABBAS: A DREAM OF THE WORED'S TRAGBdY. Forty-sixth Edition. Cr. 8vo. $6 s$.

THE SORROWS OF SATAN. Fifty. eighth Edition. Cr. 8vo. 6 s.

THE MASTER-CHRISTIAN. Fourteenth Edition. 179th Thousand. Cr. $8 v 0.6 s$.

TEMPORAL POWER: A STUDY, IN SUPREAIACY. Second Edition. Isoth Thousand. Cr. 80o. 6s.
GOD'S GOOD MAN: A Simple LOYB STORY. Sixtcenth Edition. 154th Thowsand. Cr. 8vo. 6s.

HOLY ORDERS: THE TRAGEDY OF A QUIET LIFE. Second Edition. 120th Thowsand. Cr. 800 . 65 .

THE MIGHTY ATOM. Twenty-ninth Edition. Cr. 8vo. 6s.

Also Fcap. 8vo. Is. net.

BOY: A SKETCH. Thirteenth Edition. Cr. 8vo. 6s.

Also Fcap. 8zo. Is. net.

CAMEOS. Fourtecth Edition. Cr. 8vo. 6s.

THE LIFE EVERLASTING. Sixth Edition. Cr. 8vo. 6s.

JANE: A Social Incident. Fcap. $8 v 0$. Is. net.

Crockett (S. R.). LOCHINVAR. Illustrated. Third Edition. Cr. 8vo. 6s.

THE STANDARD BEARER. Second Edition. Cr. 8vo. 6 s.

Croker (B. M.). THE OLD CANTON. MENT. Second Edition. Cr. 8vo. 6s.

JOHANNA. Second Edition. Cr. 8vo. 6s.

THE HAPPY VALLEY. Fourth Edition. Cr. 8vo. 6s.

A NINE DAYS' WONDER. Fourth Edition. Cr. 8vo. $6 s$.

PEGGY OF THE BARTONS. Seventh Edition. Cr. 8vo. 6s.

ANGEL. Fifth Edition. Cr. 8vo. $6 s$.

KATHERINE THE ARROGANT. Seocnth Edition. Cr. 8vo. 6s.

BABES IN THE WOOD. Fourth Edition. Cr. 8vo. 6s.

* Danby(Frank). JOSEPH IN JEOPARDY. Fcap. 8zo. is, net.

Doyle (Sir A. Conan). ROUND THE RED LAMP. Twelfth Edition. Cr. 8vo. $6 s$. Also Ficap. 8vo. 1s. net.

Drake (Mauricc). $\quad \mathrm{WO}_{2} . \quad$ Fifth Edition. Cr. 8vo. 6s.

Findlater (J. H.). THE GREEN GRAVES OF BALGOWRIE. Fifth Edition. $\mathrm{Cr}$. 8vo. $6 s$.

THE LADDER TO THE STARS. Second Edition. Cr. 8vo. 6s.

FIndlater (Mary). A NARROW WAY. Fourth Edition. Cr. 8vo. 6s.

THE ROSE OF JOY. Third Edition. Cr. 8vo. 6s.

A BLIND BIRD'S NEST. Illustrated. Second Edition. Cr. 8vo. 6s.

Fry (B. and C. B.). A MOTHER'S SON. Fifth Edition. Cr. 800. 6s.

Harraden (Beatrice). IN VARYING MOODS. Fourteenth Edition. Cr.8vo. 6s. HILDA STRAFFORD and THE REMIT: TANCE MAN. Twelfth Edition. Cr. 8vo. $6 s$.

INTERPLAY. Fifth Edition. Cr.8vo. os 


\section{Fiction}

Hauptmann (Gerhart). THE FOOL IN CHRIST : EmManUEL QUiNT. Translated by Thomas Seltzer. Cr. 8vo. 6s.

HIchens (Robert). THE PROPHET OF BERKELEY SQUARE. Second Edition. Cr. 8vo. 6s.

TONGUES OF CONSCIENCE. Third Edition. Cr. 8vo. 6s.

FELIX: Three Years in a Life. Tenth Edition. Cr. 8vo. 6s.

THE WOMAN WITH THE FAN. Eighth Edition. Cr. 8vo. 6s. Also Fcap. 8vo. is. net.

BYEWAYS. Cr. $8 v 0$. $6 s$.

THE GARDEN OF ALLAH. Twenty. second Edition. Cr. 8vo. 6s.

THE BLACK SPANIEL. Cr. 8vo. $6 s$.

THE CALL OF THE BLOOD. Eighth Edition. Cr. 8vo. 6s.

BARBARY SHEEP. Second Edition. Cr. 8च0. 3s. 6 d.

Also Fcap. 8zo. is. net.

THE DWELLER ON THE THRESHOLD. Cr. 800 . 6 s.

THE WAY OF AMBITION, Fourth Edition. Cr. 8vo. 6 s.

Hope (Anthony). THE GOD IN THE CAR. Eleventh Edition. Cr. 8ro. 6s.

A CHANGE OF AIR. Sixth Edition. $\mathrm{Cr}$. 800. 6s.

A MAN OF MARK. Secenth Edition. Cr. 8vo. $6 s$.

THE CHRONICLES OF COUNT AN. TONIO. Sixth Edition. Cr. 870. Es.

PHROSO. Illustrated. Ninth Edition. Cr. 8zo. 6s.

SIMON DALE. Illustrated. Ninth Edition. Cr. 8vo. 6s.

THE KING'S MIRROR. Fifth Edition. Cr. 8vo. 6s.

QUISANTE. Fourth Edition. Cr. 8vo. 6s. THE DOLLY DIALOGUES. Cr. $8 v o$. 6 s. TALES OF TIVO PEOPLE. Third Edition. Cr. 8vo. 6s.

A SERVANT OF THE PUBLIC. Illustrated. Sixth Edition. Cr. 8vo. 6s.

THE GREAT MISS DRIVER, Fourth Edition. Cr. 8vo. 6s.

MRS. MAXON PROTESTS. Third Edition. Cr. 8vo. 6s.

Hutten (Baroness yon). THE HALO. Fifth Edition. Cr. 8vo. 6s.

Also Fcap. 8vo. 1s. net.

'The Inner Shrins' (Anthor of). THE WILD OLIVE. Third Edition. Cr.8vo. 6s.

THE STREET CALLED STRAIGHT. Fouth Edition. Cr. 8vo. 6s.

THE WAY HOME. Second Edition. Cr. 8z:0. 6s.
Jacobs (W. W.). MANY CARGOLS. Thirty-third Edition. Cr. 8vo. 3s. 6al. Also lllustrated in colour. Demy Evo. 7s. 6d. ret.

SEA URCHINS. Scoenteenth Edition. Cr. 8vo. 3s. $6 d$.

A MASTER OF CRAFT. Illustrated. Tenth Edition. Cr. 8vo. 3s.6\%.

LIGHT FREIGHTS. Illustrated. Elrienth Edition. Cr. 8vo. 3s. $6 d$. Also Fcap. 8vo. is. net.

THE SKIPPER'S WOOING. Eleventh Edition. Cr. 8vo. 3s. 6d.

AT SUNIVICH PORT. Illustrated. Tenth Edition. Cr. 8vo. 3s. 6at.

DIALSTONE LANE. Iilustrated. Eighth Edition. Cr. 8vo. 35. 6d.

ODD CRAFT. Illustrated. Fifth Edition. Cr. 800. 3s. $6 d$.

THE LADY OF THE PARGE. Illustrated Ninth Edition. Cr. 8vo. 3s. $6 . t$.

SALTHAVEN. Illustrated. Third Edition. Cr. 800. 3s. $6 d$.

SAILORS' KNOTS. Illustrated. Fifth Edition. Cr. 8vo. 3s. 6d.

SHORT CRUISES. Third Edition. Cr. 820. 3s. 6\%.

James (Henry). THE GOLDEN BOWL. Third Edition. Cr. 8vo. 6s.

Le Queax(Wlillam), THE HUNCHB.ACK OF WESTIINSTER. Third Edition. Cr. 8vo. 6s.

THE CLOSED BOOK. Third Edition. Cr. 8vo. 6s.

THE VALLEY OF THE SHADOW. Illustrated. Third Edition. C\%.8vo. 6 .

BEHIND THE THRONE. Third Edition. Cr. 8vo. 6s.

London (Jack). WHITE FANG. Ninth Edition. Cr. 8vo. 6s.

Lowndes (Mrs. Belloc). THE CHINK IN THE ARMIOUR. Fourth Edition. Cr. 800. 6s. net.

MARY PECHELL. Second Edition. $\mathrm{Cr}$. 8zo. 6s.

STUDIES IN LOVE AND IN TERROR. Second Edition. Cr. 8vo. 6 s.

THE LODGER. Crown 8vo. $6 s$.

Lucas (E. Y.), LISTENER'S LURE: AN Oblique Narratron. Ninth Edition: Fcap. 8vo. 5 s.

OVER BEMERTON'S: AN EASV-GONG Chrosicle. Tenth Edition. Fcap. 800. 55.

MR. INGLESIDE. Ninth Edition. Fcap. 800. 55.

LONDON LAVENDER. Sixt/h Edition. Fcap. 8vo. 5s. 
Lyall (Edna). DERRICK VAUGHAN, NOVELIST. 44th Thousand. Cr. 8ro. 3s. 6 d.

Macnaughtan (3.) THE FORTUNE OF CHRISTINA i'NAB. Sixth Edition. Cr. 8vo. 2s. net.

PETER AND JANE. Fourth Edition. Cr. 800 . 6s.

Malet (Lucas). A COUNSEL OF PER. FECTION. Second Edition. Cr. 8vo. 6s. COLONEL ENDERBY'S WIFE. Sixth Edition. Cr. 8vo. 6 .

THE HISTORY OF SIR RICHARD CALMADI: A Romance. Ninth Edition. Cr. Evo. 6s.

THE WAGES OF SIN. Sixteenth Edition. Cr. 800. 6s.

THE C.ARISSIMA. Fifth Edition. Cr. 8vo. $6 s$.

THE GATELESS BARRIER. Fifth Edi. tion. Cr. 8avo. Gs.

Mason (A. E. W.). CLEMENTINA. lllustrated. Eighth Edition. Cr. 8vo. 6 s.

Uaxwell (W. B.). THE RAGGED MESSENGER. Third Edition. Cr. Szo. 6s.

VIVIEN. Taulf th Edition. Cr. 8vo. 6s.

THE GUARDED FLAME. Secenth Edition. Cr. 8vo. 6s. Aiso Ficap. 8\%o. is. net.

ODD LENGTHS. Second Edition. Cr. 800 . 6s.

HILL RISE. Fouth Edition. Cr. 8zo. 6s. Aiso Fcap. 8vo. is. net.

THE COUNTESS OF MAYBURY: BETWEE: YOU AND I. Fourth Edition $C r$. 8vo. $6 s$.

TIIE REST CURE. Fourth Edition. $\mathrm{Cr}$ 8vo. 6 s.

Mline (A. A.). THE DAYS PLAY. Fourth Edition. Cr. 8vo. 6s.

THE HOLIDAY ROUND. Second Edition. Cr. 8vo. 6s.

uontague (c. E.). A HIND LET LOOSE. Third Edition. Cr. 8vo. 6s.

THE MORNING'S WAR. Cr. 8vo. 6s.

Morrison (Arthur). TALES OF MIEAN STREETS. Seventh Edition. Cr. 8ro. 6 s. Also Fcas. 8vo. is. net.

A CHILD OF THE JAGO. Sixth Edition. Cr. 800 . 6 s.

THE HOLE IN THE WALL. Fourth Edition. Cr. 8vo. 6s.

DIVERS VANITIES. Cr. $8 v 0.6 s$.

ollyant (Alfred). OWD BOB, THE GREY DOG OF KENMUIR. 'With a Frontispiece. Tuelfth Edition. Cr. 8vo. 6s.
THE TAMING OF JOHN BLUNT. Second Edition. Cr. 820. 6 s.

THE ROYAL ROAD. Second Edition. Cr. 8vo. 6s.

Onlons (Ollyer). GOOD BOY SELDOM: A Romance of ADVERTisement. Second Edition. Cr. 8z'o. 6s.

THE TWO KISSES. Cr. 8vo. 6s.

Oppenhelm (E. Phillps). MASTER OF MEN. Fifth Edition. Cr. 800 . 6s.

THE MISSING DELORA. IIlustrated. Fourth Edition. Cr. 800. 6 s.

Also Fcap. 8vo. Is. ñ.

Orczy (Bayoness). FIRE IN STUBBLE Fifth Edition. Cr. 8vo. 6 s.

Also Fcap. 8vo. Is, net.

Oxenham (John). A WEAVER OF WEBS. Illustrated. Fifth Edition. Cr. 8vo. 6 .

THE GATE OF THE DESERT. Eighth Edition. Cr. 800. 6 s.

* Also Fcap. 8vo. xs. net.

PROFIT AND LOSS. Furth. Edition. Cr. 8vo. 6s.

THE LONG ROAD. Fourth Edition. Cr. 800. 6s.

Also Fcap. 8vo. 1s. net.

THE SONG OF HYACINTH, AND OTHER STomies. Second Edition. Cr. 8vo. 6 s.

MY LADY OF SHADOWS. Fourth Edition. Cr. 8zo. 6 s.

LAURISTONS. Fourth Edition. Cr. 800. $6 s$.

THE COIL OF CARNE. Sixth Edition. Cr. 8vo. 6s.

THE QUEST OF THE GOLDEN ROSE. Fowrth Edition. Cr. 8zo. 6.

MARY ALL-ALONE. Third Edition. $\mathrm{Cr}$. $800.6 s$.

Parker (Gilbert), PIERRE AND HIS PEOPLE. Seventh Edition. Cr. 8vo. 6 s. MRS. FALCHION. Fifth Edition. Cr. 8vo. 6s.

THE TRANSLATION OF A SAVAGE. Fourth Edition. Cr. 8vo. 6s.

THE TRAIL OF THE SWORD. Illustrated. Tenth Edition. Cr. 800. 6s.

WHEN VALMOND CAME TO PONTIAC : The Story of a Lost Napoleon. Secenth Edition. Cr. 800 . 6s.

AN ADVENTURER OF THE NORTH: The LAST ADVENTURES OF 'PRETTY Pierre.' Fifth Edition. Cr. 8vo. 65 .

THE SEATS OF THE MIGHTY. Illustrated. Nincteenth Edition. Cr. 800 . $6 s$.

THE BATTLE OF THE STRONG: A ROMANCE of Two KingDOMs. Illustrated. Seventh Edition. Cr. 8vo. 6 s. 
THE PONP OF THE LAVILETTES. Third Edition. Cr. 820. 35. $6 d$.

NORTHERN LIGHTS. Fourth Edition Cr. 8vo. 6r.

THE JUDGMENT HOUSE. Cr. 8vo. 6s.

Pasture (Mrg. Henry de Ia). THE TYRANT. Fourth Edition. Cr. 8\%o. $6 s$. Also Fcap. 8vo. is. net.

Pemberton (Max). THE FOOTSTEPS OF A THRONE. Illustrated. Fourth Edition. Cr. Ezo. 6s.

I CROWN THEE KING. Illustrated. $C r$. Bvo. 6s.

LOVE THE HARVESTER: A STORY OE THE SHIRES. Illustrated. Third Edition. Cr. 820. 3s. $6 d$.

THE MYSTERY OF THE GREEN HEART. Fifth Edition. Cr. 8vo. 25, net

Perrin (Allce), THE CHARM. Fifth Edition. Cr. 8zo. $6 s$.

Also Fcap. 8ro. is. net.

THE ANGLO.INDIANS. Sixth Edition. Cr. 8v0. 65.

Phillpotts (Eden). LYING PROPHETS. Third Edition. Cr. 800 . $6 s$.

CHILDREN OF THE MIST. Sixth Edition. Cr. 8so. 6s.

THE HUMAN BOY. With a Frontispiece. Seventh Edition. Cr. 8=0. 6r.

SONS OF THE MORNING. Second Edi. tion. Cr. 8vo. 6s.

THE RIVER. Fourth Edition. Cr. 850. 6s.

THE AMERICAN PRISONER. Fowrth Edition. Cr. 8\%0. 6s.

KNOCK AT A VENTURE. Third Edition Cr. 800 . 6s.

THE PORTREEVE. Fourth Edition. $C r$. 8थ\%. 65.

THE POACHER'S WIFE. Second Edition. Cr. 800. 6s.

THESTRIKING HOURS. Second Edition. Cr. 8vo. Es.

DEMETER'S DACGHTER. Third Edition. Cr. 800. 6s.

THE SECRET WOMAN. Fcap. 8vo. is. net.

PlckthaII (Marmaduke). SAÏD, THE FISHERMAN. Eighth Edition. Cr. 8zo. 6s.

Also Fcap. 8vo. is. net.

'Q'(A. T. Qulller-Conch). THE MAYOR OF TROY. Fourth Edition. Cr. 8zo. 6s. MERRY-GARDEN AND OTHER STORIES. Cr. 800. 6s.

MAJOR VIGOUREUX. Third Edition. Cr. 8v0. 6.
RIdge (W. Pett). ERB. Second Edition. Cr. 8vo. 6s.

A SON OF THE STATE. Third Edition. Cr. 800 . $35.6 d$.

A BREAKER OF LAIVS. A New Edition Cr. 8vo. 3s. 6d.

MRS. GALER'S BUSINESS. Illustrated. Second Edition. Cr. Eve. ts.

THE WICKHAMSES. Fourh Edition. Cr. 8vo. 6s.

SPLENDID BROTHER. Fourth Edition. Cr. 8zo. 6s.

Also ficap. 8vo. 1s. net.

NINE TO SIX.THIRTY. Third Edition. Cr. $8 \approx 0.6 s$.

THANKS TO SANDERSON. Second Edition. Cr. 8ro. 6s.

DEVOTED SPARKES. Secont Edition. Cr. 8to. 6s.

THE REMINGTON SENTENCE, $C$; 8vo. 6s.

Russell (W. Clark) MASTER ROCK.A. FELLAR'S VOYAGE. Illustrated. Fourth Edition. Cr. 8\%0. 35. 64.

Sldgwlck (Mrs. Alfred). THE KINS. MAN. Illustrated. Third Edition. $C r$. 8vo. 6s.

THE LANTERN-BEARERS. Third Edition. Cr. 8zo. $6 s$.

THE SEVERINS. Sixth Edition. Cr.820. $6 s$.

Also Fcap. 8vo. 1s. net.

ANTHEA'S GUEST. Fourth Edition. C, 800. 6s.

LAMORNA. Third Edition. Cr. 8\%0. 6s. BELOWV STAIRS. Second Edition. Cr. $8 v 0.65$.

Snalth (J. C.). THE PRINCIPAL GIRI. Second Edition. Cr. 820. 6s.

AN AFFAIR OF STATE. Second Edition. Cr. 800 . ts.

Somerville (E. G.) and Ross (Martin). DAN RUSSEL THE FOX. Illustrated. Secenth Edition. Cr. 800. 6s. Also Fcas. 800. is. net.

Thurston (E. Temple). MIRAGE. Fourth Edition. Cr. 8vo. 6s.

Also Fcap. 8vo. is. net.

Watson (H. B. Marriott) ALISE OF ASTRA. Thi,d Edition. Cr. 8v0. 6s.

THE BIG FISH. Third Edition, Cr. 800. 6 s.

Webling (Peggy). THE STORY OF VIRGINIA PERFECT. Third Edition Cr. 8v0. 6s.

Also Ficap. 8vo. is. net. 
THE SPIRIT OF MIRTH. Sixth Edition. Cr. 8vo. Es.

FELIX CHRISTIE. Third Edition. Cr. 8zo. 6s.

THE PEARL STRINGER. Third Edition. Cr. 8\%o. 6 s.

Westrup (Margaret) (Mrs. W. Sydney Stacey), TIDE MARKS. Second Edition. Cr. 8vo. 6s.

Weyman (Stanley). UNDER THE RED ROBE. Illustrated. Twenty-third Edition. Cr. 8vo. 6 s.

Also Fcap. 8zio. is, net.

WhItby (Beatrice). ROSAMUND. Second Edizion. Cr. 8ro. 6s.

WHiliamson (C. N. and A. M.). THE LIGHTNING CONDUCTOR: The Strange Adventures of a Motor Car. Illus. trated. Twenty-first Edition. Cr. 8vo. Gs. A lso Cr. 8vo. is. net.

THE PRINCESS PASSES: A Romance of A Motor. Illustrated. Ninth Edition. Cr. 8zo. 6s.

LADY BETTY ACROSS THE WATER. Elezenth Edition. Cr. 8 ro. $6 s$. Also Fcap. 8zo. is. net.
THE BOTOR CHAPERON. Illustrated. Eighth Edition. Cr. 8\%o. 6s.

*Also Fiap. 8vo. is. net.

THE CAR OF DESTINY. Illustrated. Seventh Edition. Cr. 8vo. 6 s.

MY FRIEND THE CHAUFFEUR. Illustrated. Tzuelfth Edition. Cr. 8vo. 6s.

SCARLET RUNNER. Illustrated. Third Edition. Cr. 8vo. $6 s$.

SET IN SILVER. Illustrated. Fourth Edition. Cr. 8vo. 6s.

LORD LOVELAND DISCOVERS AMERICA. Second Edition. Cr. 8vo. 6s.

THE GOLDEN SILENCE. Sixth Edition. Cr. 3 ro. $6 s$.

THE GUESTS OF HERCULES. Thira Edition. Cr. 8vo. 6 s.

THE HEATHER MOON. Fifth Edition. Cr. 8vo. 6s.

THE LOVE PIRATE. Illustrated. Secona Edition. Cr. 8vo. 6s.

THE DEMON. Fcap. 8vo. 1s. net.

Wyllarde (Dolf). THE PATHWAY OF THE PIONEER (Nous Autres). Sixth Edition. Cr. $8 v 0$. 6 s.

\title{
Books for Boys and Girls
}

\section{Illustrated. Crown 8vo. 3s. $6 d$.}

\begin{abstract}
Getring Wrle of Dorothy, The. Mrs. Only a Guard-Room Dog. Edith E. W. K. Clifford.

Girl of the People, A. L. T. Meade.

Hepsy Gipsy. L. T. Meade. 2s. $6 d$.

Honourable Miss, The. L. T. Meade.

Master Rockafellak's Voyagi. W. Clark Russell.

Cuthell.

Red Grange, The. Mrs. Molesworth.

Syp Belton: The Boy who would not go to Sea. G. Manville Fenn.

There was once a Prince. Mrs. M. E. Mann.
\end{abstract}

\section{Methuen's Shilling Noxels}

\section{Fcap. 8vo. Is. net}

Anns of the Frve Towns. Arnolu Bennett. BARBARY SHEkP. Robert Hichens.

* Botor Chaperon, The. C. N. \& A. M. Wiliamson.

Boy. Marie Coreili.

Charm, The. Alice Perrin.

Dan Russel the Fox. E. CE. Somerville and Martin Ross.
Demon, The. C. N. and A. M. Williamson. Fire in Stubble. Baroness Orczy.

*Gate of Desert, The. John Oxenham. Guarded Flame, Tre. W. B. Maxwell. Hal.o, Tise. Baroness von itutten. Hilt Rise. W. B. Maxwell. JAnE. Marie Corelli. 


\section{Fiction}

Methuen's Shilling Noxels-continued.

"Joseph IN Jeopardy. Frank Danby.

LADY BETTY ACROSS THE WATEK. and A. M. Williamson.

Light Fretghrs. W. W. Jacobs.

Long Road, The. John Oxenham.

Miguty Atom, The. Marie Corelli.

Mirage. E. Tempie Thurston.

Missing Delora, The. E. Phillips Oppen. beim.

Rouxd the Red Lamp. Sir A. Conan Doyle.

SAĨd, The Fishermax. Marmaduke Pickthall.
Search Party, The. G. A. Birmingham. Secret Wosax, The. Eden Phillpotts. Severins, The. Mrs. Alfred Sidgwick. Spanish Goln. G. A. Birmingham. Splendid Brother. W. Pett Ridge. Tales of Mean Steeets. Arthut Mortison. Teresa of Watling Street: Amold Bennett.

Tyrant, Tue. Mrs. Henty de la Pasture. Unoer the Red Robe. Stanley J. Weyman. Virginia Perfect. Peggy Webling.

Woman with tue FAN, ThB. Robert Hichens.

\section{Methuen's Sexenpenny Noxels}

Fcap. 8vo. 7d. net

Angel. B. M. Croket.

Вroом Squire, The. S. Baring-Gould.

By Stroke of Sword. Andrew Balfour.

* House of Whispers, The. William Le Queux.

Human Boy, The. Eden Phillpotts.

I Crown Thee King. Max Pemberton.

- Late iv Life Alice Perrín.

Lone Pine. R. B. Townshend.

Master of Men. E. Phillips Oppenheim. Mixed Marriage, A. Mrs. F. E. Penny.
Peter, a Pasastre. E. Maria Albanesi.

Pomp of the Lavilettes, Tue. Sir Giibert Parker.

Prince Rupert tie Buccaneer. C. J. Cutcliffe Hyne.

*Princess Virginia, Tue. C. N. \& A. M. Williamson.

Profit AND Loss. John Oxenham.

Red House, Tue. E. Nesbit.

Sign of the Srider, The. Bertran Mitford.

Son of the State, A. W. Pett Ridge. 


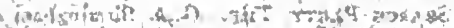

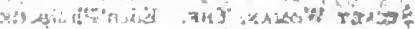
Aich An mat in:

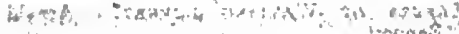

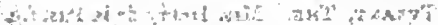

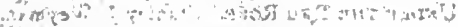
If $e^{2}$ isengents

S1, in 1 it

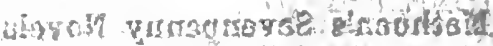

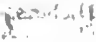

$$
\begin{aligned}
& \text { w. } 3 x^{2}=1
\end{aligned}
$$

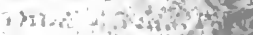

\section{(A⿱}

is

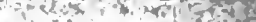

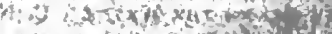

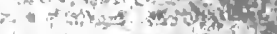

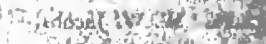

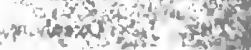

trons

$$
\text { ind }
$$

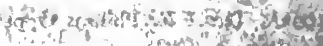

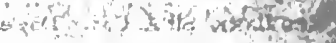

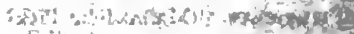

iteristi

\section{ine in res and}

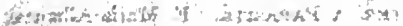

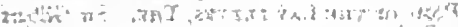
. 2 SISt

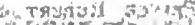

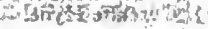

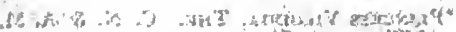
a

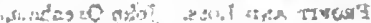

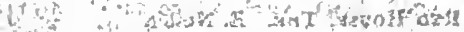

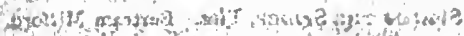

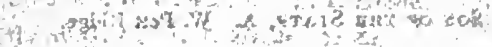

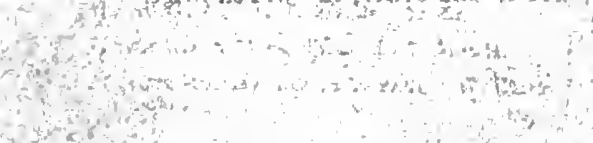

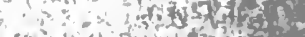

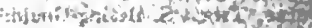

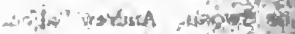

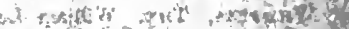

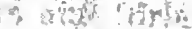

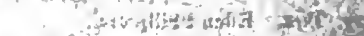

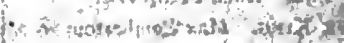

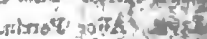

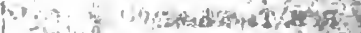

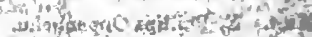
To

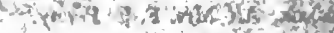

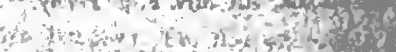
a is

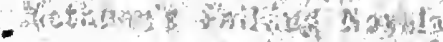

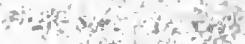



95

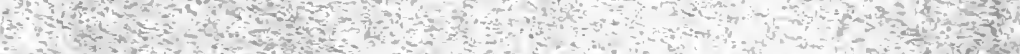
12, $\rightarrow$ tut

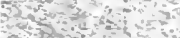

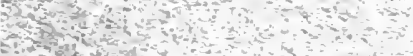

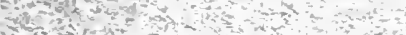


University of California

SOUTHERN REGIONAL LIBRARY FACILITY

- $\quad 405$ Hilgard Avenue, Los Angeles, CA 90024-1388

Return this material to the library

- from which it was borrowed.

$-$

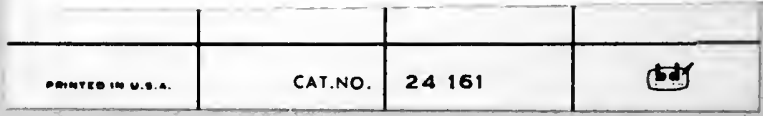




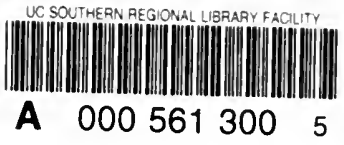


$8+8 \times 3=$

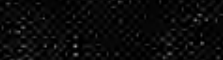

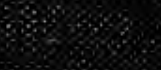

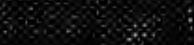

$0 \% 8 \%$

\%

$\% \%$

$8 \%$

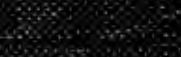

\%

$8 \%$

\% $8 \%$

$\alpha \%$ \%

$\%$

\%

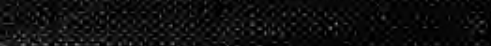

\%

$8 \%$

Hor.

\% $\%$ \%

\%

$\% \%$

$\%$ \%

\%

r

\%

\% 8

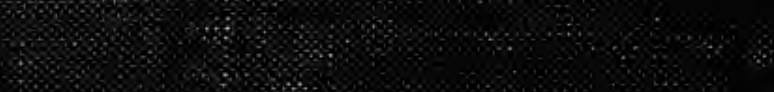

\% 